Portland State University

PDXScholar

$1-1-2011$

\title{
Rebuilding the Architectural History of the Fort Vancouver Village
}

Meredith J. Mullaley

Portland State University

Follow this and additional works at: https://pdxscholar.library.pdx.edu/open_access_etds

Part of the History Commons, and the History of Art, Architecture, and Archaeology Commons Let us know how access to this document benefits you.

Recommended Citation

Mullaley, Meredith J., "Rebuilding the Architectural History of the Fort Vancouver Village" (2011).

Dissertations and Theses. Paper 502.

https://doi.org/10.15760/etd.502

This Thesis is brought to you for free and open access. It has been accepted for inclusion in Dissertations and Theses by an authorized administrator of PDXScholar. Please contact us if we can make this document more accessible: pdxscholar@pdx.edu. 
Rebuilding the Architectural History of the Fort Vancouver Village

by

Meredith J. Mullaley

A thesis submitted in partial fulfillment of the requirements for the degree of

\author{
Master of Arts \\ in \\ Anthropology
}

Thesis Committee:

Kenneth Aimes, Chair

Douglas Wilson

Virginia Butler

Portland State University

(C)2011 


\begin{abstract}
In the mid-19th century, the Fort Vancouver employee Village was one of the most diverse settlements on the Pacific Coast. Trappers, tradesmen, and laborers from Europe, North America, and Hawaii worked and lived within a highly stratified colonial social structure. Their homes have been the site of archaeological research for nearly 50 years, but the architectural features and artifacts have received limited attention. Inspired by an 1845 description of the Village that described houses that were "as various in form" as their occupants (Hussey 1957:218), this study examined community-level social relationships in this 19th-century fur trade community through vernacular architecture and landscape.
\end{abstract}

This thesis presents the life histories and layouts of five Village houses. The architectural analysis relied on data from features, square nails, window glass, and bricks. The resulting architectural interpretations were synthesized to explore the larger vernacular landscape of the Village and investigate whether the house styles reflect processes of creolization and community development, or distinction and segregation among the Village residents. The houses all stem from a common French-Canadian architectural tradition, built by the first employees at Fort Vancouver, but the life histories also revealed that the houses were occupied (and repaired) by a second wave of employees at some time during the 1840s. A reminder that Village houses deposits may reflect multiple owners, and should not be conceptualized as the result of a single household. Finally, this thesis demonstrates that nuanced architectural data that can yet be learned from past excavation assemblages when the many nails, bricks, and window glass specimens are reanalyzed using current methods. 


\section{ACKNOWLEDGEMENTS}

During the course of this thesis project (and in the years leading up to it), I have had the great fortune to work with and learn from many members of the tightly interwoven Pacific Northwest archaeology community.

To my committee, Doug Wilson, Ken Ames, and Virginia Butler: thank you for all your time, patience, and feedback during the thesis process.

To all my anthropology professors at PSU: thank you for the theory, the methods, and the lessons in critical thinking.

To Connie Cash: you support all of the students who pass by your office window, even when we did not realize we needed the support. Thank you for being amazing.

To my classmates, dear friends, and anthro-ladies: thank you for your strength and the wonderful memories we made in and out of the classrooms. I will miss our study sessions and study breaks in the coffee shops of Portland.

To my ICF coworkers: thank you for your support, words of wisdom, humor, patience, and flexibility while I worked to finish this thesis.

A huge thank you goes out to my friends and mentors at Fort Vancouver National Historic Site. Thank you for your instruction during my field school in the 2003, and thank you for giving me the opportunity to gain experience with museum collections, historical artifact analysis, and public outreach. You were the first members of my archaeology family and you were instrumental in helping me find the career path I am currently on.

Finally, to my family: Thanks for the free meals, your love, and the countless ways you helped me get across the finish line. 


\section{TABLE OF CONTENTS}

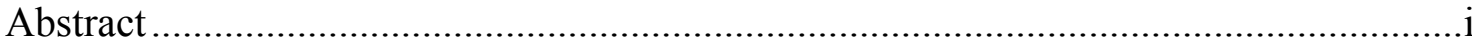

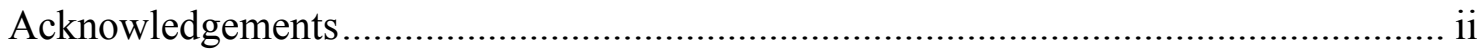

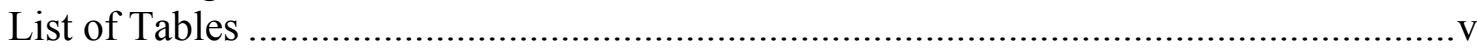

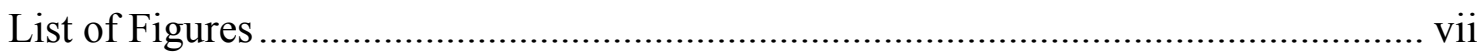

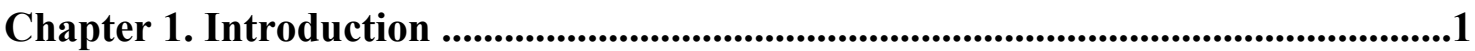

Chapter 2. Historical and Archaeological Context of the Village .................................5

Fort Vancouver: Geographic and Economic Context........................................................5

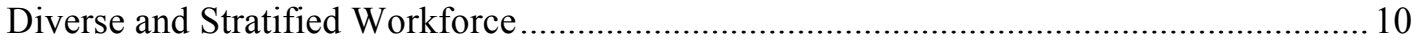

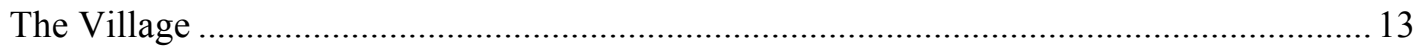

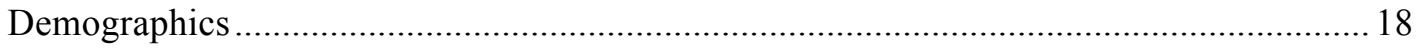

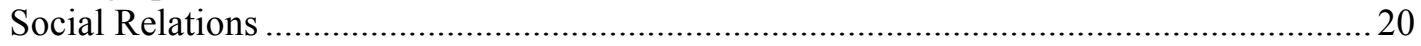

Post-HBC Activities in the Village ..............................................................................22

Archaeological Background of the Fort Vancouver Employee Village................................2

Chapter 3. Archaeological Signatures of the Village Houses.........................................28

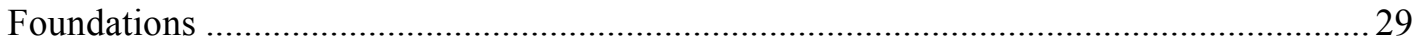

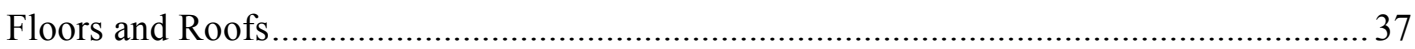

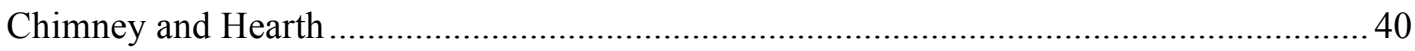

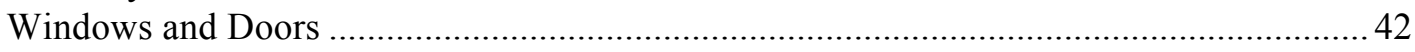

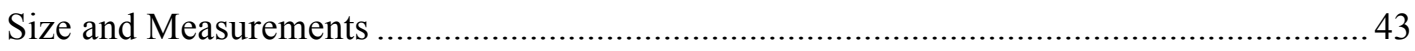

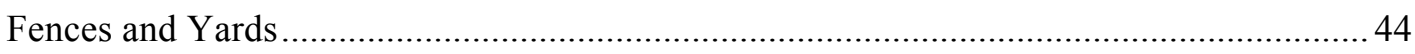

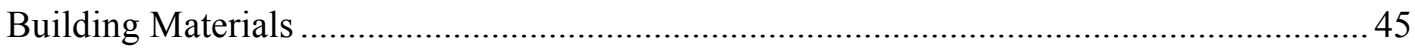

Site Formation Processes ............................................................................................. 46

Chapter 4. Literature Review and Theoretical Considerations ...................................50

Previous Research on Village Diversity …………………......................................5 50

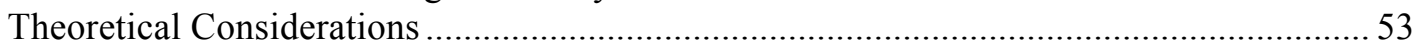

Case Studies: Architecture in Colonialist and Pluralistic Settings ........................................5 57

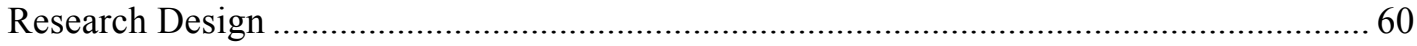

Chapter 5. Methods and Materials.......................................................................................63

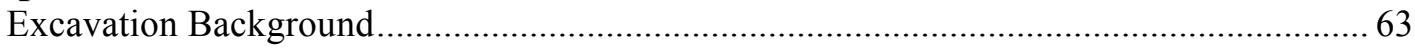

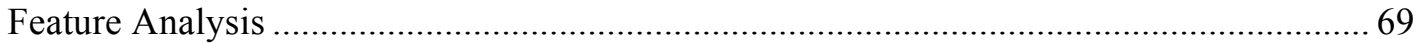

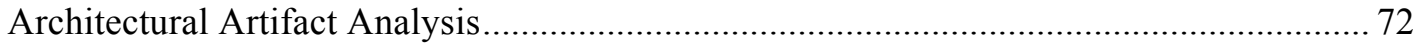

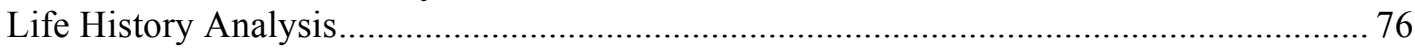

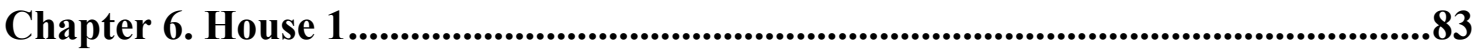

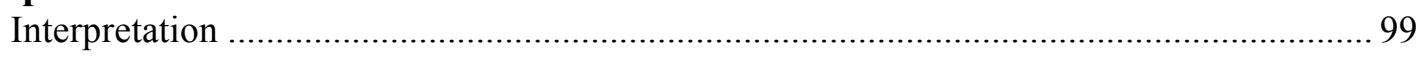

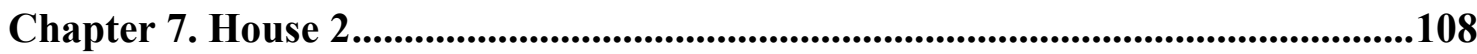

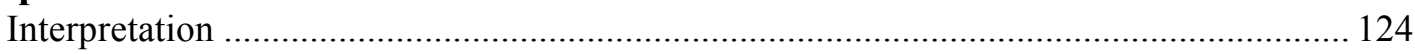

Chapter 8. House 3...............................................................................................................132

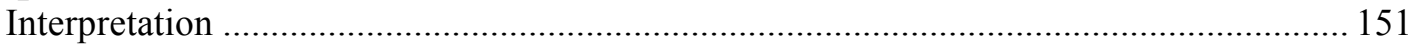

Chapter 9. House 4......................................................................................................160

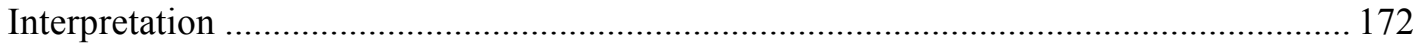

Chapter 10. House 5...............................................................................................................179

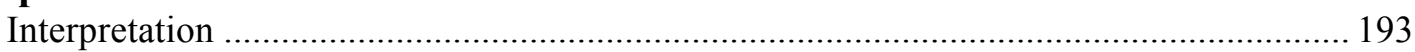


Chapter 11. Discussion .....................................................................................................201

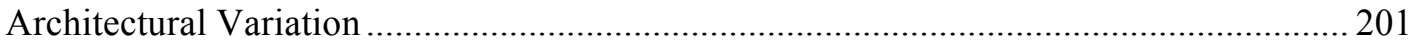

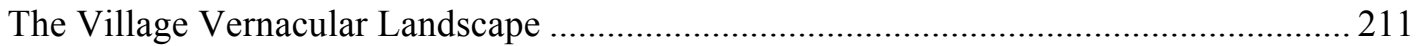

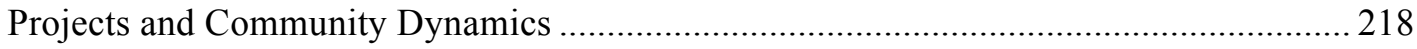

Chapter 12. Summary and Conclusions ...........................................................................224

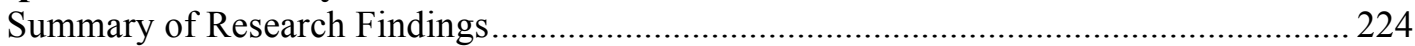

Examination of Methods and Recommendations for Future Research ........................... 228

References..................................................................................................................2234 


\section{LIST OF TABLES}

Table 1.

Table 2.

Table 3.

Table 4.

Table 5.

Table 6.

Table 7.

Table 8.

Table 9.

Table 10.

Table 11.

Table 12.

Table 13.

Table 14.

Table 15.

Table 16.

Table 17.

Table 18.

Table 19.

Table 20.

Table 21.

Table 22.

Table 23.

Table 24.

Table 25.

Table 26.

Table 27.

Table 28.

Table 29.

Table 30.

Table 31.

Table 32.

Table 33.

Table 34.

Table 35.

Table 36.

Table 37.

Table 38.

Table 39.

Table 40.

Table 41.

Table 42.

Table 43.

Table 44.
Houses and dwelling areas discovered in the Village 27

Excavation summaries of house study areas.......................................64

Accessions included in this study ...................................................67

Common Fort Vancouver Nail Varieties and Functional Categories .....74

Architectural Interpretation Data ...................................................... 77

Construction Method Interpretation Data ...........................................79

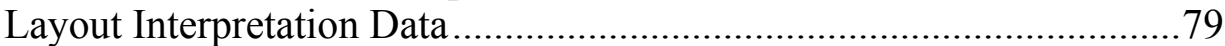

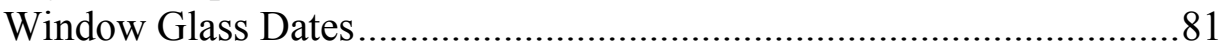

Formal Characteristics of House 1 miscellaneous features ...................84

Formal Characteristics of House 1 structural features ...........................86

House 1 Architectural Artifact counts ...............................................89

House 1 Study Area Artifact Categories and Counts.............................91

House 1 window glass fragment sizes ..................................................94

House 1 study area nail counts...........................................................95

House 1 square nail frequencies by type and penny size .....................95

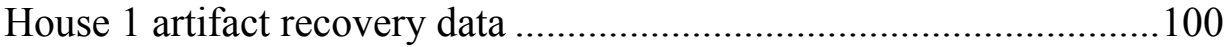

Formal Characteristics of House 2 miscellaneous features ..................109

Formal Characteristics of House 2 structural features .........................110

House 2 architectural artifact counts................................................ 113

House 2 study area artifact counts per unit...................................... 113

House 2 window glass fragment sizes ............................................. 117

House 2 study area nail counts......................................................118

House 2 square nails frequencies by type and penny size ...................121

House 2 artifact recovery data ..........................................................126

Formal Characteristics of House 3 miscellaneous features .................133

Formal Characteristics of House 3 structural features .........................135

House 3 architectural artifact counts................................................139

House 3 study area artifact counts per units ......................................139

House 3 window glass fragment sizes .............................................. 145

House 3 window glass fragment sizes comparison (1969 only)...........145

House 3 study area nail counts.......................................................... 145

House 3 square nails by type and penny size..................................... 146

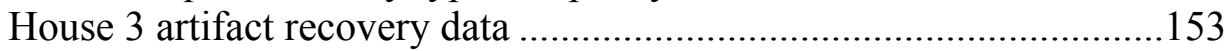

House 3 nail assemblage comparison ..............................................155

Formal characteristics of House 4 structural features...........................161

House 4 artifact counts per unit .........................................................164

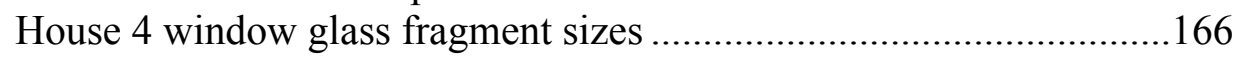

House 4 study area nail counts........................................................168

House 4 square nail frequencies by type and penny size.....................169

House 4 artifact recovery data ....................................................... 175

Formal characteristics of House 5 miscellaneous features ...................181

Formal characteristics of House 5 miscellaneous features ...................183

House 5 study area artifact counts per unit and feature ......................188

House 5 window glass fragment sizes.... 
Table 45. House 5 square nail frequencies by type and penny size.................... 191

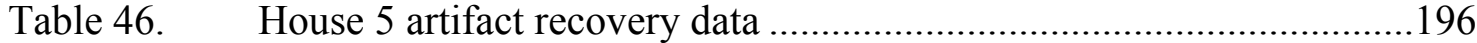

Table 47. House interpretations in brief..........................................................201

Table 48. Comparative artifact recovery data for the five houses .......................202

Table 49. Nail type frequency data for all five houses ......................................204

Table 50. Comparison of inferred formal characteristics of Houses 1-5 ............209

Table 51. Inferred occupation dates for Village houses (archaeological)............214 


\section{LIST OF FIGURES}

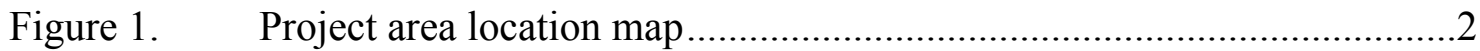

Figure 2. Covington's "Fort Environs" sketch (1846) ………..............................

Figure 3. Hudson's Bay Company posts in the Columbia Department ....................8

Figure 4. HBC organizational hierarchy ca. 1825-1860 .......................................12

Figure 5. Map of Village based off 1846 Covington Map ......................................14

Figure 6. Detail of 1854 Mansfield Map showing Village and stockade................14

Figure 7. Illustration of the Village by George Gibbs (1851) ..............................15

Figure 8. Paul Kane's sketch of the Village, looking east ………........................17

Figure 9. Gustavus Sohon's lithograph ..............................................................17

Figure 10. Plan view map of 20th century Vancouver Barracks..............................23

Figure 11. Excavations in the Village between 1968 and 2003 ..............................26

Figure 12. Examples of poteaux-sur-sole construction style ...................................30

Figure 13. Wood footing examples from Fort Vancouver ........................................31

Figure 14. An example of a pieux-en-terre structure ...............................................32

Figure 15. Detail of excavation map of OP 14, showing post features.....................33

Figure 16. The pièce-sur-pièce en queue d'aronde construction style .....................35

Figure 17. Detail of potential "balloon frame" construction......................................36

Figure 18. A sketch of a "Métis Interior" from Canada. ...........................................38

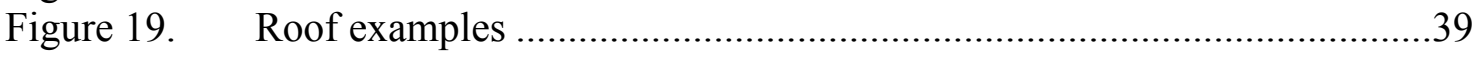

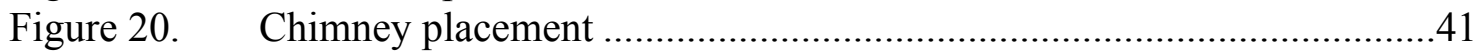

Figure 21. Hearth and chimney construction materials.........................................41

Figure 22. Window and door examples.............................................................43

Figure 23. Map of relevant Village excavations (1968-2003) ..................................64

Figure 24. Comparison of student notes and final feature plan map........................70

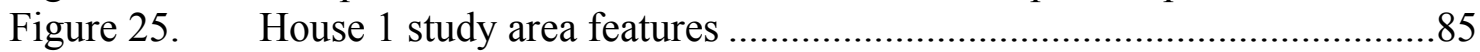

Figure 26. House 1 study area artifact density ......................................................90

Figure 27. Distribution of window glass in the House 1 Study Area.......................92

Figure 28. Overall flat glass average thickness for House 1 ...................................93

Figure 29. Comparing House 1 glass thickness modes by excavation......................94

Figure 30. Distribution of square nail types at House 1 Study Area .......................96

Figure 31. Distribution of nail manufacture types per House 1 study area units .....97

Figure 32. Lock plate from House 1 study area ……….......................................99

Figure 33. Pintle hinge from House 1 study area ...............................................99

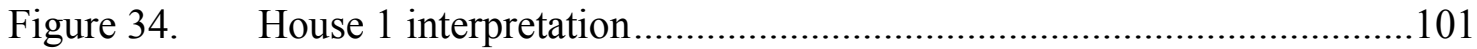

Figure 35. Nail penny sizes from the House 1 ..................................................104

Figure 36. Comparison of the window glass thickness distributions ......................106

Figure 37. Detail of Gibbs's 1851 sketch, showing "House 1" ............................107

Figure 38. Stratigraphic profiles of select House 2 units ........................................109

Figure 39. House 2 study area features ............................................................111

Figure 40. House 2 study area artifact density map ............................................114

Figure 41. Window glass spatial distribution in House 2 Study Area ...................116

Figure 42. Window glass thickness distribution for House 2 Study Area .............117

Figure 43. Comparing House 2 glass thickness modes by excavation....................117

Figure 44. Distribution of square nail types in House 2 Study Area......................119 
Figure 45. Distribution of square nail manufacture types per House 2 units .........120

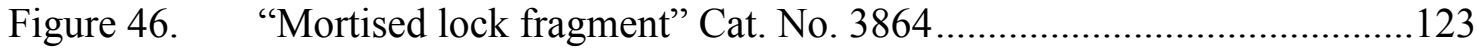

Figure 47. "Latch Part" fragment Cat. No. 4860 ................................................... 123

Figure 48. "Mortised lock part" fragment Cat. No. 157057.................................123

Figure 49. House 2 interpretation .................................................................. 125

Figure 50. Comparison of the House 2 window glass thickness distributions.......128

Figure 51. Comparison of the House 2 nail penny sizes ....................................129

Figure 52. Detail of Gibb's 1851 sketch, showing "House 2" ............................131

Figure 53. House 3 Features........................................................................... 134

Figure 54. Differing house floor outlines from student notes and final report ......136

Figure 55. House 3 study area artifact density map .........................................140

Figure 56. House 3 Study Area window glass distribution ..................................142

Figure 57. House 3 study area window glass thickness distribution.....................143

Figure 58. Comparing window glass thicknesses House 3 and horse burials........143

Figure 59. Comparing window glass thicknesses House 3-1969 and SAIP.......143

Figure 60. Distribution of HBC-era thicknesses in House 3 study area.................144

Figure 61. Distribution of square nail types in House 3 study area .....................147

Figure 62. Frequencies of nail manufacture types per excavation unit.................148

Figure 63. Pintle hinges from House 3 ........................................................... 150

Figure 64. Locking and latching hardware from House 3 .................................151

Figure 65. Cupreous key and socket from House 3 ........................................151

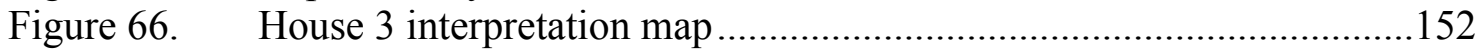

Figure 67. Comparison of the nail penny size distributions from House 3 ............157

Figure 68. Comparison of the window glass thickness from House 3 ..................158

Figure 69. Detail of 1851 Gibbs sketch, showing inferred "House 3"..................159

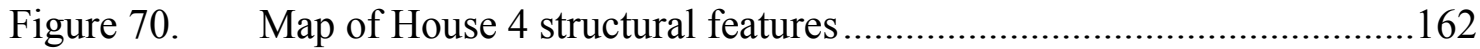

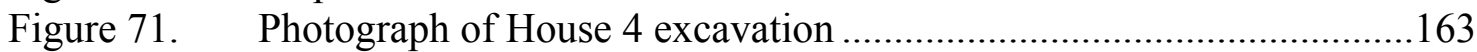

Figure 72. Artifact densities for the House 4 study area ..................................... 165

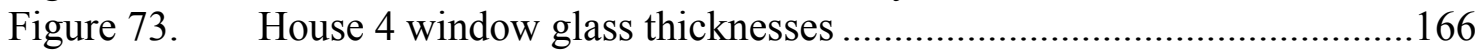

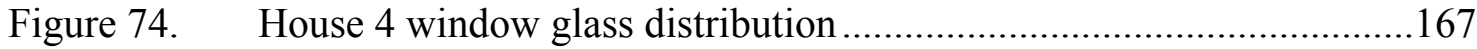

Figure 75. Frequencies of HBC-era window glass in House 4 units .....................168

Figure 76. Square nail spatial distribution at House 4 ......................................170

Figure 77. Architectural hardware found at House 4 .....................................171

Figure 78. House 4 interpretation ............................................................. 173

Figure 79. Comparison of House 4 wrought and machine cut nail penny sizes ....176

Figure 80. Detail of Gibbs's 1851 sketch, showing House 4 vicinity...................178

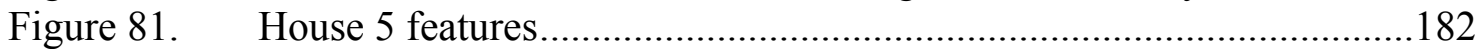

Figure 82. House 5 artifact density map...................................................... 187

Figure 83. House 5 window glass thickness modal distribution ..........................189

Figure 84. House 5 window glass thicknesses, HBC-levels only ........................190

Figure 85. Spatial distribution map of House 5 window glass.............................190

Figure 86. Spatial distribution of House 5 square nails ....................................192

Figure 87. Nail frequencies from House 5 units ...........................................193

Figure 88. House 5 interpretation................................................................. 195

Figure 89. Comparison of House 5 wrought and machine cut nail penny sizes ....199 
Figure 90. Detail of Gibbs's 1851 sketch, showing potential House 5 vicinity .....200

Figure 91. Architectural artifact density comparison .........................................203

Figure 92. Comparison of the window glass thickness from the all houses ..........205

Figure 93. Comparison of nail penny sizes from all houses .............................206

Figure 94. Comparison of house layout interpretations ....................................208

Figure 95. Dates of house construction, maintenance, and demolition..................210

Figure 96. Correlating Gibbs's sketch with archaeological data..........................212

Figure 97. Synthetic map of house locations on landscape................................213

Figure 98. Chronological and spatial development of the Village 1830-1855 .....215 


\section{CHAPTER 1 INTRODUCTION}

In the mid-19th century, the largest and most ethnically diverse historic-period settlement on the Pacific Coast developed in the shadow of Fort Vancouver's stockade. Lower-class fur trade employees and their families lived in the settlement historically referred to as "the Village" from 1825 to 1860 , during the Hudson's Bay Company's (HBC) tenure on the Columbia River. The success of the HBC's fur trapping, agricultural, and industrial endeavors at Fort Vancouver is attributable to this large labor force numbering in the hundreds and assembled from Europe, North America, and the Sandwich Islands (Hawai'i).

Fort Vancouver National Historic Site (NHS) (45CL163H) and the associated Village archaeological site (45CL300) - in modern Vancouver, Washington (Figure 1) are the location of active archaeological research. Beginning with the discovery of the first Village residence in 1968, archaeologists and historians have expanded their research beyond the administrative center of the stockade and the social elites to also explore identity, inequality, and colonialism during the fur trade. Forty years of excavation and research in the Village have revealed 16 houses and 9 potential houses or ephemeral habitation areas (Kardas 1970; Chance and Chance 1976; Chance et al. 1982; Thomas and Hibbs 1984; Thomas 1995; Gembala et al. 2004). Inspired by an 1845 description of the Village, which described houses that were "as various in form" as their occupants (Hussey 1957:218), this study examined community-level social relationships in this 19th-century fur trade community through vernacular architecture and landscape. 

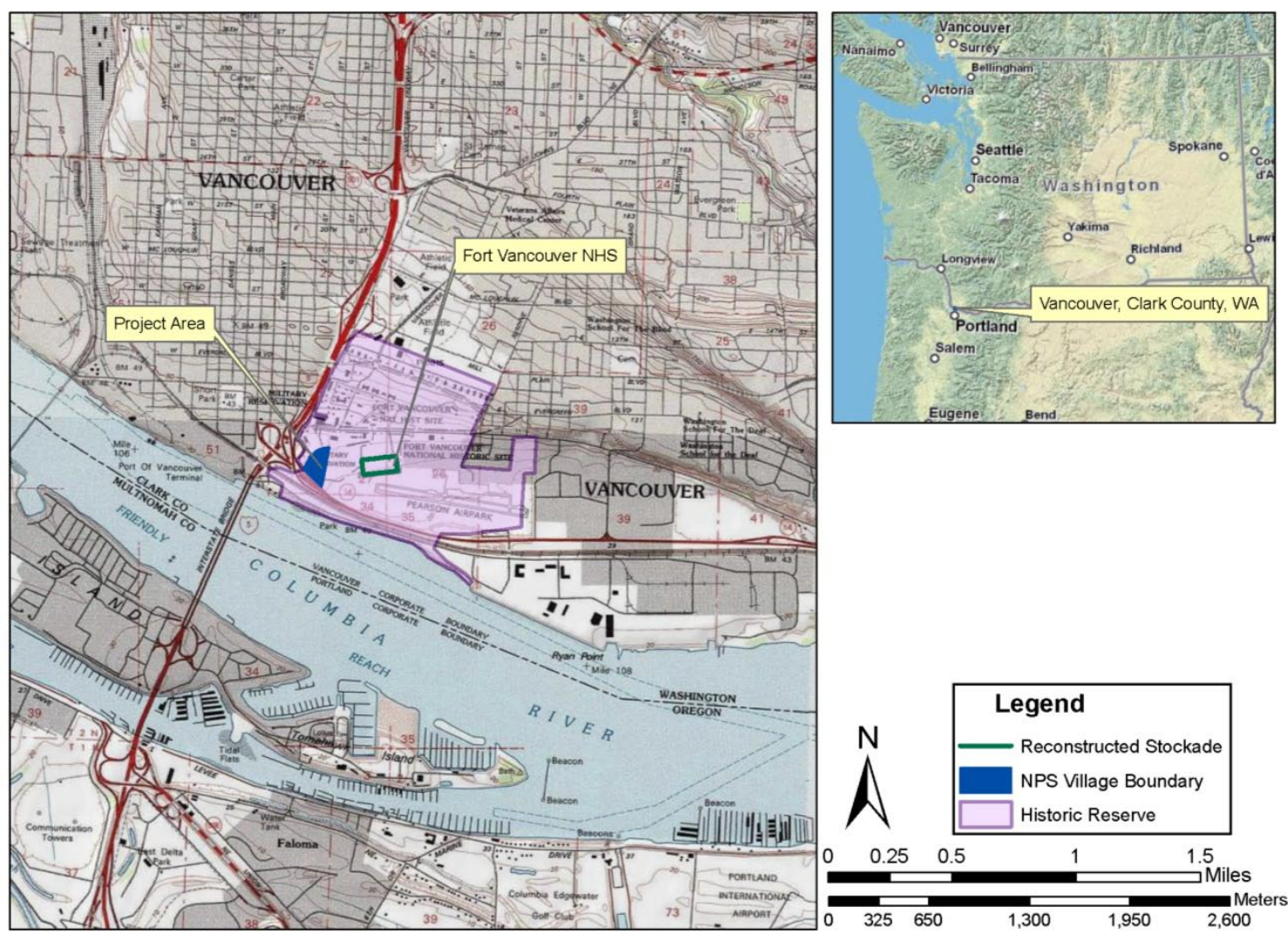

FIGURE 1: Project area location map showing Fort Vancouver NHS, the NPS-administered portion of the Village, and the encompassing Vancouver National Historic Reserve. (Map by author, 2011.)

Archaeologists have shown that architecture and the arrangement of space in pluralistic colonial settlements serve social and communicative functions (Burley et al. 1992; Monks 1992; Lightfoot et al. 1998; Loren 2000; Nelson 2007). The houses of Fort Vancouver's Village were part of a single landscape, despite being constructed by employees whose differing cultural identities were reinforced by a stratified social and work structure. The construction of houses and modification of the landscape are social practices that, like eating habits or clothing choices, are constrained by social structures, unequal power, and history (Bourdieu 1977; Lightfoot et al. 1998; Ortner 1994, 2006). Thus the styles and arrangement of houses have the potential to reveal how employees viewed themselves and their culturally diverse coworkers within the context of the 
Village community. Did the Village community implement a single architectural style? Were the employees actively emphasizing the HBC-defined job and ethnic differences? Did similar architectural elements stem from the existence of an emergent Pacific Northwest fur trade culture?

Architecture-related artifacts account for the majority of the material culture recovered from the Village, but these artifacts have received less analytical attention than domestic and personal artifacts (as is common at other historical archaeological sites) (Kardas 1971; Sprague 1980; Bray 1984; South 2002; Cromwell 2006; Hicks and Horning 2006:273). Structural features (such as post-holes, hearths, and foundation sills) and construction materials (such as bricks, nails, and window glass) reveal evidence for a building's style, function, date of occupation, and demolition. The original descriptions of these houses generally assessed location and size (based on feature and artifact distribution), and occupation dates were assigned based on the associated domestic and artifacts (ceramics, buttons, and coins). This study demonstrates that revisiting old excavation assemblages with newer analytic techniques can illuminate previously unknown architectural and landscape details. The resulting architectural life histories revealed that these five houses, all stemming from a common French-Canadian architectural tradition, had been built in the first half of the HBC's tenure at Fort Vancouver, and then occupied (and repaired) by a second wave of employees at some time during the 1840s. These findings serve as a reminder that Village houses should not be conceptualized as the possession of a single household. The houses went through multiple owners, creating a palimpsest in the architecture and in the associated artifact 
assemblages that have clear implications for archaeological research interested in exploring the cultural diversity of the community.

Chapters 2, 3 and 4 provide the historical, archaeological, and theoretical background contexts for the Village houses and the analysis of vernacular landscapes. The analytic methods are presented in Chapter 5. Chapters 6 through 10 describe the architectural features and artifacts from each house assemblage, and then present the evidence for the layout and life history interpretations. Architectural variability, the vernacular landscape, and community "projects" are discussed in Chapter 11. Chapter 12 summarizes the findings and concludes the study with a look towards future research in the Village. 


\section{CHAPTER 2}

\section{HISTORICAL AND ARCHAEOLOGICAL CONTEXT OF THE VILLAGE}

A rich historical and scholarly record documents many aspects of the North American fur trade, including the motivations, operations, and people of the Hudson's Bay Company (Hussey 1957, 1972, 1977; Kardas 1970; Erigero 1992; Brown et al. 1994; Burley 1997; Fiske et al. 1998; Cromwell 2006). This wealth of information exceeds the space available in this thesis and will not be replicated here except to briefly illuminate the economic, political, and social forces behind the formation of the culturally diverse workforce that lived in the Village.

The Village existed under an aegis of colonialism. The HBC's administrative decisions influenced the settlement's formation and demographic composition. Even the history of the Village that has been perpetuated through the written record is told from a European-American perspective. Of all the administrative records, maps, illustrations, personal journals, letters, Church records, and testimony given during the BritishAmerican Joint Commission hearings that address the Village and its residents, none have yet been attributed to a Village resident. The two characteristics of the Village that drew the most comments in these documents were the varied cultural identities of the residents and the physical appearance of their houses.

\section{Fort Vancouver: Geographic and Economic Context}

The HBC founded the first Fort Vancouver in 1825 on a bluff approximately one mile north of the Columbia River. In 1829, Chief Factor John McLoughlin moved the post to the lower prairie (known as Belle vue Point or Jolie Prairie) on the Columbia's north bank, where the reconstructed stockade now stands. Initial concerns about flooding 
and Indian hostilities were unfounded and the cost of transporting supplies between the bluff and the river proved unreasonable (Thomas and Hibbs 1984:30). Agricultural fields and grazing pastures surrounded the stockade, extending miles upstream. Southwest of the stockade, along the river near the wharf, was an area of workshops and storage warehouses known as the Riverside Complex. The Village was north of the Riverside Complex, extending to the road that is now East 5th Street. On the north side of this road was the church, HBC cemetery, and a few other buildings (Figure 2) (Hussey 1957).

When the HBC established Fort Vancouver, the North American fur trade was a 200-year old industry and was beginning to decline. Competing fur companies had decimated beaver populations as each tried to capitalize on the high European demand for beaver pelts (Kardas 1971:25; Eccles 1988; Erigero 1992:3-4; Rogers 1993:32; Cromwell 2006:44). A royal charter in 1670 originally granted the London-based HBC a trade monopoly over all lands that drained into Hudson's Bay (Hussey 1957:8; Erigero 1992:3). The company had no dealings in the Pacific Northwest until 1821 when the HBC merged with its primary rival, the North West Company (NWC), and acquired the 1,800,000 square-km (700,000 square-mile) Columbia Department (Figure 3), all NWC posts, and NWC employees (Hussey 1957:9-15; Eccles 1988:333; Erigero 1992:5; Cromwell 2006:48).

The Columbia Department was costly to manage because of its size and distance from England (Kardas 1971:27-28; Ross 1976:120; Erigero 1992:11). Supply ships bringing European goods required at least a year to complete a round trip between London and the Pacific Northwest. After arriving at Fort Vancouver, supplies had to be transported to the subsidiary posts. The HBC immediately implemented cost-cutting 


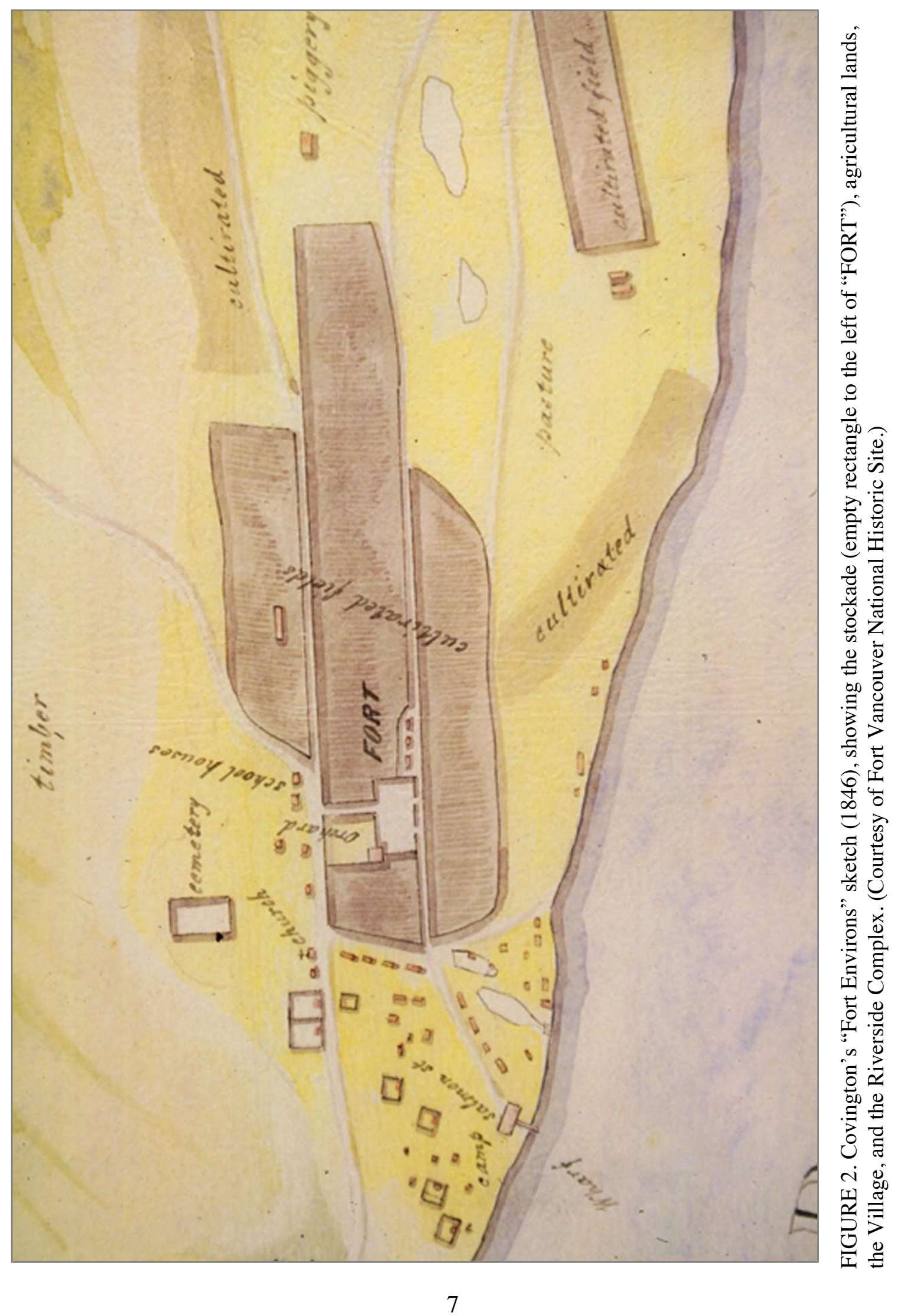




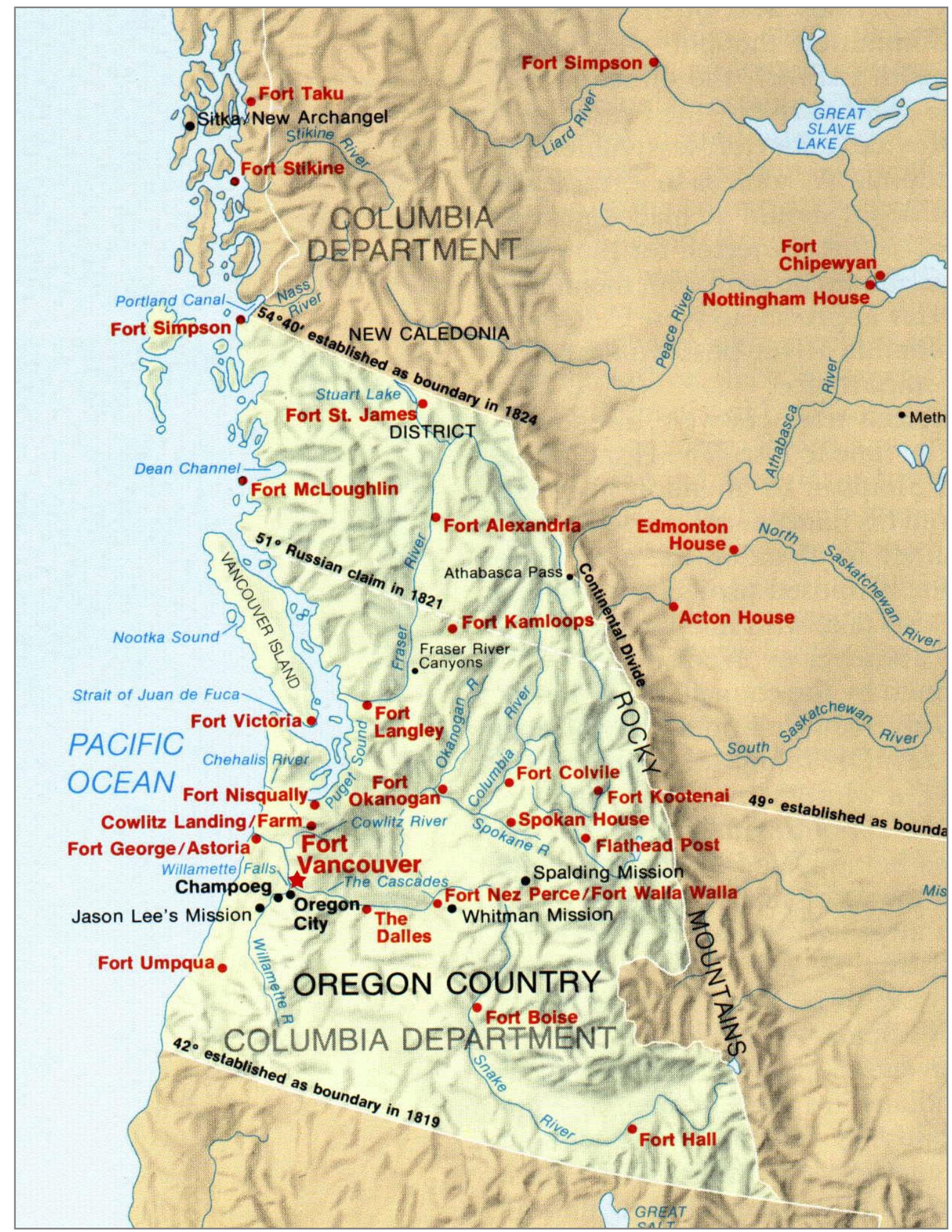

FIGURE 3. Hudson's Bay Company posts in the Columbia Department (yellow area) and other notable historic settlements and U.S. military posts. (Courtesy of Fort Vancouver National Historic Site.) 
measures and encouraged self-sufficiency among its posts (Irving 1967; Kardas 1971:2526,29; Ross 1976:120; Erigero 1992:4,6). By initiating an agricultural program, building a sawmill, and pursuing other production industries at Fort Vancouver, the HBC was able to support its forts with many local goods and succeed in the Pacific Northwest, where other companies had faltered (Kardas 1971:5; Cromwell 2006:45-46).

Fort Vancouver was the headquarters of the Columbia Department from 1829 to 1846, the post's principle period of activity and development. During this time, the HBC employed over 200 trappers, tradesmen, and laborers in its agricultural and industrial operations (Steele 1977; Erigero 1992:37). The fur trade formed the backbone of Fort Vancouver's operations, but the HBC also devoted approximately 19,200 to 25,600 acres (7,770 to 10,360 hectares) of land surrounding Fort Vancouver to large-scale crop production, livestock grazing pastures, orchards, and ornamental gardens (Carley 1982:2). The sawmill, gristmill, dairies, blacksmith shop, carpenter's shop, cooperage, tanneries, shipbuilding, and salmon processing facilities all reduced the Columbia Department's dependence on European imports. The economic focus shifted to these industries when fur returns dropped in the 1840s and 1850s - a result of the HBC's overtrapping of the Columbia River and Snake River basins (Ross 1976:1325).

Ironically, the agricultural and industrial success of Fort Vancouver advertised the region's settlement potential to American settlers and contributed to the loss of British control in the Pacific Northwest (Hussey 1957:1). The only agricultural production, industrial manufacturing, and marketing center in the Pacific Northwest, Fort Vancouver was a natural destination for scientists, explorers, missionaries, and settlers who passed through the region (Kardas 1971:4-5; Steele 1975:90; 1977:175; Erigero 1992). Despite 
HBC orders to the contrary, Fort Vancouver's Chief Factor, Dr. McLoughlin, provided supplies and aid to those entering Oregon Territory (Erigero 1992:37). The HBC was allowed to continue operations on their existing land holdings following the 1846 annexation of Oregon Territory by the United States, but import fees implemented at the mouth of the Columbia River limited Fort Vancouver's operations to the point that by the early 1850s supply ships stopped visiting Fort Vancouver altogether (Steele 1975; Ross 1976:121). The HBC relocated its Columbia Department headquarters to Fort Victoria on Vancouver Island, British Columbia in 1847 (Gembala et al. 2004:11; Cromwell 2006). In 1849, the U.S. Army established Columbia Barracks (later known as Vancouver Barracks) on the hill above Fort Vancouver. Fort Vancouver continued to operate, albeit with a smaller workforce and fewer industries, until 1860 when the HBC formally abandoned Fort Vancouver and left the property in the care of the U.S. Army (Erigero 1992).

\section{Diverse and Stratified Workforce}

The HBC's highly stratified social order determined an individual's job, duties, wages, and place of residence based on perceived ethnicity (Ross 1976:6; Erigero 1992; Hamilton 2000; Lightfoot 2005:23; Cromwell 2006:79). Housing within the stockade was reserved for the relatively few elite commissioned officers and gentlemen, who oversaw the day-to-day fur trade operations at the post (Hussey 1957:216). The administrative jobs were assigned to men of English or Scottish descent, and occasionally FrenchCanadian descent.

The employees who lived in the Village were part of the "lesser" servant-class, which included men of French-Canadian, Métis, Iroquois, local Native American, and 
Anglo-Saxon descent. There were four categories of servant class jobs: Gentlemen, Tradesmen, Voyageurs, and Laborers (Figure 4) (Ross 1976:6; Cromwell 2006). The tradesman and laborer occupations were land-based and the voyageur class included water-based and fur trapping occupations. The only servant-class employees allowed to live inside the stockade were those whose jobs took place there, such as clerks, bakers and kitchen staff (Ross 1976:7; Thomas and Hibbs 1984:31).

Changes in the fur trade economy influenced the composition of the workforce and the Village population. In the early years of Fort Vancouver (1827 to 1837), when fur trading was the company's chief economic focus, French-Canadians, Métis, and Iroquois dominated the workforce. Employed in water-based and trapping jobs, these men had made the journey from eastern Canada where they had worked for the Montreal-based NWC, which had operated in the Pacific Northwest since 1810 (Towner 1984:793-811; Cromwell 2006:83; Jameson 2007:72-73). Voyageurs did not live in the Village yearround. For nine months of the year these employees were assigned to fur brigade expeditions throughout Oregon, Washington, Idaho, and Northern California. They returned during the summer when the animal pelts were thin, and were sometimes housed by coworkers or camped in open areas (Hussey 1957:6; Cromwell 2006:56).

When Fort Vancouver's land-based industries expanded in the 1830s and 1840s additional employees were hired for more manual labor needs, including agricultural field hands, cooks, livestock herders, and sawmill operators. Some of these employees lived in the Village, while others likely lived closer to the sawmill upriver. These jobs were most 


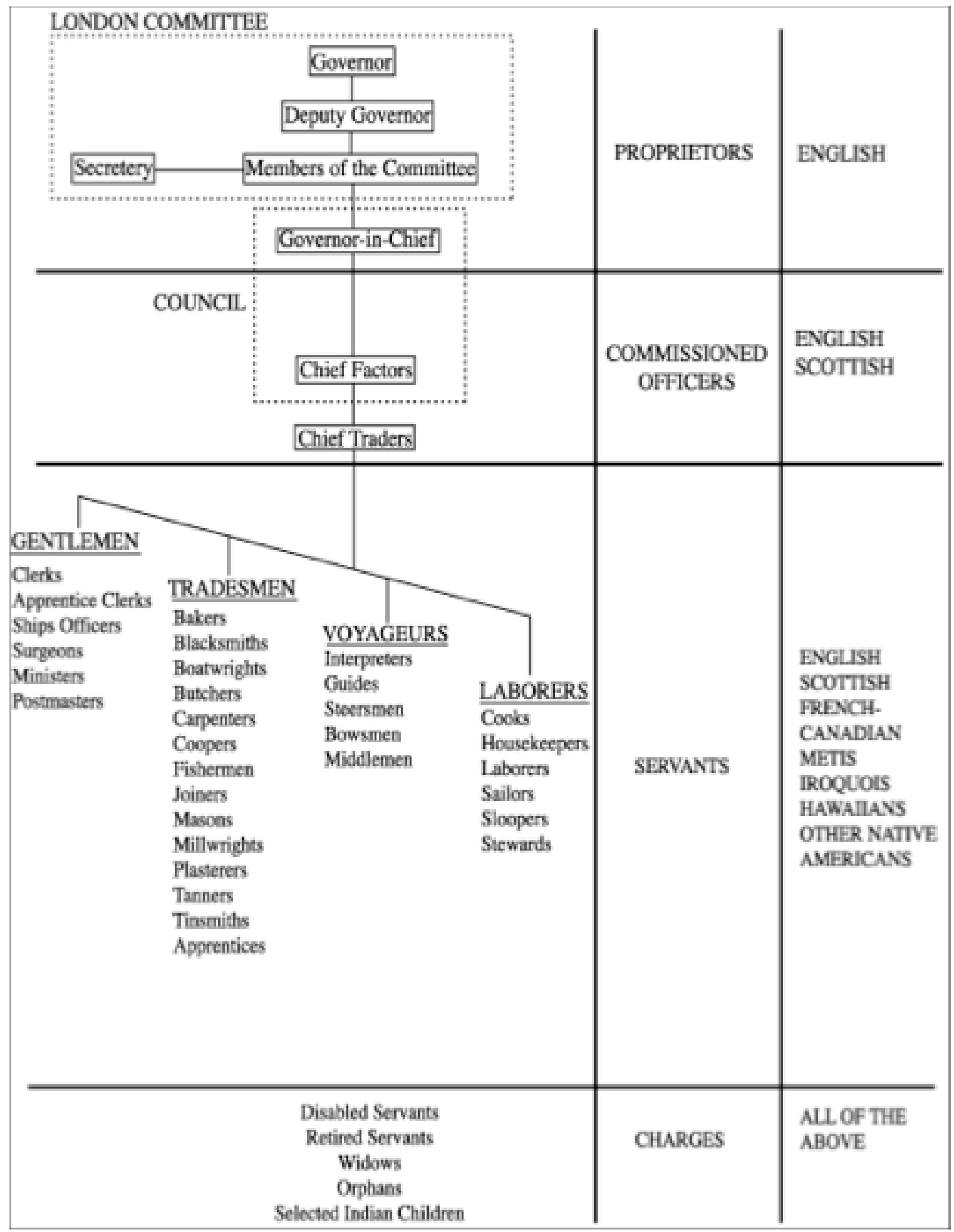

FIGURE 4. HBC organizational hierarchy ca. 1825-1860 (Cromwell 2006:85). 
commonly assigned to Native Hawaiians and local Native Americans, whose traditional subsistence practices had undoubtedly been disrupted by disease and fur trapping (Kardas 1971:116; Towner 1984:793-811; Gibson 1988:376; Rogers 1993:35-37; Cromwell 2006:73). Anglo-Saxon employees continued to hold many of the tradesmen jobs, including bakers, blacksmiths, coopers, masons, and millwrights (Towner 1984:798-799).

\section{The Village}

The earliest known written reference to the Village dates to 1832 , but it may have existed as early as 1827 when Fort Vancouver's dock was being constructed on the lower prairie (Wilson 2005:5). Historic maps, illustrations, and commentaries suggest the Village was a stable settlement, approximately 700 feet $(213 \mathrm{~m})$ west of the stockade, with an estimated average of 30 to 50 houses arranged in "deliberate clusters" (Hussey 1957:217-218; Thomas and Hibbs 1984:43-44). Two broad house-lined roads formed the primary arteries of the community, one north-south road led from the wharf and pond to the Catholic Church and another ran east-west through the middle of the settlement (Figures 5 and 6) (Hussey 1957:218).

The houses have been variously described as little "huts" and wooden "shacks." The Village residents were responsible for building their own homes on their own time and wages, but the structures were never entirely theirs to control (Hussey 1957:216-220; 1977:48-49). Employees were often required to lodge travelers who visited Fort Vancouver and the fur brigade members during the summer (Hussey 1957:218-220). The HBC owned the structures and likely retained the right to assign vacant houses to other employees and rent them to the U.S. Army (Hussey 1977:49). 


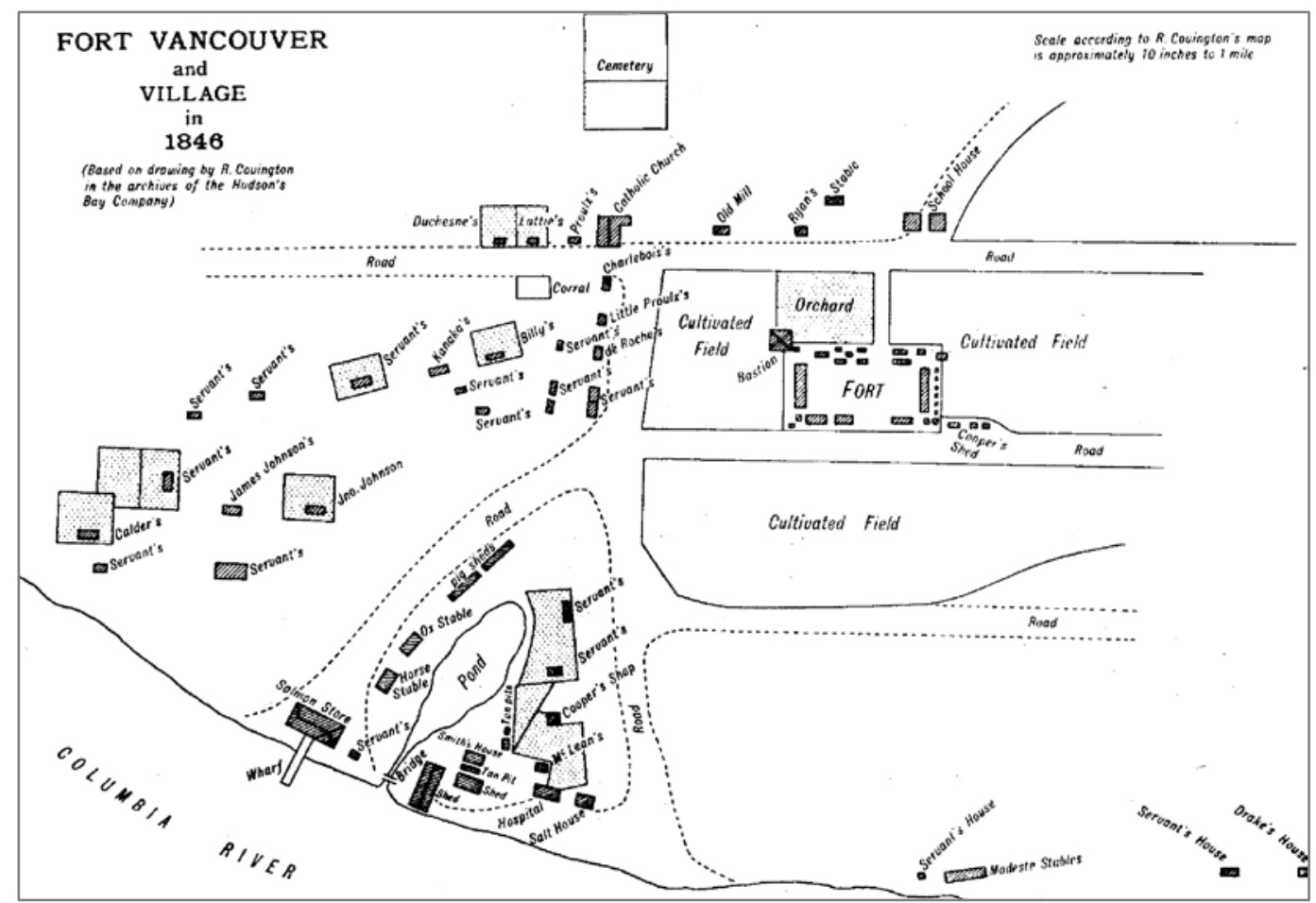

FIGURE 5. Map of Fort Vancouver and Village based off a 1846 map by R. Covington, with occupant names attributed to some structures (Thomas and Hibbs 1984).

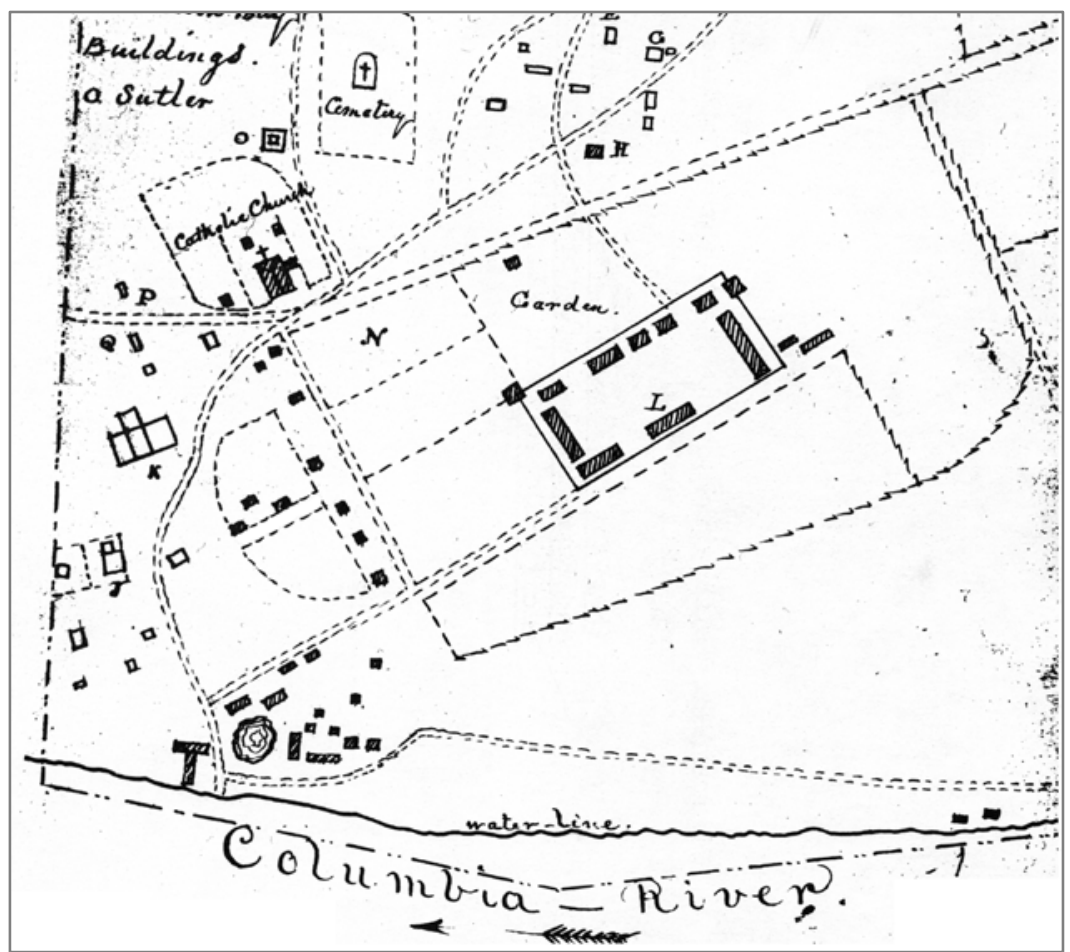

FIGURE 6. Detail of 1854 Mansfield Map showing Village at left. (Courtesy of Fort Vancouver National Historic Site.) 
An American visitor to Fort Vancouver in 1845, Joel Palmer, declared that the houses were "as various in form as were the characteristics of their inmates" seems to associate house form with occupant identity (Hussey 1957:218). It is not clear what type of formal variation Palmer was referring to. HBC millwright William F. Crate, in his testimonial to the British-American Commission, described the Village landscape as such:

Some dwellings were built in "Canadian style" (2 or 4-inch planks); some were built in "American cottage fashion" (framed and weatherboarded); some were of squared timbers; a "very few" were of logs; and a number were of "edged slabs" from Company's sawmill (the slabs applied with flat side out). The houses were generally one story high, but some had one and a half stories. A number were ceiled inside, and some were even papered. More were plastered with clay. They generally contained two or three rooms, although many had but a single room (Hussey 1957:218-219).

This description by Crate points to a few different construction methods and materials but also gives the impression that most were one-story high, one-room houses. If the illustrative record of the Village is accurate, many houses resemble the "Canadian style" wall construction. The variation Palmer spoke of might refer to differences in the types of hearths, roofing materials, and placement of structural elements like doors, windows, and side-sheds (Figures 7-9). The illustrative record is based on three circa-1850s drawings by George Gibbs (Figure 7a-c), Paul Kane (Figure 8), and Gustavus Sohon (Figure 9).

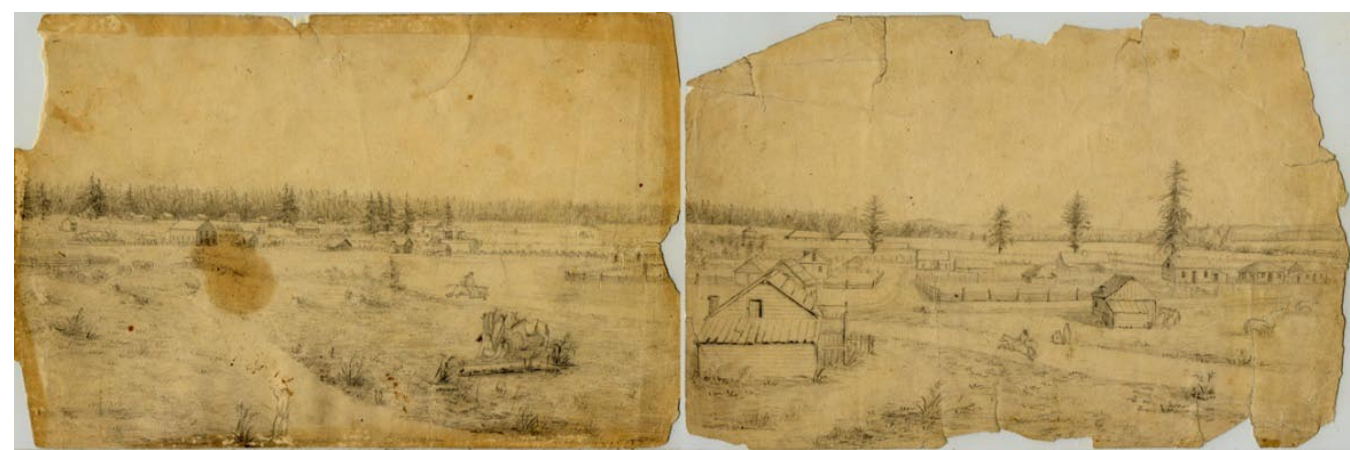

FIGURE 7a. Illustration of the Village by George Gibbs (1851), looking east, Stockade in distance. (Courtesy of Fort Vancouver National Historic Site.) 


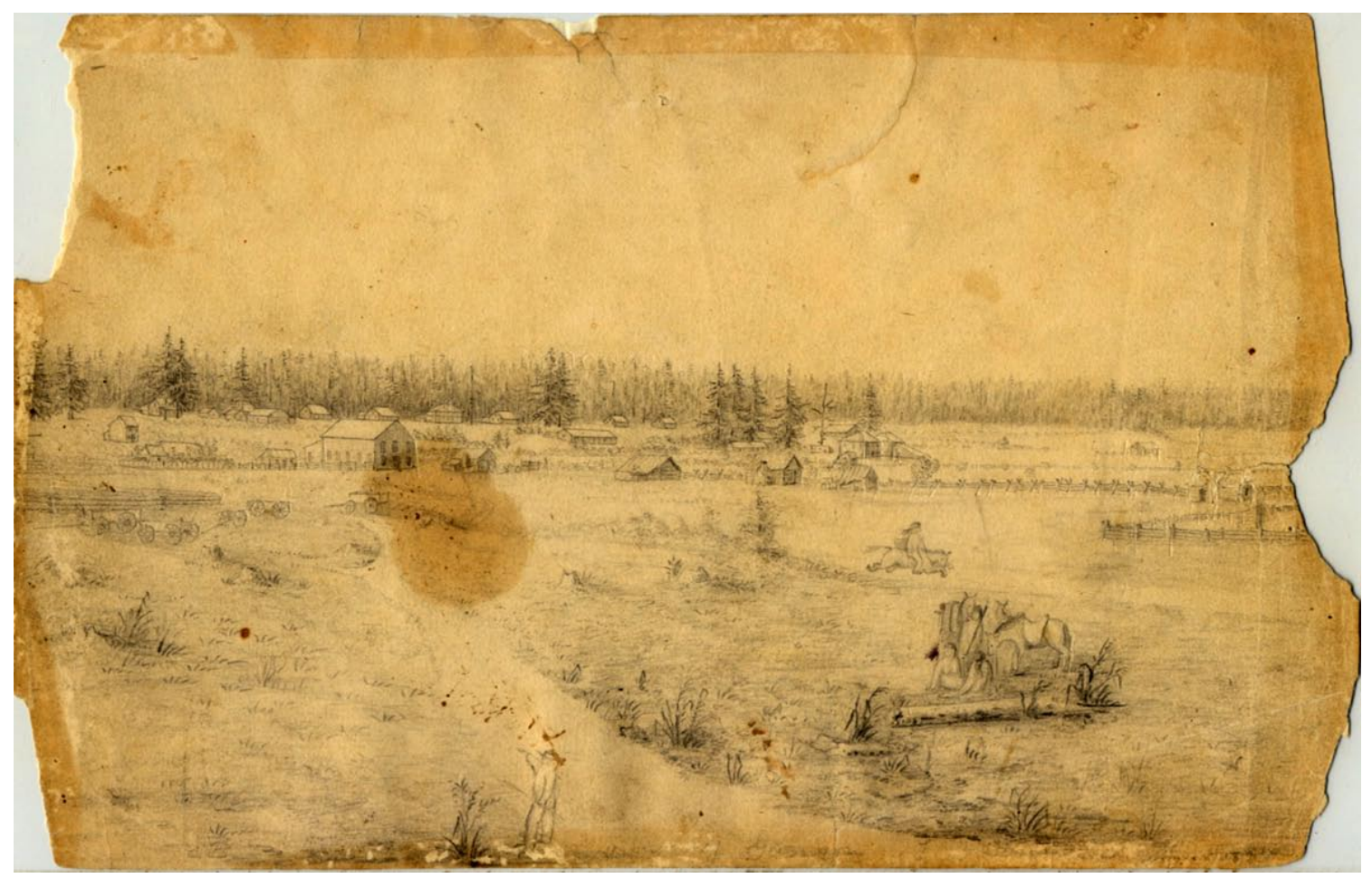

FIGURE 7b. Left half detail of the 1851 Gibbs sketch of the Village. (Courtesy of Fort Vancouver National Historic Site.)

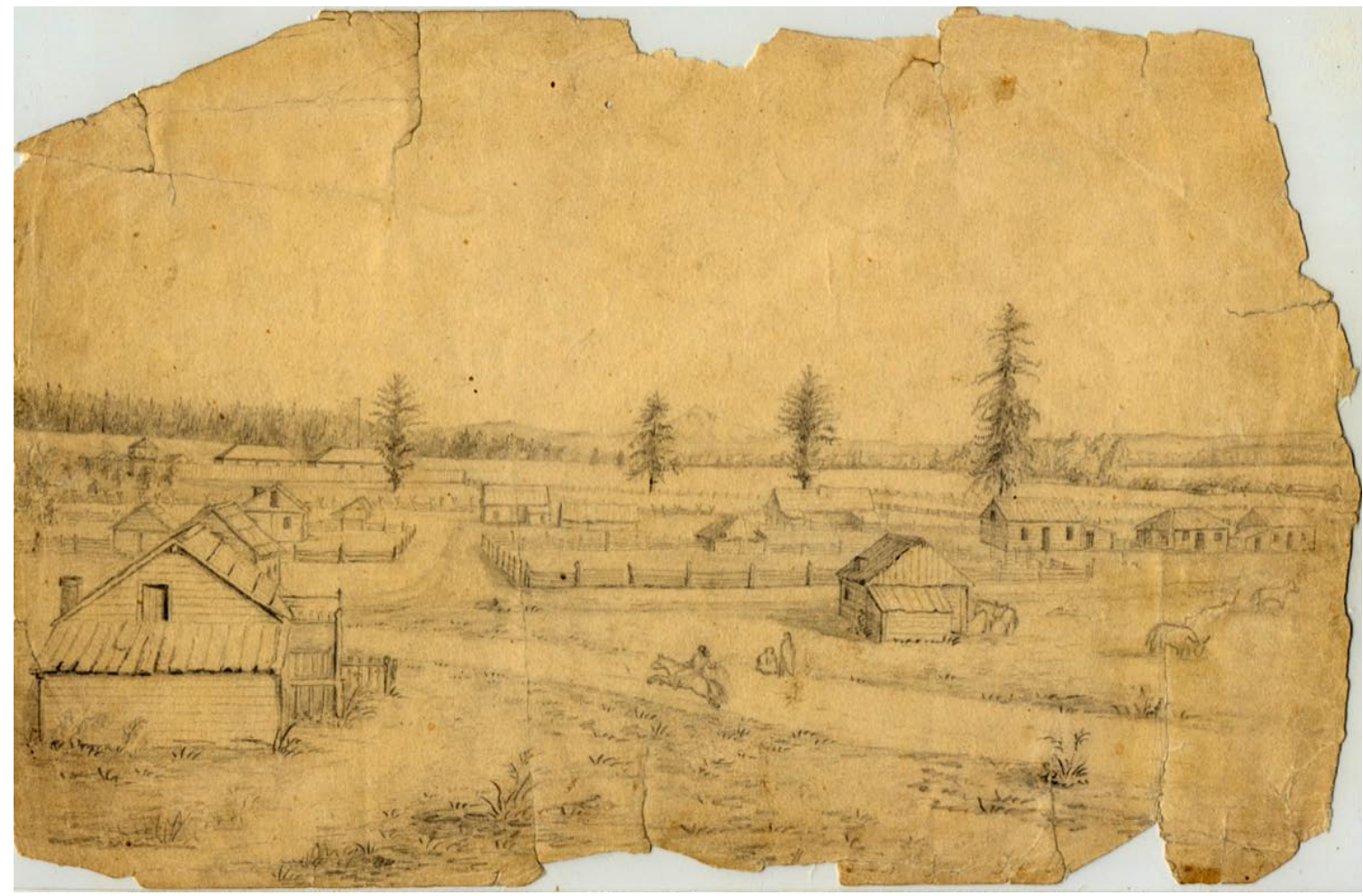

FIGURE 7c. Right half detail of the 1851 Gibbs sketch of the Village. (Courtesy of Fort Vancouver National Historic Site.) 


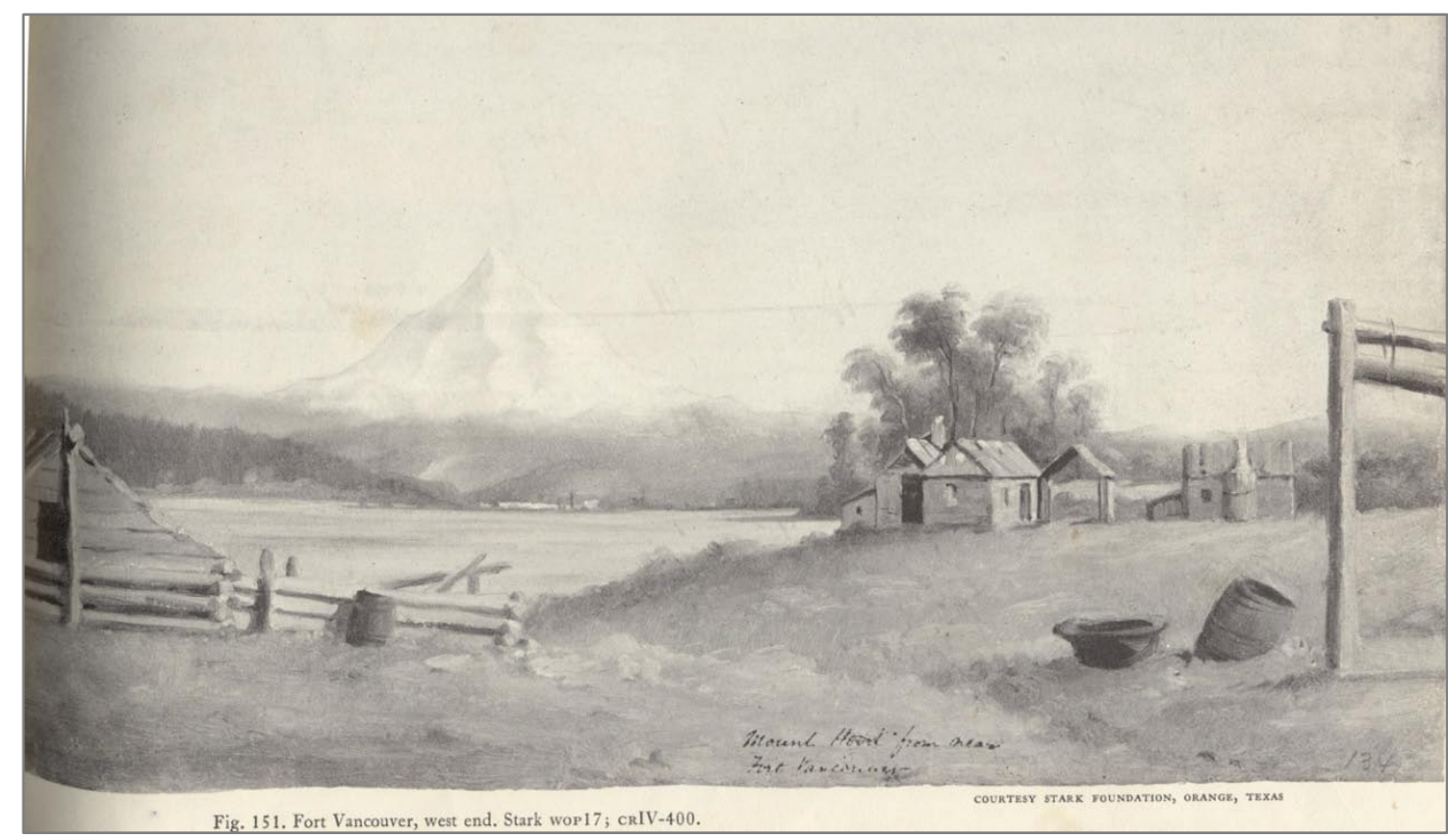

FIGURE 8. Paul Kane's sketch of the Village, looking east. (Courtesy of Fort Vancouver National Historic Site.)

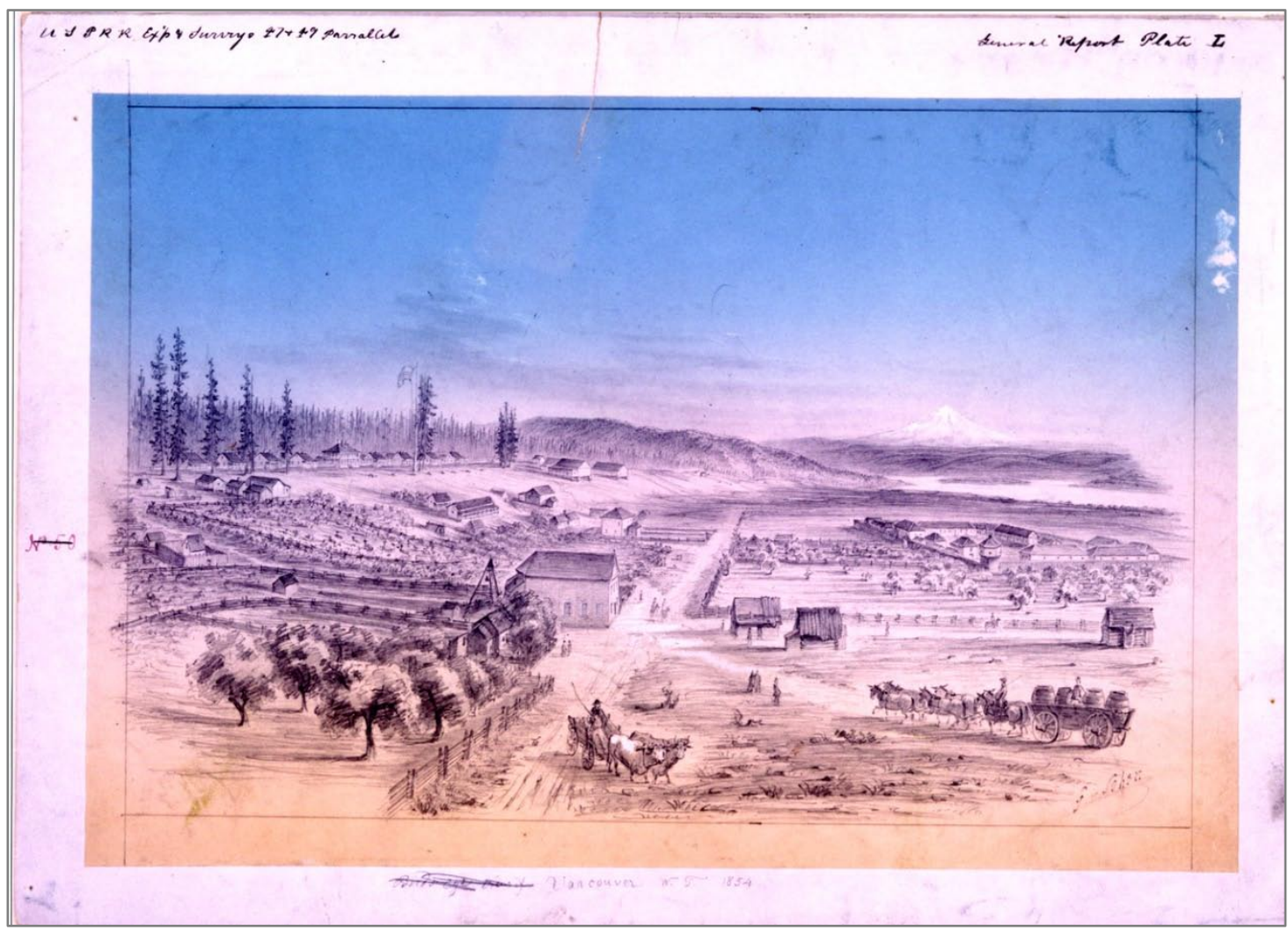

FIGURE 9. Gustavus Sohon's lithograph of the Village and Vancouver Barracks. (Courtesy of Fort Vancouver National Historic Site.) 
In addition to the possibility that employees built their homes using architectural traditions specific to their cultural backgrounds, ethnic identity affected what goods and materials employees could access to build their houses (Cromwell 2006:123-126). The HBC donated lumber from the company sawmill, but the employees had to purchase the other construction materials from the HBC Sale Shop (Thomas and Hibbs 1984:45). An employee's purchasing ability was not only influenced by his annual credited wages, which were influenced by his job-class and perceived ethnicity, but the sale price of imported and country-made goods could vary "year-to-year, season to season" and be adjusted according to "a person's social, cultural, and economic status" (Ross 1976:149). For example, Hawaiian employees were charged much more $(\cos t+200 \%)$ for goods (but earned less annually) than their European coworkers. It is little wonder that houses associated with well-paid Scottish tradesmen (blacksmith, carpenter, cooper) were allegedly perceived as being of a "better class" (Thomas and Hibbs 1984:298).

\section{Demographics}

The Village was diverse in age, gender, religion, and class in addition to ethnicity. The population included the Native American or Métisse wives and children of employees as well as "charges" of the company (widows, orphans, or disabled employees) (Hussey 1957:216; Kardas 1971:198-210; Thomas and Hibbs 1984:30; Cromwell 2006:66). Much to the dismay of the Anglican and Catholic Churches, these informal marriages á la façon du pays could be officiated by any company officer or through the simple act of cohabitation. Most women were Chinookan, Salishan, and Sahaptin speakers from Columbia Basin tribes, but women from Alaska, California, the Great Basin, and the Great Lakes were also present (Kardas 1971:210-211; Thomas and 
Hibbs 1984:32). Many of the Chinook women brought slaves with them to the Village (Ames 2001:2-5; Hajda 2005:570,573). Reverend Beaver comments on Native Hawaiian wives, but no other records corroborate their presence (Rogers 1993:67). The children at Fort Vancouver were not frequently discussed outside baptism records, but they were nevertheless present. The first school in the region was established in 1832 to teach the children who lived at Fort Vancouver (Cromwell 2006:55). Like the Métis employees, who themselves were the offspring of fur trade unions in the east, these children represent the biological consequences of the fur trade.

Like everything else at Fort Vancouver, the Village population size likely peaked sometime in the $1840 \mathrm{~s}$. The shift from trapping to manufacturing and mercantile activities at the fort probably resulted in a more employees living in the Village than had lived there previously. In the 1850 s, the workforce and Village population shrank along with the HBC's business on the Columbia River. Precise population estimates are difficult because no $\mathrm{HBC}$ records specifically address its demographics. Every employee is listed on the HBC rosters, but many were away on brigade expeditions for most of the year, while others worked and lived in the stockade, or near sawmills, dairies, and distant agricultural fields upstream (Thomas and Hibbs 1984:31; Rogers 1993:44). Based on a study of the employee rosters, an estimated 100 to 200 male employees lived in the Village from 1828 to 1843 (Towner 1984:793-811). This estimation method leaves out the families and charges. While some church marriage, baptism, and death records identify the names of spouses and children, these records are not all inclusive.

To account for the non-employees living in the Village, house-based estimates use the historical descriptions of the Villages that provide building counts and assume an 
average of 10 people (bachelors or families) residing in each house (Hussey 1957:218220). During Fort Vancouver's peak years, observers estimated there were 30 to 100 houses, which translates to a population of 300 to 1000 . The accuracy of this method depends entirely on the estimated building counts provided by visitors and traveler, which varied widely and possibly included outbuildings, sheds, and barns in addition to the residential structures (Hussey 1957:218-220; Thomas and Hibbs 1984:45).

\section{Social Relations}

The colonial social structure of Fort Vancouver emphasized difference in order to reinforce status. The company elites separated their living quarters from the servant class in a clear physical manifestation of class distinction. Evidence of how members of the "lesser" servant class viewed each other is less apparent. The close relationship between job-class and ethnicity makes class struggles indistinguishable from racial prejudice. For example, in 1840 the European and French-Canadian employees protested the hiring wages of Hawaiian laborers, and in the following year the Hawaiian annual wages were cut from $£ 17$ to $£ 10$ (Thomas and Hibbs 1984:34). Regardless of whether the catalyst was perceived value of job responsibilities or racial entitlement, the European and FrenchCanadian employees attributed higher monetary values to themselves than to their Hawaiian associates.

Multiple historical sources suggest the Village was ethnically segregated, with "separate streets for French-Canadians, for Kanakas, and for Englishmen and Americans" (Hussey 1957:218; Thomas and Hibbs 1984:44; Neilson 2003:4-5). Ethnicity-based neighborhoods were not uncommon in the fur trade. Archaeological research at Fort Ross, a Russian fur trade post in Northern California, confirmed the existence of separate 
"neighborhoods" for its Russian, Alaskan, and Native Californian employees (Lightfoot et al. 1998). The employee residences at Fort Nisqually and Fort Langely, HBC posts contemporaneous to Fort Vancouver, were also reportedly organized by ethnicity (Stilson 1991:18.11; Neilson 2003:5). Claims about ethnic clustering in the Village are based only on the surnames and identities of male employees/heads of households: "Joe Tayenta," "Charlebois," "Little Proulx's," "Kanaka's," "Billy's," and "Jon Johnson's" (Covington 1846; Thomas and Hibbs 1984:44; Leslie O'Rourke pers comm. 2009). The fact that many families were multi-ethnic, with Métisse or Native American wives and Métis children, is ignored.

There are examples of the colonial powers creating distinctions where the parties involved saw none. In the Canadian fur trade "French Métis" and "British Métis" were perceived and treated differently by the colonial powers because the French and British employees had unequal status, but from the Métis perspective both groups were part of a single, self-recognized community (Burley et al. 1992:14; Burley 2000:28). Could a similar scenario have occurred at Fort Vancouver?

The 1850 Oregon Territory Census for Clark County documented the Village living arrangements when the fur trade activities were in decline and Fort Vancouver was focusing its efforts on agriculture and production industries. The census, which lists individuals by house, clearly shows men from the Sandwich Islands, Canada, England, Scotland, and Oregon cohabiting in the Village (Cromwell 2006:75-76). Cromwell (2006:77-78) provides a list of 11 houses most likely from the Village, each with three to six "laborers" and "farmers" ranging in age from 16 to 45 years old. Unless women and young children were purposefully excluded from the census, it seems the Village of the 
1850s included many 'households' of single male employees who remained after the families had retired to the Willamette Valley and elsewhere in the region.

\section{Post-HBC Activities in the Village}

The U.S. Army arrived in 1849 and rented some of the better Village structures for the Quartermaster Department offices and residences, at the same time the HBC was downsizing its operations and workforce (Erigero 1992:35; Hussey 1957:219; Thomas and Hibbs 1984:49-50, 723). In 1854 twenty structures "built of slabs" were still inhabited by HBC employees, but the structures were no longer maintained and had begun to decay (Hussey 1957:219). The U.S. Army treated the uninhabited structures with disregard and cannibalized them for firewood, windowpanes, and other building materials for their own structures because construction materials were often scarce and expensive (BAJC 1865:193; Hussey 1957:219-220; Thomas and Hibbs 1984:51, 56-57). Most of the decaying Village dwellings were moved or destroyed by 1859 and much of the un-usable materials were swept into the nearby pond (Hussey 1957:219). In March of 1860 only nine HBC structures remained outside the stockade; of these, six were torn down and three were kept because they had some remnant value, including the Salmon House, Johnson House, and Field House. In 1866 the structures associated with the Fort Vancouver stockade mysteriously burned in a fire. The last of the "HBC squatters" were not successfully driven out until the 1870s, at which point the main Village area was turned into an open field with Quartermaster Depot buildings around the periphery (Gembala et al. 2004:11; Wilson 2005). Eventually the Quartermaster structures were torn down. 
The U.S. Army retained ownership of the land into the 20th century and from 1933 to 1941 the Civilian Conservation Corps (CCC) operated their Pacific Northwest regional headquarters out of Vancouver Barracks. The U.S. Army constructed a number of large barracks and warehouses over the northern portion of the former Village (Figure 10) (Gembala et al. 2004).

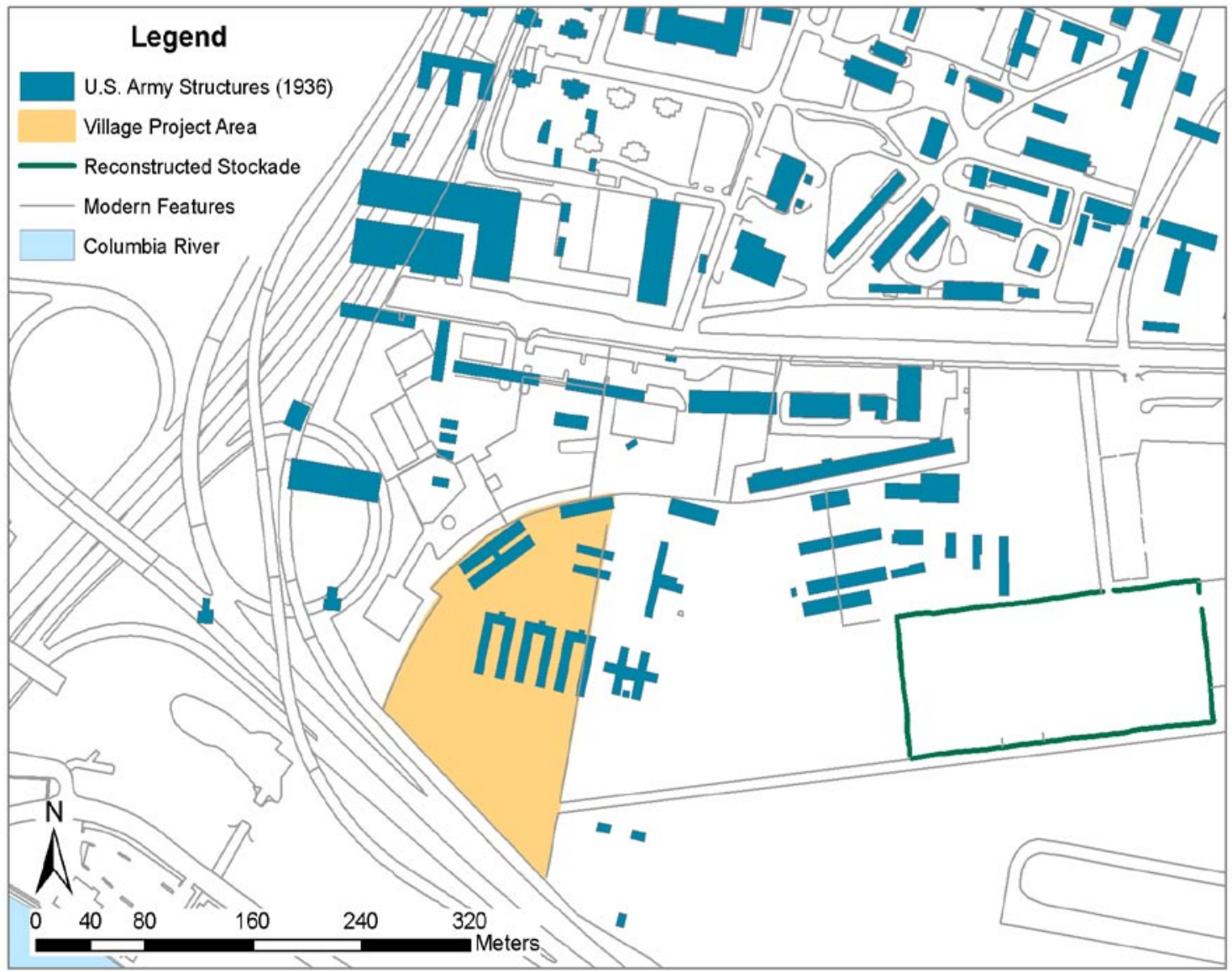

FIGURE 10. Plan view showing the location of early 20th century U.S. Army buildings at Vancouver Barracks, relative to the Village and the Fort Vancouver stockade. (Map by author, 2011.)

\section{Archaeological Background of the Fort Vancouver Employee Village}

The Village archaeological site (45CL300) is bordered to the north by East $5^{\text {th }}$

Street; to the south by the Columbia River; to the west by the Interstate 5 (I-5) corridor; and to the east by an arbitrary line $400 \mathrm{ft}$. west of the reconstructed stockade (Thomas 
and Hibbs 1984:1). The Village site extends onto lands administered by the National Park Service (NPS), the United States Army Reserve (USAR), the City of Vancouver (COV), and the Washington State Department of Transportation (WSDOT). The portion of the Village that is administered by the NPS as part of the Fort Vancouver NHS includes only 6.1 acres of the original approximately 34-acre Village.

Early archaeological research in the Village was both NPS-sponsored and cultural resources management (CRM)-driven. The creation of the Vancouver National Historic Reserve (VNHR) in 1996 established a cooperative historic preservation and archaeological management plan for Fort Vancouver NHS, the U.S. Army Reserve Vancouver Barracks, Pearson Air Museum, and Officer's Row. The NPS has managed archaeological research at the reserve in recent years.

Until 1968, the Village was overlooked while archaeological research at Fort Vancouver NHS focused on the Stockade and its interior structures. Edward Larrabee and Susan Kardas, contracted by the NPS, conducted the first systematic archaeological investigation of the Village in 1968 and 1969. After two field seasons, they had delineated the eastern site boundary, found the remains of four HBC-era houses (designated as Houses 1,2, 3, and 4), and proved there were substantial intact deposits within the NPS-owned portion of the Village (Larrabee and Kardas 1968; Kardas 1970; Kardas 1971:269; Cromwell 2006:15). Susan Kardas subsequently (1971) wrote the first comprehensive ethnographic, historic, and archaeological study of the Village and was the first researcher to focus on the employees, their families, and fur trade social dynamics outside Fort Vancouver's stockade. Multiple WSDOT cultural resource management investigations were conducted on the western and southern edges of the 
Village between 1974 and 1981, prior to the realignment of the SR-14 and I-5

interchange (Figure 11). Most of this property can no longer be accessed. An additional four "dwelling areas" and seven houses were found during these investigations, providing more data on HBC and early U.S. Army architectural trends (Table 1) (Chance and Chance 1976; Chance et al. 1982; Carley 1982; Thomas and Hibbs 1984). Dwelling areas have diffuse boundaries with few or no structural remains (perhaps a fire pit or outdoor hearth), but artifact assemblages that are consistent with identified house sites.

The Systemwide Archaeological Inventory Program (SAIP) (2001 to 2003) project for the Village was only the second large-scale systematic survey of the NPSadministered portion of the Village (Figure 11). Using a combination of shovel tests, block excavations, and geophysical survey techniques archaeologists discovered five previously unknown HBC-era dwellings (only one was explored with block excavations), georeferenced the Kardas excavation maps based on relocated house features and 19681969 trenches, and collected data on the site's extensive 20th-century activities that had been previously ignored (Gembala et al. 2004:16,31,40). To date, these data have not been fully synthesized in a report. Table 1 presents all houses and dwelling areas indentified in the Village as of 2010. 


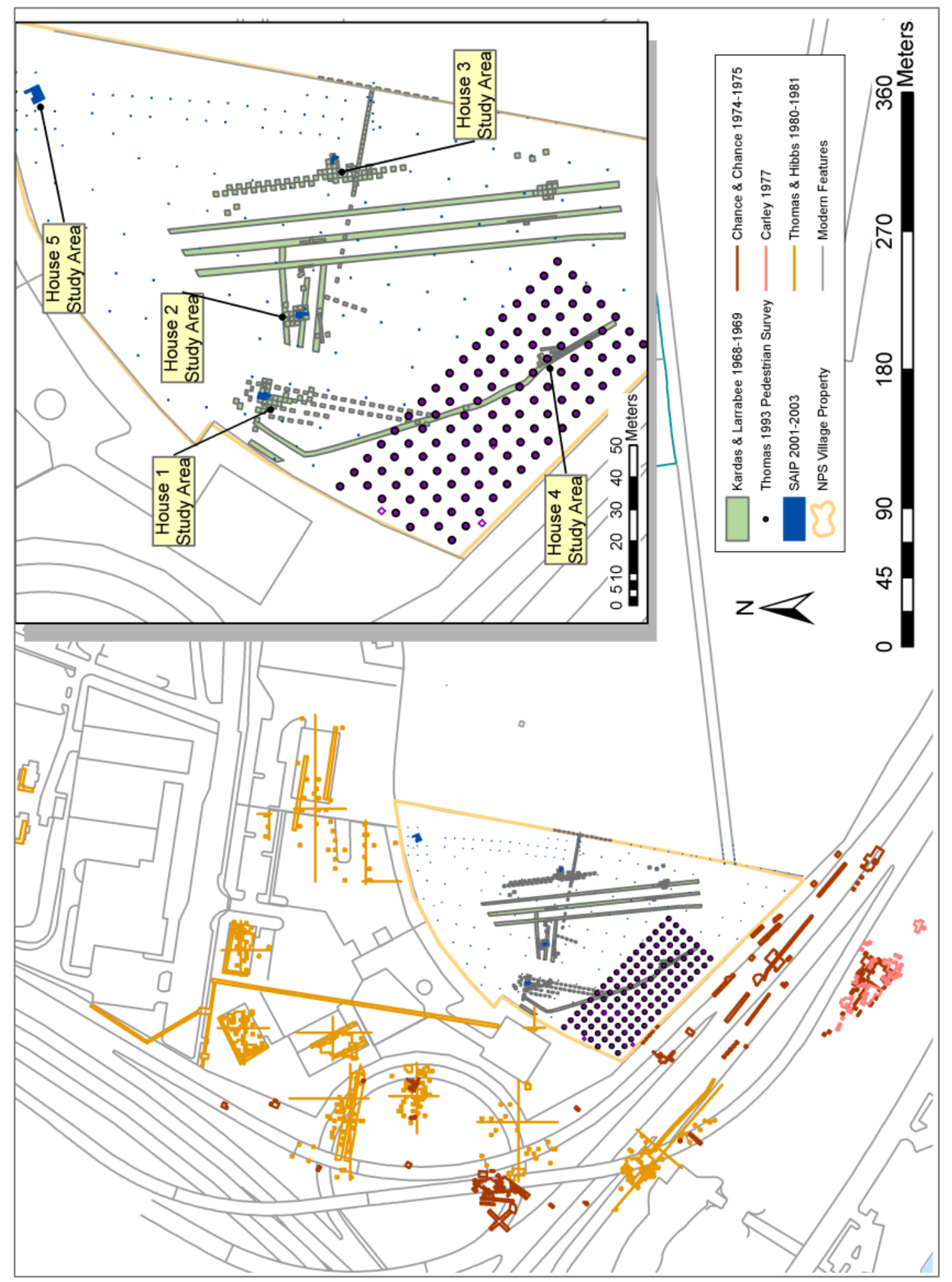

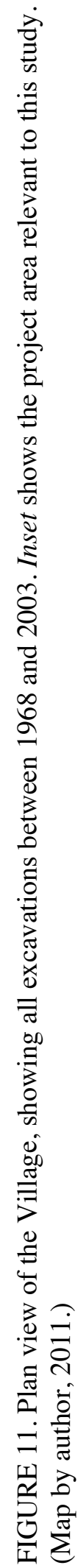


TABLE 1

HOUSES AND DWELLING AREAS DISCOVERED IN THE VILLAGE

\begin{tabular}{lll}
\hline \multicolumn{1}{c}{ Designation } & \multicolumn{1}{c}{ Type } & \multicolumn{1}{c}{ Excavator/ Year } \\
\hline House 1* & Structure & Kardas and Larrabee 1968; NPS 2002-2003 \\
House 2* & Structure & Kardas and Larrabee 1969; NPS 2002-2003 \\
House 3* & Structure & Kardas and Larrabee 1969; NPS 2003 \\
House 4* & Structure & Kardas and Larrabee 1969 \\
OP 6 & Dwelling Area & Thomas and Hibbs 1980-1981 \\
OP 14 (John Johnson's House) & Structure & Thomas and Hibbs 1980-1981 \\
OP 20A (Kanaka's House) & Structure & Thomas and Hibbs 1980-1981 \\
OP 53 & Dwelling Area & Thomas and Hibbs 1980-1981 \\
OP 54 & Dwelling Area & Thomas and Hibbs 1980-1981 \\
OP 55 (Servant's House) & Structure & Thomas and Hibbs 1980-1981 \\
OP 56 (Charlebois' House) & Structure & Thomas and Hibbs 1980-1981 \\
OP 57 (Little Proulx' House) & Structure & Thomas and Hibbs 1980-1981 \\
OP 58 (William Kaulehelehe's House) & Structure & Thomas and Hibbs 1980-1981 \\
OP 60 & Dwelling Area & Thomas and Hibbs 1980-1981 \\
House 5* & Structure & NPS 2001-2003 \\
House 6 & Structure & NPS 2003 \\
House 7 & Structure & NPS 2003 \& 2010 \\
House 8 & Structure & NPS 2003 \\
\hline
\end{tabular}

Note: Occupant names were assigned by Thomas and Hibbs (1984)

* Houses at the focus of this study 


\section{CHAPTER 3}

\section{ARCHAEOLOGICAL SIGNATURES OF THE VILLAGE HOUSES}

Thus far, no historical documents or illustrations have been identified that describe the process of constructing the Village houses, only their final appearances. This summary of HBC-era vernacular architecture draws on previous historical and archaeological research to identify and describe the archaeological signatures of the houses based on what researchers know from the documentary record. The body of comparative research came from Fort Vancouver's stockade (Caywood 1955; Hoffman and Ross 1972), more recent Village excavations (Thomas and Hibbs 1984; Thomas 1995), Fort Nisqually's employee village (Stilson 1990; 1991), and French Prairie in Oregon's Willamette Valley (Hébert 2007). No primary sources were consulted for this study. This comparative research provides a backdrop of archaeological signatures against which Houses 1-5 can be assessed. While most house discoveries in the Village have been based on criteria established by Kardas and Larrabee, later archaeologists identified additional archaeological signatures through more in-depth feature and artifact analyses (Chance et al. 1982; Thomas and Hibbs 1984).

The following discussion uses a number of francophone architectural terms to describe certain French Canadian construction methods. For those studying Frenchinspired architectural traditions from the southeast United States or eastern Canada, there may be some terminological confusion because similar terms are used to describe different regional variations of these foundation and wall construction styles (Ritchie 1971:67). The terms used here are those commonly accepted by staff at Fort Vancouver 
NHS and also used by Michel Hébert (2007) in his research on French Canadian architecture in the Pacific Northwest region.

\section{Foundations}

The Village houses were what architectural historians refer to as "impermanent earthfast" structures, meaning the walls and foundations were built directly into or on the surface of the ground. The "Canadian-style" houses mentioned in Crate's testimonial were likely built using one of two earthfast construction methods that archaeologists have documented at Fort Vancouver (Garth 1947:221-222; Hussey 1957:218; Thomas and Hibbs 1984:46). Other archaeologists have documented variations of these foundations at French communities in Lousiana (Maygarden 2006), Canada (Burley et al. 1992), and Oregon's Willamette Valley (Hébert 2007).

Poteaux-sur-sole (post on sill) construction refers to the wooden sills that support the vertical (upright) wall framing posts (Figure 12a,b). The poteaux-sur-sole structures in the Fort Vancouver stockade used wooden and brick footings to elevate the wooden sills, allowing for easier repair and replacement in the case of deterioration in the damp Pacific Northwest climate (Hussey 1957; Thomas and Hibbs 1984:46). This is consistent with French-Canadian and Métis structures from other regions that were commonly constructed using stone footings or foundations (Hébert 2007:28). The placement of wooden sills directly on the ground without an extra foundation layer is uncommon in the wider world of French-inspired architecture, but it appears to be the standard in the HBC employee communities, a decision made perhaps for the sake of time and efficiency. Louis Caywood's (1955:10) excavation of multiple structures inside the Fort Vancouver stockade revealed wood footings (douglas fir) placed at $10 \mathrm{ft}$. intervals to support the 
foundation sills. The footings of the bakery (at Fort Vancouver) were approximately $76 \mathrm{x}$ $30 \mathrm{~cm}$ (2.5 x $1 \mathrm{ft}$.$) and 7.5 \mathrm{~cm}$ (3 in.) thick (Hoffman and Ross 1972:9). Figure 13a shows examples of the footings found by Caywood and Figure 13b shows the alignment of the bakery footings originally discovered by Caywood (1955:19) and mapped by Hoffman and Ross (1972:9). Three structures at the Fort Nisqually village were found with wooden sills placed directly on the ground, another two with the sills laid into trenches that were approximately 40-60 cm (16-24 in.) wide and 12-22 cm (5-9 in.) deep (Stilson 1991:18.10). These foundation sills measured $20-26 \mathrm{~cm}$ (8-10 in.) wide, but may have originally been as wide as $30 \mathrm{~cm}$ (12 in.) having "shrunk" from desiccation and deterioration in the ground.

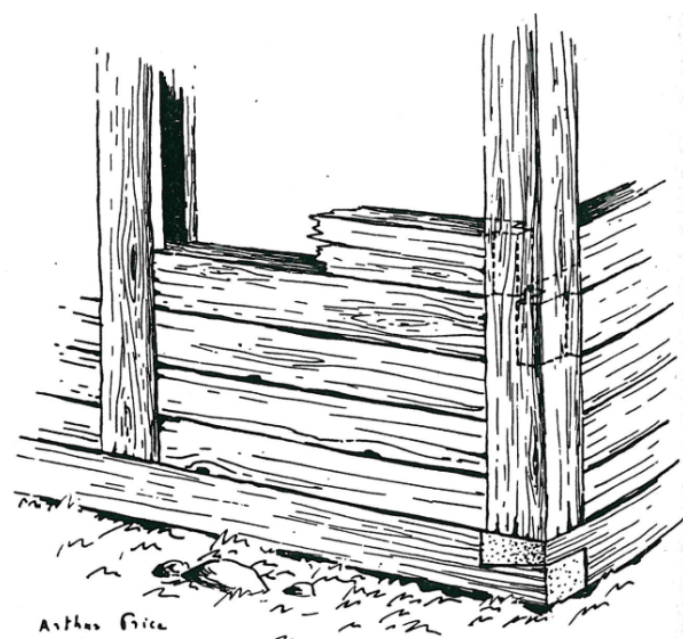

(a)

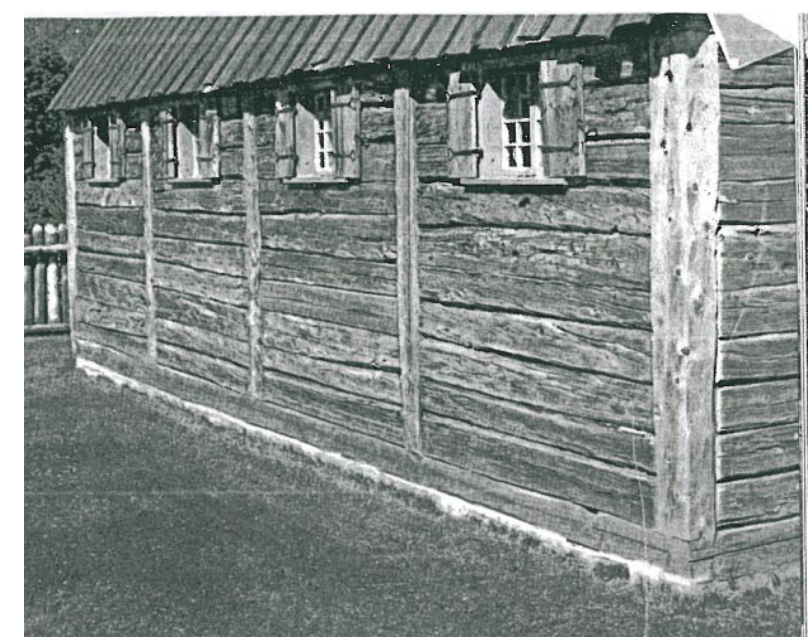

(b)

FIGURE 12. Examples of the poteaux-sur-sole construction style: (a) also shows the grooved wall construction method; $(b)$ this structure is a reconstruction. In both examples, the wood sills lay directly on the ground surface, with upright wall posts placed at relatively even intervals (Barbeau 1945:10-11). 


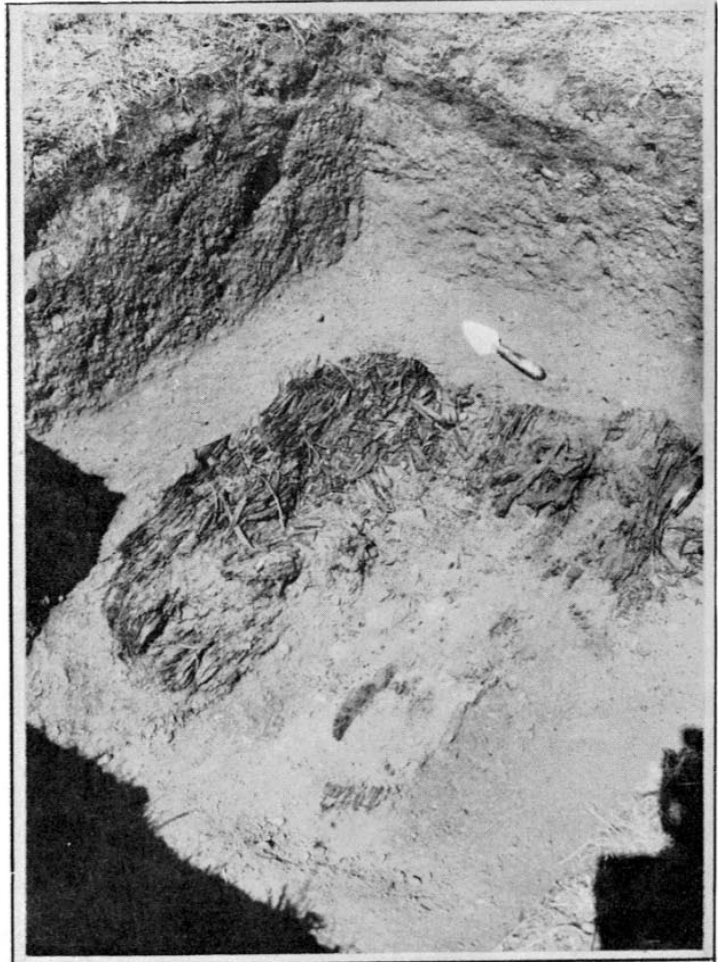

A. Typical slab footing found for most of the

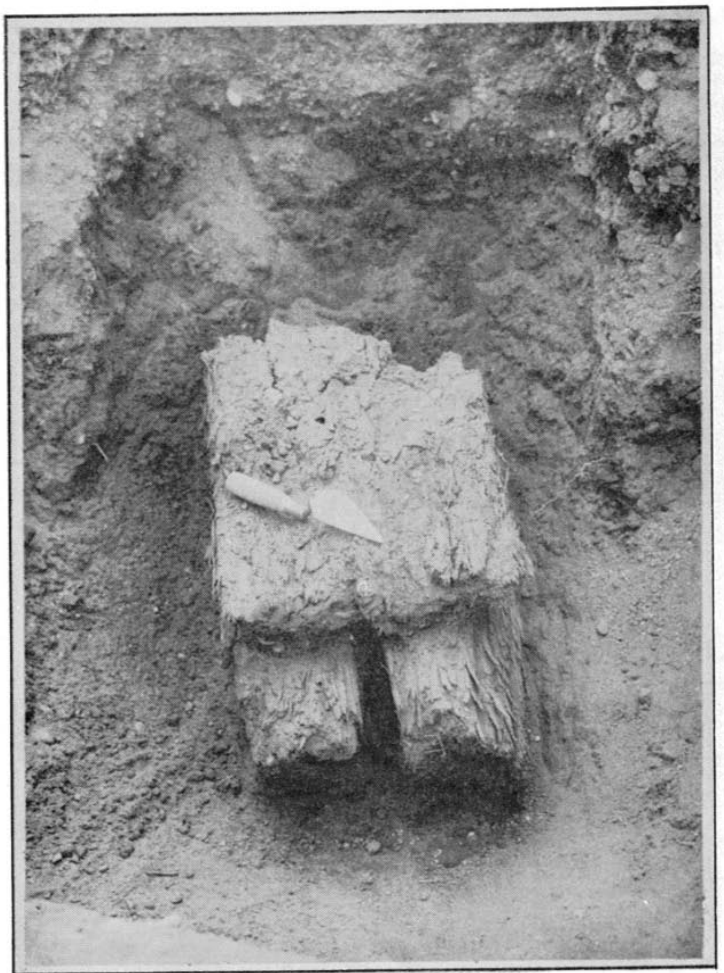

B. Block footing found in northeast corner of Chief Factor's house.

FIGURE 13a. Photographs of Louis Caywood's 1952 excavations, showing two types of wood footings found in the stockade (Caywood 1955: Plate III).

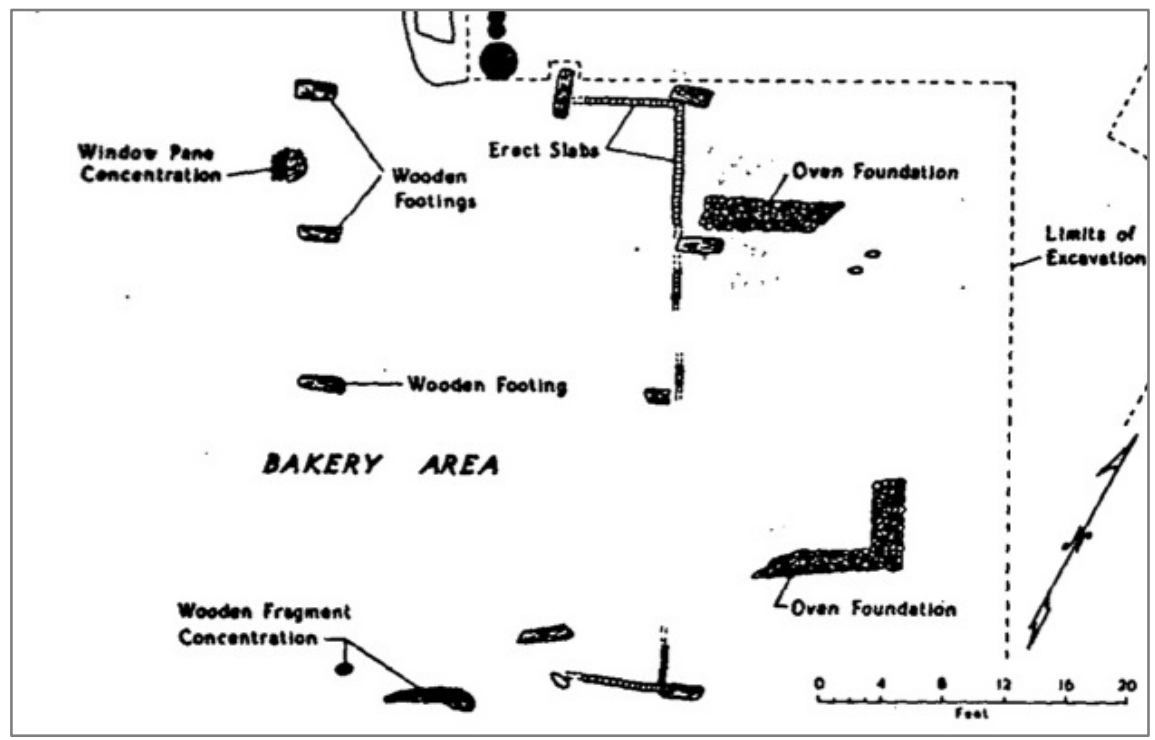

FIGURE 13b. Detail of plan view excavation map of the Northeast Corner of Fort Vancouver, showing the arrangement of the wood footings and connecting slabs that form the footprint of the poteaux-sur-sole structure (Hoffman and Ross 1972:8). 
Pieux-en-terre (pile in the ground) structures have no foundation or sill, but instead are built by setting the vertical wall framing posts into prepared holes or trenches (Figure 14). This method put the structure at greater risk for deterioration. Pieux-en-terre structures at Fort Vancouver differed from other regions, where round or unsquared timbers were placed side by side like a stockade wall and then insulated with chinking materials (Maygarden 2006:216; Hébert 2007:41,45). OP 14, excavated in 1980-1981, was interpreted as pieux-en-terre structure basedon the rectangular arrangement of post features (Figure 15). Compared to the poteaux-sur-sole structures, this method was often used during "precarious economic times" in Canada, when an "expedient, low cost" structure outweighed the risk of deterioration (Hébert 2007:45). Pieux-en-terre structures may also have been the preferred construction style when the builders perceived theirs would be a short-term occupation. Earthfast construction was often considered "adequate" in the American South, where residents expected plantation crops to "play out" before their buildings deteriorated (Carson et al. 1981:141)

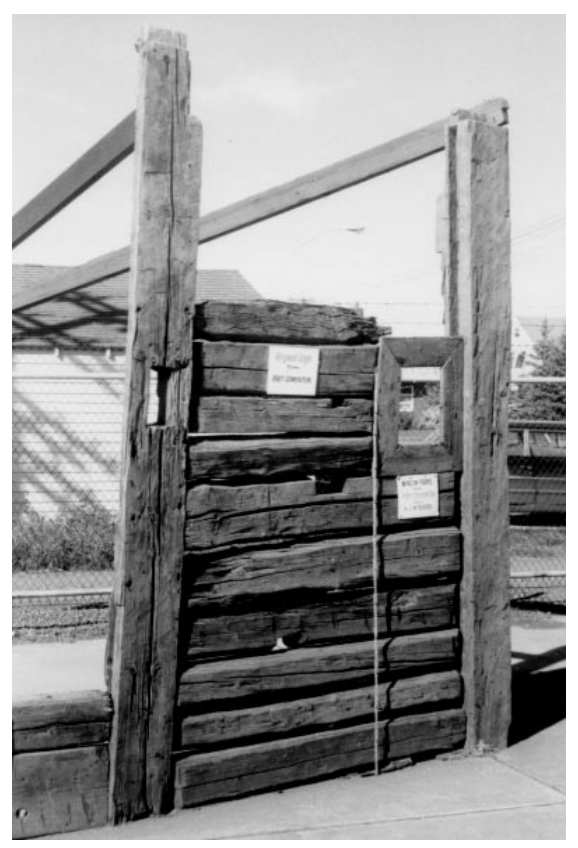

FIGURE 14. An example of a pieux-en-terre structure; a reconstruction from Fort Edmondton in Canada. This uses the same wall construction as poteaux-sur-sole, just lacking a sill support. (Courtesy of Fort Vancouver National Historic Site.) 


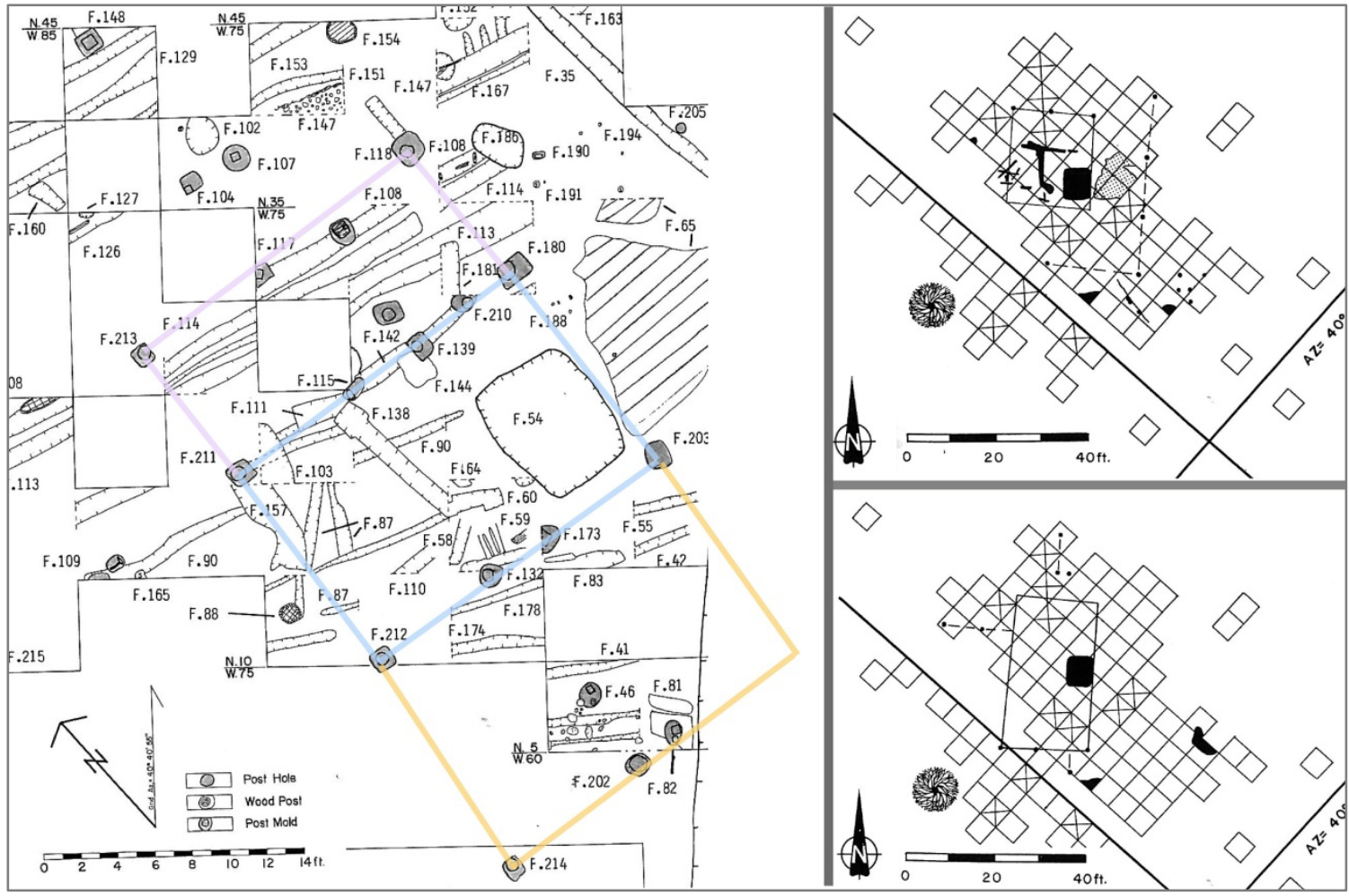

FIGURE 15. Detail of excavation map of Operation 14 features (left), emphasis on the post features. Blue lines mark the post features associated with the initial construction (component 141). Pink lines indicate the post features associated with the first expansion of this house, see also upper right for the outline of component 14-2 and a nearby fence line (dotted and dashed line). The orange lines and the lower right image represent component 14-3, a subsequent expansion of the house. Components distinguished and dated by diagnostic artifacts and straigraphy (Thomas and Hibbs 1984:120,291,295).

\section{Walls}

Although historic references variously describe walls made of logs, boards, and "squared slabs from the mill," the most common wall construction within Fort Vancouver's stockade (and at most other HBC posts) was a tenon-and-groove joint system, also called pièce-sur-pièce or the "Red River frame" (Figures 12a-b, 14) (Hébert 2007:39-40; DAHP 1978):

Walls were started by placing vertical framing posts, usually squared, at regular intervals around the perimeter of the building. Longitudinal grooves were cut on two faces of the posts and horizontal timbers were set 
one upon another until the height of the roof plate was reached (Thomas and Hibbs 1984:46).

References to "Canadian-style" walls in the Village likely refer to this style.

Pièce-sur-pièce walls were used with both poteaux-sur-sole and pieux-en-terre foundations. The coulisse, or vertical wall posts, would have needed to be at least 6 in. thick, large enough to hold the 5-10 cm (2-4 in.) thick horizontal squared timbers that formed the walls (Hussey 1957). The archaeologists who excavated OP 14 recorded the dimensions of all structural features associated with this complex pieux-en-terre structure. The widths of the square post features making up this structure's west wall were $20 \mathrm{~cm}$ (8 in.) wide, and none of the foundation-related post features at OP 14 were smaller than $15 \mathrm{~cm}$ (6 in.) (Thomas and Hibbs 1984:120,128,285). Multiple postholes, surrounding the wooden posts, were $37 \mathrm{~cm}(1.2 \mathrm{ft}$.) wide. It is safe to assume the wall posts on poteux-sur-sole were the same size as the pieux-en-terre.

The pièce-sur-pièce wall construction method was unique to the French-Canadian and Métis settlements in Canada. The method developed sometime in the 17th century, and by the early 19th century Canadian structures were distinct from the earthfast structures of the other French colonial settlements, as well as their European predecessors dating to the Middle Ages (Hébert 2007:35; Ritchie 1971). Hébert (2007:36-39) describes two variations on pièce-sur-pièce. The pièce-sur-pièce en coulisse is what has been described above - vertical posts placed at the four corners and at intermittent intervals (often 2-3 m [6-10 ft.]) with horizontal planks placed in tenon-in-groove joints (Figure 12a,b). Pièce-sur-pièce en queue d'aronde uses vertical posts within the lengths of the walls, but the corner posts are replaced with dovetail corner notches (Figure 16). Dovetail corner notches are frequently associated with Métis structures from the late 1800s to the 
early 1900s, perhaps as a variation on the Swedish (“American”) log cabins (Burley 2000:29-31; Hale 1960:123; Ritchie 1971:66-67). However, Hébert (2007:39) cites an example dating to ca. 1805, suggesting that pièce-sur-pièce en queue d'aronde construction techniques were contemporary with the HBC occupation of Fort Vancouver.

FIGURE 16. The pièce-sur-pièce en queue d'aronde wall style can be used with poteaux-sur-sole or pieux-en-terre foundations (Hébert 2007:40).

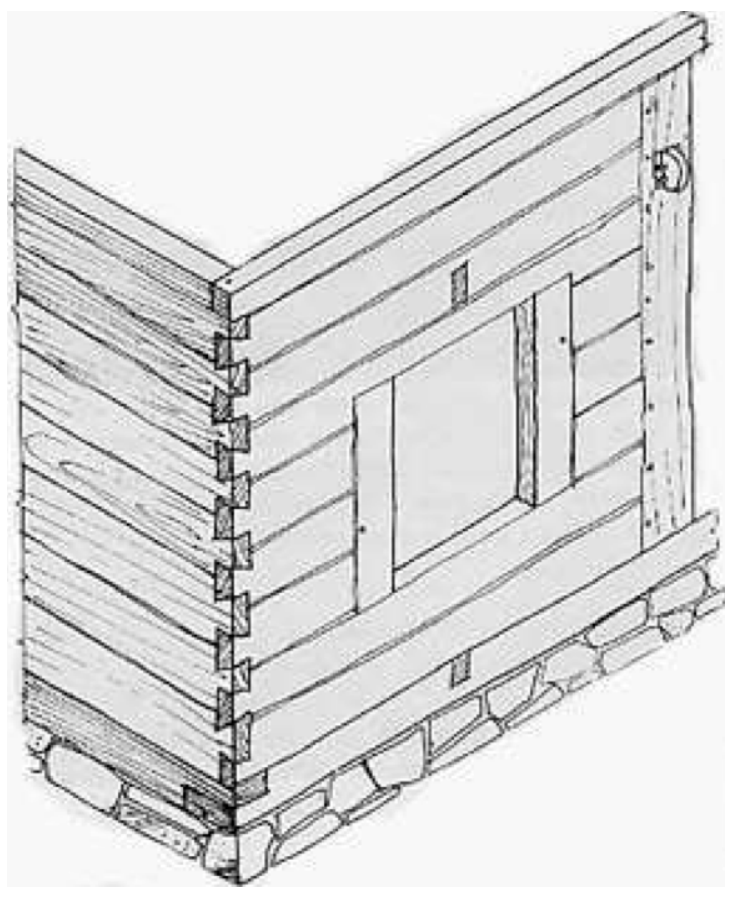

The "American cottage" style refers to another wall construction method and has no direct correlation with foundation type and wall construction. These "balloon frames" required more nails than their tongue-and-groove or log cabin counterparts because each board is nailed to the vertical framing posts (Chapman and Ozbun 2002:53). Presumably the upright wall posts would not be visible. The house in the foreground of Gibbs's sketch includes a side shed with no visible vertical wall posts, just a wall of horizontal wood slabs or boards (Figure 17) (Thomas and Hibbs 1984:47). Balloon frame construction gained in popularity in the eastern United States in the 1830s, after mechanized sawmills and nail manufacturing lowered the cost of building materials 
(Ritchie 1971:69). Stilson (1990:46) suggests that balloon frame structures leave behind six or more nails per square foot $\left(64.6 / \mathrm{m}^{2}\right)$, and the tongue-in-groove wall construction leaves four or fewer nails per square foot $\left(43.1 / \mathrm{m}^{2}\right)$ (based on screening techniques that use $1 / 4$ in. $(6.4 \mathrm{~mm})$ mesh screens). Nail frequency is likely a more reliable tool for interpreting wall styles than timbers that have degraded underground. This assumes the timbers and their associated nails were not removed by acts of scavenging or disposal by other people.

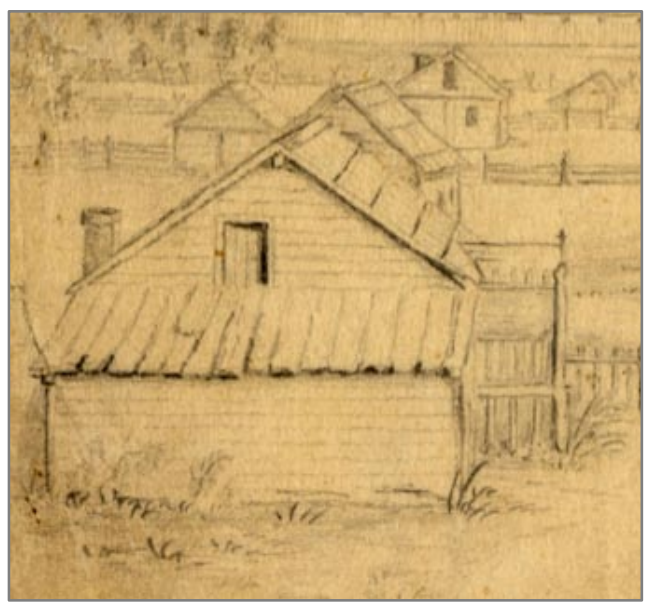

FIGURE 17. Detail of 1851 Gibbs drawing, showing a potential "balloon frame" shed attached to the side of this house, or at least what visitors may have thought was an "American style cottage" (Courtesy of Fort Vancouver National Historic Site.)

Some visitors describe seeing weatherboard siding in the Village, but this claim is unlikely. Inside the stockade, only the chief factor's house, the priest's house, the new office, and the sale shop had weatherboard siding, but in each case it was applied over a Canadian-style wall (Thomas and Hibbs 1984:46). Most likely what Crate termed "American cottage style" is similar to what others claim was "weatherboard siding" in the Village. The "weatherboarded" structures were likely built using wooden slabs, fastened to the wall posts with the flat side out. The "slabs" or puncheons Crate refers to were the rounded waste left over from the sawmill logs (Hussey 1977:49; Thomas and Hibbs 1984:47). 


\section{Floors and Roofs}

Archaeologists working in the Village consider compact gray ashy silt deposits, interpreted as the interior earthen floor, as a primary indicator of structure locations (Thomas and Hibbs 1984:727). This sediment often contains bisque, charcoal, and artifacts. At OP 14, archaeologists observed that the A-horizon had been removed so the earthen house floor of the pre-1835 structure immediately overlay the sterile B-horizon (Thomas and Hibbs 1984:285). Most Village employees would have been familiar with architectural traditions that included packed earthen floors (Neilson 2003:13).

Finding a gray silt floor embedded with small artifacts does not preclude the presence of a wood floor. The wood floor at OP14 was only installed after 1846 when the house was expanded, allowing for artifact deposition prior to its addition. Artifacts can also fall through the gaps between floors boards that are not fitted closely together. Stilson (1991:6.12) cites Dr. Tolmie describing his 1833 dwelling in the Bachelor's Quarters at Fort Vancouver, where there were gaps as wide as $7.5 \mathrm{~cm}$ (3 in.) between floorboards.

Wood floors were present inside most stockade buildings, an indication of their financial cost, time requirement, and permanence. Wood flooring requires specific nail varieties that can be sunk below the wood's surface, such as clasp or "bonnet" head nails and T-head nails (Sanders et al. 1983:166-168; Stilson 1990:35). These nails ranged in size from 6d and 8d to 20d (Stilson 1991:6.10). In a few structures in Fort Nisqually's Village, floorboards were fastened to "sleepers" along the walls. Depending on the width of the structure, a minimum of two or three nails would be needed for each floorboard (at the ends and middle) (Figure 18). Even a low-density distribution of flooring nails within 
the walls can indicate the presence of a wood floor (compared to a high density around and outside the walls) (Stilson 1991:6.10; Chapman and Ozbun 2002:56). Although a less permanent form of wood floor involves laying unfastened puncheons or timber slabs directly on the ground (Chapman and Ozbun 2002:56).

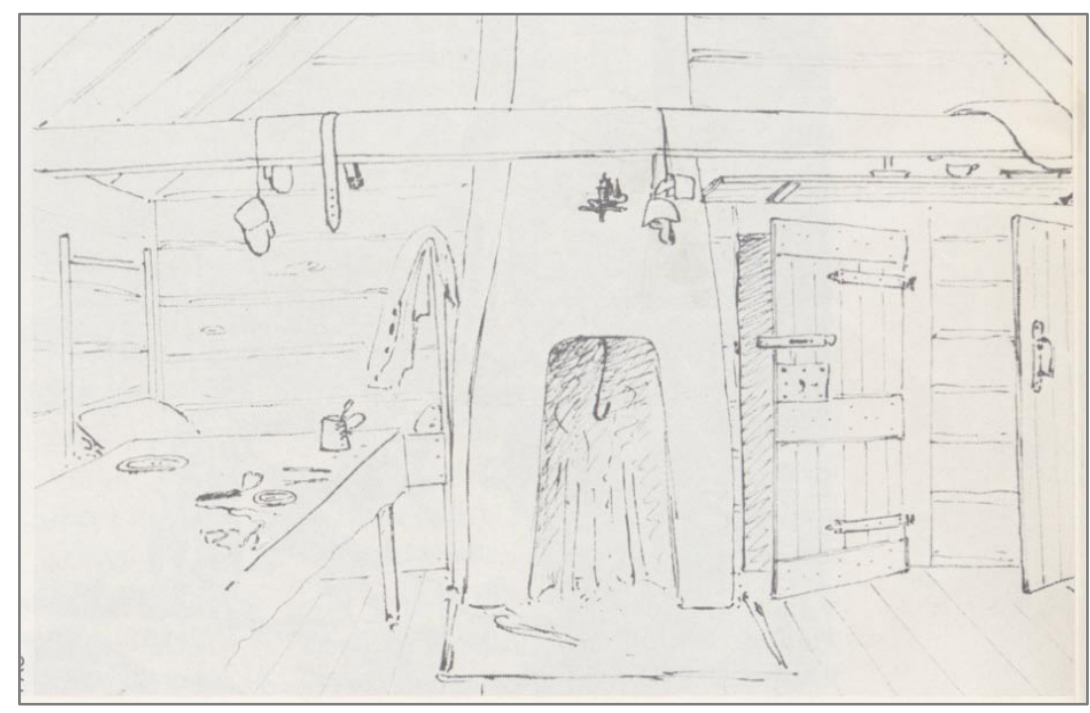

FIGURE 18. A sketch of a "Métis Interior" from Canada. Floorboards are drawn near the door, but the area around the hearth appears to without floorboards. Also note the rafter beam at the top. (Courtesy of Fort Vancouver National Historic Site.)

Gibbs's and Sohon's sketches (Figures 7 and 9) show most Village structures with long boards laid side-by-side on the roof (Figure 19a-b). Within the stockade, rafters were fastened upon the top of the upright wall posts; presumably similar FrenchCanadian style houses built in the Village used the same roofing methods (Hussey 1957). During the 1820s and 1830s inside the Fort Vancouver Stockade roofs were simple gables covered with one-foot wide $(30 \mathrm{~cm})$ sawed boards were the primary roofing material, but during the 1840 s the sawed boards were replaced with shingles and shakes and the roofs on some of the important structures were changed to hip gables (Figure 19d) (Hussey 1957). 
(a)

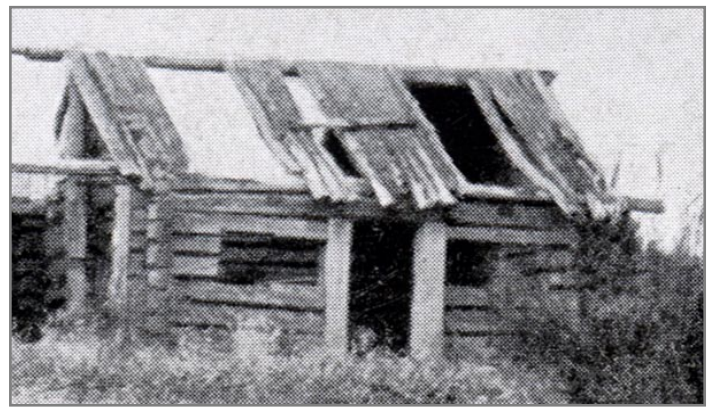

(b)

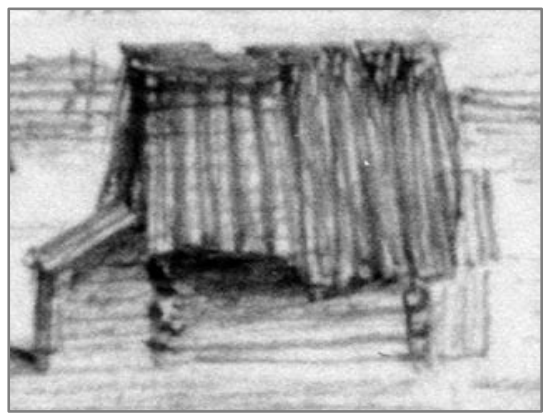

(c)

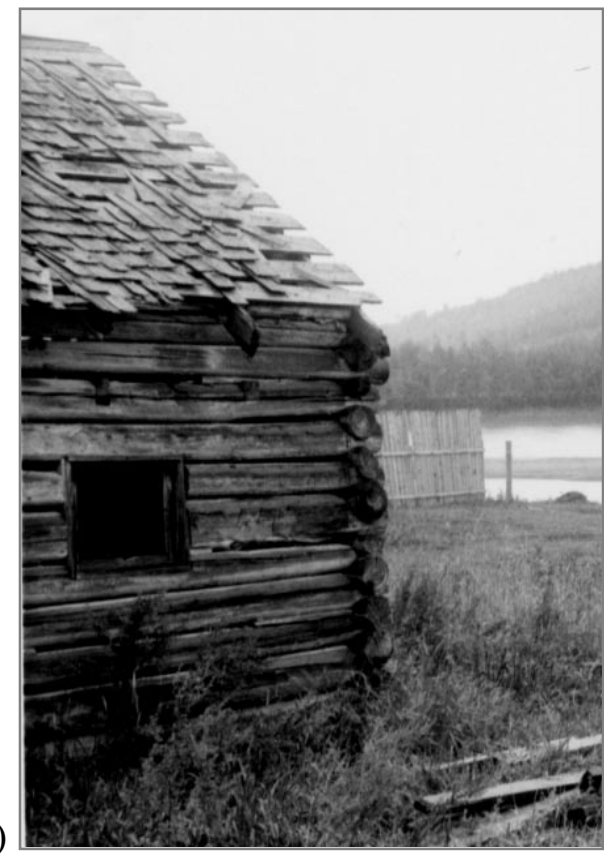

(d)

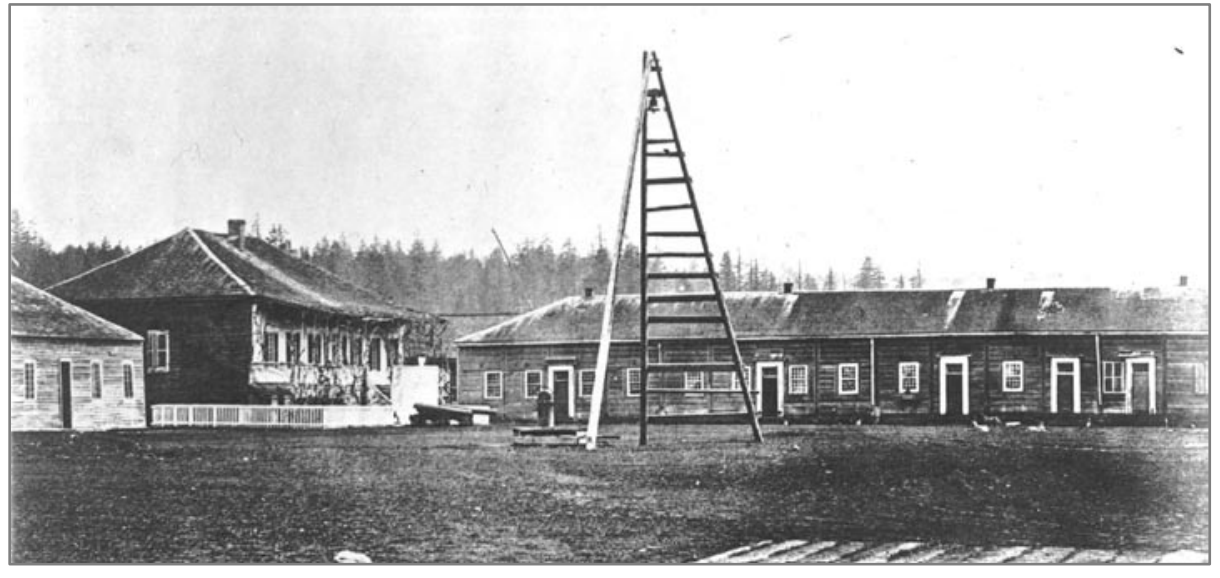

FIGURE 19. Roof examples: Some simple gable roofs were covered with long boards laid side by side, such as this (a) 1838 house from Fort Nascopie (Barbeau 1945), and this $(b) 1854$ sketch Village house by Paul Kane. (c) shows a roof with smaller shingles from a cabin at Fort St. John. $(d)$ shows hipped gables of Chief Factor's house and Bachelor's Quarters at Fort Vancouver. (Unless otherwise noted, images courtesy of Fort Vancouver National Historic Site).

The utilitarian structures (barns, stables, worksheds) likely continued using used or sawed boards or cedar bark roofs, despite the risk of leaks (Garth 1947:221). When compared to roofs made of long wood planks, shingled roofs provided greater weatherproofing, but also used more nails, thus increasing the cost for the builder (Ross 
1976:1325). Because of this cost increase shingles are often found at more permanent structures (Chapman and Ozbun 2002:56). Roofing nails were generally small and are found evenly distributed across house sites. There is also a chance that some methods of roofing leave behind no nail evidence: John Ball, a former instructor at Fort Vancouver's school, built the roof of his Willamette Valley cabin with cedar bark tied to the rafters with "wood strings" rather than fastened with nails (Speulda 1988:10).

\section{Chimney and Hearth}

Evidence for formal chimneys is absent in the written record and ambiguous in illustrations. The right half of the Gibbs sketch (Figure 7c) shows a few chimneys: one appears to be a small pipe extending from a shed, another is squared on the side of a house but the material is not identifiable (Thomas and Hibbs 1984:47). Chimney placement varied: some were attached to the exterior of the structure (Figure 20a), others were within the roofline (Figures 20b). In an illustration of the Village, Paul Kane (Figure 20a) depicts a chimney made from vertical wooden planks and clay or mud, which is consistent with most chimneys in the stockade, except the Chief Factor's House, which used bricks (Garth 1947:222). Unlike stone chimneys (Figure 21a), these wood and clay chimneys could be quickly made from easily accessible materials (Figure 21b) (Hébert 2007:51; Burley et al. 1992:100). It is also possible that some houses had open fire areas (Nielson 2003:13). 


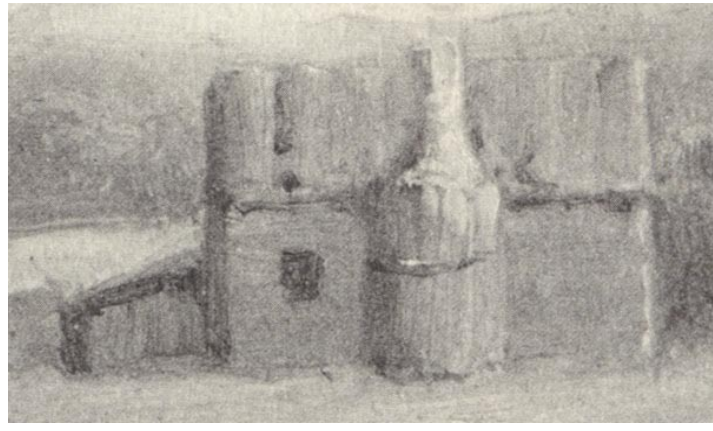

(a)

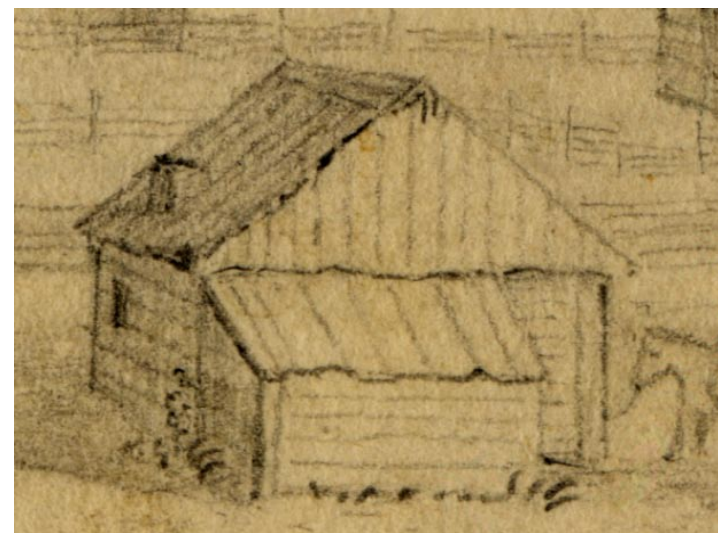

(b)

FIGURE 20. Chimney location: Some chimneys were placed on the exterior of Village structures (a) (Kane sketch), others inside the structure, appearing only through the roof (b) (Gibbs sketch). (Courtesy of Fort Vancouver National Historic Site.)

(a)

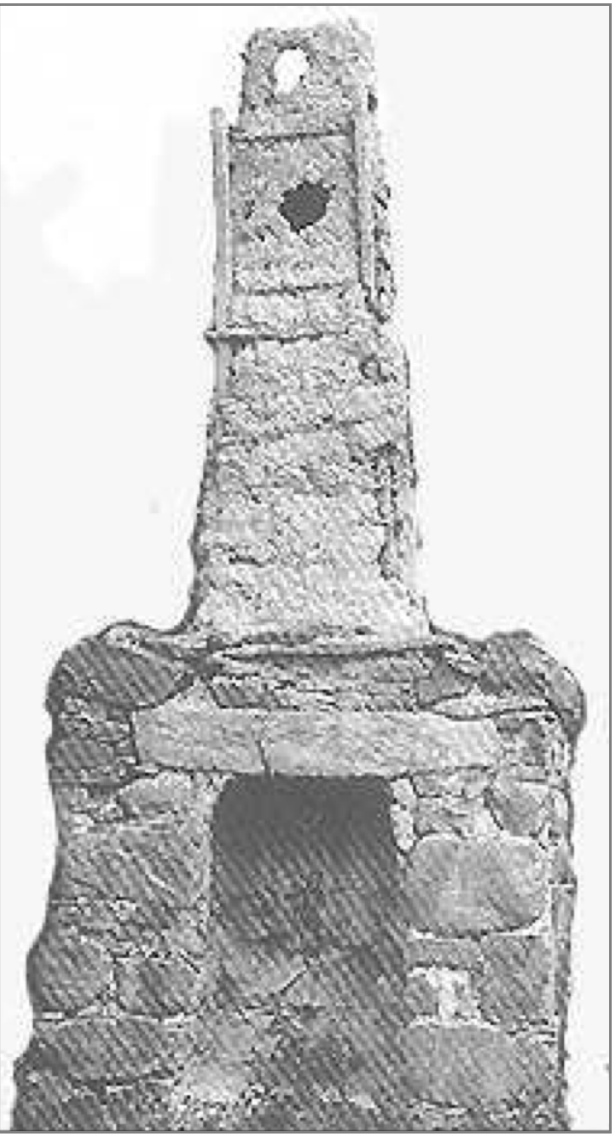

(b)

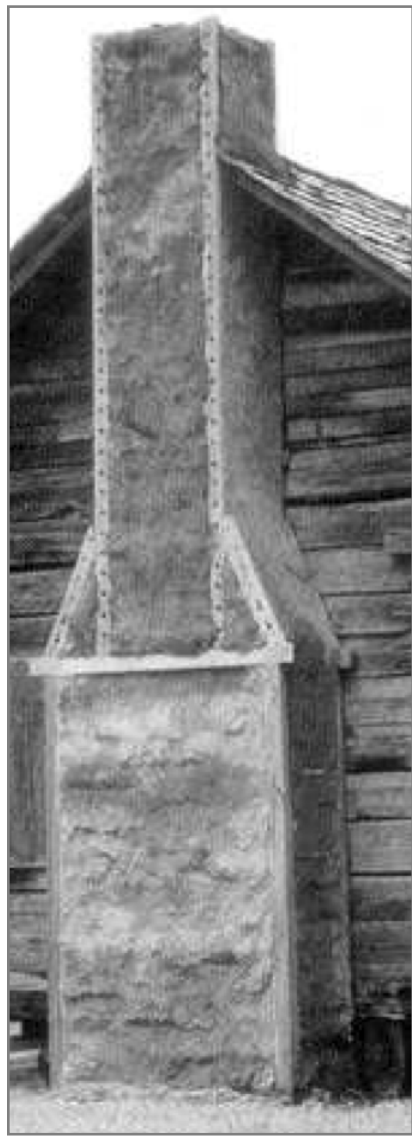

FIGURE 21. Hearth and chimney materials: Stone hearths and chimneys (a) were common in Canada, but clay and wood chimneys (b) were also reported in French Prairie (Hébert 2007:140-141). 


\section{Windows and Doors}

Some Village structures were described as having "glazed windows" and "hinged doors" (BAJC 1865). Windows and doors were often placed next to a coulisse (upright wall post) and gaps would be made in the walls of horizontal timbers (Figures 22a-c) (Ross 1976:1346; Hébert 2007:57). To frame the door, a second upright coulisse would be placed two or three feet away from the primary support coulisse.

A door's location may be inferred based on the presence of relatively close post features, hardware items, and nails bent more than 90 degrees (clinched) (Stilson 1991; Chapman and Ozbun 2002:54,56). Even after the conversion to machine-cut nails, wrought nails were preferred for door construction because they provided more flexibility for clinching (Nelson 1962:8-9; Hampton Adams 2002:71). Common door hardware recovered at Fort Vancouver includes: butt or pintle hinges, a thumb latch and handle, or a case lock and doorknob or pull (Ross 1976:1346).

The location of a window is based only on the distribution of window glass and window-related hardware, such as latches or thin finishing nails. An area with a high concentration of large window glass fragments is a likely candidate for a window's location (Willis 2008:21). Windows in the 1840s and 1850s were made of multiple panes, each 7 x 9 in. or 8 x 10 in. (Figure 10b) (Ross 1976:1346; Stilson 1990:32). There are some theories (Chance et al. 1982:307; Stilson 1991:18.14) that window glass was a luxury item and relative window density may indicate opulence. In other francophone communities, leather and oiled paper were used instead of window glass (Hébert 2007:60). Figure 22 shows additional examples of windows and doors from Canada. 


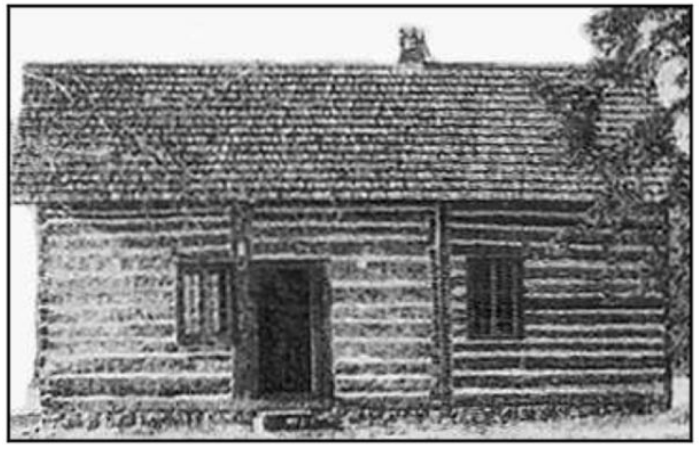

(a)

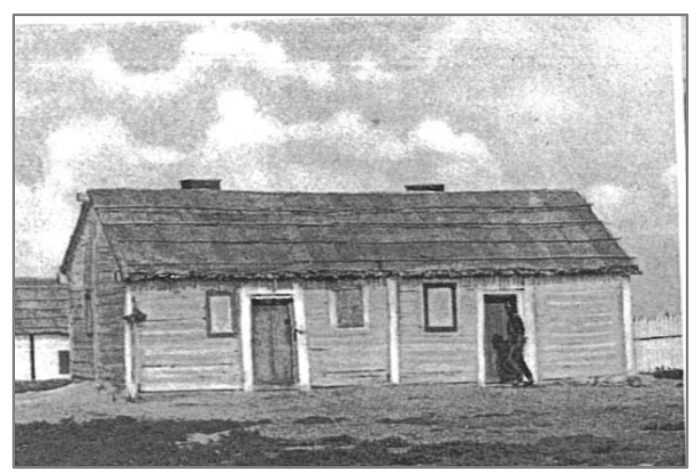

(b)

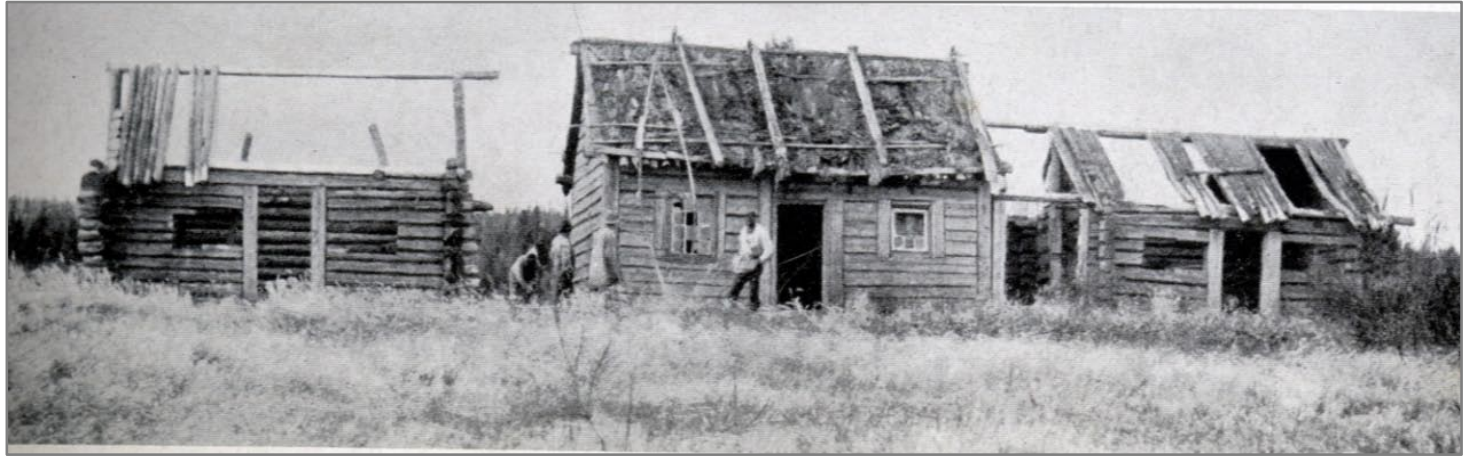

(c)

FIGURE 22. Windows and Doors. (a) 1805 house in Wisconsin (Hebert 2007:39), (b) Fort Good Hope, and (c) houses at Fort Nascopie, built in 1838 (Barbeau 1945:10)

\section{Size and Measurements}

In the available historical accounts, most Village houses are described as small, one-room "huts" (Hussey 1957:218). Although two and three rooms were not uncommon, it is unclear whether observers counted the attached sheds as "rooms" or if they were referring to interior walls and partitions (Hussey 1957:218). Interior partitions were of lighter construction than the exterior walls, leaving less substantial features in the archaeological record (Hébert 2007:48-49). Attached sheds (often termed lean-tos), however, are built on the exterior of the main structure and appear to extend no higher than the top of the walls. The Gibbs sketch (Figure 7b-c) shows several structures with additions extending from the main structure. Some additions run the entire length of the house, others are only one-third the length of the main structure. One Canadian tinner 
used the shed attached to his one-room house for dressing fish and wild game (Hussey 1957:217). Other illustrative examples of side sheds at the Village can be seen in Figures 19b, 20a, and 20b.

The smallest structure discovered in Nisqually Village was 3 x 3 m (10 x $10 \mathrm{ft}$. and the largest was $8 \times 4 \mathrm{~m}$, with a $4 \times 2$ m addition $(26 \times 13 \mathrm{ft}$., with a $13 \times 6.5 \mathrm{ft}$. addition). The sill lengths and distance intervals between vertical wall posts revealed the measurement system of the builders. Some structures in the Village and at Nisqually Village were built with post features spaced at $1.5 \mathrm{~m}(5 \mathrm{ft}$.$) and 3 \mathrm{~m}(10 \mathrm{ft}$.$) intervals$ while others were built based on the unique French-Canadian toise unit of measure, or 2 m (6.5 ft.) increments (Stilson 1991: 4.1,18.10; Thomas and Hibbs 1984; Thomas 1987). The $1.5 \mathrm{~m}$ (5 ft.) interval can be attributed to both English and French-Canadian construction styles, because the French pied closely corresponds with the English foot. However, Hébert (2007:130) suggests that French Canadian/Métis structures were commonly rectangular. He refers to a repeated 4:5 ratio (with coulisses placed at intervals multiples of 5 pieds) and a 3:4 ratio variation (presumably using the toise) that resulted in a $5.4 \times 7.3 \mathrm{~m}$ (18 ft. $\times 24 \mathrm{ft}$.) structure. This is not to insinuate that English builders were incapable of building rectangular structures, but it may suggest that the $3 \times 3 \mathrm{~m}(10 \times 10$ ft.) square houses were built according to a different measurement system.

\section{Fences and Yards}

Both the Gibbs Sketch (Figure 7c) and Covington's Map (Figure 5) suggest that some properties may have been fenced. The dwellings Covington labeled "Dechesne's," "Lattie's," "Billy's," “Jon. Johnson," "Calder's," and "Servant's" in the Village and Riverside Complex are enclosed by larger rectangles (Figure 5). Archaeologists 
interpreted a series of smaller postholes surrounding the house at OP 14 as a fence line (Figure 15c) (Thomas and Hibbs 1984:728). Testimony by Daniel Bradford to the BAJC (1866:244) suggests there were a few "small patches of gardens" in the Village, possibly meant to supplement the company rations, which were not enough to feed an employee's family (Kardas 1970). The fences may have served social functions to define one's yard from the neighbors and claim garden space.

\section{Building Materials}

Nails, window glass, and bricks used by the British in the 1800s have physical attributes, resulting from manufacturing techniques, that distinguish them from materials used by the U.S. Army in the late-19th century and 20th century. English bricks were, as their name suggests, manufactured in England and brought to the Pacific Northwest as imported goods and occasionally as ballast for HBC ships. These bricks were larger than modern bricks, and range in color from yellowish-grey to a deep purple (Gurke 1982:72). Like English bricks, the term "American brick" refers to the manufacture location. At some point before 1846, the HBC initiated its own local brick production, but the HBC also imported many American bricks from the Willamette Valley kilns in the early 1840s. When the U.S. Army arrived, American bricks were imported from California until the Willamette Valley kilns increased their supplies (Gurke 1982:80-81).

Wrought and machine-cut nails have distinct periods of common use. Nails were hand wrought for most of the HBC's tenure of the Columbia River (1829-1860), imported from England and supplied by the local company blacksmiths. Hand wrought nails are characterized by shanks that range from square to rectangular in cross-section and taper on all four sides. Their size and shape is not uniform because they were hand- 
manufactured to serve specific functions. Britain, and by extension all British colonial sites, was at least twenty years behind the United States in adopting machine cut nails in place of hand wrought nails (Hampton Adams 2002:70). The HBC started importing British and possibly American machine cut nails in the mid-1840s (Ross 1976:89; Stilson 1990:31; Pierson et al. 2009). The U.S. Army brought in large shipments of American machine-cut nails, and would have used these for their modifications to the houses they rented from the HBC (Nelson 1962; Pierson et al. 2009).

Windowpanes steadily increased in thickness through the 19th century due to changing manufacturing processes. Both the HBC and U.S. Army imported glass in large, but infrequent, bulk orders. The result is a site-wide continuity in glass thickness for a set amount of time (Chance and Chance 1976; Roenke 1978, 1982). A Fort Vancouverspecific window glass chronology can be used to estimate a date of construction down to specific decades (Roenke 1978, 1982). The major and minor modal distributions of thickness can indicate additions to a structure or the existence of a number of structures through time (Roenke 1978:43). Roenke assigned dates to window glass fragments found in the Village pond using associated artifacts in discrete stratigraphic deposits, The window glass accessible to the $\mathrm{HBC}$ ranged in average thickness from $0.09 \mathrm{~mm}$ to 1.65 $\mathrm{mm}$ (0.035 in. to $0.065 \mathrm{in}$.). Window glass ranging from 1.90 to $2.40 \mathrm{~mm}$ (0.075 in. to 0.095 in.) was imported during the U.S. Army occupation of the site (Roenke 1982).

\section{Site Formation Processes}

The expected archaeological signatures can be altered by a variety of natural and cultural site formation processes. Structural additions, remodeling, length of occupation, demolition practices, and post-depositional disturbances affect the archaeological remains 
of a house. The "identification of formation processes [...] must precede behavioral inference" in all research using archaeological evidence (Schiffer 1983:675). Postdepositional formation processes, especially, can create unexpected spatial patterns or alter the physical remains to the extent that the archaeological patterns no longer clearly represent the original structure (Deetz 1996:128).

In addition to features associated with foundations, floors, and other structural elements, nail concentrations are often used to distinguish the location of structures from a secondary refuse disposal sites containing structural debris (Fontana 1965; Schiffer 1972:161; Young 1994:56). The condition of the nails in these deposits reveal further information about a structure's history and enable archaeologists to distinguish structures from disposal areas (Young 1994). Structures that burned or deteriorated in place have a high number of unaltered (not bent) nails that were either lost during construction or fell when the wood rots away; there are few pulled (bent in gentle arcs) or clinched (bent 90 degrees) (Young 1994:57). When buildings are razed or pulled down intentionally, the location of the structure has a high number of complete unaltered nails (lost during construction) and pulled nails (bent as boards are pulled off the frame), but few clinched nails. Nails are often clinched during demolition, as a safety precaution, so secondary disposal deposits contain a high number of clinched and pulled nails that remained in the wood.

Maintenance, lateral cycling (reuse), and recycling, all prolong the use of durable cultural materials and delay their deposition into the archaeological context (Schiffer 1972:158). The U.S. Army reportedly salvaged firewood and windowpanes from Village structures (Thomas and Hibbs 1984:729). Reuse of bricks, nails, windows, and wood can 
subtract data from the house sites and add misleading data to other house sites. All or some evidence of a brick chimney or hearth may disappear if the bricks are reused in other structures. Lateral cycling of a window from an earlier building can misrepresent the age of a structure (Schiffer 1972:159; 1977; Roenke 1978).

Knowing how each house "died" and how the Village site as a whole was formed can help translate the patterns observed in the archaeological record. In the 1850s, the Village was observed to be in decline and decay (Thomas and Hibbs 1984:31). Some houses were being propped up to keep from falling down. There are also references to the U.S. Army burning, moving, and knocking over the "remaining buildings." Distribution of demolition debris may obscure house layout interpretation if structure debris were pushed away. The distribution of artifacts relative to the foundation features at OP 14within and to the east of the residence-implied the direction of demolition (Thomas and Hibbs 1984:152).

Cultural and natural forces impact the archaeological record long after materials have been deposited, potentially altering the formal and spatial attributes of the artifacts (Schiffer 1987; Nielsen 1991:483). The archaeological materials that remained in a primary refuse deposit context may have been subject to trampling or altered during later landscape modifications and large-scale construction. At least in rainy climates, trampling is less likely to disperse artifacts horizontally (Nielsen 1991:501). Multiple construction phases may result in overlapping and truncated features, such as at OP 14 . 20th-century activities and buildings can obscure the 19th-century results. At Fort Nisqually, the large quantity of window glass left over from the 20th-century town built on top of the older fur trade settlement skewed the primary mode for window glass dates 
and masked secondary and tertiary modes (normally suggesting modifications) (Stilson 1991). Ephemeral earthfast wood structures in the damp Pacific Northwest climate are prone to rot and may leave few definitive remains - other than postholes and post molds - for archaeologists to find, resulting in ambiguous results (Blanchette 2000). Archaeology is another post-depositional disturbance. The excavation of archaeological deposits removes the patterns from the ground. The act of backfilling units mixes the order and contents of previously distinct stratigraphic deposits. At archaeological sites where multiple excavations have taken place, potentially following different methodologies, it is important to know where the previous excavations took place. If a site were looted, however, such records would not be available. Archaeologists may encounter areas devoid of artifacts, or depending on the methods of their predecessors, devoid of only specific artifact types or sizes.

The preceding chapter provided the archaeological expectations against which the five house assemblages in this study were compared. Once original forms was established, the next step was to explore its function within the larger vernacular landscape. 


\section{CHAPTER 4}

\section{LITERATURE REVIEW AND THEORETICAL CONSIDERATIONS}

The theoretical framework of this study draws on built environment archaeology, practice theory, and comparative case studies from colonialist and pluralistic sites.

\section{Previous Research on Village Diversity}

The Village cultural and class diversity has been hard to see archaeologically. Archaeologists using three different approaches have revealed a surprising level of homogeneity between house assemblages (Kardas 1971; Bray 1984; Cromwell 2006). Kardas' investigation of diversity was limited by what we now understand to be simplistic, ethnocentric theories of acculturation and ethnicity that dominated 1970s historical archaeology. She expected the presence of distinctive ethnic markers (artifacts attributable to a specific ethnic group) and variation in the relative frequencies of artifact types would indicate the presence of Native American wives and the non-European employees in Houses 1, 2, 3, and 4. She found no obvious differences, proclaiming, "if we had only archaeological data from the site we would conclude it to have been predominantly European in culture" (Kardas 1971:417).

Very few artifacts traditionally characteristic of Hawaiians, Iroquois, or local Native American tribal members were found, relative to the many European goods (Kardas 1971:411-418; Cromwell 2006:17). Recent material culture studies of Hawaiians (Rogers 1993) and Iroquois (Jameson 2007) in the Pacific Northwest theorize that "traditional" material evidence of the Hawaiians and Iroquois in the Village had been recovered, but misinterpreted as Chinook by Kardas and Larrabee (1970). However, these few alleged "ethnically diagnostic" items reveal very little about the ethnic differences 
between houses or the social relationships of the employees. Moreover, these studies still privilege "traditional" material culture items over European-manufactured items in the process of identity construction. Hawaiian, Iroquois, and other HBC employees had been exposed to European colonialism and material goods prior to their arrival at Fort Vancouver where their possessions originated from HBC warehouses. There is ample archaeological evidence of Native Americans and Métis in other regions incorporating European trade goods into their material culture, and assigning new meanings either as functional cognates for traditional materials or as part of unique cultural traditions (Burley 1989; Silliman 2005).

Kardas had no prior speculation as to what ethnic groups may have inhabited Houses 1,2,3, or 4, but the archaeologists analyzing the Village houses excavated in 1980 and 1981 (OP 6, OP 20A, OP 14, OP 55, OP 56, OP 57, and OP 58) had reason to believe their assemblages represented different ethnic groups (Bray 1984). Based on R. Covington's 1846 map, in which houses were labeled with the last names of select male residents, archaeologists identified two French Canadian houses, two Hawaiian houses, one Scottish house, and three "Indian use areas." Using the Spearman's rho statistical analysis, Tamera Bray (1984) compared the frequencies of specific artifact types to test whether similarities and variations between the house assemblages corresponded to Covington's ethnic identifications. Like Kardas, Bray assumed the non-European residents (Native American wives and employees, and Native Hawaiian employees) would have possessed a greater number of trade goods and traditional cultural items. Bray found "no dramatic differences" between the assemblages, only "minimal distinctions" in the form of subtle trends and unique artifacts (Bray 1984:817-821). 
Bray's results mirror Kardas' (1971:411), who saw “individual variation” among her four houses, but not enough to "be assigned to any particular ethnic group." Even with a presupposition of what the assemblage's ethnic character would be, there was no visible diversity.

Most recently, Robert Cromwell approached ethnic diversity at Fort Vancouver through a filter of job class and income, because the HBC assigned jobs and social class based on perceived ethnicity. Cromwell (2006:24) considers it "unrealistic" to correlate the house assemblages with the ethnicity of the occupants because most of the goods were purchased from the HBC sale shop, which sold only European-manufactured products. Kardas (1971:416) concluded that the wives and employees were too young or too underprivileged to learn the traditions of their birth cultures and, therefore, were unable to replicate their own material cultures or express their identities at Fort Vancouver. Cromwell, in contrast, argues that the employees and their wives chose which ceramics they purchased based on income and cultural preferences. Using the consumer choice theoretical framework, Cromwell ranked the form and function of ceramic vessels according to Miller's and other derivative indices, and then compared the ceramic assemblages of Village Houses 2, 3 and 4 against each other and also against assemblages from the Chief Factors House and the bachelors' quarters' privies within the stockade. Cromwell (2006:301) found that the ceramic value indices indicated 1) few economic differences between the Village houses, and 2) fewer differences (not statistically significant) than expected between the low-income Village houses and the elite residences inside the stockade. 
Previously, archaeologists have confined research on the material culture of the Village to the bounded space of the houses. The architecture itself has never been used to examine questions of diversity or social and power relations. Not only were the architectural artifacts left out of Kardas' and Bray's "all-assemblage” comparisons, but Kardas and Larrabee did not analyze or consistently provide accurate counts for these artifact types (Larrabee and Kardas 1968; Kardas 1970; Amos-McGraw 2008; Willis 2008). Even if the architectural artifacts are just another group of pre-fabricated European good sold in the Sale Shop, the composite forms of the houses were direct products of the residents.

\section{Theoretical Considerations}

The archaeology of the built environment, with its emphasis on the close relationships between people and buildings, forms the theoretical framework of this study. Although the built environment can refer to industrial, urban, rural, modern, or past structures as well as terraces, levees and other earthworks, the majority of research has focused on domestic vernacular architecture of the past (Hicks and Horning 2006:280-281). Vernacular architecture is built without formal design plans, its form and organization typically address the daily physical and cultural needs of the occupants, and the style is acceptable to the community (Upton and Vlach 1986:xvi; Burley 2000:31). "Vernacular builders use whatever materials are available and whatever skills they possess" (Upton and Vlach 1986:xvii).

The variety of theoretical approaches to vernacular architecture and the range of interpretive potential are its strengths (De Cunzo and Ernstein 2006:266). James Deetz introduced Henry Glassie's structuralism-based vernacular architectural theory to North 
American historical archaeologists in the 1960s (Clark and Corbett 2006:152). Glassie's (1975) ideas that each builder unconsciously carried his or her culture's architectural traditions were further developed by Deetz, and extended by Leone (Deetz 1982:719; Hicks and Horning 2006:278). These pioneers drew their inspiration from linguistics and discussed vernacular design in terms of "grammar" and "mental templates" that are based in a culture's worldview (Upton and Vlach 1986:xxii).

Beginning in the 1960s, an explosion of research (conducted by architectural historians and archaeologists alike) comprehensively described the architectural traditions of many cultural groups the world over (Deetz 1996; Hicks and Horning 2006:281). During his research on early American vernacular architecture in the Chesapeake region, Deetz also observed stylistic and functional differences between houses built by members of different social classes. Deetz and Glassie demonstrated that changing vernacular styles could represent changes in social values and worldview. Too often, however, the architectural elements (such as door placement, masonry styles, and room divisions) identified in these culture-specific studies were taken out of context and used by other scholars as stylistic markers to identify the presence of ethnic groups at other sites.

Currently, architectural theory is moving away from models "based in representation and language" that discuss design in linguistic terminology, and toward ideas of space and material culture (Upton and Vlach 1986:xxii; Clark and Corbett 2006:153; De Cunzo and Ernstein 2006:265; Hicks and Horning 2006:287). This approach allows scholars to focus on the architecture of everyday life, particularly how vernacular architecture and the arrangement of space interacts with human behavior on a daily basis. These approaches often emphasize the changing nature of the built 
environment, and in recent years historical archaeological research has applied the idea of a human life cycle (birth, growth, and death) to the analyses of structures (Hicks and Horning 2006:290).

While community archaeology and landscape archaeology are not synonymous, once the attention turns to the relationships and interactions in a community the discussions of space become more complex. The built environment is only one element of landscape archaeology (Branton 2009:51-52). Multiple lines of evidence from the built and natural environments, including botanical, geophysical, architectural, and archaeological, have been applied to the study of commercial and industrial cities, rural towns and villages, seaports, maroon communities, logging camps, gardens, walls, roads, farmsteads, plantations, and homelots (Paynter 2000:12; Nassaney et al. 2001: 223).

Landscape archaeology is a part of a larger "multiscalar" direction that historical archaeologists have taken in the 21st century to pursue anthropological-based research themes at sites ranging from households to global systems (Paynter 2000; Voss 2008; Orser 2010). Some form of landscape archaeology has always existed in settlement pattern studies and human ecology, although the field began to develop in earnest in the 1980s and 1990s (Rubertone 1989; Steadman 1996:52). Landscapes are no longer treated as "static backdrops" against which humans actions occur, but rather as places that are created and "imbued with meaning" and act as "dynamic participants in past behavior" (Branton 2009:51; Orser 2010:115; Paynter 2000). The interrelationship between place and human behaviors is the core concept of landscape archaeology. A true understanding of the North American historical landscape is tied to the archaeology of everyday places, 
and considers ecological, economic, and social components (Branton 2009:51; Steadman 1996:52).

Built environment and landscape archaeology frequently draw on the tenants of practice theory (Kent 1990:9; Burley et al. 1992; Lightfoot et al 1998; Hicks and Horning 2006:284; Branton 2009:52). Practice theory is based on the idea that an individual's worldview, identity, and external social structures shape his or her repeated daily routines (habitus), which in turn reproduce and reinforce the social laws that contributed to their creation (Bourdieu 1977; Lightfoot et al. 1998; Ortner 1994; 2006a; 2006b). Unlike other anthropological theories, "neither individuals nor social forces have precedence," instead "there is a dynamic [...] relationship between the practices of real people and the structures of society, culture, and history" (Ortner 2006b:133). Within sociocultural anthropology, practice theory reintroduced power and inequality to discussions about social relations and the effect of identity construction on human behavior (Ortner 1994). Social theorists, architectural historians, and archaeologists agree that physical spaces, like social structures, are a part of the social process that influences human behaviors (Rapoport 1969; Bourdieu 1977; Lightfoot et al. 1998). Practice theory allows scholars to explain how and why vernacular architecture is tied to culture, but most archaeologists refer to the early form of practice theory, as explained by Bourdieu and others in the 1970s.

More recently Sherry Ortner (2006a; 2006b:129) has expanded practice theory, allowing for more nuanced discussion of complex social relations, especially relations of power, that include the potential for change and resistance. The reproduction of social laws is never total or flawless, making them vulnerable to instabilities and changing 
forces from the inside (Ortner 2006a:7). Ortner's (2006b) concept of "power and projects" has important implications for vernacular architecture studies.

Using a game analogy, Ortner (2006b) suggests that social life is "actively played" toward an end ("projects"). Individuals are "enmeshed" in a multiplicity of social relations throughout their lives and may play multiple games simultaneously, each with its own set of "rules" (Ortner 2006a; 2006b:130). Playing these "serious games" involves both routine actions and intentionalized actions [emphasis added]. The routine, and often unconscious, actions coincide with Bourdieu's (1977) original concept of habitus. The intentionalized actions constitute "agency" (Ortner 2006b:136). Agency and one's ability to pursue or sustain a project are "differentially shaped, nourished, or stunted under different regimes of power" (Ortner 2006b:137). Projects emerge when "structurally defined differences of social categories and differentials of power" produce the intention to exercise power, respond to it, or negotiate the social structure (Ortner 2006b:145). Intentions may range from unconscious needs to well crafted plots; they grow out of one's life circumstances and are not always about domination or resistance (Ortner 2006b:134,147).

\section{Case Studies: Architecture in Colonialist and Pluralistic Settings}

Buildings are public and permanent forms of expression that can encode messages, shape perceptions and elicit social behaviors (Rapoport 1982; Upton and Vlach 1986:xix; Loren 2000; Nassaney et al 2001:222). Colonial powers in the North American fur trade used the built environment to emphasize their place in the hierarchical social structure (Monks 1992:37; Lightfoot et al. 1998; Hamilton 2000:219; Nelson 2007). The separation of officer and laborer living quarters reinforced the hierarchical command 
structure at remote Canadian fur posts (Hamilton 2000:219). The form and spatial organization of the stockade and interior structures at Upper Fort Garry (Manitoba, Canada) were designed to communicate its economic and social dominance over the nearby Red River settlement (Monks 1992:37). A similar psychological goal is attributed to the human-landscape of Fort Vancouver (Nelson 2007). The Russian managers at Fort Ross (Northern California) segregated their employees into ethnic neighborhoods to maintain the colonial hierarchy (Lightfoot et al. 1998). Buildings are fixed-featurescostly and time consuming to change - so a social status based on fixed features is difficult to change (Monks 1992:37; Nelson 2007:35). The effectiveness of such encoded messages depend on a culture-specific grammar, and in pluralistic colonial settings the landscape messages can be interpreted and experienced differently depending on a person's race, class, gender, or other social identity (Rapoport 1982:81; Paynter 2000:13).

The multidirectional cultural exchanges common in colonial and post-colonial settings affect one's ability to replicate traditional cultural practices, social laws, and worldviews, sometimes providing new options. The study of vernacular architecture in pluralistic communities has revealed a range of responses to colonial policies, strategies for negotiating new social relations, and dealing with new cultural practices (Lightfoot et al. 1998; Cusick 2000; Loren 2000). Members of a pluralistic community can select structural components from a large pool of past architectural knowledge (Burley 2000:31). The ethnogenesis of the South Saskatchewan River Métis identity in the late 1800s was observed by Burley (2000) through their homes, which included elements drawn from their European ancestry and ongoing interactions with Ukrainian settlers. 
Buildings can communicate resistance to or acceptance of a colonial structure. The investment in architecture's symbolic function increases with greater social differentiation (McGuire and Schiffer 1983:55). "People strategically modify their surroundings to communicate their role in society or modify the way they are perceived or remembered" (Branton 2009:58). The Métis responded to Canadian political dominion through a reorganization of their architectural grammar. House exteriors projected a Georgian style worldview, but the interior arrangement of space was consistent with the open-floor plans of Métis wintering village structures (Burley 2000:32). Deetz (1996:163) called structures like these "hybrid houses," they accommodate the old and new traditions in an effort to negotiate changes in worldview (or to imitate changes to negotiate power relations). Another example comes from the Louisiana/Texas border in the mid-18th century where French, Spanish, Native American, African and [mixedblood] creoles formed multiethnic households in violation of colonial segregation policies (Loren 2000:94). Faunal remains, domestic, and trade artifacts were found in similar percentages and types, suggesting a similar lifestyle and cultural background. The architecture of one house, however, conformed to the ideal French style, suggesting this household was trying to cultivate good relations with the crown, while the other was a conglomeration of styles and would not have been seen as "proper" by the French or Spanish colonial powers (Loren 2000:94). At Fort Ross in Northern California, archaeologists analyzed activity areas within the houses and the arrangement of the houses as material evidence of "daily practices," the everyday behaviors and actions of the residents. They observed that within the segregated "ethnic neighborhoods," the 
Alaskan employees and their Native Californian wives were arranging and using space in ways consistent with their traditional communities (Lightfoot et al. 1998).

Change is the nature of vernacular landscapes (Upton and Vlach 1986:xx), but changes of architectural form, which archaeologists have observed, are not always tied to worldview (Carson et al. 1981:177). Changes can occur in the needs of the occupants, in the composition of the community, and in the availability of resources. The Red River settlement started with expedient homes, but over time turned to dovetail notches and other more permanent construction techniques (Burley et al. 1992:125-129, 134-137). Technological advancements can also affect the vernacular landscape. Balloon framing became popular at the same time when house construction was made easier and cheaper by mass-produced nails and standardized lumber (Rubertone 1989:50-51). The need for community assistance diminished as building became easier for smaller groups of people.

\section{Research Design}

Knowing the intentions of past peoples is improbable, but understanding the difference between routine and intentional actions may help identify which research questions archaeological deposits can answer. Rather than seeking to define the specific identities of the residents of individual houses, these research questions approach the houses as components of the landscape, just as the residents are part of a settlement community. The house and community are where the daily tasks of people participate in the ongoing production of identities and social structure, while also creating the activity areas that archaeologists characterize and study (Burley et al. 1992; Lightfoot et al. 1998:201; Voss and Allen 2008:5). An understanding of history, power, and culture contextualizes these daily actions and behaviors. The preceding vernacular architecture 
literature review demonstrates that many factors (identity, economics, or social relations) potentially influenced the final form of the Village houses. The purpose of this research is not to assign an ethnicity to the individual Village residents, but the social relationships in the Village through how the members organized their living spaces and the ideas communicated through the exterior architectural styles. Are the Village residents building distinctive house styles to communicate ethnic or job class differences? Are the house styles a homogenous amalgamation of different architectural styles, like the South Saskatchewan Métis communities? The following research questions address two lines of inquiry: the physical forms of the houses and the community-level social implications. Architectural Variation and Vernacular Landscape Research Questions

Did the Village community implement a single architectural style? Based on the architectural analyses, life histories and layouts will be interpreted for five houses. Each house will be categorized by its 1) general construction method, 2) layout and style, 3) size, and 4) dates of construction and maintenance. Given that 30 to 50 houses may have populated the Village, how do the five houses in this study relate (spatially and temporally) with the larger Village landscape? Moreover, how do the archaeologically confirmed locations of Houses 1-5 compare or contrast with the historical record? Photographic evidence from 1860 confirms the appearance of the Fort Vancouver stockade, but only hand drawn illustrations exist of the Village, and there is some question as to their architectural accuracy. Can Houses 1-5 be associated with the historical maps and illustrations of the Village (Covington, Gibbs, etc), like the houses excavated in the 1980s? 


\section{Projects and Community Dynamics Research Questions}

Were the Village houses designed and built in pursuit of individual or collective projects (if so, what kind) or were they the result of more routine actions? How did this community with diverse geographic and ethnic origins conceptualize itself? The theoretical literature suggests that more variation (wall construction, size, and location of windows and doors) should be expected if no overarching community identity or shared "project" was present in the Village. If employees were actively emphasizing the HBCdefined job and ethnic differences, the architectural variation and changes in the styles should correspond to changes in the workforce demographics. Alternatively, a community with a shared value system, collective project, or identity is likely to develop style conformity and a homogenous architectural landscape (Burley 2000:31). Did similar architectural elements stem from the formation of an emergent Pacific Northwest fur trade culture at Fort Vancouver? What were the social, historical, and economic factors that influenced the form of the vernacular landscape? Some houses were inhabited by families, others by multiple men. Some employees had more financial access than others to building materials. These differences mean that houses may be influenced by different "projects" over the 30-year occupation of the Village. 


\section{CHAPTER 5 \\ METHODS AND MATERIALS}

Research questions addressing the built environment of the Village require an understanding of the houses' physical attributes and their relative placement on the landscape. The arrangement of the houses is based on the historical documents, archaeological excavations, and remote sensing survey results. This study used the life history approach (Hicks and Horning 2006:290) to emphasize physical change through time, These architectural life histories include 1) the construction method; 2) the size, shape, and layout of the house; 3 ) the demolition details; 4) the dates of construction, maintenance, and "death"; and 5) the effects of post-depositional formation processes on the overall archaeological patterns of the site (Nelson 1962; Fontana 1965; Roenke 1978; 1982; Nielson 1991; Young 1994; Chapman and Ozbun 2002). The interpretations of archaeological patterns in this study drew on comparative data from previous studies of 19th century architecture in the Pacific Northwest. The methods used to extrapolate these data patterns from the architectural artifacts and features are detailed in the following sections.

\section{Excavation Background}

This study analyzed previously excavated assemblages. The level of detail available in the field records, excavation reports, and artifact catalog affected the availability of data used in the architectural analyses. The two multi-year excavation projects conducted within the NPS-administered portion of the Village were spaced thirty-five years apart and used two different field and preliminary laboratory methodologies (Table 2). Figure 23 shows the areas excavated for each project. The Fort 
Vancouver National Historic Site curates all the artifacts collected from these excavations and most of the associated field records.

TABLE 2

EXCAVATION SUMMARIES OF HOUSE STUDY AREAS

\begin{tabular}{|c|c|c|c|c|}
\hline & $\begin{array}{l}\text { No. of } \\
\text { Units }\end{array}$ & $\begin{array}{c}\text { Approx. Area } \\
\text { Excavated }\left(\mathrm{m}^{2}\right)\end{array}$ & No. of Artifacts & Artifacts $/ \mathrm{m}^{2}$ \\
\hline \multicolumn{5}{|c|}{ Kardas 1968-1969 } \\
\hline House 1 & 54 & 91.58 & 340 & 3.7 \\
\hline House 2 & 21 & 41.54 & 3326 & 80.1 \\
\hline House 3 & 26 & 54.52 & 1909 & 35 \\
\hline House 4 & 14 & 17.82 & 481 & 26.9 \\
\hline \multicolumn{5}{|c|}{ SAIP 2001-2003 } \\
\hline House 1 & 8 & 7.50 & 294 & 39.2 \\
\hline House 2 & 6 & 6 & 980 & 163.3 \\
\hline House 3 & 4 & 4 & 492 & 123 \\
\hline House 5 & 19 & 18.5 & 4228 & 228.5 \\
\hline
\end{tabular}

Note: The totals include all excavation units examined in this study.

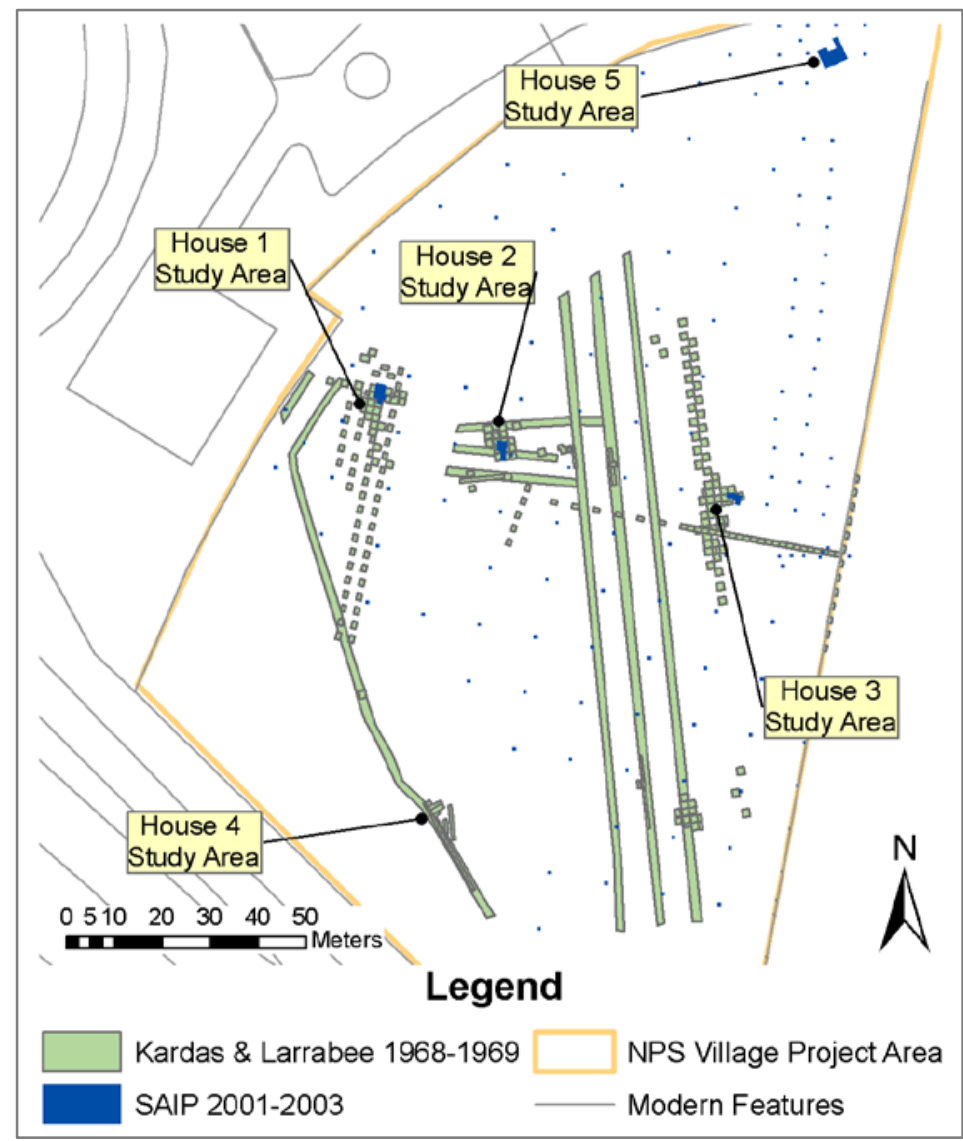

FIGURE 23.Plan view map showing the relative placement and area excavated of the Kardas and SAIP excavations. (Map by author, 2011) 
In 1968 and 1969 archaeologists used backhoes and bulldozers to scrape off the sod layer to expose large areas and excavate long shallow trenches. These large-scale exploratory methods allowed archaeologists to quickly identify where archaeological deposits were clustered before targeting dense concentrations of artifacts and features with hand-excavated $0.76 \mathrm{~m}$. (2.5-ft.) wide trenches and $1.5 \times 0.9 \mathrm{~m}(5 \times 3 \mathrm{ft}$.) excavation units. Many Village features were discovered as a result, including four houses, a well, and four animal burials, but the spatial data for artifacts was less refined. Artifacts were grouped and cataloged according to excavation unit levels that ranged from 15 to $51 \mathrm{~cm}$ (6 to 20 in.) in thickness. Screening excavated sediment was not consistently appliedthe 1969 excavation report only confirms the screening of House 2 and portions of House 3, but the screen mesh size was not specified. The field notes from Susan Kardas and Edward Larrabee (the field supervisors) were not curated at Fort Vancouver NHS, and could not be consulted during research.

The SAIP field methods (associated with the 2001-2003 field schools) produced detailed vertical provenience, but with less horizontal coverage than the 1968-1969 excavations (Table 2). Thirty-seven 1 x $1 \mathrm{~m}$ SAIP block excavation units were excavated by hand following natural strata. When a stratum was thicker than $5 \mathrm{~cm}$ in $\mathrm{HBC}$ deposits or $10 \mathrm{~cm}$ in all other deposits, arbitrary levels were used. Identified features were excavated separately from the surrounding units and its artifacts were bagged separately. All excavated sediments were screened through nested $1 / 4$ and $1 / 8$ in. $(6 \mathrm{~mm}$ and $3 \mathrm{~mm})$ mesh hardware cloth and all encountered artifacts were recovered (Gembala et al. 2004:20-24). Microartifact soil samples were also taken at the end of each level of each excavation unit to determine whether unique archaeological data were falling though the 
standard 1/8 in. $(3 \mathrm{~mm})$ screen mesh. These samples and other select matrices (hearth contents, post hole fill) were water screened through 1/16 in. $(1.6 \mathrm{~mm})$ window screen mesh. Most of the microartifact samples remained unprocessed at the time of this study, and for those samples that were water screened, most brick and bisque was not saved (too numerous and too small to offer analytic benefits) and the window glass proved too small and too fractured to obtain accurate thickness measurements. Artifacts smaller than 1/8 in. $(3 \mathrm{~mm})$ from these fine resolution samples were not included in my study.

During the SAIP excavations, collected artifacts from each unit level were sorted in the field according to artifact type (such as beads, bricks, ceramics, flat glass, nails, and tobacco pipes) and bagged separately. Artifact bags were numbered sequentially for the entire unit, entered onto a bag catalog, and taken into the lab for cleaning and postfield processing. Additional sorting was done prior to washing in the lab and each artifact type was given a Lot and Spec designation according to its provenience (Excavation Unit No., or Feature No., and Level). These artifacts were then analyzed according to the Fort Vancouver Archaeology Lab Manual (Wilson et al. 2003).

The current cataloging procedure used at Fort Vancouver National Historic site, uses Microsoft Access Database software to upload the analyzed artifact data to the Interior Collections Management System (ICMS) - formerly Automated National Catalog System (ANCS+). Each excavation is given a unique curation accession number (Table 3), and each item has a unique catalog number. This relational database can be searched for information including artifact data, field provenience, and curation location. The artifacts are stored in clear plastic bags with acid-free archival labels identifying the artifact and its provenience. The bags are stored in specialized grey plastic bins (to 
maximize artifact preservation) and organized first by material type, then Lot and Spec (Cromwell 2006:319-320). At the start of this research, most of the SAIP assemblages had been analyzed, but many artifacts are awaiting quality control checks before cataloging.

TABLE 3

ACCESSIONS INCLUDED IN THIS STUDY

\begin{tabular}{lccccc}
\hline & \multicolumn{2}{c}{ Kardas \& Larrabee } & \multicolumn{3}{c}{ NPS Field School/SAIP Excavations } \\
Accession & ACC 0116 & ACC 0120 & ACC 2997 & ACC 3011 & ACC 3023 \\
\hline Year & 1968 & 1969 & 2001 & 2002 & 2003 \\
House 1 & $\mathrm{X}$ & & & $\mathrm{X}$ & $\mathrm{X}$ \\
House 2 & & $\mathrm{X}$ & & $\mathrm{X}$ & $\mathrm{X}$ \\
House 3 & & $\mathrm{X}$ & & & $\mathrm{X}$ \\
House 4* & & $\mathrm{X}$ & $\mathrm{X}$ & $\mathrm{X}$ & $\mathrm{X}$ \\
House 5 & & & & & \\
\hline
\end{tabular}

* The vicinity of House 4 was tested in 1993 and 1994, but these accessions were not included in the study because House 4 was not explicitly reinvestigated.

The artifacts collected by Kardas and Larrabee were cataloged and analyzed elsewhere, following a different system. Many artifacts, including nails, brick, and window glass, were minimally analyzed; only provenience, artifact type, and count were recorded. More attention was paid to personal and domestic artifact types. The 1968 and 1969 Village collection was eventually cataloged in ANCS+, but only the data written on the original bag labels were entered. Most of these artifacts had not been analyzed according to current standards.

The house study areas included the excavation units originally identified as part of the house sites in 1968 and 1969, plus the units immediately surrounding the house sites to ensure scattered architectural remains were not prematurely excluded. Three SAIP excavation blocks were wholly included within the boundaries of the 1968 and 1969 house sites and a fourth (House 5) had not yet been analyzed. 
Five stratigraphic deposits have been established based on the observations of Kardas and Larrabee in 1968 and 1969, the SAIP excavations at House 5, and shovel tests, with the understanding that each excavation had different methods for recording sediments. Kardas and Larrabee (1968:7-8) observed that strata were 3-6 inches shallower near House 1 (west side) than around House 3 (the east side). Although field forms distinguish 19th century U.S. Army and HBC strata during the SAIP excavations, this designation depended more on artifact types present than sediment differences; both were contained within the A-horizon (Stratum IV).

- Stratum I: National Park Service sod and organic horizon. This brown (10YR $4 / 3$ ) to dark grayish brown (10YR 4/2 and 10YR 3/2) silt loam represents the fill added by the NPS to landscape the park and level the ground surface. It ranged in thickness from 2 to $7 \mathrm{~cm}$. Gravel content ranged from $1 \%$ to $40 \%$.

- Stratum II: 20th century U.S. Army construction and demolition activities. The sediment colors and gravel content varied as most of these contexts were mixed because of ground disturbance during construction or demolition of the 20th century structures. Artifact assemblages included large amounts of concrete, brick, wood, and wire nails.

- Stratum III: This is the 1894 flood silt. It was not uniformly observed across the Village, only in part of House 5 and in a few shovel tests. This thin layer of dark brown (10YR 3/3) silt with minimal structure and no gravels has been observed during excavations of the Stockade, and is a reliable indicator of undisturbed HBC sediments (Pierson et al 2009:16).

- Stratum IV: This contains the 19th century U.S. Army/HBC Village deposits. It is a dark brown (10YR 3/3) gravelly silty loam (15-25\% pebbles and granules). Within this stratum are house-specific deposits. The boundary between Strata IV and V is diffuse.

- Stratum V: The B-Horizon is culturally sterile and composed of a dark yellowish-brown (10YR 4/4 and 4/6) gravelly sandy loam. On average, this is 
at least $35 \mathrm{~cm}$ below the ground surface. Kardas and Larrabee observed this at $12-15$ inches $(30-38 \mathrm{~cm})$ below surface in the area of House 1.

My initial intention was to correlate stratigraphic deposits (and the associated artifacts and features) across excavations to help unite the data from the 1968-1969 and SAIP excavations at each house. In course of examining field forms, it because clear that stratigraphic data were inconsistently recorded in 1968 and 1969, and with the exception of House 5, the SAIP excavations took place in backfilled deposits, which rendered the tight vertical provenience nearly irrelevant. Distinctions between HBC and non-HBC deposits could be made at House 5 because it had not been previously excavated.

\section{Feature Analysis}

Feature analysis was entirely archival, drawing physical attributes and provenience data from the SAIP field notes, the 1968 and 1969 excavation reports, and the 1969 student field notebooks. The measurements were based on the sketch maps and as such are open to the possibility of human error. SAIP features were assigned unique feature numbers, then excavated and documented separately from the surrounding matrices. The SAIP feature forms were the primary source for feature shape, size, and content descriptions. Occasionally the feature forms referenced level forms and field notebooks that contained additional information.

Fewer details were recorded for the features found in 1968 and 1969. Kardas and Larrabee did not assign feature numbers to their houses, so I assigned arbitrary numbers for this study. Feature dimensions were gleaned from the plan view maps and the assemblage discussions in the final excavation reports. The 1969 student field notes occasionally documented archaeological remains that were not reported in the final 
excavation reports, but shared formal attributes with feature types recorded at other Village house sites (Figure 24). These features were included based on the assumption that the students were recording what they observed as they excavated the house sites. Without the field notes of Susan Kardas or Edward Larrabee, it was not possible to determine the reasoning behind the exclusion of some features from the final report. As far as the field notes indicate, features were discovered during the excavation of a unit, but were not excavated separately. Artifacts that were collected from features were cataloged with the rest of the unit. Occasionally those found within distinct sediments were noted as such, but postholes were not excavated separately like they were during the SAIP excavations.
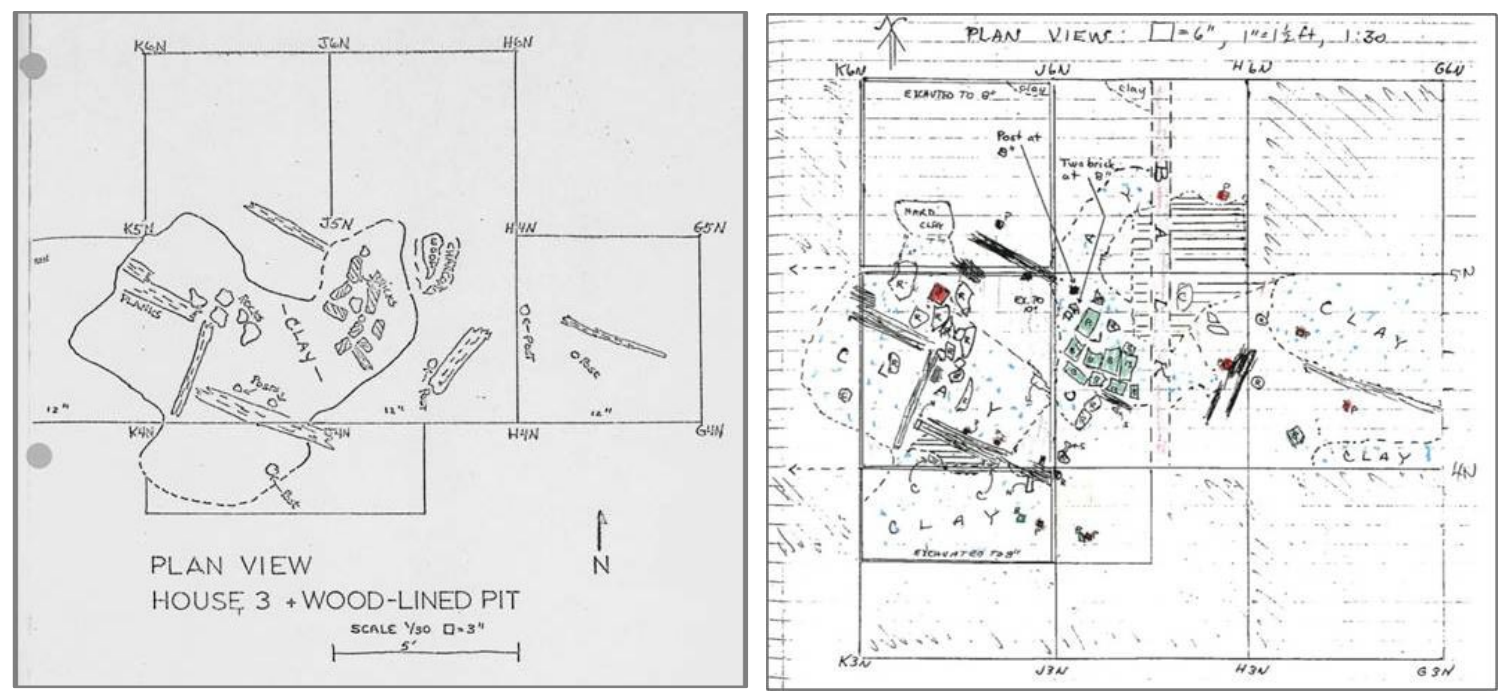

FIGURE 24. Comparison of the excavation plan views of House 3, as documented in the final excavation report (left) (Kardas 1970) and by a field school student in 1969 (right). (Courtesy of Fort Vancouver National Historic Site.)

Based on stratigraphic context and feature contents distinctions were made between 20th century and 19th century features, between structural and non-structural features. For the most part, my analysis and discussion used the in-field feature type identifications, which during the SAIP excavations were confirmed by the NPS 
archaeologists who assigned the feature numbers. Kardas and Larrabee appeared to only discuss the 19th century structural features in the reports, with mention of intruding postHBC features when disturbed contexts needed addressing. Some features were reinterpreted because subsequent research and excavations have increased our current understanding and expectations of Village features. Common features types include:

- House floors are grayer in color, more compact, and have a higher silt and clay content than the surrounding A-Horizon sediments. Many "floors" appear truncated by post-HBC disturbances, and may not represent the full original size of the structure.

- Hearths were identified in the field based on their contents (often ash, bone, fire-cracked rock, charcoal, burned sediments, and in the case of House 3, brick). The hearths ranged from small (size) circular features to larger scatters of bricks and stones.

- Planks or Boards and other dimensional wood remains are considered structural, but specific functions were not always clear.

- Posts and Post Holes are most often characterized by the remains of a vertical wood post in a smaller pit with sediment that is often darker than the surrounding matrices. Wall support posts found at OP 14 were $15-20 \mathrm{~cm}$ (6 to 8 in.) wide.

- Other structural features such as pits and sediment stains, which could not always be definitively identified as structural, were found in proximity to other structural features.

- Miscellaneous Features not related to the 19th century structures were discussed separately. These included 1968 and 1969 excavation balks, 19th century non-structural features (burials), and 20th century U.S. Army or NPS disturbances.

Features within the study areas were scanned and saved as digital image files, then uploaded into ArcGIS 9.3, a Geographic Information Systems (GIS) digital mapping 
software. The scanned images were aligned with a digital map of the Village and all the study area excavation units, and then the shape and components of the features were traced to create digital shapefiles. The resulting map showed all features from all excavation years in relation to one another. Following feature identification, the GIS shapefiles of 19th century structural features were grouped separately from the other miscellaneous feature types. The interpretation of a house's form was based on the spatial relationship between the construction artifacts and these mapped structural features.

\section{Architectural Artifact Analysis}

This study relies on the analytic results of architectural artifact classes: window glass, square nails, and bricks. After the study areas had been established, the ANCS+ system was queried for nail, window glass, and brick from the relevant 1968 and 1969 excavation units. The search returned a list of catalog numbers and curatorial storage locations. The SAIP assemblages were not yet in ANCS+, but the storage boxes were organized by house and material type, allowing for easy artifact retrieval.

Post-field laboratory processing is an ongoing, multi-year process involving Northwest Cultural Resources Institute (NCRI) staff, student interns, and volunteers. Many SAIP artifacts and the House 2 window glass and nails excavated in 1969 had already undergone laboratory analysis. These data were directly incorporated into this study if the analysis forms had been previously approved by NCRI staff. With the help of Adam Wilde (2009 WSU summer intern), I analyzed the remaining window glass, square nails, and bricks from Accessions 0116, 0120, and 3011, and addressed any outstanding errors identified by NCRI staff. 
Artifact analysis followed methods specifically developed for the Fort Vancouver National Historic Site archaeological laboratory (Wilson et al. 2003). Provenience data were recorded for all artifacts in as much details as was available on the artifact labels in the specimen bags. The provenience data were crosschecked with the 1968 and 1969 master artifact catalog and the SAIP lot and spec lists. Formal artifact data were recorded on spreadsheet-based analysis forms specific to nails, flat glass, and bricks. Architectural hardware objects were compared to Ross' (1976) material culture research, but not formally recorded on analysis forms. Wood fragments were not analyzed in the lab or counted as part of the architectural assemblage unless identified as part of a feature, because indeterminate wood fragments could not definitively be distinguished as HBC or U.S. Army. After analysis was completed these forms were entered into Microsoft Excel spreadsheets; ultimately the data will be integrated into the NPS database.

Square nails were classified under four general categories: 1) Wrought Nail, 2) British Machine-Cut Nail, 3) American Machine-Cut Nail, and 4) [Indeterminate] Square Nail. Most indeterminate square nails are corroded shafts, missing heads and tips. Indeterminate square nails have minimal analytical value, being neither temporally or functionally diagnostic. Wire nails were excluded from the analysis because they did not come into common use in the Pacific Northwest until about 1900 (Pierson et al. 2009:3941). As the Village houses were demolished before the 1870s, wire nails (although used in France at the time) would probably not have reached the Village for use in the HBCera construction and maintenance. The presence of wire nails did assist in the identification of 20th century deposits or mixed 19th-20th deposits, but details analysis of these wire nails was not necessary for this particular project. 
To establish nail function, a comparative collection and identification guide was used to assign "Fort Vancouver nail typology" style numbers whenever possible (Ross 1976:903-905; Pierson et al. 2009) (Table 4). These styles were defined based on the shapes of the nail heads and tips, and occasionally the size. Fragmented nails, unless they included a unique nail head style, were often not identified beyond "wrought" or "machine cut". More often the heads or tips were broken, preventing identification. Length (measured in centimeters) and penny size are only recorded for complete nails. Because of inherent variation among the hand wrought nails, the penny sizes do not always directly correlate to the more standardized machine-cut penny sizes (Ross 1976:888-923; Pierson 2006). For this study, however, the penny sizes are used to identify general size populations of the same nail style that may have different functions.

TABLE 4

COMMON FORT VANCOUVER NAIL VARIETIES AND FUNCTIONAL CATEGORIES

\begin{tabular}{|c|c|c|c|c|}
\hline \multirow[b]{2}{*}{ Function } & \multicolumn{2}{|c|}{ Hand Wrought } & \multicolumn{2}{|c|}{ Machine Cut } \\
\hline & Variety No. & Size & Variety No. & Size \\
\hline General Construction & 1002; & & $\begin{array}{c}2001 ; 2002, \\
2005\end{array}$ & $3 d-40 d$ \\
\hline Heavy Construction & $\begin{array}{c}1008,1009,1014 \\
1017,1081\end{array}$ & $20-60 d+$ & 2002 & 20-40d \\
\hline Flooring & 1001,1060 & $8 d-9 d$ & 2001 & $9 d-10 d$ \\
\hline Light Construction & & & 2004 & \\
\hline Roofing & 1002,1060 & $4 d$ & & $4 d$ \\
\hline Finishing & 1001 & $5 d-7 d$ & 2001 & $3 d$ \\
\hline Shingling & 1002 & $2 d-5 d$ & $2001 ; 2004$ & $3 d-4 d, 6 d-8 d$ \\
\hline Siding & 1060 & & 2001 & $8 \mathrm{~d}$ \\
\hline Molding & 1001 & & 2001 & \\
\hline Walls & 1060 & $8 d-10 d$ & & \\
\hline Hinges & 1038,1022 & & & \\
\hline Doors & 1060 & $5 d-9 d$ & & \\
\hline
\end{tabular}

Source: Pierson (2006), Pierson et al. (2009), Ross 1976, Steele et al. (1975), Chapman and Ozbun (2002).

Analysts also recorded nail completeness (complete, head, shank, or tip) and surface modifications (bent shaft, broken tip, flattened, missing head, or sheared). The 
bent nails were further classified into pulled and clinched. It was not realized until late in the statistical analysis that some analysts did not consistently identify whether a bent nail was pulled or clinched; only describing the nails "bent at right angle." In this situation, the "right angle" bent nails were reclassified as clinched, and the nails whose condition was only "bs" or "bent shaft" were assumed pulled.

Flat glass could be either window or mirror glass. Mirror glass, identified by a silver residue on one side, was excluded from this study. Each window glass fragment was measured using a size target, which is a series of concentric rings measuring out from the center at $6 \mathrm{~mm}, 10 \mathrm{~mm}, 15 \mathrm{~mm}, 20 \mathrm{~mm}, 30 \mathrm{~mm}, 40 \mathrm{~mm}$, and $50+\mathrm{mm}$. Fragments are centered on the "bull's eye" and the maximum dimension is measured to the closest ring, without intersecting the artifact. The size of window fragments, in combination with provenience data, was used to infer breakage patterns resulting from demolition and post-depositional formation processes. Digital calipers were used to measure glass thickness to two decimal places in millimeters. Measurements were converted to inches for the thickness analysis following Roenke's (1982) established methodology for window glass analysis. Weight (in grams) and glass color (colorless, light aqua, or light green) data were collected for the assemblages analyzed after 2007, but these data were not factored into this study.

Brick was classified as English Brick, American Brick, or [Indeterminate] Brick, based on color, inclusions, and size. Distinguishing English from American brick only provides evidence of the location of manufacture, and general date ranges. English bricks traveled to Fort Vancouver as ballast on HBC supply ships and were associated with HBC building activities. American bricks, made in the Willamette Valley, were sold to 
the $\mathrm{HBC}$ in the 1800s, but the common red bricks used in the 20th century are also indentified as American bricks. Provenience was the most important attribute of bricks collected in the Village.

Brick fragments were measured with the same size target used for window glass; if larger than $50 \mathrm{~mm}$ fragments were measured with tape or calipers. If the brick had at least two opposing flat sides, then a complete measurement was taken for Length, Width, and/or Thickness. Only two of the five houses included whole bricks, House 3 and House 5. Weight was measured in grams, often to two decimal places, using an electronic balance in the lab. Fort Vancouver-specific brick types have been established and if known were recorded, along with surface modifications.

\section{Life History Analysis}

The life history interpretations relied heavily on spatial analysis, specifically the spatial relationships between features and artifact concentrations (Table 5). Artifact frequency tables and charts created using Microsoft Excel listed specific artifact attributes according to excavation unit. The final data spreadsheets for each house were "joined" to the excavation unit shapefiles in ArcGIS to visually represent the spatial distributions.

The disparate field and laboratory methodologies used for the two projects resulted in different resolutions of spatial data, which ultimately affected the spatial analysis of the house life histories. The SAIP artifact densities were not directly compared to the Kardas artifact densities because of the effects of screening methods and mesh size on artifact recovery rate. At Houses 1-4 the 1968-1969 artifact densities are used to infer the life history. Similarly, the size of the artifacts could not be compared 
between the two assemblages because matrices were not consistently screened in 1968

and 1969. Elevation data was difficult to compare between projects because of differences in vertical resolution and the presence of mixed contexts in some SAIP excavation blocks.

TABLE 5

ARCHITECTURAL INTERPRETATIVE DATA

\begin{tabular}{|c|c|c|c|c|}
\hline \multirow[t]{2}{*}{ Artifact Class } & \multicolumn{4}{|c|}{ Life History Interpretation Component } \\
\hline & $\begin{array}{c}\text { Construction } \\
\text { Method }\end{array}$ & Layout & Dates & $\begin{array}{c}\text { Death/Formation } \\
\text { Processes }\end{array}$ \\
\hline Window Glass & $\sim$ & Provenience & Thickness (mm) & Size $(\mathrm{mm})$ \\
\hline Square Nails & $\begin{array}{l}\text { Density; } \\
\text { Functional Style; } \\
\text { [Penny] Size }\end{array}$ & $\begin{array}{l}\text { Functional Style; } \\
\text { Provenience; } \\
\text { [Penny] Size }\end{array}$ & Manufacture Type & Nail Condition \\
\hline Bricks & $\sim$ & Provenience & Manufacture Type & Size $(\mathrm{mm})$ \\
\hline Hardware & $\sim$ & $\begin{array}{l}\text { Identification; } \\
\text { Provenience }\end{array}$ & $\sim$ & $\sim$ \\
\hline Features & $\begin{array}{l}\text { Foundation } \\
\text { Features }\end{array}$ & $\begin{array}{l}\text { All feature types, } \\
\text { Provenience }\end{array}$ & $\sim$ & $\sim$ \\
\hline
\end{tabular}

General house locations were distinguished from secondary refuse deposits by artifact frequencies $\left(\mathrm{n} / \mathrm{m}^{2}\right)$, presence or absence of structural features, and nail condition. Artifact densities were based on area $\left(\mathrm{m}^{2}\right)$ rather than volume $\left(\mathrm{m}^{3}\right)$ because the former allow for inter-house comparisons; terminal depths could not be consistently confirmed for the 1968-1969 excavation units. Structural features were considered the primary indicator of a house location. In most cases, the units with the greatest architectural artifact density overlapped with these features, further supporting the location inference. When high artifact densities (equal to or greater than the average density of the featurecontaining units) were observed outside the features, nail conditions (unaltered, pulled, and clinched) were tabulated to identify the source of the artifact concentration, such as a secondary refuse deposit (Young 1994). Units containing structural features but with low 
artifact densities were not immediately discounted as part of the house, because site formation processes could have altered the artifact patterning.

The specific walls of the structures were inferred by the alignment of foundation features, the limits of the house floor, the presence or clustering of large nails and spikes (20d-60d), and a decrease in artifact density (often by one-half) as one moves away from the house footprint. The sizes of the houses were extrapolated and estimated based on the greatest visible extents of the house floor and foundation features. In most cases these size estimates were tenuous because entire walls were not excavated.

The extensive literature on earthfast and impermanent architecture suggests the construction methods of the foundation, walls, floor, and roof could be extrapolated from foundation features, nail type, and nail frequency (Table 6) (Burley et al. 1992; Hébert 2007; Maygarden 2006; Speulda 1988; Carson et al. 1981). Common nail types are presented in Table 4 . If the average nail density was less than $43 / \mathrm{m}^{2}$, the walls were likely a pièce-sur-pièce construction method (non nail-intensive); whereas balloon frames, built by nailing each board to the frame, were inferred if the average nail density was greater than $64 / \mathrm{m}^{2}$. Flooring and roofing nails (Table 6) should be evenly distributed across the house footprint, because roofs and floors frequently covered the entire structure. No specific measure was identified to distinguish between board roofs and shingled roofs, although the latter used more nails and would likely produce a higher density of small roofing nails.

TABLE 6 CONSTRUCTION METHOD INTERPRETATIVE DATA

\begin{tabular}{lcccc}
\hline \hline Artifact Class & Foundation & Wall Type & Roof Material & Floor Type \\
\hline Square Nails & $\sim$ & Density & no. 1002 or 1060 & no. 1001, 1060; \\
Features & Posts or Timbers & $\sim$ & size: $2 \mathrm{~d}, 4 \mathrm{~d}$ & size: $8 \mathrm{~d}-9 \mathrm{~d}$ \\
\hline \hline
\end{tabular}


The layout of the house and placement of windows, doors, hearths, and other architectural elements was interpreted based on the distribution of features and artifacts (Table 7). The distribution of specific nail styles and sizes revealed the presence of trim related to window frames, doors (Thomas 1987; Amos-McGraw 2008). Doors are often indicated by presence of compact sediments, door hardware, and nail types used for the doorframe (no. 1001) and door construction (no. 1060). Specific nail types were considered "clustered" if they were present in one excavation unit, but absent in nearby units (or at least lower in number). Statistical comparison tests were not used. Larger window glass fragment sizes were assumed to be in proximity to where the window was broken. The available spatial data are dependent on the excavation's provenience data; in some cases door and window locations can only be generally assigned to a wall (Stilson 1991). A cluster of bricks might indicate a brick hearth or chimney, but a lack of bricks does not indicate a lack of any hearth because different hearth and chimney forms existed.

TABLE 7

LAYOUT INTERPRETATIVE DATA

\begin{tabular}{lccc}
\hline \hline Artifact Class & Window Location & Door Location & Hearth \\
\hline Window Glass & High density & $\sim$ & $\sim$ \\
Square Nails & Finishing/trim nails; & Clinched nails; style & $\sim$ \\
Bricks & no. 1001, size 5d-7d & no.1001 \& 1060 & High density \\
Hardware & $\sim$ & $\sim$ & Locks, Latches, etc \\
Features & $\sim$ & Posts & $\begin{array}{c}\text { Charcoal, bisque, food } \\
\text { remains, FCR, wood }\end{array}$ \\
\hline \hline
\end{tabular}

The temporally diagnostic attributes of window glass (primary and secondary thickness modes) and square nails (manufacture type) indicate whether a structure was built entirely at one time or if a structure "has been subjected to additions, alterations, or 
simple maintenance" (Nelson 1962:1; Roenke 1978:43). The relative abundance of wrought and machine cut nail manufacture type distinguished early component (HBC, 1829 to 1860 ) from the late component (U.S. Army, 1849 to 1900) construction phases, while window glass data could narrow the dates to a specific decade. These provided the initial dates, terminus post quem, of the construction and maintenance, not the final demolition dates (Hampton Adams 2002:67).

Based on Roenke's research on window glass from early historic period sites across the Pacific Northwest (1978), including the Village (1982), window glass fragments ranging in thickness from 0.035 to 0.075 in. were taken to signify the $\mathrm{HBC}$ occupation period (Table 8). The Village was allegedly demolished in the mid 1860s, which likely means most fragments equal to and thicker than 0.085 in. post-date the $\mathrm{HBC}$ occupation period. These thicker fragments were not included in the spatial analyses. Since windows were often adjacent to coulisse (wall support posts) with planks placed around the window frame, it was assumed that most windows were installed during initial construction (primary mode). Cutting holes in existing walls would require greater effort. A window repair phase and structural additions at a later date would both produce a secondary mode.

TABLE 8

DATE RANGES FOR WINDOW GLASS THICKNESS

\begin{tabular}{lcc}
\hline Date Range & $\begin{array}{c}\text { Interval Midpoint } \\
\text { (inches) }\end{array}$ & $\begin{array}{c}\text { Interval Midpoint } \\
\text { (millimeters) }\end{array}$ \\
\hline $1830-1840$ & 0.045 & $\sim 1.15$ \\
$1834-1845$ & 0.055 & $\sim 1.40$ \\
$1840-1850$ & 0.065 & $\sim 1.65$ \\
$1850-1860$ & 0.075 & $\sim 1.90$ \\
$1855-1885$ & 0.085 & $\sim 2.15$ \\
$1870-1900$ & 0.095 & $\sim 2.40$ \\
\hline
\end{tabular}

Note: Chronology based on Roenke 1982 
The dates derived from window glass thicknesses technically refer to the time of manufacture, and even then, window replacement might have taken place separate from other repairs. Originally the plan was to date features by the square nails and window glass found within them, then develop a house-specific chronology of features to track the structure's construction and maintenance over time (Thomas and Hibbs 1984:281; Stilson 1990, 1991). However, although some artifacts were noted as coming from the “east half of pit” or "grey sediment," most 1968 and 1969 features (particularly posts) were not excavated separately from the rest of the unit, and could not be dated by featurespecific artifact assemblages. Moreover, even though some of the SAIP features contained a couple window glass fragments, Roenke's method requires multiple window fragments because there is inherent variation in the thickness of any specific windowpane. Three or four fragments of different thicknesses may simply represent parts of one pane, rather than multiple panes manufactured at different times.

The "death" of each house was inferred from square nails and window glass. Ratios of complete unaltered, pulled, and clinched nails were tabulated and assessed following the methods established by Young (1994) to identify how each structure "died," either by decay, forced demolition, or other means. The distribution of artifacts might indicate the direction in which the structure fell.

The demolition dates, or perhaps more accurately the end of occupation dates, were estimated based on the first major drop in window glass thickness distribution. For example at the houses in this study, the majority of a window glass assemblage might fall within a range of three to four thickness intervals, with minimal (10-20\%) different between the relative frequencies. These modes represent windowpanes that were installed 
in the house at one time or another. The first thickness interval with a frequency of $30 \%$ or less of the primary mode was inferred to be background construction debris that postdate the last active window installation of the house's occupation. In most cases, this "end" date coincided with the $1855-1885$ post-HBC glass ( 0.085 in.), but occasionally the drop occurred sooner. Likewise, a lack of machine cut nails combined with an earlier drop in window glass frequencies suggest a pre-1845 "death."

A note on measurement units in the following chapters: Excavations in the 1960s used English units of measure and the SAIP excavations used metric units of measure. For consistency throughout the document metric units are listed first with English units in parentheses. In an effort to avoid imposing artificial precision in the English-to-metric conversions, the following rules were used:

- No more than one decimal point was used for the conversion of feet in whole integers to meters: $5 \times 3 \mathrm{ft}$. became $1.5 \times 0.9 \mathrm{~m}$.

- Inches in whole integers were converted to whole integers in centimeters: 6 in. became $15 \mathrm{~cm}$.

- If English measurements included a decimal point, the metric conversions (feet to meters; inches to centimeters) matched the number of digits after the decimal point.

- Scaling between meters, centimeters, and millimeters took place after the initial conversions (feet to meters; inches to centimeters).

- When converting the SAIP metric measurements to English units, the English measurements were allowed one additional decimal place beyond what the metric precision was: $45 \mathrm{~cm}$ became $17.7 \mathrm{in}$. and $2.5 \mathrm{~m}$ became $8.2 \mathrm{ft}$. 


\section{CHAPTER 6 \\ HOUSE 1}

The "domestic concentration" known as House 1 was found outside the Civilian Conservation Corps (CCC) era paved loop road, approximately $14 \mathrm{~m}$ (47 ft.) from the western NPS property boundary. In 1968, trenches of alternating 1.5 x $0.9 \mathrm{~m}(5 \mathrm{x} 3 \mathrm{ft}$.) squares, which were enlarged to $1.5 \times 1.5 \mathrm{~m}(5 \times 5 \mathrm{ft}$.) in areas of high artifact concentrations, were aligned with the west side of the CCC road. Thirteen excavation units were associated with the remnants of House 1, based on an artifact density threetimes greater than the surrounding areas (Kardas 1970:13). For this analysis, the House 1 study area included an additional 41 excavation units from 1968, totaling 54 units (excavated area: $91.5 \mathrm{~m}^{2}$, approximate excavated volume: $11.5 \mathrm{~m}^{3}$ ). In 2002 and 2003, archaeologists excavated seven 1 x $1 \mathrm{~m}(3.2 \times 3.2 \mathrm{ft}$. $)$ units and one 1 x $0.5 \mathrm{~m}(3.2 \times 1.6$ ft.) unit (excavated area: $7.5 \mathrm{~m}^{2}$, excavated volume: $1.9 \mathrm{~m}^{3}$ ) in a depression "near" the projected House 1 location. Archaeologists knew they had rediscovered House 1 when they found two rock-and-wood post features that matched those Larrabee and Kardas (1968) had documented on the north edge of the "domestic concentration." No field notes for the 1968 season are on file at Fort Vancouver; the only records of the excavation are the artifact tags and the excavation reports. As the first house site discovered in the Village, many of the subsequent house site discoveries were based on the archaeological signatures observed at House 1 (Larrabee and Kardas 1968; Kardas 1970; Thomas and Hibbs 1984). 


\section{Stratification}

The 1968 and SAIP excavations encountered minimal stratigraphic variation within the House 1 study area. With the exception of one northern unit that was excavated to a depth of $20 \mathrm{in} .(50 \mathrm{~cm})$ below surface, no 1968 units were excavated deeper than 12 in $(30 \mathrm{~cm})$. Excavations did not seemingly penetrate below the dark brown sandy loam A-Horizon (Stratum IV) (Larrabee and Kardas 1968:8). Archaeologists encountered a compact grayish brown deposit 4-6 in. (10-15 cm) below surface and within the A-Horizon (Larrabee and Kardas 1968:8). The SAIP excavations revealed a thick homogenous A-Horizon (brown or dark brown silty loam with $20-40 \%$ gravels) and a B-Horizon beginning at $45 \mathrm{cmbd}$ (or $35 \mathrm{cmbs} / 12 \mathrm{in}$. bs). This A-Horizon represented a mixed context containing 19th and 20th century artifacts, likely backfill from the 1968 excavations. A 20th Century trash pit to the north borders, and possibly truncates part of House 1 and its "yard". Larrabee and Kardas (1968: 21) stated that these 20th century disturbances rarely penetrated deeper than $1 \mathrm{ft} .(30 \mathrm{~cm})$ below surface, but the 2002 discovery of buried concrete at 40cmbs in EU02 and EU04 suggests deeper disturbances associated with the debris pit to the north.

\section{Features}

Sixteen features were recorded in the House 1 study area (Figure 25), including three "miscellaneous" features (Table 9) and thirteen structural features (Table 10).

\section{TABLE 9}

FORMAL CHARACTERISTICS OF HOUSE 1 MISCELLANEOUS FEATURES

\begin{tabular}{lccccc} 
& & $\begin{array}{c}\text { Max. } \\
\text { Diameter/ } \\
\text { No. }\end{array}$ & $\begin{array}{c}\text { Width } \\
(\mathrm{cm})\end{array}$ & $\begin{array}{c}\text { Depth } \\
(\mathrm{cmbs})\end{array}$ & Location \\
\hline $2002-01$ & 1968 Excavation Baulk $(\mathrm{cm})$ & 200 & 150 & $0-45$ & EU01-EU04 \\
$2002-13$ & Concrete* & $200+$ & $100+$ & $21-45$ & EU02 \& EU04 \\
NA & 20th Century Trash Pit & NA & NA & NA & North of House 1 \\
\hline
\end{tabular}

* Max. length and width of feature complex, based on area excavated 


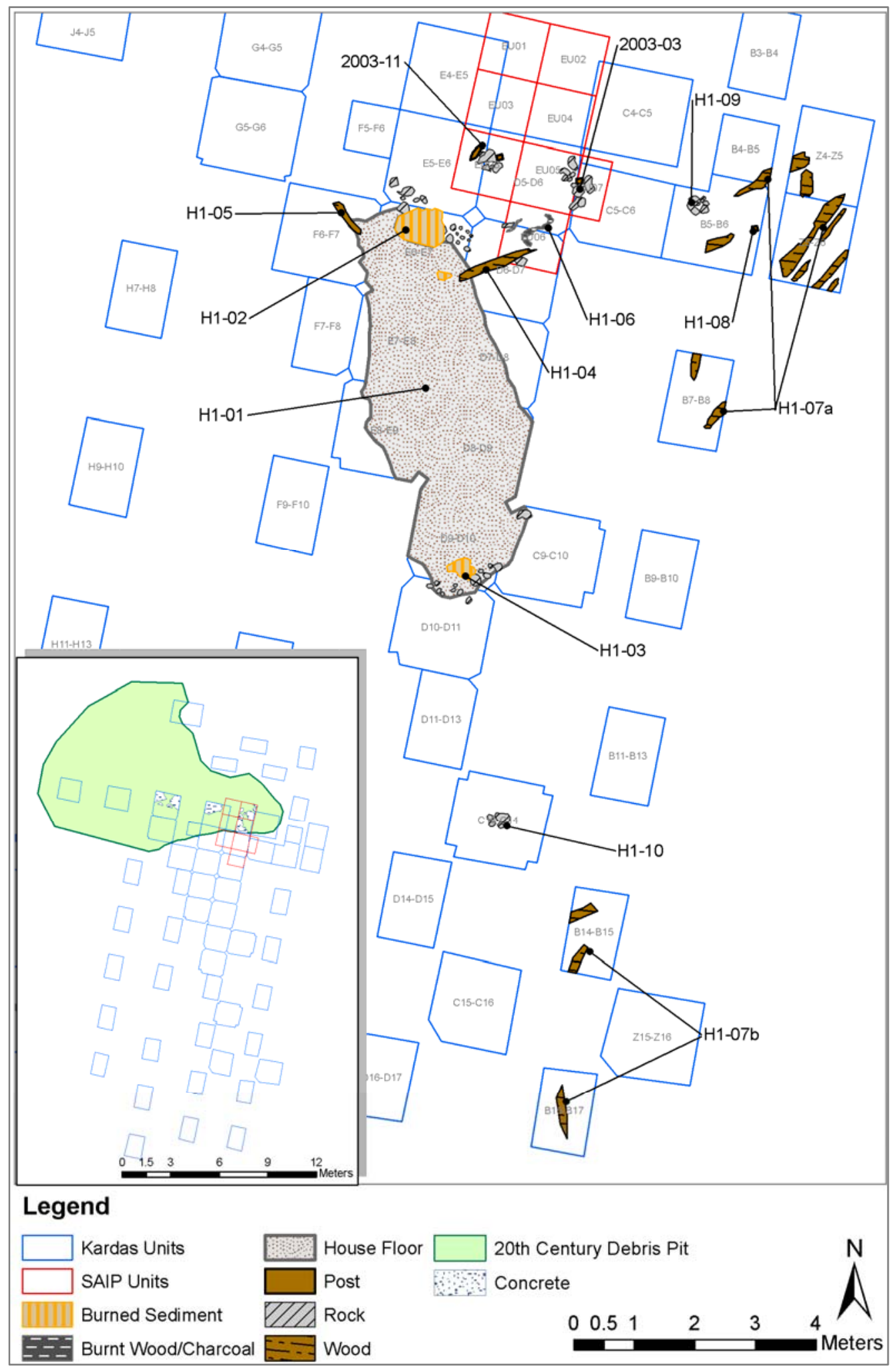

FIGURE 25. House 1 Study Area Features. Excavation baulks too small to show on inset image (Map by author, 2011). 
The "miscellaneous" features included 1968 excavation balks and 20th century U.S. Army disturbances (Figure 25, Table 9). Feature 2002-01 is approximately $1.5 \mathrm{~m}$ (5 ft.) wide, covering the majority of EU01-EU04, and lines up with what would have been the unexcavated 1968 unit D4-D5. A smaller unexcavated baulk found in the northeast corner of EU07 (resembling the space between units C4-C5 and C5-C6) and plastic sheeting overlaying a patch of ash, bisque, and charcoal found at $30 \mathrm{cmbd}$ in EU06 provides further confirmation of the placement of the SAIP units in relation to the 1968 excavations. Feature 2002-01 had greater artifact diversity and richness than the previously excavated portions of EU01-EU04, but was still a disturbed context consistent with the "pit with 20th century debris" north of House 1 documented by Larrabee and Kardas (1968:21-22). The outline of this pit appeared darker in plan views of the 1968 excavation. The artifacts were a mixture of 20th and 19th century items, regardless of elevation, and haphazardly deposited concrete (Feature 2002-13) was found in EU02 and EU04 at approximately 21 and $27 \mathrm{cmbd}$, (8 and 10 in.), respectively.

TABLE 10 FORMAL CHARACTERISTICS OF HOUSE 1 STRUCTURAL FEATURES

\begin{tabular}{|c|c|c|c|c|c|}
\hline No. & Type & $\begin{array}{l}\text { Max. } \\
\text { Diameter/ } \\
\text { Length } \\
(\mathrm{cm})\end{array}$ & $\begin{array}{l}\text { Width } \\
(\mathrm{cm})\end{array}$ & $\begin{array}{l}\text { Depth } \\
(\mathrm{cmbs})\end{array}$ & Location \\
\hline H1-01 & House Floor & 610 & 305 & $10-15$ & C9-10; D6-10; E6-9; F6-7 \\
\hline H1-02 & Burned Area, Rocks & $178^{*}$ & 79 & NA & E5-7 \\
\hline H1-03 & Burned Area, Rocks & $128 *$ & 75 & NA & D9-10 \\
\hline H1-04 & Plank & 120 & 16 & NA & D6-7 \\
\hline H1-05 & Plank & 68 & 12 & NA & F6-F7 \\
\hline H1-06 & Charcoal Stain & 58 & 14 & NA & D5-D7 \\
\hline H1-07a & Plank Cluster & $470 *$ & 237 & $15-30+$ & Z4-Z6, B4-B6, B7-B8 \\
\hline $\mathrm{H} 1-07 \mathrm{~b}$ & Plank Cluster & $401 *$ & 70 & NA & B14-15; B16-17 \\
\hline H1-08 & Post & 9 & 7.5 & NA & B5-B6 \\
\hline H1-09 & Posthole & 39 & 37 & NA & B5-B6 \\
\hline H1-10 & Posthole & 38 & 26 & NA & C13-C14 \\
\hline 2003-03 & Posthole & 92 & 66 & 20 & C5-C6, D5-D6 \\
\hline $2003-11$ & Posthole & 56 & 39 & 20 & D5-D6, E5-E6 \\
\hline
\end{tabular}

* Max. length and width of feature complex (cluster), based on area excavated. 
Thirteen structural features were recorded in the House 1 study area (Figure 25; Table 10). Feature H1-01 was the primary source of artifacts (Larrabee and Kardas 1968:8). This grayish sediment covers approximately $18.5 \mathrm{~m}^{2}\left(200 \mathrm{ft}^{2}\right)$ and was a darker color with a higher charcoal and clay content than the surrounding matrices. This deposit was no more than $5 \mathrm{~cm}$ ( 2 in.) thick and was first encountered at depths ranging from10 to $15 \mathrm{~cm}$ (4 to 6 in.) below the surface. The eastern and northern edges of the house floor were broken and less discernable than the western and southern edges (Kardas 1970:13). A patch of compact grayish brown sediment containing traces of bisque and charcoal, found in the southwest corner of EU06, may be associated with the northeast corner of the house floor. A rock was found on top of the sediment, but this rock was likely not part of the original deposit, as it is not in 1968 photographs. Admittedly the identification of the "characteristic" house floor at House 1 is circular in its logic. All subsequent house site discoveries have been based, at least partially, on the presence of grayish "clay" deposits similar to those identified by Kardas and Larrabee.

Two patches of burned earth and ash with associated rock clusters, Features H102 and H1-03, were located at the northern and southern ends of Feature H1-01. These areas of bisque, charcoal, and ash were $79 \times 57 \mathrm{~cm}(2.5 \times 1.8 \mathrm{ft}$.$) and 48 \times 33 \mathrm{~cm}(1.5 \times 1$

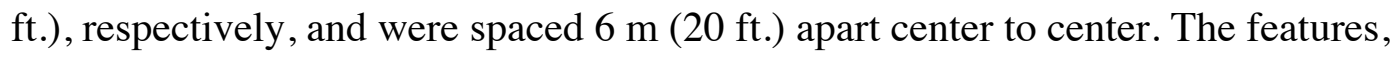
including the rocks, were interpreted as hearths, but contained no bones (Larrabbe and Kardas 1968: 23). Neither feature was excavated, so their contents remain unknown. The arrangement of the rocks appears linear. If these were post features rather than hearth features, the burned matrices could be explained as a result of fire-treating wood posts to 
prevent deterioration (Schiffer 1987:167-168) or demolition-related burning of the in situ structural remains

Wood remains within the house area were minimal and concentrated at the north end of Feature H1-01. Two rotted boards (H1-04 and H1-05) extend from either side of the northern burn area (H1-02) and a curved line of charcoal (H1-06) is approximately $1.5 \mathrm{~m}$ (5 ft.) to the northeast. There were two clusters of wood planks $4 \mathrm{~m}$ (13 ft.) to the northeast (H1-07a) and $7 \mathrm{~m}$ (23 ft.) to the southeast (H1-07b) of the house floor. The wood planks, many of which lay horizontally in a northeast-southwest orientation, were found deeper than the House 1 deposit, 15-30 cm (6-12 in.) below surface but were not considered part of the 20th century debris pit. Some of these planks "were squared, with sawed edges" (Larrabee and Kardas 1969:22). Precise measurements were not provided, though some were reportedly at least $1.5 \mathrm{~m}(5 \mathrm{ft}$.) long. A few window glass and square nails were collected from the same units, but neither the report (Larrabee and Kardas 1968) nor the artifact catalog confirm direct association with the wood planks. Within the H1-07a cluster, a single vertical 7.5-cm (3-in.) wide squared piece of wood (Feature H108) protrudes at the eastern edge of unit B5-B6.

To the north of the house floor, three rock features (2003-11, 2003-03, and H109) are aligned in a west-east orientation. Feature 2003-11 includes five rocks (cobbles and small boulders) encircled around a small $10 \mathrm{~cm}$ (4 in.) vertical wood post on the northeast edge of unit D5-D6. By 2003 this wood had degraded. The base of the rocks is approximately $30 \mathrm{~cm}$ ( $12 \mathrm{in}$.) below datum. Feature $2003-03$ is a larger cluster of 11 rocks encircling a small $7.5 \mathrm{~cm}$ (3-in.) vertical wood post (by 2003 only eight rocks remained and the wood had decayed). This feature was also, at the base of the rocks, approximately 
$30 \mathrm{~cm}$ (12 in.) below datum. The midpoints of these two features were $1.5 \mathrm{~m}(5 \mathrm{ft}$.$) apart.$ Feature H1-09 contained no wood, just a smaller cluster of six or seven cobbles $2 \mathrm{~m}$ (6.6 ft.) from the Feature 2003-03 midpoint and $3.6 \mathrm{~m}$ (11.8 ft.) from the midpoint of Feature 2003-11. Four feet to the east of this is Feature H1-08, a piece of wood located just south of the rock feature alignment. There are no rocks east of Feature H1-09, only the wood planks (H1-07a) described above. This rock feature alignment may have continued further to the west. In unit F5-F6 scattered stones were found, but were not mapped, photographed or explicitly recorded as a post feature (Larrabee and Kardas 1968:23).

\section{Architectural Artifacts}

Archaeologists recovered 634 architectural artifacts from the House 1 study area $\left(10.9 / \mathrm{m}^{2}\right.$ combined average density) (Tables 11 and 12). The 1968 units containing structural features had an average density of $6.9 / \mathrm{m}^{2}$ (min: $0.7 / \mathrm{m}^{2}$, max: $14.7 / \mathrm{m}^{2}$, std. dev.: $4.31 / \mathrm{m}^{2}$ ). This is approximately three times higher than the surrounding units, which is consistent with the observations by Larrabee and Kardas (Figure 26) (Kardas 1970:13) . Most of the artifacts were fragments smaller than $1.3 \mathrm{~cm}(0.5$ in.) (Larrabee and Kardas 1968:41). With the use of screens the SAIP excavations recovered nearly 300 artifacts from one-tenth of the area, most likely the backfill of the 1968 excavations.

TABLE 11

HOUSE 1 ARCHITECTURAL ARTIFACT COUNTS

\begin{tabular}{|c|c|c|c|c|c|c|c|}
\hline Excavation & $\begin{array}{l}\text { Window } \\
\text { Glass }\end{array}$ & $\begin{array}{l}\text { Square } \\
\text { Nails }\end{array}$ & Brick & $\begin{array}{c}\text { Architectural } \\
\text { Hardware }\end{array}$ & Total & $\begin{array}{c}\text { Avg. Density } \\
\mathrm{n} / \mathrm{m}^{2}\end{array}$ & $\begin{array}{l}\text { Std. } \\
\text { Dev. }\end{array}$ \\
\hline Acc 0116 (1968) & 34 & 303 & 0 & 3 & 340 & 4.9 & 4.86 \\
\hline $\begin{array}{l}\text { Acc } 3011 \text { (2002); } \\
\text { Acc } 3023 \text { (2003) }\end{array}$ & 131 & 103 & 60 & 0 & 294 & 38.5 & 15.15 \\
\hline Total & 165 & 406 & 60 & 3 & 634 & 10.9 & 15.12 \\
\hline
\end{tabular}




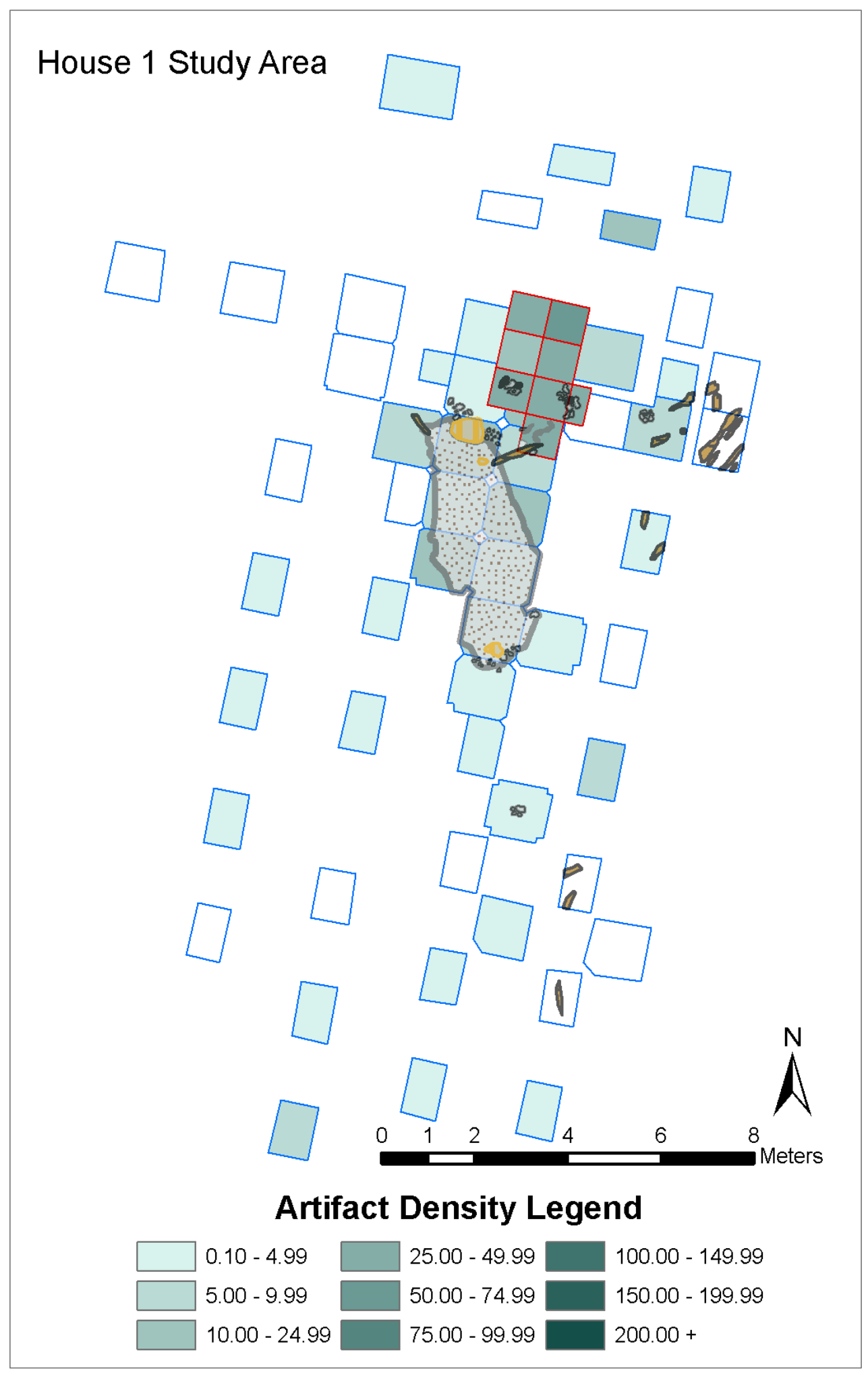

FIGURE 26. Architectural artifact density distribution $\left(\mathrm{n} / \mathrm{m}^{2}\right)$ in House 1 Study Area. White colored units contained no architectural artifacts. (Map by author, 2011). 
TABLE 12

HOUSE 1 STUDY AREA ARTIFACT CATEGORIES AND COUNTS

\begin{tabular}{|c|c|c|c|c|c|c|c|c|c|c|c|}
\hline Unit & WG & SN & $\mathrm{B}$ & Total & $\mathrm{n} / \mathrm{m}^{2}$ & Unit & WG & SN & B & Total & $\mathrm{n} / \mathrm{m}^{2}$ \\
\hline B1-B2 & 1 & 1 & & 2 & 1.4 & E5-E6 & & 5 & & 5 & 2.2 \\
\hline B4-B5 & 1 & 2 & & 3 & 3.6 & E6-E7 & & 34 & & 34 & 14.7 \\
\hline B5-B6 & 11 & 4 & & 19 & 8.9 & E7-E8 & & 17 & & 17 & 7.3 \\
\hline B7-B8 & & 1 & & 1 & 0.7 & E8-E9 & & 29 & & 29 & 12.5 \\
\hline B11-B13 & 1 & 6 & & 7 & 5.0 & F5-F6 & & 2 & & 2 & 3.5 \\
\hline В18-B19 & & 2 & & 2 & 1.4 & F6-F7 & & 14 & & 14 & 6.0 \\
\hline C2-C3 & 12 & 14 & & 26 & 22.4 & F9-F10 & & 1 & & 1 & 0.7 \\
\hline C4-C5 & 2 & 10 & & 12 & 5.2 & F11-F13 & & 3 & & 3 & 2.2 \\
\hline C9-C10 & & 7 & & 7 & 3.0 & F17-F18 & & 2 & & 2 & 1.4 \\
\hline C13-C14 & 1 & 4 & & 5 & 2.2 & F19-F20 & & 9 & & 9 & 6.5 \\
\hline C15-C16 & & 2 & & 2 & 1.1 & G0-G1 & & 2 & & 2 & 0.8 \\
\hline D1-D2 & 1 & 2 & & 3 & 2.7 & H9-H10 & & 4 & & 4 & 2.9 \\
\hline D5-D6 & 4 & 23 & & 27 & 11.6 & H11-H13 & & 2 & & 2 & 1.4 \\
\hline D6-D7 & & 20 & & 20 & 8.6 & H14-H15 & & 2 & & 2 & 1.4 \\
\hline D7-D8 & & 28 & & 29 & 12.5 & EU 01 & 11 & 13 & 18 & 42 & 42 \\
\hline D8-D9 & & 18 & & 18 & 7.8 & EU 02 & 34 & 24 & 9 & 67 & 67 \\
\hline D9-D10 & & 12 & & 12 & 5.2 & EU 03 & 12 & 4 & 3 & 19 & 17 \\
\hline D10-D11 & & 8 & & 8 & 3.5 & EU 04 & 1 & 20 & 6 & 27 & 27 \\
\hline D11-D13 & & 2 & & 2 & 1.4 & EU 05 & 25 & 12 & 5 & 42 & 42 \\
\hline D16-D17 & & 1 & & 1 & 0.7 & EU 06 & 21 & 20 & 7 & 48 & 48 \\
\hline D18-D19 & & 2 & & 2 & 1.4 & EU 07 & 9 & 6 & & 15 & 30 \\
\hline E4-E5 & & 5 & & 5 & 2.2 & EU 08 & 18 & 5 & 12 & 35 & 35 \\
\hline
\end{tabular}

$\mathrm{WG}=$ window glass; $\mathrm{SN}=$ square nails; $\mathrm{B}=$ brick; $\mathrm{n} / \mathrm{m}^{2}=$ artifact density per excavation unit

Brick. No brick was collected or recorded during the 1968 excavation. Sixty

fragments of American brick (50 mm and smaller, weighing a total of 266.8 grams) were collected in 2002 and 2003 when 1/8 and 1/4 in. screens were used. Fifty-three fragments came from previously excavated and backfilled deposits, only seven fragments were found in the previously unexcavated baulk (Feature 2002-01). Based on the proximity of Feature 2002-01 to the 20th century debris pit and the presence of concrete, these brick fragments were not likely associated with the HBC structure.

Window Glass. No window glass was listed in the 1968 report artifact tables, but it was collected from the northern excavation units around the post and wood features, and near the 20th century trash pit (Figure 27) (Larrabee and Kardas 1968:36-39). Approximately $26 \%$ of the House 1 architectural assemblage was window glass. With the 


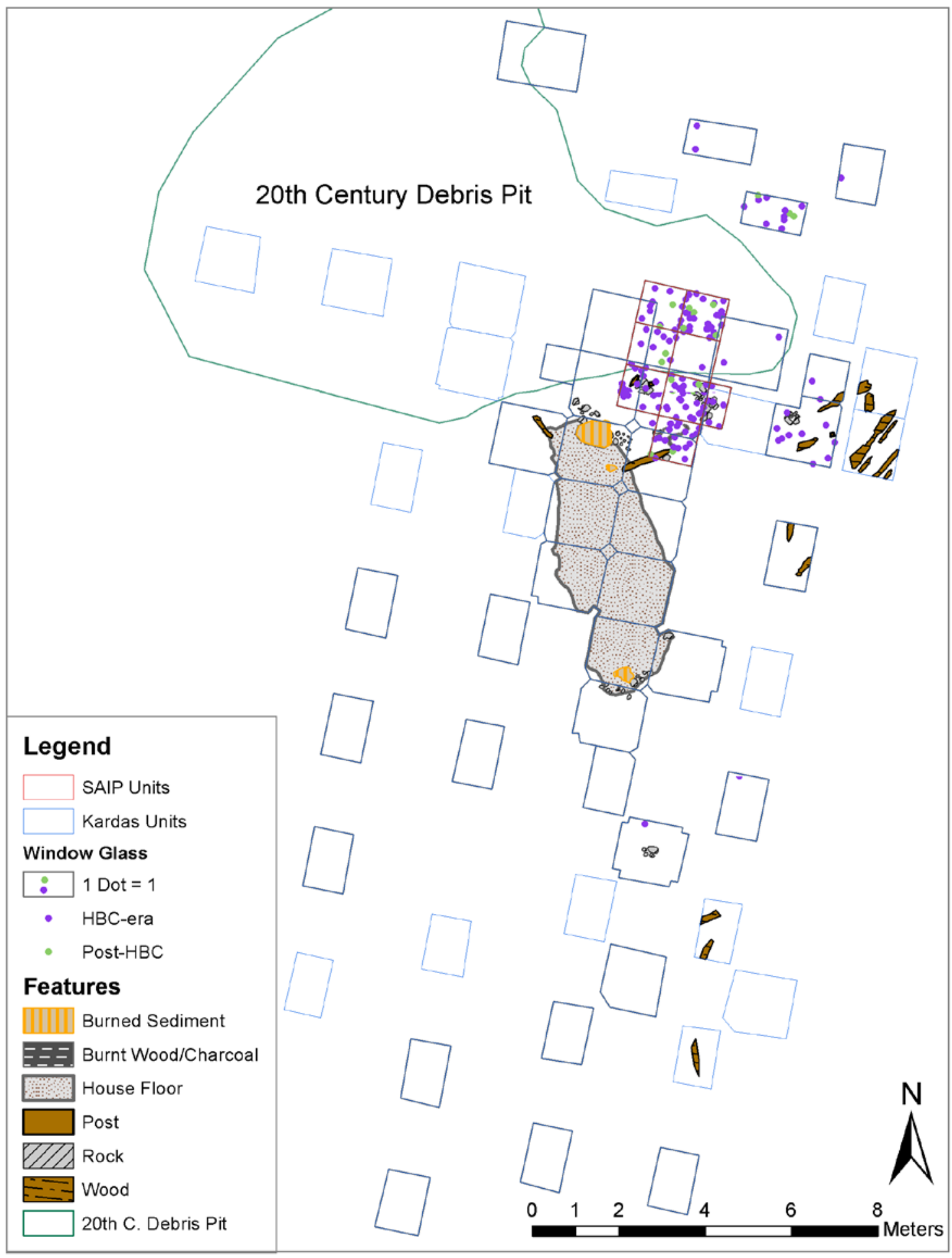

FIGURE 27. Distribution of window glass in the House 1 Study Area. HBC-era window glass fragments (purple) outnumber post-HBC (green) window glass (Map by author, 2011). 
exception of one fragment found in $\mathrm{C} 13-\mathrm{C} 14$ and one fragment in B11-B13, no window glass was recovered south of the 6-line or west of the E-line in 1968. The chance placement of the SAIP excavation units confines the window glass data to the structure's north exterior (Figure 27).

The window glass found at House 1 ranged in thickness from $0.37 \mathrm{~mm}(0.015 \mathrm{in}$. to $3.45 \mathrm{~mm}(0.136 \mathrm{in})$. The primary window glass thickness mode is 0.045 inches $(32 \%$ of total assemblage) and the secondary mode is 0.055 inches (26\%) (Figure 28). These thicknesses correspond to the date range of 1830 to 1845 (Roenke 1982).

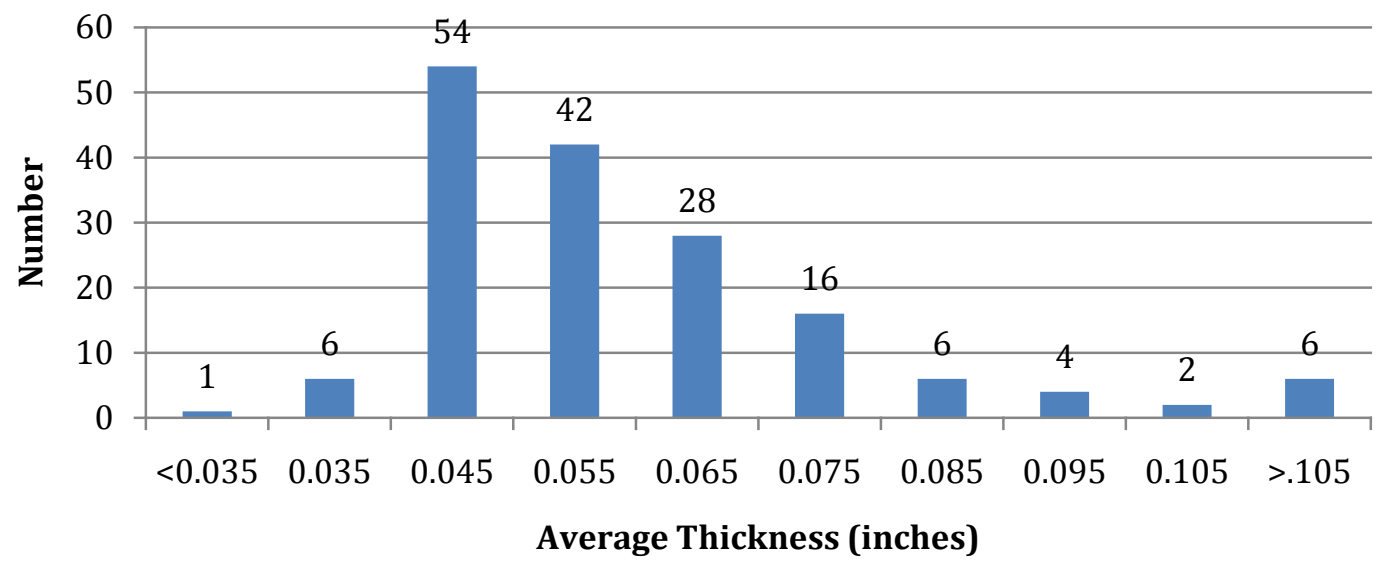

FIGURE 28: Overall flat glass average thickness for House 1. (Chart by author, 2011)

The relative frequencies are almost equal between the Kardas and SAIP assemblages (Figure 29). Even though the SAIP excavations recovered a greater number of window glass fragments, the use of screens did not create a sampling bias that altered the thickness distribution. All of the 0.065 inch fragments were found within six inches of the surface, with 0.045 and 0.055 found equally between 0-6 and 6-12 in. below surface. Horizontally, the distribution of window glass was not wide enough to identify clusters of HBC-era and post-HBC-era thicknesses. 


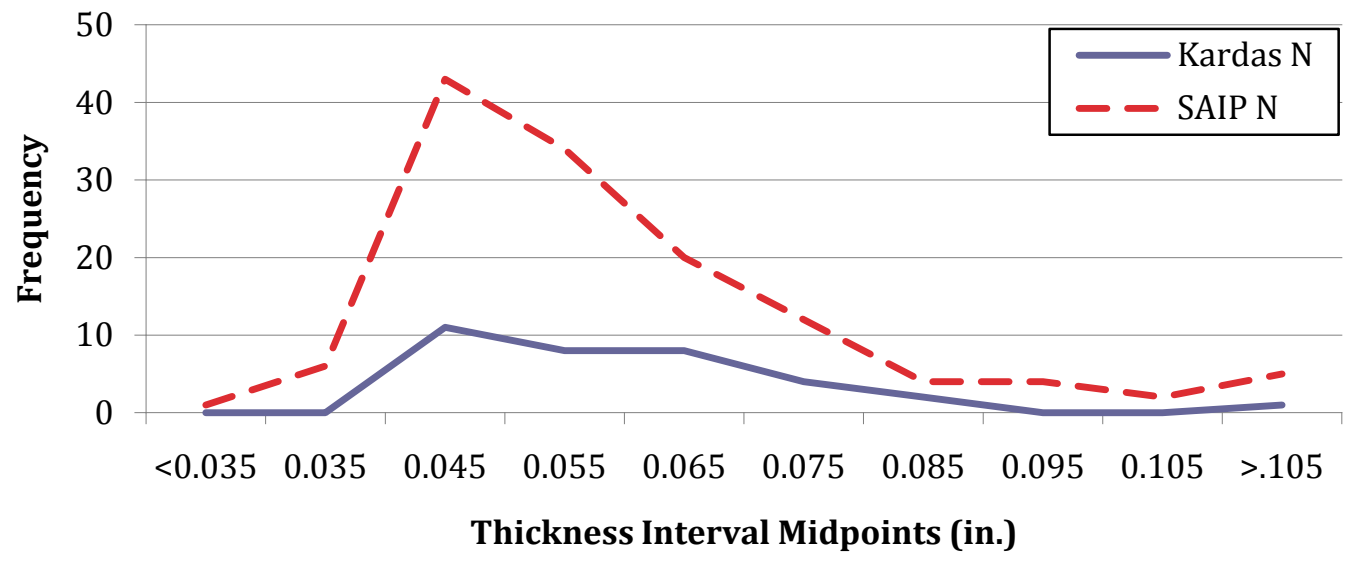

FIGURE 29: Comparing glass thickness modes by excavation. (Chart by author, 2011)

The window glass fragments were small, with $81 \%(n=134)$ smaller than or equal to $20 \mathrm{~mm}$ (Table 13). The only two fragments larger than $50 \mathrm{~mm}$ were recovered north of the 20th century debris pit in 1968 and may not be directly associated with House 1 . The absence of glass around the house floor may be a combined result of artifact size and no screening in 1968. As the SAIP excavations screening methods quadrupled the number of glass fragments recovered, it is possible that the window glass was overlooked south of the Kardas 6-line and west of the E-line.

TABLE 13

HOUSE 1 WINDOW GLASS FRAGMENT SIZES

\begin{tabular}{lccccccccc}
\hline & \multicolumn{9}{c}{ Size $(\mathrm{mm})$} \\
& 6 & 10 & 15 & 20 & 30 & 40 & 50 & $>50$ & Total \\
\hline Kardas (n) & 0 & 0 & 4 & 8 & 16 & 3 & 1 & 2 & 34 \\
SAIP (n) & 3 & 42 & 51 & 26 & 9 & 0 & 0 & 0 & 131 \\
\hline
\end{tabular}

Nails. Square nails comprised nearly 64\% $(n=406)$ of the House 1 architectural assemblage. Hand wrought nails were most common $(n=213 ; 52.5 \%)$, but machine cut nails still accounted for $39 \%(n=156)$. Another 37 square nails were too fragmented or corroded for the analysts to determine manufacturing method (Tables 14 and 15). Within the units containing structural features, the combined Kardas and SAIP nail density is 7.4 
nails $/ \mathrm{m}^{2}$. This is far lower than the 43 nails $/ \mathrm{m}^{2}\left(4\right.$ nails $\left./ \mathrm{ft} .{ }^{2}\right)$ maximum limit for tongue-ingroove construction (Stilson 1990). Figure 30 shows the spatial distribution of hand wrought, machine cut, and square nails.

TABLE 14

HOUSE 1 STUDY AREA NAIL COUNTS PER EXCAVATION

\begin{tabular}{lcccc}
\hline \hline & Total & Wrought & Machine Cut & Square \\
\hline Kardas 1968 & 303 & 201 & 92 & 9 \\
SAIP 2002-2003 & 103 & 12 & 64 & 28 \\
Total & 406 & 213 & 156 & 37 \\
\hline \hline
\end{tabular}

TABLE 15

HOUSE 1 SQUARE NAIL FREQUENCIES BY TYPE AND PENNY SIZE

\begin{tabular}{|c|c|c|c|c|c|c|c|c|c|c|c|c|c|c|}
\hline Type & $2 d$ & $3 d$ & $4 d$ & $5 \mathrm{~d}$ & $6 \mathrm{~d}$ & $7 d$ & $8 \mathrm{~d}$ & $9 \mathrm{~d}$ & $10 \mathrm{~d}$ & $12 d$ & $16 \mathrm{~d}$ & $\begin{array}{l}20- \\
60 d\end{array}$ & $\begin{array}{l}\text { Frag. } \\
\text { Nails }\end{array}$ & $\mathrm{n}$ \\
\hline $\begin{array}{l}\text { Wrought } \\
\text { Nails }\end{array}$ & & & & 1 & 2 & 2 & 5 & 5 & 9 & 3 & 3 & 14 & 170 & 213 \\
\hline $\begin{array}{l}\text { American } \\
\text { Cut Nails }\end{array}$ & & 1 & & & 5 & 1 & 6 & 2 & 2 & 1 & & 5 & 67 & 90 \\
\hline $\begin{array}{l}\text { British } \\
\text { Cut Nails }\end{array}$ & & & & 3 & 2 & 1 & 2 & 4 & 2 & & 1 & & 16 & 31 \\
\hline Cut Nails & & & & 1 & & & & & & 1 & & & 33 & 35 \\
\hline $\begin{array}{l}\text { Square } \\
\text { Nails }\end{array}$ & & & & & & & & & & & & & 37 & 37 \\
\hline Totals & 0 & 1 & 0 & 5 & 9 & 4 & 13 & 11 & 13 & 5 & 4 & 17 & 321 & 406 \\
\hline
\end{tabular}

Wrought nails (43 complete and 170 fragmentary) were found in 39 excavation units (Figures 30 and 31a-c). The greatest density of wrought nails surrounded the structural features. The fragmentary wrought nails $(n=170)$ could not be grouped by pennyweight sizes. The 43 complete nails ranged in size from $5 \mathrm{~d}$ to than $60 \mathrm{~d}$ (Table 15 ). The most represented size class is $10 \mathrm{~d}(\mathrm{n}=9)$. Large nails and spikes used in heavy construction (20d-60d) accounted for nearly one-third $(n=14)$ of the wrought nail assemblage, all in or adjacent to units containing house floor sediments. Another 19 wrought nails (43\%) are $8 \mathrm{~d}-10 \mathrm{~d}$, commonly used in flooring and general construction. No small wrought nails (2d-4d), used to apply roofing shingles, were recovered. 


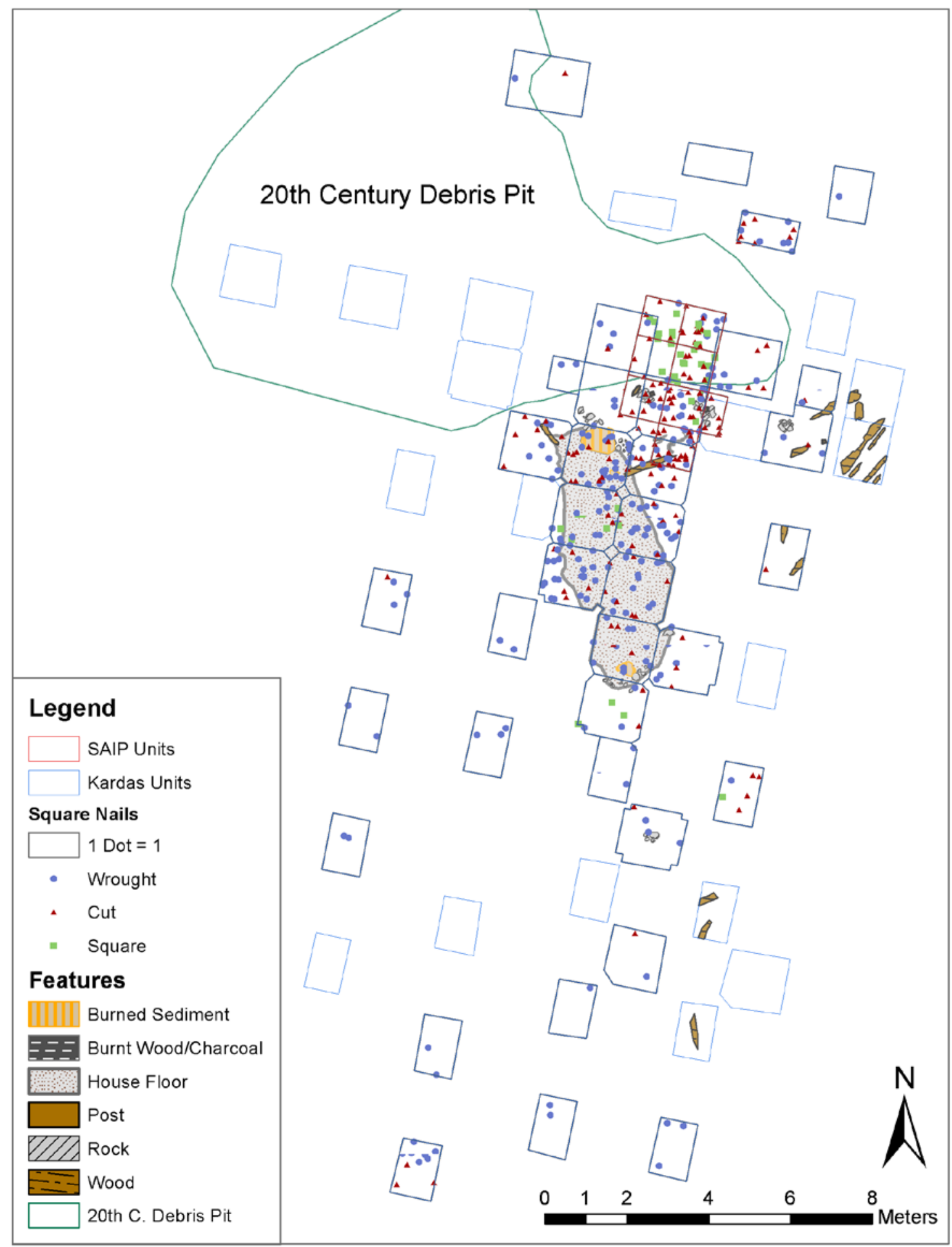

FIGURE 30. Distribution of square nail types at House 1 Study Area. The two units outside the structural features with the highest nail counts are F19-F20 (lower left) and C2-C3 (upper right) Machine cut nails are most frequent in the SAIP units (Map by author, 2011). 
Only 86 wrought nails in the House 1 assemblage could be identified as one of eleven style varieties. One half $(n=43)$ was rosette sharps (variety no. 1002) ranging from 8d-20d. Clasp nails (variety no. 1001), commonly a finishing or flooring nail, made up $15 \%(n=13)$ of the identified nails (6d-16d). The remaining indentified styles included 18 nail types commonly used in heavy construction (variety nos. 1009, 1014, 1017, 1081), and 12 smaller nails with specific functions like siding and door construction (including variety nos. 1005, 1060, 1024).

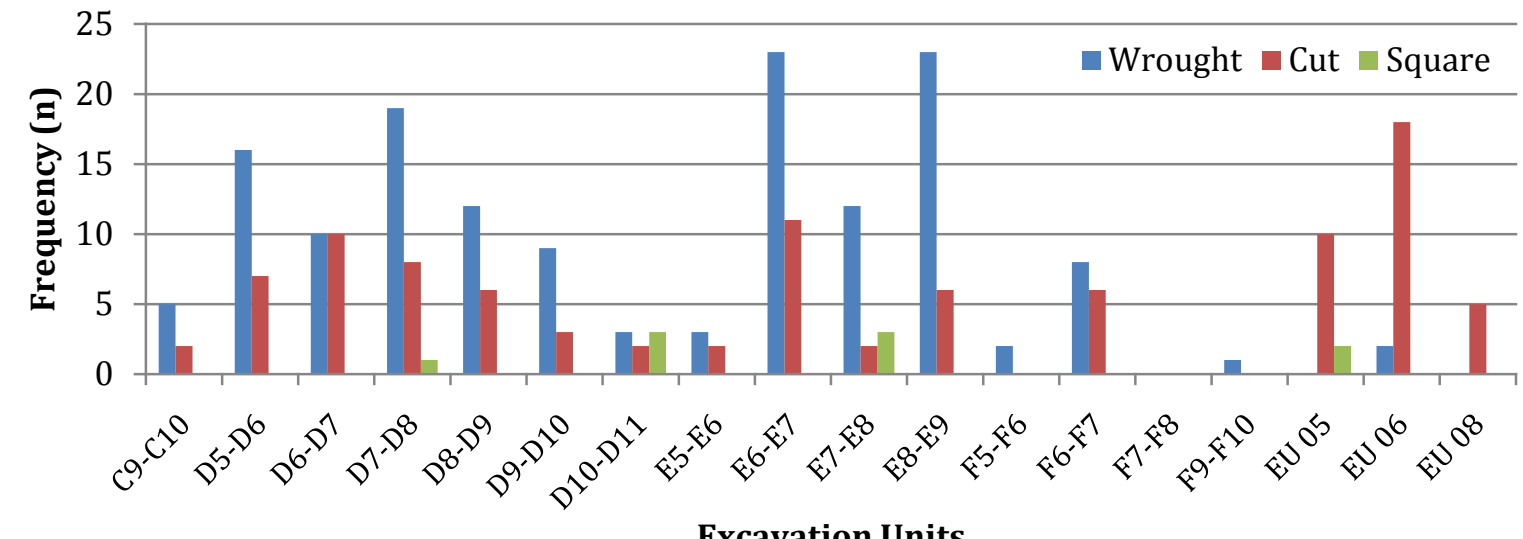

Excavation Units

FIGURE 31a: Nail distribution in units containing house floor deposits (Chart by author, 2011).

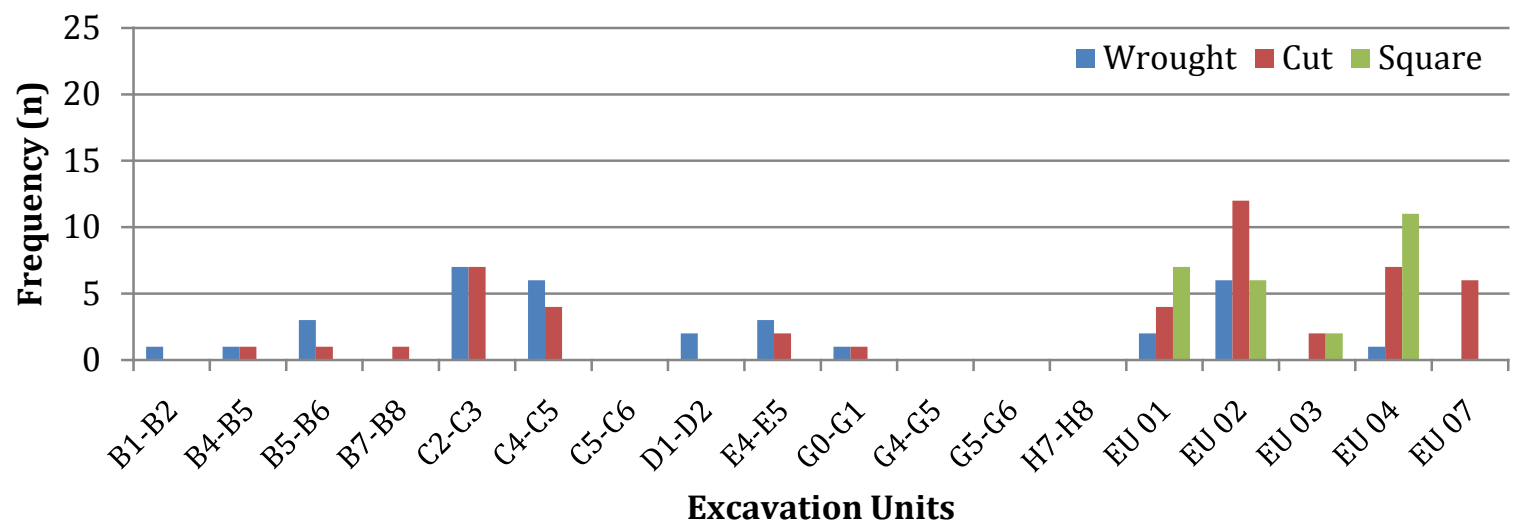

FIGURE 31b: Nail distribution in northern units (Chart by author, 2011). 


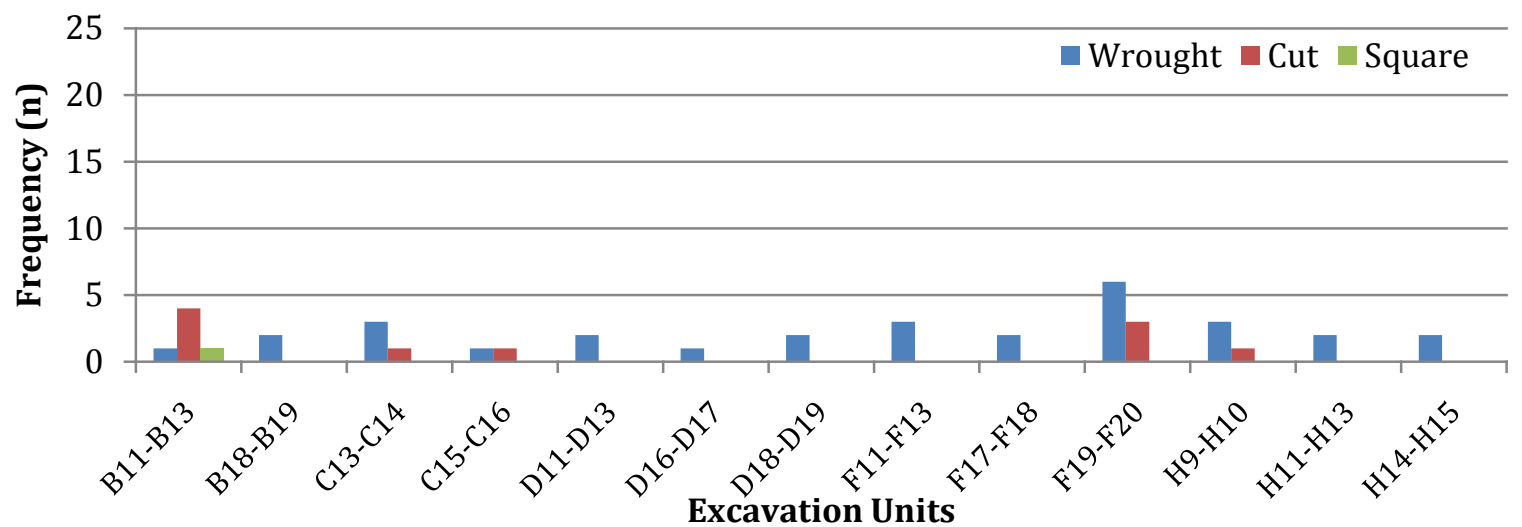

FIGURE 31c: Nail distribution in southern units (Chart by author, 2011)

Machine cut nails (41 complete and 115 fragmentary) were found in 32 units (Figures 30 and 31a-c). Fifteen units had three or fewer machine cut nails. The units containing the house floor had an average of 6.5 machine cut nails (min. $n=2$; max. $\mathrm{n}=11$ ). The complete machine cut nails range in size from $3 \mathrm{~d}-40 \mathrm{~d}$, and nearly half are between $6 \mathrm{~d}-8 \mathrm{~d}$ (Table 15). Ninety machine cut nails were identified to style variety: 23 are British Cut Clasp (no. 2001) ranging from 5d-16d and 58 are American common cut nails (no. 2002) ranging from 3d-40d. Both types are used in light-to-medium general construction.

Overall, the study area contained approximately $20 \%$ complete and $80 \%$ fragmentary nails. Some fragmentation may have occurred post-curation: this analysis identified only 84 “complete” squared nails, but 166 complete nails were reportedly collected in 1968 (Larrabee and Kardas 1968:33). The complete wrought nail assemblage (of which 20 were unaltered, 18 were pulled, and 5 were clinched) is comparable with the 3 unaltered: 3 pulled: 1 clinched nail condition ratio that forms at the site of a structure that has been intentionally torn down (Young 1994). The machine-cut nail ratio (28:11:1) falls between the ratios associated with structures that deteriorated in place and those that 
were intentionally torn down. Because machine-cut nails are more rigid than hand wrought nails, many pulled or clinched nails may have snapped, becoming excluded from a ratio that requires complete specimens.

Two hardware items may have been associated with House 1, although neither was found within the primary House 1 concentration (Larrabee and Kardas 1968). The lock plate shown in Figure 32 had unknown provenience, but it is the only lock-related artifact collected during the 1968 season. The hand forged hinge strap was not found in the collection, however a pintle hinge (Figure 33) was found south of the main dwelling area, in F17-F18, not far from a secondary concentration of square nails. The hinge is 14 $\mathrm{cm}$ (5.5 in.) long, which is consistent with the driven pintles found at Fort Vancouver, where they were commonly used with strap hinges on doors (Ross 1976:836).

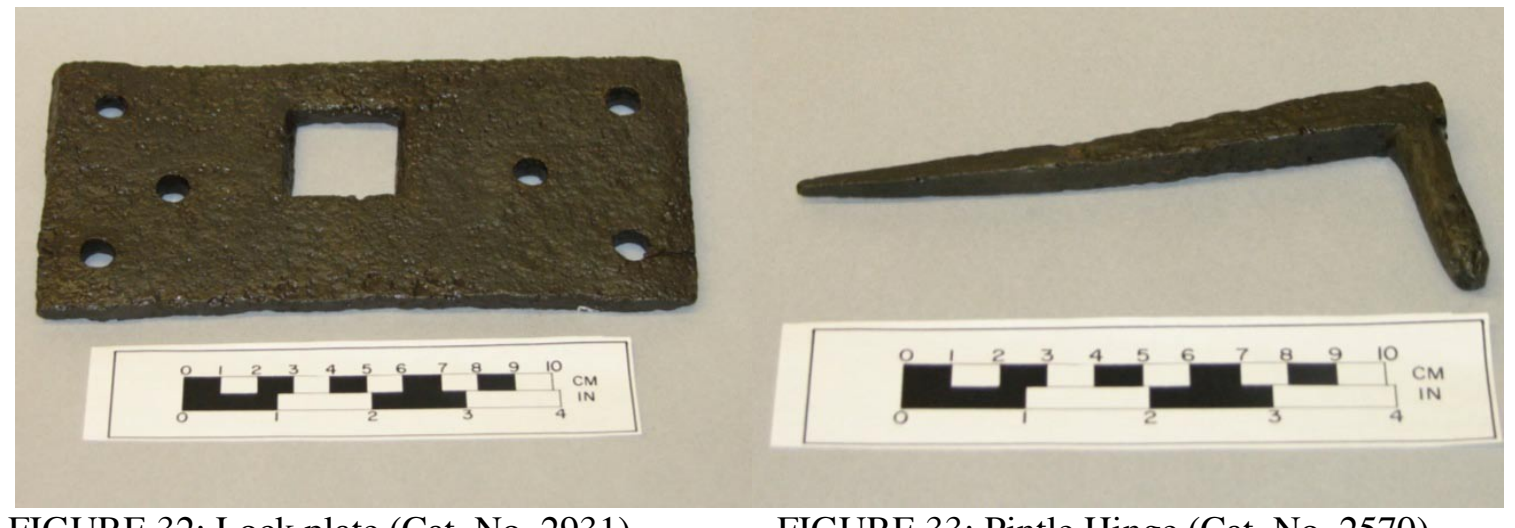

FIGURE 32: Lock plate (Cat. No. 2931), FIGURE 33: Pintle Hinge (Cat. No. 2570) unknown provenience (Photo by author, 2011) found in F17-F18 (Photo by author, 2011)

\section{Interpretation}

Relative to the other four houses in this study, House 1 had a comparably low artifact density and sparse structural features that limited the level of interpretive detail. Larrabee and Kardas (1968:41) concluded that its demolition had removed features and 
obscured the structure's outline to the extent that they could only "assign the location and limits of the dwelling." The intrusion of a World War II-era debris pit at the north end of the study area also likely contributed to the current condition of the House 1 site (Figure 25). No additional evidence - in the form of overlooked structural features or highdensity artifact concentrations in the expanded study area (Figure 26) — was found to suggest that the general location of House 1 differed from the original 1968 interpretation (Larrabee and Kardas 1968). The square nail clusters found to the north and south of the house floor-Units C2-C3 and F19-F20, respectively-(Figure 30) may have been deposited during the widespread demolition of the Village in the 1850s, but these nails were too fragmented and too sparsely distributed (avg. density $2.1 / \mathrm{m}^{2}$; and many southern units contained no artifacts at all) to provide meaningful data related to House 1. The subsequent architectural analysis focused on 29 units (21 from 1968, 8 from SAIP) where the higher artifact densities overlapped with the gray house floor deposit and other structural features (Table 16, Figure 34). The average artifact density of units containing structure-related features was $6.9 / \mathrm{m}^{2}$ (ranging from $0.7 / \mathrm{m}^{2}$ to $14.7 / \mathrm{m}^{2}$ ).

TABLE 16 HOUSE 1 ARTIFACT RECOVERY DATA

\begin{tabular}{lrrrr}
\hline \hline & \multicolumn{2}{c}{ Window Glass } & \multicolumn{2}{c}{ Square Nails } \\
& KARDAS & \multicolumn{1}{c}{ SAIP } & KARDAS & \multicolumn{1}{c}{ SAIP } \\
& $1968-1969$ & \multicolumn{1}{c}{$2001-2003$} & $1968-1969$ & $2001-2003$ \\
\hline Excavation Units $(\mathrm{n}$ and area $)$ & $21\left(42.5 \mathrm{~m}^{2}\right)$ & $8\left(7.5 \mathrm{~m}^{2}\right)$ & $21\left(42.5 \mathrm{~m}^{2}\right)$ & $8\left(7.5 \mathrm{~m}^{2}\right)$ \\
Avg. frequency $\left(\mathrm{n} / \mathrm{m}^{2}\right)$ & 0.4 & 17.5 & 5.2 & 13.6 \\
Min $\left(\mathrm{n} / \mathrm{m}^{2}\right)$ & 0 & 1 & 0 & 4 \\
Max $\left(\mathrm{n} / \mathrm{m}^{2}\right)$ & 5 & 34 & 14 & 24 \\
Std Deviation $\left(\mathrm{n} / \mathrm{m}^{2}\right)$ & 1.19 & 9.90 & 4.39 & 7.20 \\
\hline \hline
\end{tabular}




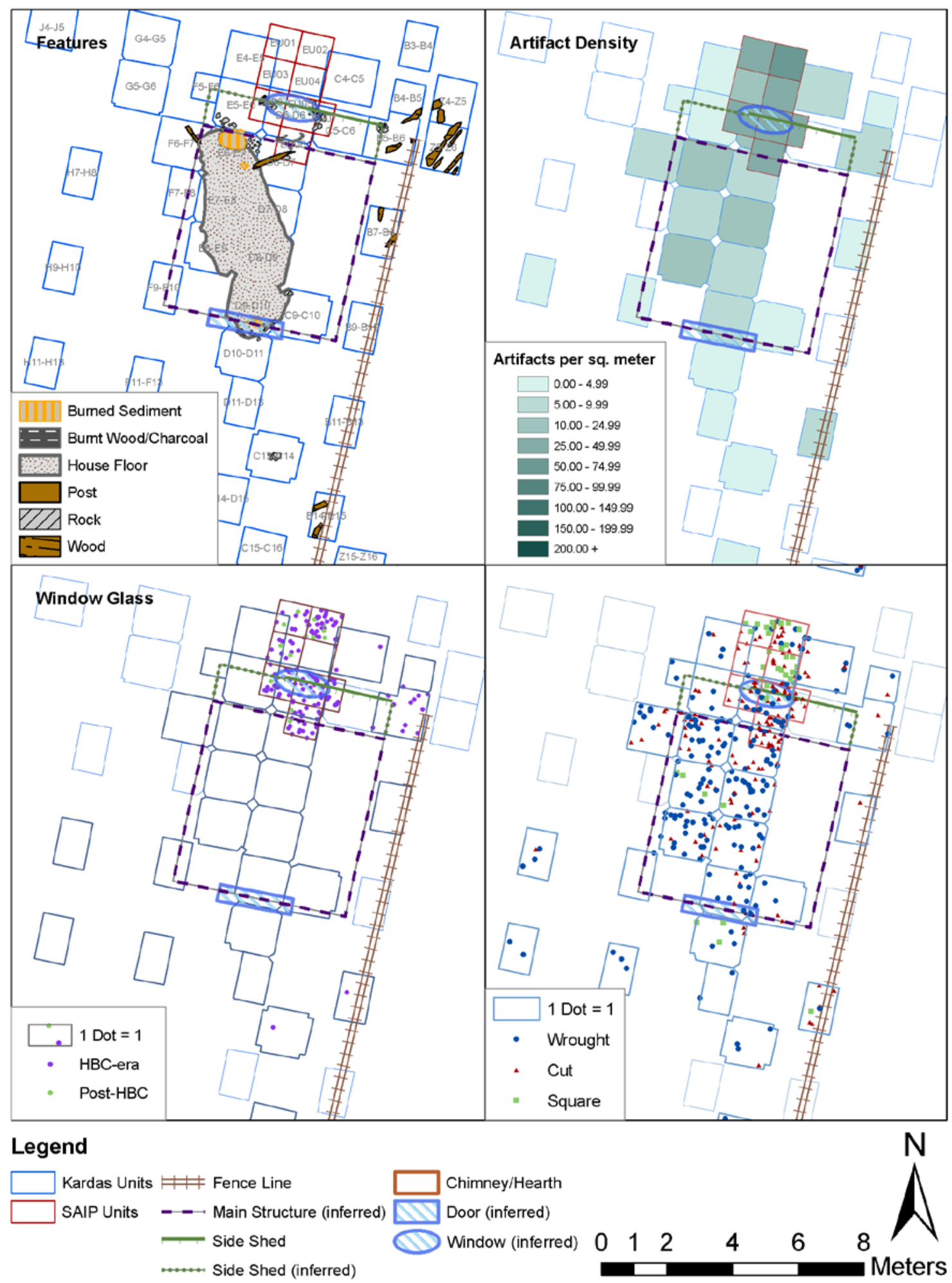

FIGURE 34. House 1 interpretation, showing features (upper left), artifact densities (upper right), window glass (lower left), and square nail distribution (lower right) (Map by author, 2011). 
Although the features that most closely resemble a solid wall are the four rock cluster post features north of the house floor (Feat. H1-09, 2003-03, 2003-11, and an unmapped rock cluster in unit F5-F6) (Figure 34), this alignment is more likely the wall of an ancillary shed that extended from the north wall of the main structure. Two of these features include wood posts that are $7.6 \mathrm{~cm}$ and $10.2 \mathrm{~cm} \mathrm{(3} \mathrm{and} 4$ in.) wide; both are smaller than the standard coulisse, but could be sturdy enough to support the walls of a shed added to the structure sometime after its initial construction.

The north wall of the main structure was defined by the edge of the house floor, the spatial relationship of the aforementioned post features, and large square nails. The shed wall alignment is $1.2 \mathrm{~m}$ (4 ft.) from the north edge of the house floor, which might represent the north wall of the main structure. Of the 18 identified large nails or spikes (20d-60d) commonly used in heavy construction related to rafters, foundations, or walls, 8 were collected immediately south of this shed wall, around House 1's proposed north wall (Figure 34). The exact provenience of these nails within each $5 \times 5 \mathrm{ft}$. excavation unit is unknown, but the clustering of these large nails and spikes around the house floor suggests they are associated with House 1. No clear foundation features were identified within this alignment. Feature H1-02 is within this alignment at the northernmost extent of the earthen floor, but without further excavation it cannot be positively identified as either a hearth or a burned posthole (Figures 25 and 34) (Larrabee and Kardas 1968; Schiffer 1987:167-168).

The location of the southern wall was inferred based on the decrease in artifact density beyond the southern edge of the house floor (Figure 34). On average, the house floor artifact densities are at least twice as high as the units south of the house floor 
(Figure 34, Table 12). The placement of Feature H1-03 within the southernmost extent of the house floor suggests it was associated with the south wall. The size of feature H1-03 resembles a large $(48 \mathrm{~cm} ; 1.5 \mathrm{ft}$. diameter) posthole that could have contained a 15 to 25 cm-wide (6 to 10 in.) structural wall post (Thomas and Hibbs 1984; Stilson 1990), but further excavation is needed to confirm whether the contents of Feature H1-03 are consistent with a post feature.

The west and east walls are not so well defined, however, the 1968 preliminary report describes the eastern edge of the house floor as "less discernable" than the western edge. It is possible that the house continued to the east of the earthen floor feature, presumably Feature H1-09 (shed wall) represents the eastern extent of the house. The inferred east wall in Figure 34 is based on a perpendicular line drawn south from H1-09. No other post features attributable to the main structure were identified. Although $95 \%$ of the large wrought nails (20d-60d) were collected from the house floor units, east of the proposed west wall. No clustering was observed that would indicate the location of another post on either the east or west side. Wood planks lay to the east of House 1 in three loci along a north-south-oriented $30.5 \mathrm{~m}(100 \mathrm{ft}$.) distance. There is a chance that the wood in Z5-Z6 and Z4-Z5 (H1-07a) could be wallboards, but the southern planks (H1-07b) are unlikely to be wall-related-over $6.7 \mathrm{~m}$ (25 ft.) from the house floor and surrounded by few nails (Figure 34).

The spatial limits of the preceding interpretation suggest House 1 was House 1 was approximately $5.5 \mathrm{~m}$ (18 ft.) east-west and at least 18-20 ft. (5.5-6 m) long northsouth, with an additional $1.2 \mathrm{~m}$ (4 ft.) wide shed. The posts of the shed are spaced at intervals of $2 \mathrm{~m}(6.5 \mathrm{ft}),. 1.5 \mathrm{~m}(5 \mathrm{ft}$.$) , and 2 \mathrm{~m}(6.5 \mathrm{ft}$.$) , respectively. The 2 \mathrm{~m}(6.5 \mathrm{ft}$. 
spacing could reflect the use of the toise measurement interval common in FrenchCanadian architecture.

The shed wall post features suggest that at least part of House 1 had a pieux-enterre foundation. The walls of House 1 were likely pièce-sur-pièce, based on a low average nail density (Table 16). Both the Kardas and SAIP excavations recovered fewer than 43 nails $/ \mathrm{m}^{2}$ from the main house area, which is consistent with Stilson's (1990) expectations. With over $80 \%$ of the square nails fragmented, nail function cannot be assigned to the majority of the assemblage based on size class or style identification. It is unlikely that House 1 had wood floors. Most of the artifacts were found embedded in the floor deposit, suggesting wood floors were not present in House 1. Archaeologists recovered no small (2d-4d) wrought nails commonly used to apply roofing shingles, (Figure 35).

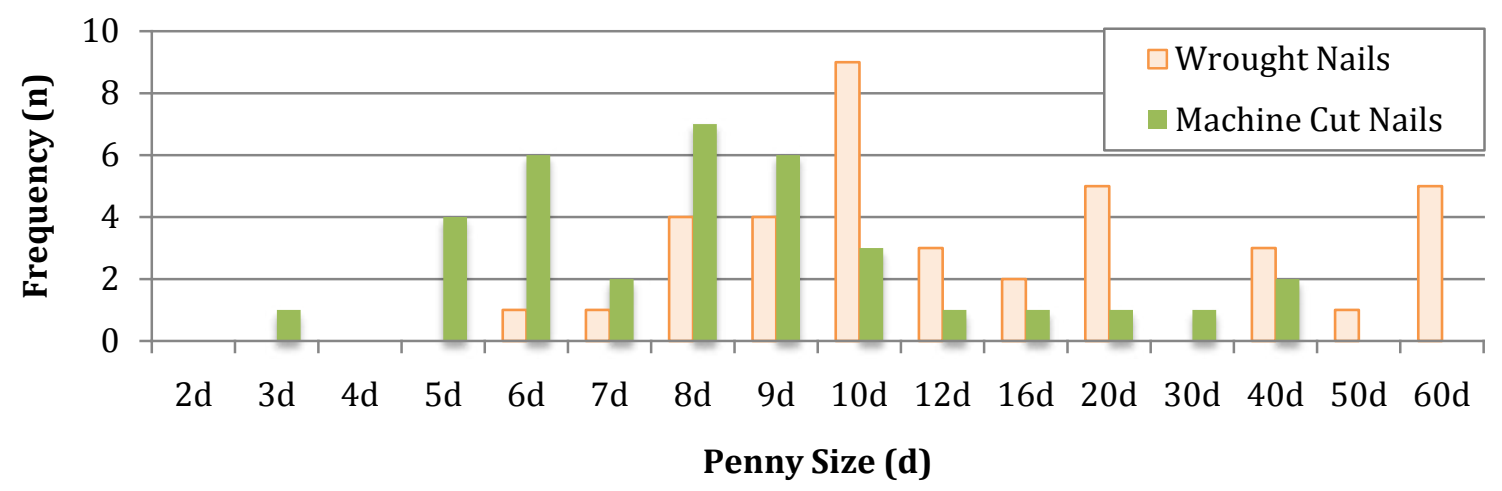

FIGURE 35. Penny size (d) distribution of wrought and machine cut nails from the House 1 assemblage (Chart by author, 2011).

The evidence for the arrangement of the house is minimal. Door and window locations could not be confirmed and there was no clear hearth-feature. Interpretations about doors and windows are also hindered by the inability to assign functional classifications (size and style) to nearly $80 \%$ of the nail assemblage. The door's location 
is unsubstantiated. A door lock plate and a hinge strap were attributed to House 1 (Larrabee and Kardas 1968), but no specific provenience was provided and the wrought clench and clasp nail styles commonly associated with door construction were not numerous or clustered. No food debris was recovered from either Feature H1-02 or H103 to support the original "hearth areas" interpretation (Larrabee and Kardas 1968:21). Features H1-02 and H1-03 (Figure 25) are circular concentrations of bisque, charcoal, and ash associated with rock clusters. Feature H1-02, at the north end of the compact house floor is similar in size to hearth features seen House 2 and House 3, and may merit its original interpretation. The relative dearth of brick fragments suggests there were few windows and no formal chimney or hearth. The 165 window glass fragments are confined to a small area north of the main house floor and near a 20th-century debris pit. A window could have been added with the shed. No window glass was collected from the house floor.

Despite its limited spatial data, the window glass assemblage remains temporally diagnostic. House 1 was likely built between 1834 and 1840, when the equally abundant 0.045-in. and 0.055-in.-thick windowpanes (comprising 32\% and 26\% of the assemblage, respectively) were both available for purchase at the HBC Sale Shop (Figure 36). House 1 underwent limited modifications or repairs during the mid- to late 1840s. At least one windowpane was replaced, based on 0.065 -inch thick window glass fragments near the shed. Machine-cut nails were also recovered around the house floor, but at lower frequencies than the wrought nails (Figure 35). There are not enough machine-cut nails to suggest a new structure. These modifications consisted of light-to-medium general construction, using mostly $5 \mathrm{~d}-10 \mathrm{~d}$ nails. The machine cut nails only outnumbered 
wrought nails in the northern units, in the SAIP excavation units around the shed, which may indicate that the shed was added after 1845. Based on the low number of window glass fragments thicker than 0.075 in., House 1 apparently underwent no maintenance after 1850. These dates are consistent with the manufacture dates of ceramics collected from House 1 (1833-1847) (Kardas 1970:15; Dana Holschuh 2010, pers. comm.).

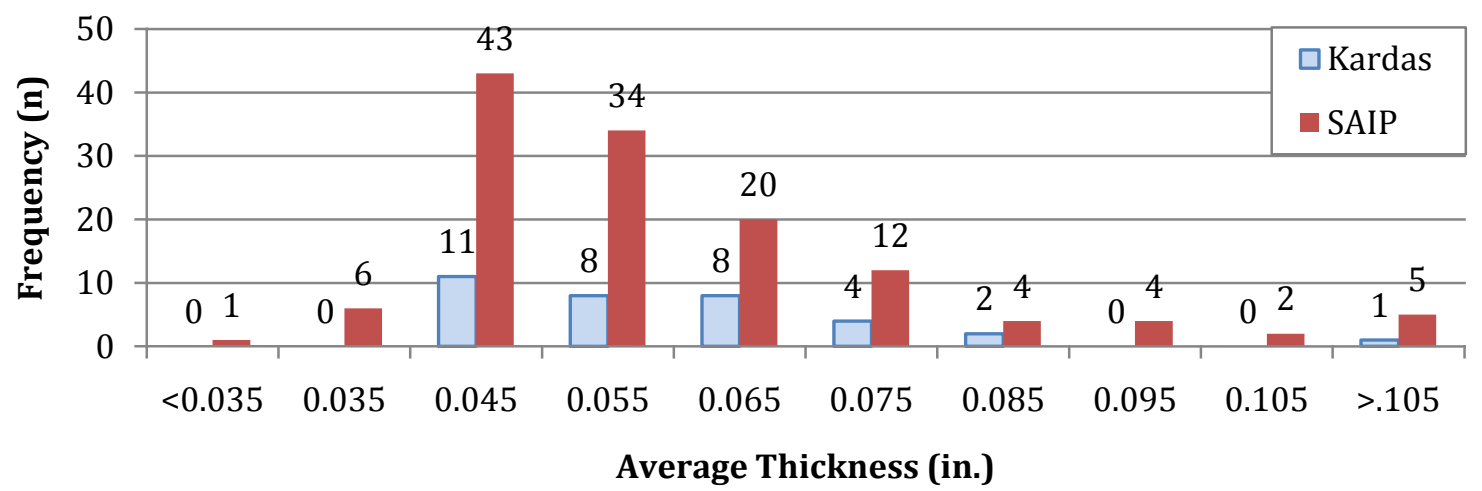

FIGURE 36. Comparison of the window glass thickness distributions recovered from study areas of House 1 (Chart by author, 2011).

House 1 shares many similarities with a 1-1/2 story, side-gabled structure identified by NCRI staff as "House 1" in the 1851 George Gibbs illustration of the Village (Figures 7 and 37). This illustration was drawn near the end of House 1's lifespan, likely after the modifications were completed. As an east-west oriented pieux-en-terre structure with pièce-sur-pièce walls and few windows, the House 1 interpretation is consistent with the illustration. (The alignment of House 1 was inferred based on the angle of the shed's post features.) No shed is illustrated on the north wall, but it could be obscured by visual perspective. Nor does the illustration positively identify the roof type or the location of windows and doors on the other three walls. A fence appears to pass directly behind "House 1" in Gibbs's drawing, giving weight to the interpretation a fence line to the east (Figure 34). 


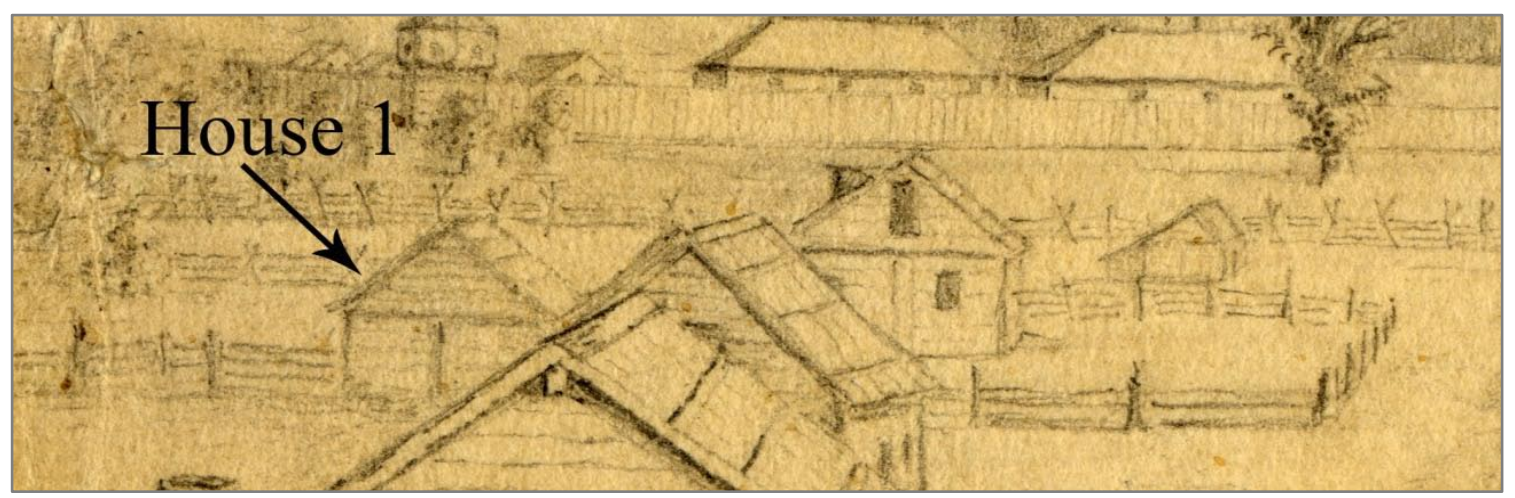

FIGURE 37. "House 1" as drawn by George Gibbs (detail of full 1851 illustration) (Courtesy of Fort Vancouver National Historic Site).

House 1 was likely among the many deteriorating Village structures in the 1850s, but it did not collapse from decay alone. Nor did it burn down, despite some evidence of charred wood. The condition of the nail assemblage (abundant unaltered and pulled nails, and few clinched) reflects a structure that was intentionally torn down (Young 1994). After cannibalizing House 1 for usable materials, the U.S. Army likely dismantled the structure. 


\section{CHAPTER 7 \\ HOUSE 2}

Archaeologists recovered thousands of artifacts from the gray, charcoal-filled deposit within the CCC loop road, $27 \mathrm{~m}$ (90 ft.) east-southeast of House 1. Twenty-one units were excavated in 1969, some of which were screened and likely contributed to high artifact densities (Kardas 1970:19, 22, 24-44). In 2002, archaeologists excavated six units in a depression, overlapping the 1969 excavations.

\section{Stratigraphy}

Two profile drawings are the only sources for House 2-specific stratigraphic data in the final report (Figure 38) (Kardas 1970:32-33). Both profiles show cross sections of the grey "house floor." The root zone, equivalent to Stratum I, contained artifacts that had likely been at the surface when the NPS placed fill (Cromwell 2006: 207). Sediments became increasingly compact with depth. Both the "hard-packed light grey clay" (2) and the "porous dark grey clay" (3) contain brick and charcoal fragments. These two layers correspond to Stratum IV. The dark grey deposit is thicker in the south, and appears to have served as some kind of fill (either for a natural depression or an excavated pit). The thinner, lighter grey deposit caps the darker deposit. The profiles identify a "sterile brown sandy loam" (4) underlying and surrounding the cultural Village sediments; this likely corresponds with Stratum V, the B-horizon or a rocky A-horizon. In the first profile, this sterile sediment is shown immediately beneath the root zone in unit $9 \mathrm{~V} 15 \mathrm{~N}-9 \mathrm{~V} 16 \mathrm{~N}$, which students observed having higher gravel content.

The sediments observed during the SAIP excavations were less distinct because previous excavation and recent burrowing-rodent activity mixed the matrices. Artifacts 
from the 19th and 20th century were mixed as deep as 50-60 cmbd (20-24 in.), likely the 1969 excavation backfill, and the culturally sterile dark yellowish brown B-Horizon sediments were visible at the surface. Two sediment features, described in the following section, correspond with the unexcavated baulks between the 1969 excavation units.

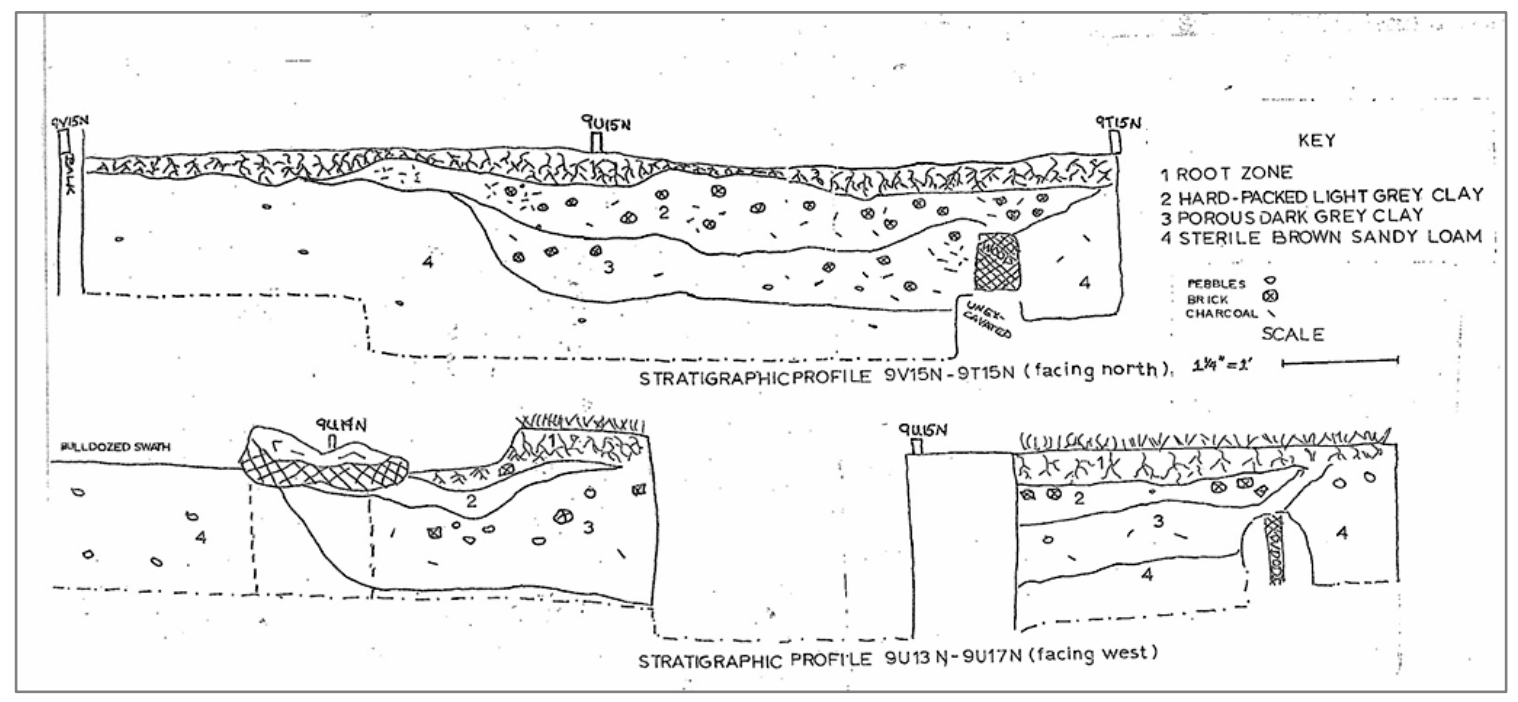

FIGURE 38. Stratigraphic profiles of select House 2 units (Kardas 1970:32-33).

\section{Features}

Fewer features were identified in the House 2 study area than at the other four houses (Tables 17 and 18, Figure 39). Kardas (1970:25) documented only four architectural features at House 2. Figure 39 also shows the location of a 1936 CCCbarracks structure directly over the House 2 study area, a potential source of disturbance.

TABLE 17

FORMAL CHARACTERISTICS OF HOUSE 2 MISCELLANEOUS FEATURES

\begin{tabular}{lccccl}
\hline \hline No. & Type & $\begin{array}{c}\text { Max. } \\
\text { Diameter/ } \\
\text { Length }(\mathrm{cm})\end{array}$ & $\begin{array}{c}\text { Width } \\
(\mathrm{cm})\end{array}$ & $\begin{array}{c}\text { Depth } \\
(\mathrm{cmbs})\end{array}$ & \multicolumn{1}{c}{ Location } \\
\hline $2002-05$ & $\begin{array}{c}\text { 1969 Excavation Baulk } \\
\text { Machine Crushed }\end{array}$ & 100 & 40 & 40 & EU01, 03, 04 \\
Gravel Concentration & 10 & 8 & 22 & EU05 \\
NA & 1969 Excavation Baulk & 100 & 100 & 22 & EU06 \\
\hline
\end{tabular}

Notes: * Max. length and width of feature complex, based on area excavated 
Twentieth century features recorded in 2003 included two 1969 excavation baulks and a concentration of machine-crushed gravel. The machine crushed gravel concentration was small, in both diameter and thickness. It was found in a layer that contained mixed artifact contexts and is significant only as evidence of disturbed contexts. The excavation baulks proved helpful in confirming the relative alignment of the SAIP and 1969 excavation units. Sediment differences in EU01-EU04 line up with the area of a baulk between $9 \mathrm{~T} 15 \mathrm{~N}-9 \mathrm{~T} 16 \mathrm{~N}$ and $9 \mathrm{~T} 14 \mathrm{~N}-9 \mathrm{~T} 15 \mathrm{~N}$. The highly active rodent population may have blended the backfill and the unexcavated baulks over time. Another distinct sediment difference in level 3 of EU06 resembled the 6-inch $(15 \mathrm{~cm})$ thick baulk and corners of 9T13N-9T14N and 9U13N-9U14N.

TABLE 18 FORMAL CHARACTERISTICS OF HOUSE 2 STRUCTURAL FEATURES

\begin{tabular}{|c|c|c|c|c|c|}
\hline No. & Type & $\begin{array}{c}\text { Max. } \\
\text { Diameter/ } \\
\text { Length }(\mathrm{cm})\end{array}$ & $\begin{array}{l}\text { Width } \\
(\mathrm{cm})\end{array}$ & $\begin{array}{l}\text { Depth } \\
\text { (cmbs) }\end{array}$ & Location \\
\hline $\mathrm{H} 2-01$ & House Floor & 341 & 194 & 17 & 9T13N-9T16N; 9U13N-9U16N \\
\hline $\mathrm{H} 2-02$ & Angular Stone & 65 & 40 & 11 & $9 \mathrm{~T} 13 \mathrm{~N}-9 \mathrm{~T} 15 \mathrm{~N} ; 9 \mathrm{UU} 13 \mathrm{~N}-9 \mathrm{U} 15 \mathrm{~N} ;$ \\
\hline $\mathrm{H} 2-03$ & Foundation Sill & 120 & 16 & 25 & $9 \mathrm{~T} 14 \mathrm{~N}-9 \mathrm{~T} 16 \mathrm{~N} ; 9 \mathrm{UU} 14 \mathrm{~N}-9 \mathrm{U} 15 \mathrm{~N} ;$ \\
\hline H2-04 & Hearth & 32 & 28 & 14 & $9 \mathrm{~V} 15 \mathrm{~N}-9 \mathrm{~V} 17 \mathrm{~N} ; 9 \mathrm{U} 16 \mathrm{~N}-9 \mathrm{U} 17 \mathrm{~N}$ \\
\hline 2002-02 & Charred Plank & 15 & 5 & $3-31$ & EU01, EU03 \\
\hline
\end{tabular}

Notes: * Max. length and width of feature complex (cluster), based on area excavated. When depths are singular, they represent base depths.

Feature H2-01, the grayish house floor sediment covers a 2 x 3 m (7 x $10 \mathrm{ft}$. lateral area over portions of six units. Most of the artifacts collected from these units came from the gray sediment. Feature H2-01 was first encountered at approximately 15 cmbs (6 in. bs). It resembles the House 1 floor in color, texture, and content, but Kardas (1970:25) described its size and shape as "distorted." The CCC-barracks building may have contributed to this distortion. Although not explicitly called out in the excavation report, the profile drawings (Figure 38) show two distinct gray "clay" deposits stacked 
together (Kardas 1970). The lower, darker, and more porous gray sediment ranges from 7.5 to $30 \mathrm{~cm}$ ( 3 in. to $1 \mathrm{ft}$.) thick.

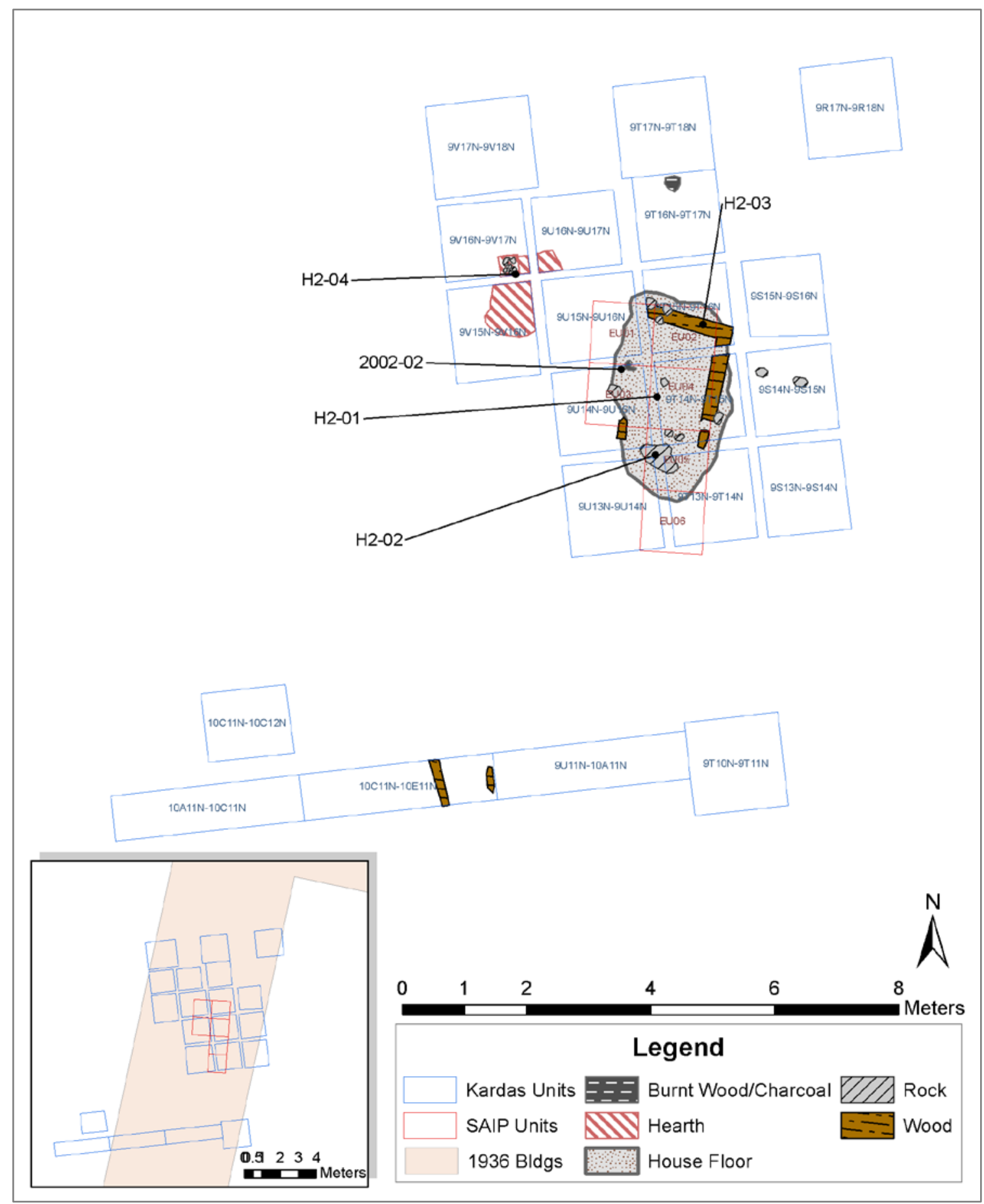

FIGURE 39. Map of House 2 study area structural features and inset shows the relative location of a 20th century structure, which may have caused disturbances (Map by author, 2011). 
Foundation features included two milled "cedar" timbers (Feat. H2-03) that lined the north and east sides of this grey deposit and a large limestone boulder (Feat. H2-02). The "foundation stone," was not recorded in its original location though the original location is not indicated (Kardas 1970:25). Based on photographs and report illustrations,

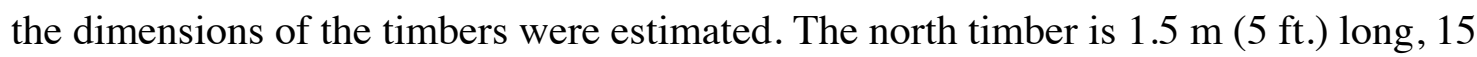
$\mathrm{cm}(6 \mathrm{in}$.$) wide, and 20 \mathrm{~cm}(8$ in.) thick. The east timber is $1.8 \mathrm{~m}(6 \mathrm{ft}$.$) long and 19 \mathrm{~cm}$ (7.5 in.) wide; thickness could not be determined. The student field notes also call attention to decomposed wood at $30 \mathrm{cmbs}(12 \mathrm{in.} \mathrm{bs})$ in unit $10 \mathrm{C} 11 \mathrm{~N}-10 \mathrm{E} 11 \mathrm{~N}$ and charred sediments between 7.5 and $17.5 \mathrm{~cm}$ ( 3 and $7 \mathrm{in}$.) in unit 9T16N-9T17N that were not attributed to House 2 in the final report (Kardas 1970). These features were not designated as such and are not associated with high artifact densities; they may represent scattered demolition debris.

Neither the outline of the gray "clay" floor nor the timbers were visible in 2002 or 2003. EU02 should contain the southern portion of 9T15N-9T16N, which includes a cedar timber. The timbers are depicted as being embedded within the B-Horizon. A brown-yellow-brown sediment stripe, which could be the former trench for the timber, was noted in the east half of EU02 at level 7. The wood could have decayed during the 40-year time span or was removed in 1969. The charred plank (Feat. 2002-02) is close to a wood fragment that paralleled the north-south plank in the 1969 plan view on the west side of the grey deposit (Kardas 1970:34).

At 12-15 cmbs (5-6 in.) a small hearth was identified in unit 9V16N-9V17N.

Casually referenced as an exterior fire pit in the final report (Kardas 1970:25), the student field notes from 1969 provided the following details. The hearth included fire-modified 
rocks, bone, charcoal, and personal artifacts like bottle glass and pipe stems within a onesquare foot area. A compact clay-laden sediment immediately surrounds the hearth.

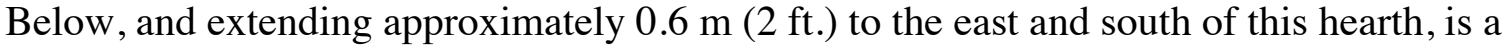
concentration of charcoal and bone that extends from 10 to $28 \mathrm{cmbs}$ (4 to $11 \mathrm{in}$. bs).

\section{Architectural Artifacts}

The House 2 study area contained 4,277 architectural artifacts, most of which were concentrated around the compact earthen floor (Tables 19 and 20, Figure 40). Screening partially contributed to the high artifact density. The artifacts collected during the SAIP excavations were from previously excavated deposits, and although some artifacts originated from intact baulks, they were not consistently bagged separately and cannot be attributed to either the backfill or the intact areas.

TABLE 19

HOUSE 2 ARCHITECTURAL ARTIFACT COUNTS

\begin{tabular}{|c|c|c|c|c|c|c|c|}
\hline Excavation & $\begin{array}{c}\text { Window } \\
\text { Glass }\end{array}$ & $\begin{array}{l}\text { Square } \\
\text { Nails }\end{array}$ & Brick & $\begin{array}{l}\text { Architectural } \\
\text { Hardware }\end{array}$ & Total & $\begin{array}{l}\text { Avg. Density } \\
\mathrm{n} / \mathrm{m}^{2}\end{array}$ & $\begin{array}{l}\text { Std. } \\
\text { Dev. }\end{array}$ \\
\hline Acc 0120 (1969) & 2187 & 1100 & 6 & 3 & 3296 & 82.3 & 156.36 \\
\hline $\begin{array}{l}\text { Acc } 3011(2002) \& \\
\text { Acc } 3023(2003)\end{array}$ & 701 & 269 & 11 & 0 & 981 & 139.7 & 30.35 \\
\hline Total & 2888 & 1369 & 17 & 3 & 4277 & 95.1 & 139.91 \\
\hline
\end{tabular}

TABLE 20

HOUSE 2 STUDY AREA ARTIFACT COUNTS PER UNIT

\begin{tabular}{|c|c|c|c|c|c|c|c|c|c|c|c|}
\hline Unit & WG & SN & $\mathrm{B}$ & Total & $\mathrm{n} / \mathrm{m}^{2}$ & Unit & 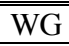 & 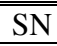 & $\mathrm{B}$ & Total & $\mathrm{n} / \mathrm{m}^{2}$ \\
\hline 9R17N-9R18N & 43 & & & 43 & 18.5 & 9U16N-9U17N & 3 & 6 & & 9 & 6.0 \\
\hline 9S13N-9S14N & 144 & 101 & & 245 & 130.3 & $9 \mathrm{~V} 15 \mathrm{~N}-9 \mathrm{~V} 16 \mathrm{~N}$ & 2 & 29 & & 31 & 14.8 \\
\hline 9S14N-9S15N & 123 & 98 & 4 & 225 & 119.7 & $9 \mathrm{~V} 16 \mathrm{~N}-9 \mathrm{~V} 17 \mathrm{~N}$ & 4 & 13 & & 16 & 10.9 \\
\hline $9 \mathrm{~S} 15 \mathrm{~N}-9 \mathrm{~S} 16 \mathrm{~N}$ & 10 & 79 & & 89 & 47.3 & $9 \mathrm{~V} 17 \mathrm{~N}-9 \mathrm{~V} 18 \mathrm{~N}$ & 15 & 27 & & 42 & 18.1 \\
\hline 9T10N-9T11N & 7 & 17 & & 24 & 10.3 & $10 \mathrm{~A} 11 \mathrm{~N}-10 \mathrm{C} 11 \mathrm{~N}$ & 31 & $65^{\circ}$ & & 96 & 41.4 \\
\hline 9T13N-9T14N & 437 & 15 & & 452 & 240.4 & $10 \mathrm{C} 11 \mathrm{~N}-10 \mathrm{E} 11 \mathrm{~N}$ & 10 & $37^{\circ}$ & & 47 & 20.3 \\
\hline 9T14N-9T15N* & 1013 & 313 & 2 & 1328 & 706.4 & $10 \mathrm{C} 11 \mathrm{~N}-10 \mathrm{C} 12 \mathrm{~N}$ & 7 & $0^{\circ}$ & & 7 & 4.8 \\
\hline 9T15N-9T16N* & 18 & 70 & & 98 & 52.1 & EU01 & 124 & 36 & 2 & 161 & 161 \\
\hline 9T16N-9T17N & 3 & 8 & & 11 & 5.9 & EU02 & 99 & 43 & 3 & 145 & 145 \\
\hline 9T17N-9T18N & 5 & & & 5 & 2.2 & EU03 & 85 & 35 & 2 & 121 & 121 \\
\hline $9 \mathrm{U} 11 \mathrm{~N}-10 \mathrm{~A} 11 \mathrm{~N}$ & 3 & 15 & & 18 & 7.8 & EU04 & 105 & 38 & & 143 & 143 \\
\hline $9 U 13 N-9 U 14 N$ & 89 & 10 & & 99 & 52.7 & EU05 & 145 & 30 & 2 & 177 & 177 \\
\hline $9 \mathrm{U} 14 \mathrm{~N}-9 \mathrm{U} 15 \mathrm{~N} *$ & 193 & 132 & & 325 & 172.9 & EU06 & 58 & 31 & 2 & 91 & 91 \\
\hline $9 \mathrm{U} 15 \mathrm{~N}-9 \mathrm{U} 16 \mathrm{~N}$ & 19 & 65 & & 84 & 44.7 & SAIP MULTI. & 85 & 56 & & 141 & NA \\
\hline
\end{tabular}

$\mathrm{WG}=$ window glass; $\mathrm{SN}=$ square nails; $\mathrm{B}=$ brick; $\mathrm{n} / \mathrm{m}^{2}=$ artifact density per excavation unit *Portions of these units were excavated together as one, but the details are unclear, so the recovered artifacts have been equally divided among the units involved 


\section{House 2 Study Area}
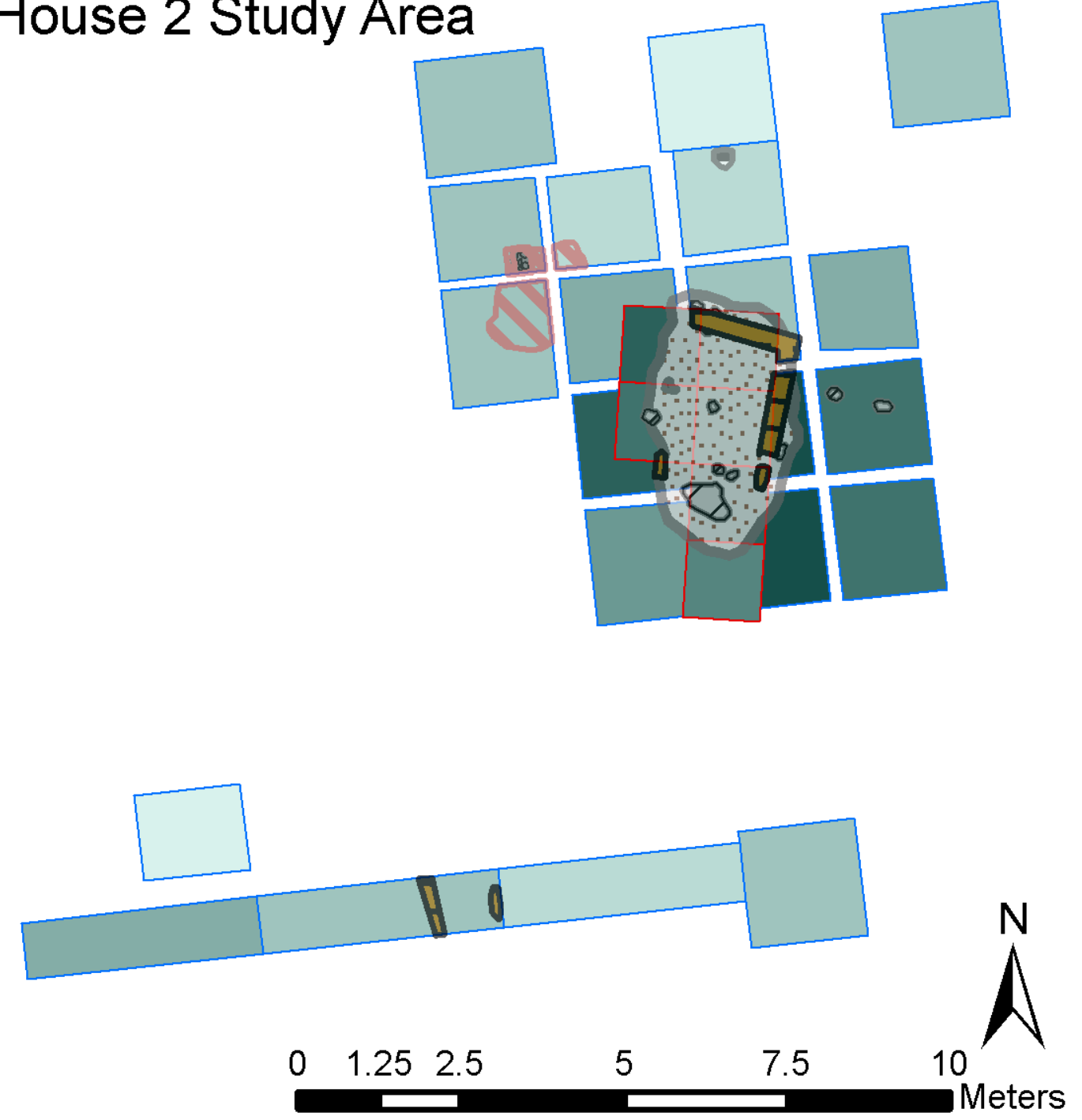

\section{Artifact Density Legend}

\begin{tabular}{|l|l|l|l|}
\hline & $0.10-4.99$ & $25.00-49.99$ & $100.00-149.99$ \\
\hline $5.00-9.99$ & $50.00-74.99$ & $150.00-199.99$ \\
\hline & $10.00-24.99$ & $75.00-99.99$ & $200.00+$ \\
\hline
\end{tabular}

FIGURE 40. House 2 study area artifact density map (Map by author, 2011) 
Brick. Kardas and Larrabee did not provide counts for bricks at House 2, so it is unclear if the six bricks in the curated collection were the only bricks discovered in 1969. The 1969 stratigraphic profiles (Figure 38) show "brick and charcoal" fragments scattered throughout the gray clay deposits, but this quantity of bricks was not found in the curated collection (Kardas and Larrabee 1970:32-33). (Based on the pebble-sized depiction, these "bricks" may be "bisque," which is commonly observed in the house floors.) The SAIP excavations recovered only 11 additional brick fragments. All bricks were recovered above $40 \mathrm{cmbs}$. The majority of the brick was American brick: only one of which was complete; the other 12 were no larger than $50 \mathrm{~mm}$ in length. Four partial English bricks (Type 1 and Type 5) were identified by their distinctive yellow-purple coloring. Each English brick had at least one full dimension (width, length, thickness) ranging from 81 to $108 \mathrm{~mm}$ (3.2 in. to $4.25 \mathrm{in}$.). The bricks were located closer to the compact floor than the hearth.

Window Glass. In total, 2888 window glass fragments were recovered from the House 2 study area (Figure 41). Such great quantities were recovered that the archaeologists did not list the total count of the House 2 window glass in the 1969 excavation report (Kardas 1970).

House 2 window glass thicknesses ranged from $0.062 \mathrm{~mm}(0.024$ in.) to $3.34 \mathrm{~mm}$ (0.131 in.). For both the 1969 and SAIP assemblages, the overall primary thickness mode was 0.055 inches (1969 $n=758$; SAIP $n=224$ ), which correlates to the $1834-1845$ date range (Figures 42 and 43) (Roenke 1982). The secondary mode is 0.065 inches, which dates to 1840-1850. Even though post-HBC window glass was present across the entire study area, HBC-era window glass dominated the units east and north of the house floor 
(Figure 41). Post-HBC window glass outnumbered HBC-era window glass only in a few south wall and far northern units.

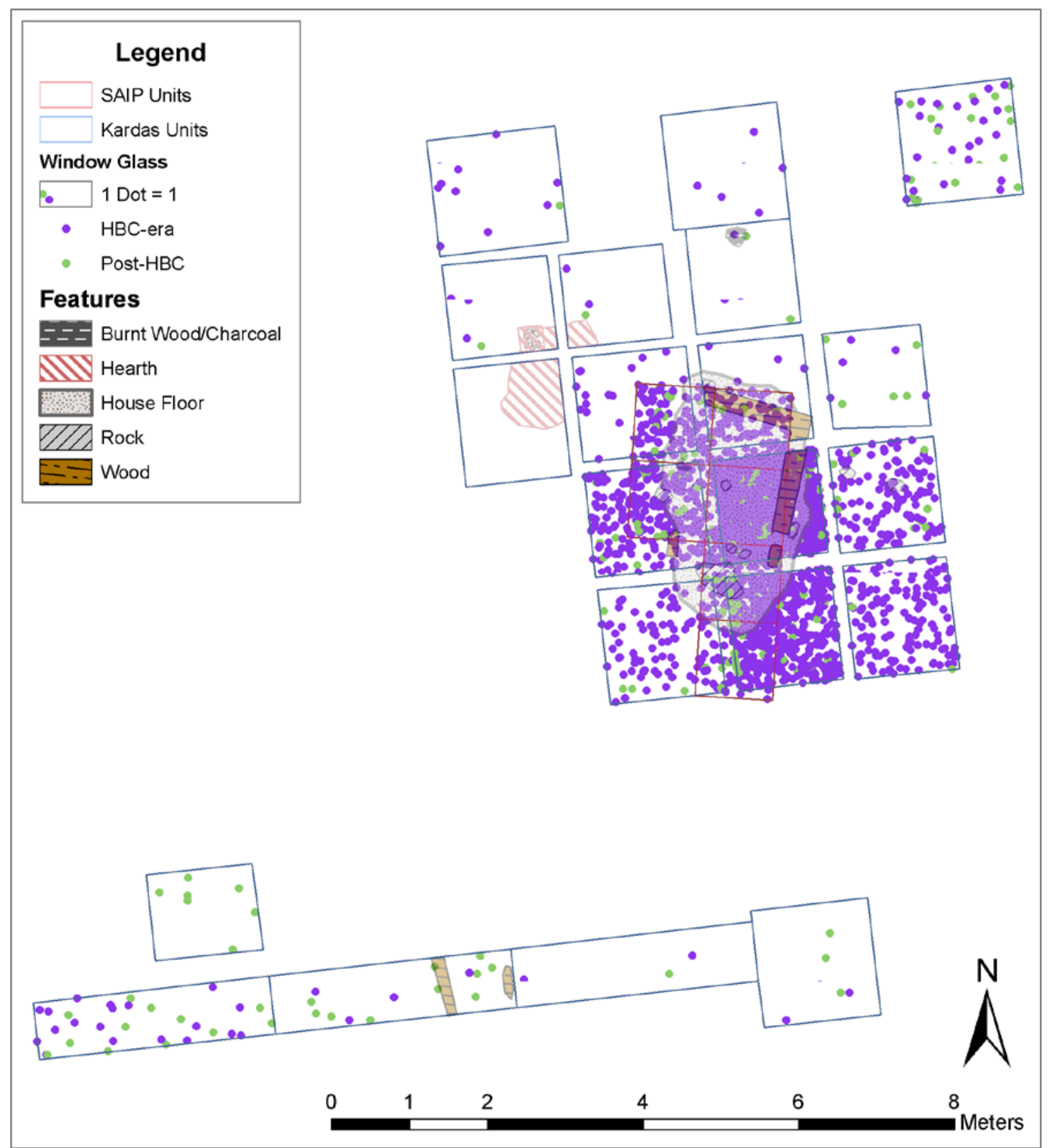

FIGURE 41. Window glass distribution in House 2 Study Area, showing HBC-era glass (purple) and post-HBC-era glass (green) (Map by author, 2011). 


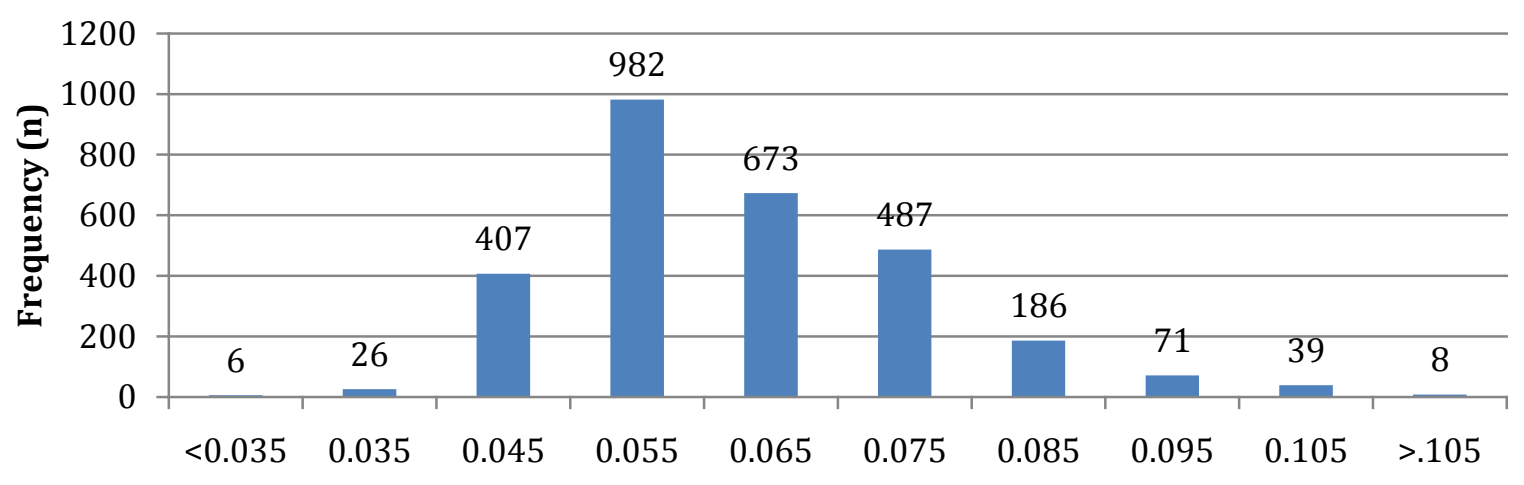

Average Thickness (inches)

FIGURE 42. Window glass thickness distribution for House 2 Study Area (Chart by author, 2011).

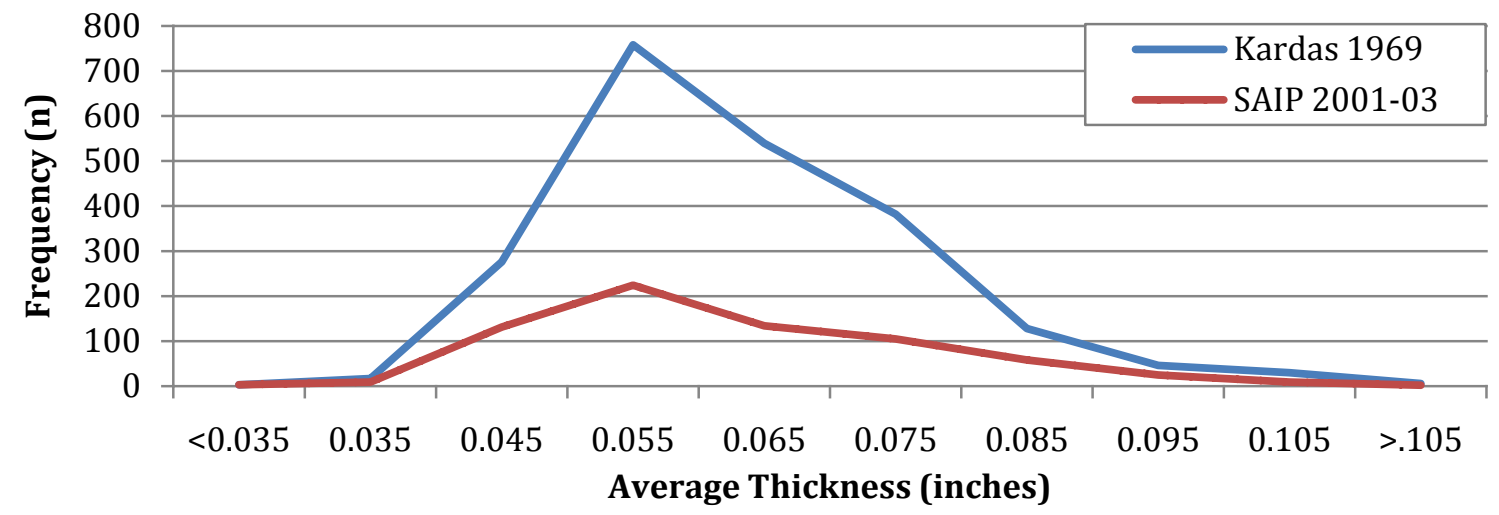

FIGURE 43. Comparing glass thickness modes by excavation (Chart by author, 2011).

Most window glass fragments measured between 15-30 mm long (0.6-1.2 in.)

(Table 21). Three fragments were too small and fractured to be measured for thicknessno flat surface could be found. The large window glass fragments (greater than $40 \mathrm{~mm}$ [1.5 in.]) were found along the east wall, which is also the area of the greatest window glass concentration.

TABLE 21

HOUSE 2 WINDOW GLASS FRAGMENT SIZES

\begin{tabular}{lccccccccc}
\hline \hline & \multicolumn{1}{c}{ Size $(\mathrm{mm})$} \\
& 6 & 10 & 15 & 20 & 30 & 40 & 50 & $>50$ & Total \\
\hline Kardas (n) & 2 & 149 & 774 & 539 & 518 & 146 & 35 & 25 & 2187 \\
SAIP (n) & 20 & 247 & 268 & 100 & 48 & 15 & 1 & 2 & 701 \\
\hline \hline
\end{tabular}


$\underline{\text { Square Nails. }}$. The House 2 square nails accounted for $30 \%(n=1266)$ of the architectural artifact assemblage. The nails in units $10 \mathrm{~A} 11 \mathrm{~N}-10 \mathrm{C} 11 \mathrm{~N}$ and $10 \mathrm{C} 11 \mathrm{~N}-$ $10 \mathrm{E} 11 \mathrm{~N}$ were mistakenly overlooked during analysis. These nails factor into the densities for those units, but they contribute no attribute data to the life history interpretations. For this reason, they are not tabulated in the following tables, causing the nail totals to differ from Table 19 at the start of this section.

Hand wrought $(40.18 \%)$ and machine cut (43.88\%) nails were almost equally represented in the 1969 assemblage (Table 22). The SAIP excavations returned nearly three times as many machine cut nails as hand wrought nails, adjusting the relative percentages to $36.33 \%$ and $46.52 \%$, respectively. Overall the square nail assemblage was highly fragmentary $(73.5 \%)$. It is not clear how many formerly complete nails fragmented during archaeological processing and curation. A combination of screening and working in previously excavated areas resulted in the SAIP nail assemblage being composed of an even higher quantity of fragmented nails than the original 1969 excavation. Nail fragments with heads vastly outnumbered the shank and tip fragments, nearly $3: 1$. This negates the possibility that nails being broken into many parts artificially inflated the nail assemblage. Between complete nails and fragments with heads, an MNI of 709 can be established. Like the window glass, the units with the greatest density of square nails were those along the east wall. Figures 44 and $45 \mathrm{a}-\mathrm{c}$ shows the distribution of these nail types.

TABLE 22

HOUSE 2 STUDY AREA NAIL COUNTS

\begin{tabular}{lcccc}
\hline \hline & Total & Wrought & Machine Cut & Square \\
\hline Kardas 1969 & 998 & 401 & 438 & 159 \\
SAIP 2002-2003 & 268 & 59 & 151 & 58 \\
Total & 1266 & 460 & 589 & 217 \\
\hline \hline
\end{tabular}




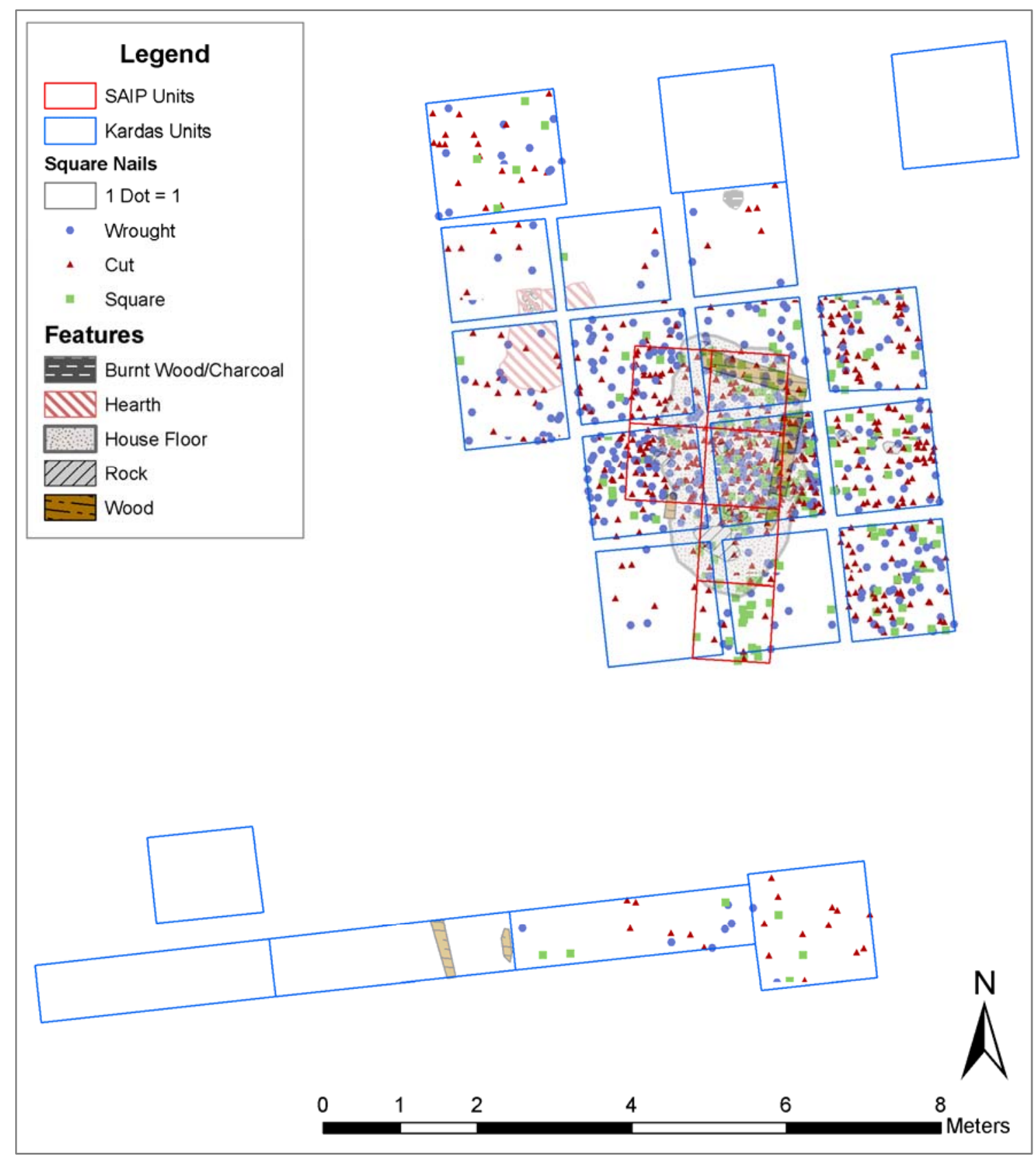

FIGURE 44. Distribution of square nail types in House 2 Study Area (Map by author, 2011) 


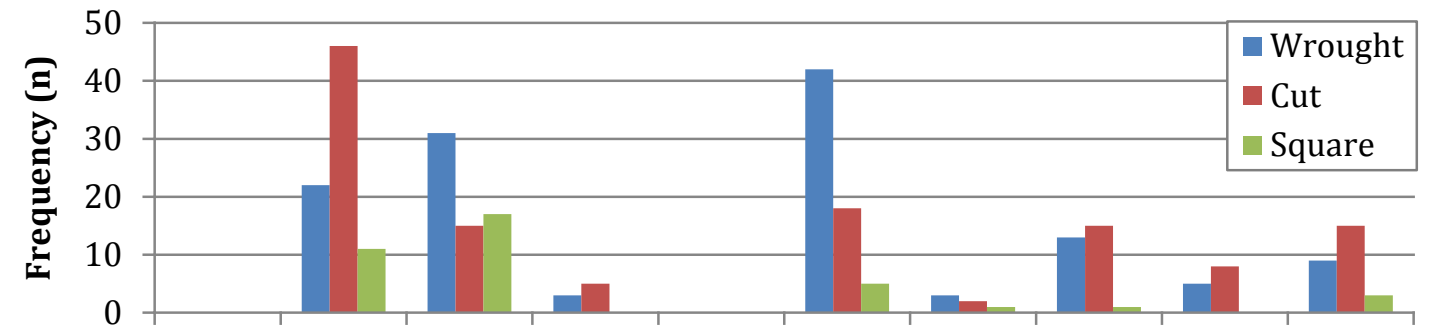

9R17N- 9S15N- 9T15N- 9T16N- 9T17N- 9U15N- 9U16N- 9V15N- 9V16N- 9V17N9R18N 9S16N 9T16N 9T17N 9T18N 9U16N 9U17N 9V16N 9V17N 9V18N Excavation Units (North Wall)

(a)

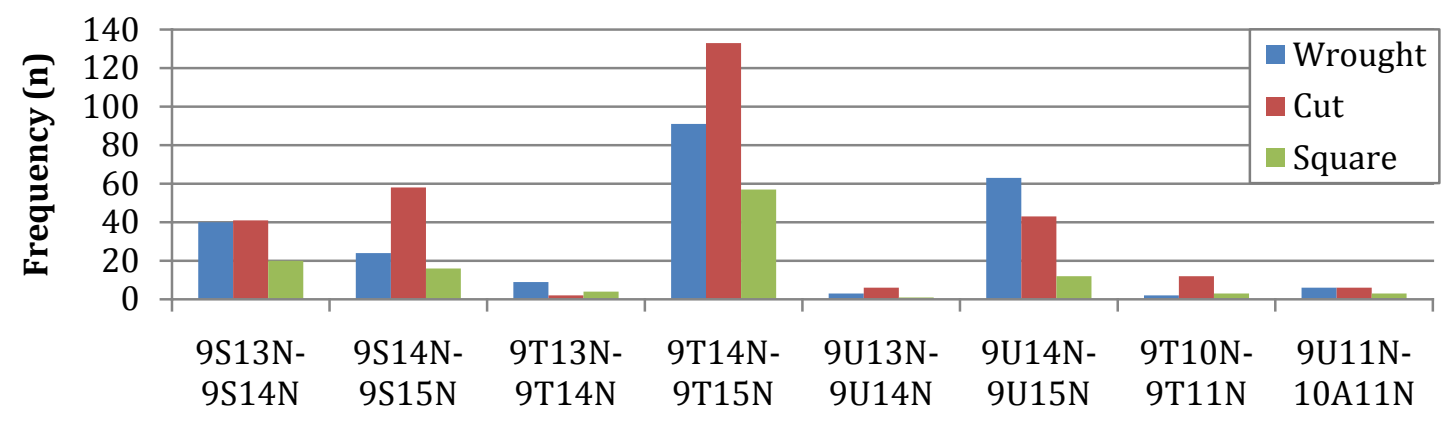

Excavation Units (East and South Walls)

(b)

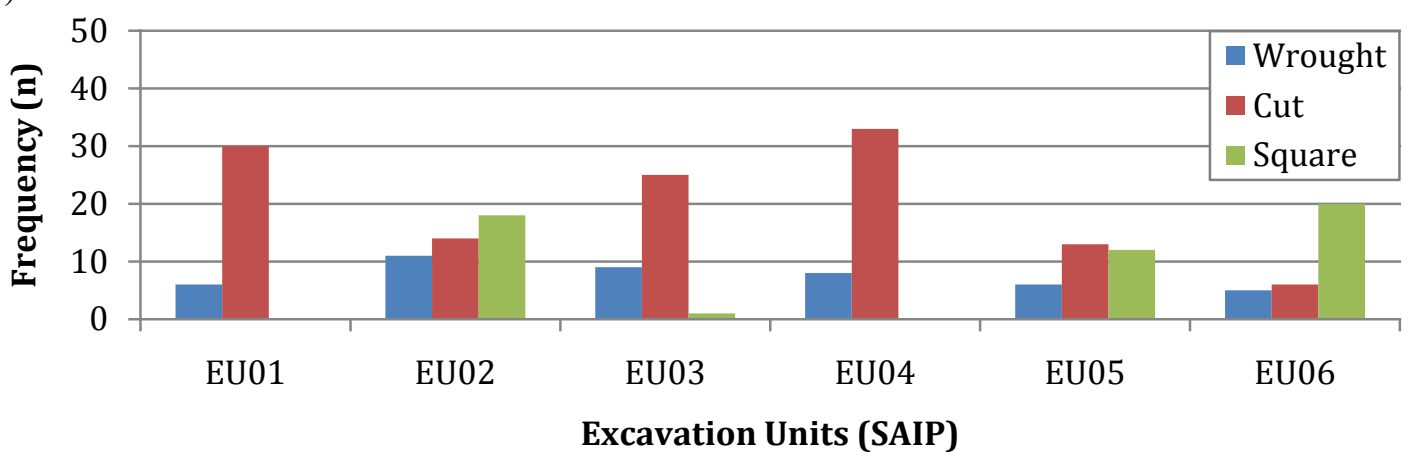

(c)

FIGURE 45. The distribution of square nail manufacture types in the House 2 Study area (Chart by author, 2011).

A total of 460 nails were identified as hand wrought, of which there were 151 complete and 309 fragmentary. The complete wrought nails ranged in size from $3 \mathrm{~d}$ to over 60d (Table 23). This assemblage included 278 wrought nails that could be identified by style. The previous analysis of the 1969 House 2 nail assemblage only identified the nails as far as their head shape (Amos-McGraw 2008). Thus, all rose-head nails found at 
House 2 were classified as "rosette sharps" (Variety no. 1002), ignoring at least three other common rose-head nail varieties that are distinguished by size and/or tip shape (Ross 1976: 886-923; Pierson 2006).

TABLE 23

HOUSE 2 SQUARE NAIL FREQUENCIES BY TYPE AND PENNY SIZE

\begin{tabular}{|c|c|c|c|c|c|c|c|c|c|c|c|c|c|c|}
\hline Type * & $2 \mathrm{~d}$ & $3 \mathrm{~d}$ & $4 d$ & $5 \mathrm{~d}$ & $6 \mathrm{~d}$ & $7 d$ & $8 \mathrm{~d}$ & $9 \mathrm{~d}$ & $10 \mathrm{~d}$ & $12 \mathrm{~d}$ & $16 \mathrm{~d}$ & $\begin{array}{l}20- \\
60 d \\
\end{array}$ & $\begin{array}{l}\text { Frag. } \\
\text { Nails }\end{array}$ & $\mathrm{N}$ \\
\hline \multicolumn{15}{|l|}{ Wrought } \\
\hline Nails & & 4 & 8 & 5 & 6 & 9 & 20 & 26 & 24 & 2 & 13 & 36 & 307 & 460 \\
\hline \multicolumn{15}{|l|}{ American Cut } \\
\hline Nails & 3 & 23 & 31 & 4 & 8 & 12 & 12 & 12 & 13 & 15 & 9 & 3 & 184 & 329 \\
\hline \multicolumn{15}{|l|}{ British Cut } \\
\hline Nails & & & 7 & 1 & & & 8 & 1 & & & 1 & 1 & 32 & 51 \\
\hline Cut Nails & & 3 & 4 & & & & 2 & 1 & 1 & 2 & 2 & 0 & 194 & 209 \\
\hline Square Nails & & & & 2 & 1 & & & & & & & & 214 & 217 \\
\hline Totals & 3 & 30 & 50 & 12 & 15 & 21 & 42 & 40 & 38 & 19 & 25 & 40 & 931 & 1266 \\
\hline
\end{tabular}

Rosette head nails are, expectedly, the most common wrought nail style at House $2(n=186)$. Many of these were fragmentary $(n=95)$ or had damaged tips and could be variety nos. 1002, 1009, or 1060. Only one positively identified wrought clench style nail was recovered from House 2, but this is the second most frequent wrought nail recovered at the Sale Shop and Fur Store (inside the stockade) (Hoffman and Ross 1974; Pierson 2006). Thankfully, because attention was paid to size/length, nails used for small, general, and heavy construction can be distinguished. The complete rosette nails ranged in size from $3 \mathrm{~d}$ to greater than $60 \mathrm{~d}$. The most represented sizes were in the $8 \mathrm{~d}$ to $10 \mathrm{~d}$ range, those used for general light-to-medium construction. More nuanced discussion of nail functions requires more formal attributes than just head style and size. Although similar in size, variety no. 1002 and variety no. 1060 had different functions - general construction and siding, respectively. Some of the larger rosette head spikes were identified as varieties no. 1009 and no. 1066. Clasp nails, variety no. 1001, were the 
second most abundant $(n=67)$ nail style identified at House 2. Ranging from $3 d$ to $30 d$, half of the clasp nails fell into the $8 \mathrm{~d}$ to $10 \mathrm{~d}$ size range. Six other nails were assigned to five style categories (Variety nos. 1006, 1008, 1011, 1017, 1019, 1027, and 1032) but few of these are commonly discussed in the nail literature.

A total of 589 machine cut nails were recovered and analyzed from the House 2 assemblage. Less than one-fourth of these nails $(n=177)$ were complete, the other 412 were fragmentary. The complete machine cut nails ranged in size from $2 \mathrm{~d}$ to $60 \mathrm{~d}$, with the $7 \mathrm{~d}$ through $12 \mathrm{~d}$ sizes most represented (Table 23 ). Five cut nail varieties were identified, but two of these (no. 2005 and no. 2006) were each only represented by one specimen. The British cut clasp nail (no. 2001) accounts for only $13.5 \%$ of the machine cut nails, ranging from $4 \mathrm{~d}$ to $20 \mathrm{~d}$ (but only representing six size classes). These nails were imported by the HBC and predate the U.S. Army's arrival at Fort Vancouver. The American common cut nail (no. 2002) is the most abundant variety $(n=236)$. Style no. 2002 was found in every size class. The Reverse Crimp cut nail variety (no. 2004) was most abundant in sizes $3 \mathrm{~d}$ and $4 \mathrm{~d}$, although $7 \mathrm{~d}$ to $10 \mathrm{~d}$ specimens were identified.

For both wrought nail and machine cut nail assemblages, complete unaltered and complete pulled nails outnumber clinched nails nearly $3: 1$. The complete wrought nails included 50 unaltered, 67 pulled, and 18 clinched nails. Among the complete machine cut nails, 92 were unaltered, 81 were pulled, and only 4 were clinched. The low number of clinched machine cut nails is expected given that they are more rigid than their wrought counterparts, and more prone to breaking when bent.

Hardware. Three door- or window-related hardware artifacts were associated with House 2: two lock parts and one latch part (Figures 46-48). These are located near the 
timber sills. The two lock parts were recovered units 9T14N-9T15N, 9T14N-9T16N. The latch part was collected from unit 9S15N-9S16N. The smaller of the mortised lock parts (fragmented, Catalog No. 3864) may have been for a window. No hinges or doorknobs were reported near House 2.

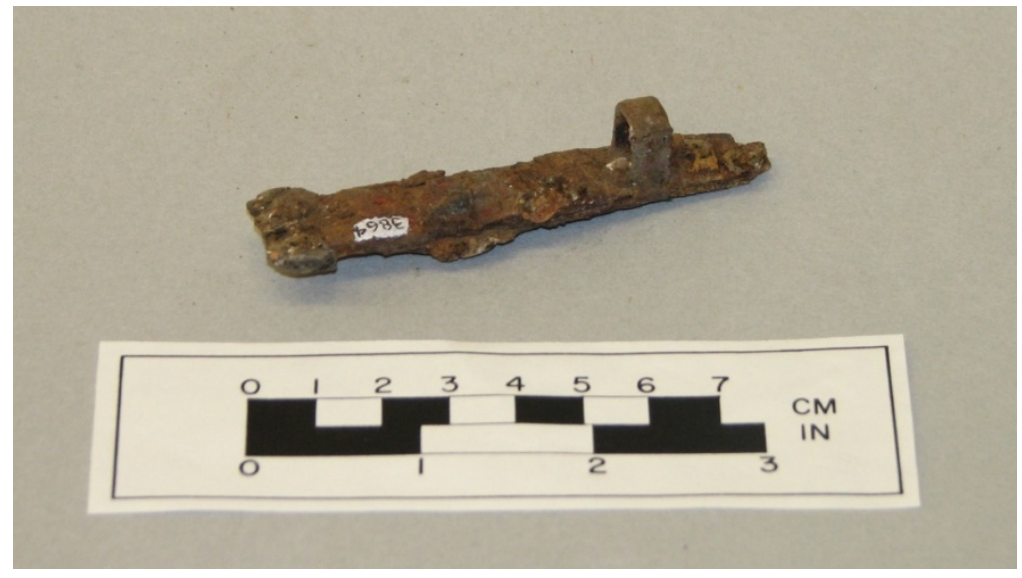

FIGURE 46. "Mortised lock fragment” Cat. No. 3864 (Photo by author, 2011).

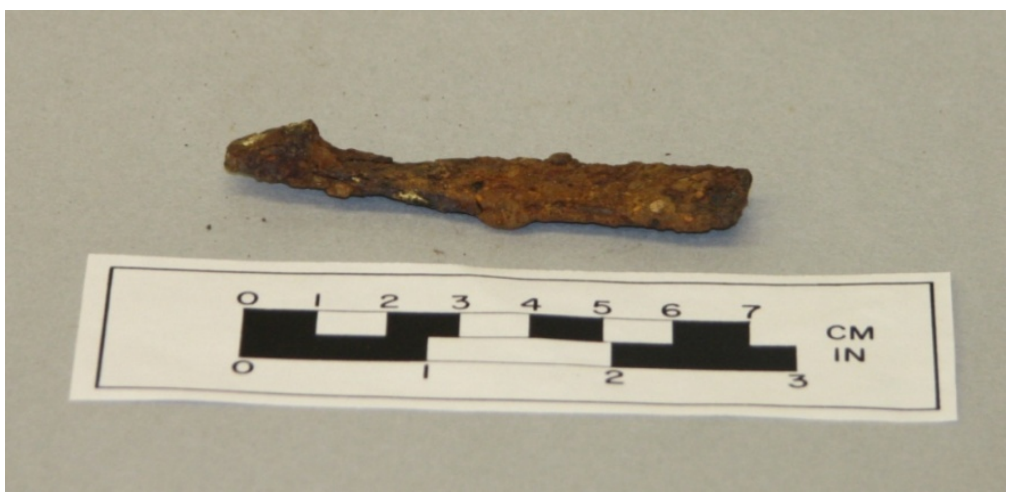

FIGURE 47. Cat. No. 4860 “Latch Part” fragment (Photo by author, 2011).

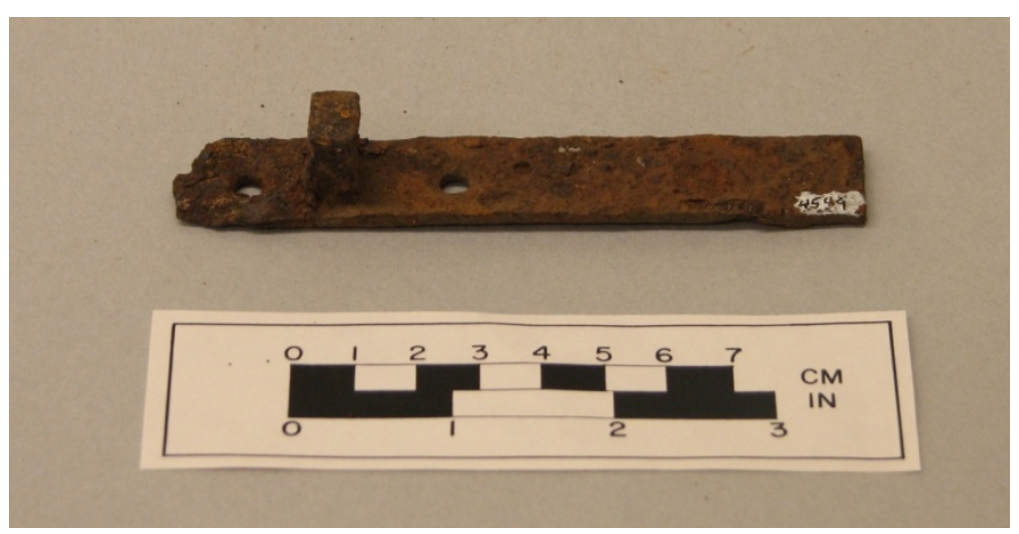

FIGURE 48. Cat. No. 157057 “mortised lock part” fragment (Photo by author, 2011). 


\section{Interpretation}

House 2 was likely a square or rectangular poteaux-sur-sole structure. The 41.5$\mathrm{m}^{2}$ House 2 study area only captures the northeast corner of the house. The northeast corner is well established by two timbers that form a right angle to frame the house floor edges. From that corner, the east and north wall alignments were inferred based on the angle of the timbers and artifact densities (Figure 49). Extending beyond the lengths of the timbers, the east wall is defined by a dense concentration of square nails and window glass (greater than 100 artifacts $/ \mathrm{m}^{2}$ ). The alignment of the north sill intersects a hearth feature approximately $3.6 \mathrm{~m}(12 \mathrm{ft}$.$) west of the northeast corner. If this hearth was placed$ in the center of the wall, then the east-west length of House 2 may be as long as $6.2 \mathrm{~m}$ (24 ft.). Brick accounted for less than $0.5 \%$ of the architectural artifacts. If ever brick was part of the hearth or chimney, it may have been removed and reused by other residents or the U.S. Army.

Alternatively, the west and south walls could only be approximated because they fell outside the excavated areas. Although a few remains may have scattered to the south during demolition, as suggested by the pieces of wood and artifacts in the southern excavation units (Figure 49), the average artifact density of the southern units is nearly four times lower than the area immediately around the house floor. This matches the lower densities of the units north of the hearth and the foundation sill, suggesting that both sections are outside the structure. This establishes an approximately $6 \mathrm{~m} \mathrm{(20 \textrm {ft } . )}$ limit for the north-south length of the house (Figure 49). 


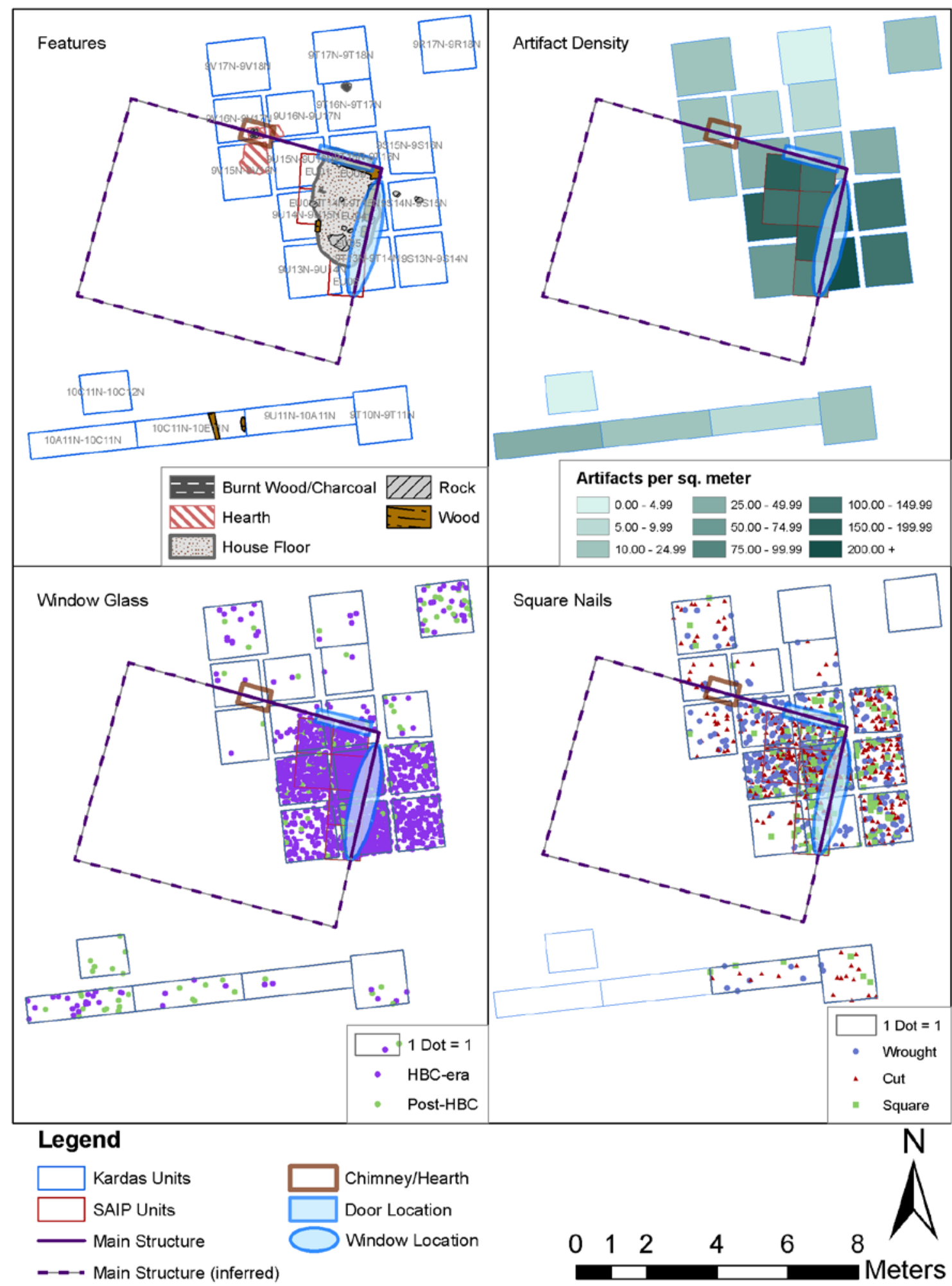

FIGURE 49-House 2 interpretation, showing features (upper left), artifact densities (upper right), window glass (lower left), and square nail distribution (lower right) (Map by author, 2011). 
The foundation sills were likely placed into trenches and then the clay-rich earthen floor was built up within the foundation frame. Profile drawings show the wood sills extending below the floor deposit (Figure 38) (Kardas 1970:32-33). At approximately $20 \mathrm{~cm}$ ( $8 \mathrm{in}$.) wide, these "cedar" timbers are slightly smaller than the foundation sills observed at Nisqually Village, but they are large enough to support wood posts. House 2 had the largest nail assemblage and one of the highest artifact densities in this study, regardless of field methodology (Table 24 ). The combined $32.3 / \mathrm{m}^{2}$ nail density suggests a pièce-sur-pièce wall, rather than a balloon frame (Stilson 1990).

TABLE 24

HOUSE 2 ARTIFACT RECOVERY DATA

\begin{tabular}{lrrrr}
\hline \hline & \multicolumn{2}{c}{ Window Glass } & \multicolumn{2}{c}{ Square Nails } \\
& KARDAS & \multicolumn{1}{c}{ SAIP } & KARDAS & \multicolumn{1}{c}{ SAIP } \\
& $1968-1969$ & $2001-2003$ & $1968-1969$ & $2001-2003$ \\
\hline Excavation Units $(\mathrm{n}$ and area $)$ & $21\left(41.5 \mathrm{~m}^{2}\right)$ & $6\left(6 \mathrm{~m}^{2}\right)$ & $21\left(41.5 \mathrm{~m}^{2}\right)$ & $6\left(6 \mathrm{~m}^{2}\right)$ \\
Avg. frequency $\left(\mathrm{n} / \mathrm{m}^{2}\right)$ & 54.7 & 102.2 & 27.1 & 35.2 \\
Min $\left(\mathrm{n} / \mathrm{m}^{2}\right)$ & $<1$ & 58 & 0 & 30 \\
Max $\left(\mathrm{n} / \mathrm{m}^{2}\right)$ & 538 & 145 & 184 & 43 \\
Std Deviation $\left(\mathrm{n} / \mathrm{m}^{2}\right)$ & 123.54 & 30.25 & 41.68 & 4.71 \\
\hline \hline
\end{tabular}

Evidence of a wood floor is insubstantial, but in light of the large and predominately fragmented nail assemblage, its presence cannot be fully ruled out. Nails commonly used in flooring (16 wrought and 9 machine cut clasp nails, sizes $8 \mathrm{~d}-10 \mathrm{~d}$ ) were found around the northeast corner. This location might reflect the practice of nailing floorboards along the walls, which would be similar to nail patterns seen at Nisqually Village. However, these nails are neither abundant nor evenly distributed enough along the inferred north and east walls to positively confirm the presence of a wood floor. The deep vertical and horizontal spread of the hearth debris (charcoal, bone, bisque) could have formed if there was a gap in the floorboards around the hearth, like in Figure 18. 
Window location was evidenced by concentrations window glass and specific nail types used for finishing and trim. The east wall contained multiple windowpanes. Based on the quantity of window glass in two units 9T13N-9T14N $(\mathrm{n}=437)$ and $9 \mathrm{~T} 14 \mathrm{~N}-9 \mathrm{~T} 15 \mathrm{~N}$ $(n=1013)$, a window was probably installed on the north end of the east wall in the early 1840s (Figure 49, Table 20) (Willis 2008:21). The units around this east wall concentration of window glass also contained four complete $5 \mathrm{~d}-7 \mathrm{~d}$ and 26 fragmented wrought clasp nails (variety no. 1001), which could have been used for finishing the frame around windows and doors. Based on the low density of window glass fragments north of the house (Figure 49), especially compared to the units bordering the east wall, it appears that the north wall contained no windows. The north wall window glass thickness distribution matches the east wall window glass, suggesting these fragments were scattered from the east wall during demolition or post-depositional trampling. As the excavation area only captured approximately $25 \%$ of the former house footprint, more windows may be present on the west and south walls. The only HBC-era window glass in the southern wall is $0.055 \mathrm{in}$. and $0.065 \mathrm{in} .\left(\mathrm{n}=19 ;\right.$ or $\left.3 / \mathrm{m}^{2}\right)$.

Latching hardware and clinched nails in the northeast corner suggest a door location. Three door-related pieces of hardware (two lock parts, and a latch) were found in the northeast corner of the house, near the timber sill (units 9T14N-9T15N, 9T15N9T16N, and 9S15N-9S16N). Unit 9T14N-9T15N also contained the highest concentration of clinched wrought nails (clasp and rosette), which are commonly associated with door construction and trim work. Doors were built off of vertical wall posts, so this door was likely adjacent to the northwest corner post, which also sits within unit 9T15N-9T16N. It seems unusual that the door would be located on the wall facing 
away from the roadway, but this may have been a secondary door. It seems reasonable to assume a door was located on the unexcavated south façade, opening toward the eastwest road that crosscut the Village.

House 2 was likely built between 1840 and 1845 , when both 0.055 -in. and 0.065 in. window glass were readily available. The eastern windows were installed at this time. House 2 was built after House 1. While House 1 had nearly equal percentages of 0.045 in. and 0.055 -in. window glass, House 2 is dominated by 0.055 -in. glass (Figure 50 ). Despite the presence of 0.045 -in. window glass (the quaternary mode), rather than infer that the House 2 was built in the late 1830s when these windowpanes were manufactured, it more is likely that the Sale Shop inventory still had some 0.045 -in. window glass.

Alternatively, these windowpanes could have been taken from another structure.

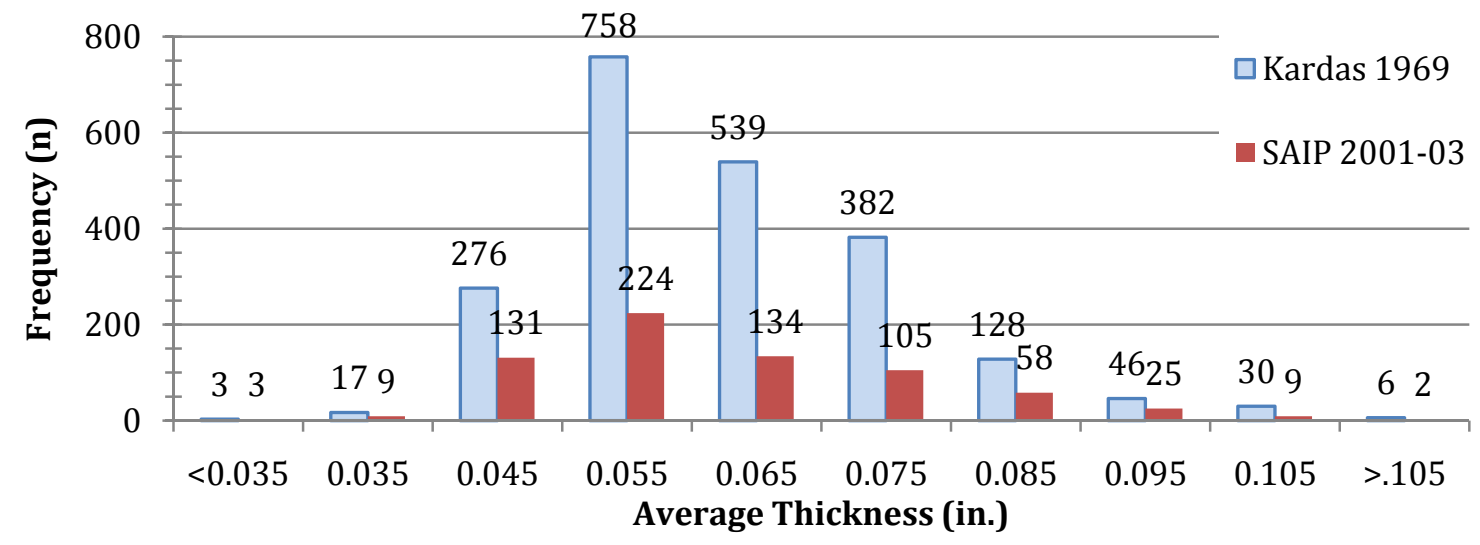

FIGURE 50. Comparison of the window glass thickness distributions recovered from study areas of House 2 separated by excavation (Chart by author, 2011).

The slight dominance of machine cut nails (46.52\%) over hand wrought (36.33\%) suggests that there was a second phase of substantial construction or structural modification in the 1850s (Amos-McGraw 2008). The east wall windows were also replaced sometime in the early $1850 \mathrm{~s}$, based on the abundance of 0.075 -in. glass in these units. It is even possible that some of the 0.065 -in. glass was part of a refurbishment 
phase. It is not known whether this maintenance was performed by U.S. Army renters or by HBC employees who intended to stay longer in the Village. These repairs adhered to the function and character of the initial construction (Amos-McGraw 2008:9). The penny sizes of the machine cut nails are consistent with the penny size trends of the wrought nails (Figure 52). Among both nail manufacture types, the general construction nails (8d12d) were much more common than finishing nails (5d-7d) (Figure 51). The residents focused their resources on practical elements of the structure rather than decorative details (Amos-McGraw 2008:9). No repairs or modifications were made to the structural supports, as the machine cut nail assemblage lacked large spike sizes (20-60d) among the machine cut nails (Amos-McGraw 2008:11). The presence of nearly 5 times more 2d-4d machine cut nails $(\mathrm{n}=57)$ than wrought nails $(\mathrm{n}=12)$ may have resulted from re-roofing the house, perhaps with shingles (Figure 52) (Amos-McGraw 2008:11). Most of these small machine cut nails clustered along the east wall, which presumably was also the edge of the roof. The lack of roofing-related wrought nails may be a result of these nails being thrown away with the old shakes or shingles. The roof that was on the house when it was demolished is what entered the archaeological record immediately around House 2.

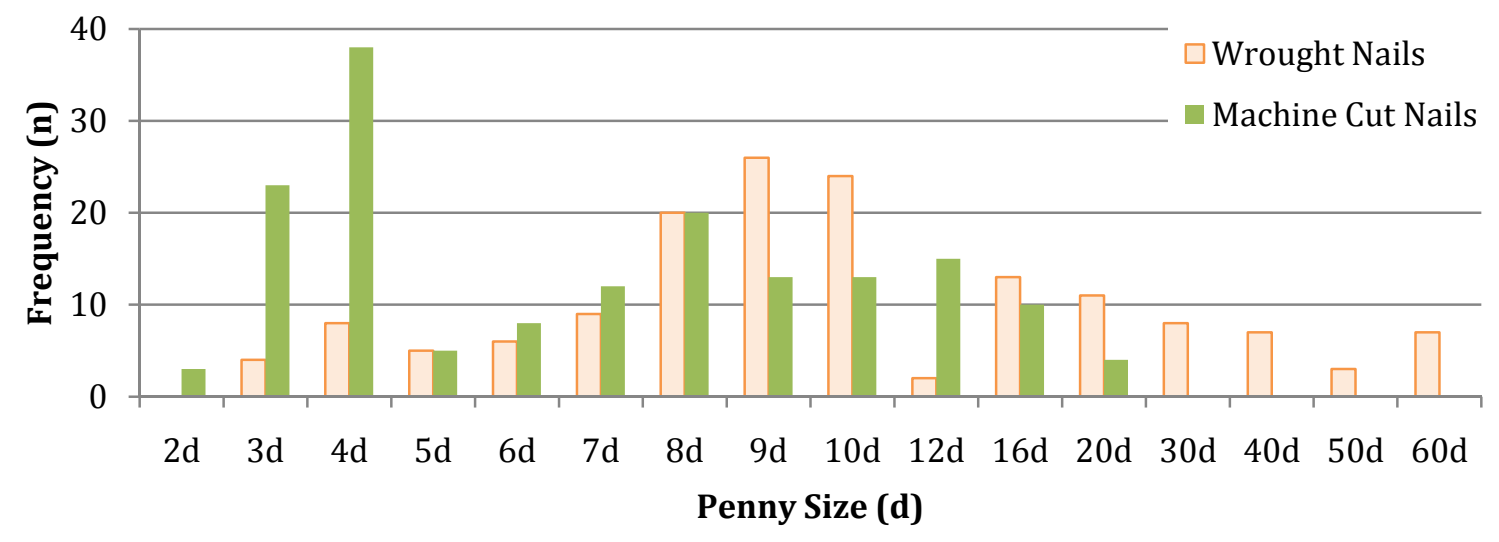

Figure 51. Comparison of the nail penny size distributions recovered from study area of House 2 separated by manufacture type (Chart by author, 2011). 
The sharp drop in the frequency of window glass $0.085 \mathrm{in}$. and thicker suggests that windows were not added or replaced at House 2 after 1855 (Figure 50). The end of the structure's life history was near. The hand wrought and machine cut nails exhibit similar percentages of complete and fragmentary specimens, suggesting the same site formation processes affected them. The condition of the nails (nearly $75 \%$ fragmented and with more bent nails than unaltered nails) indicates that House 2 was forcibly torn down. It likely fell to the southeast, where the densest artifact concentration was recorded. Units 9R17N-9R18N and 10A11N-10C11N have dense concentrations surrounded by areas of lower artifact density; it is possible these were temporary refuse piles during demolition, before the structural debris were hauled to the pond. The upper root layer and compact light-grey deposit, which overlay the dark grey house floor and the foundation sills, (together comprising the upper $30 \mathrm{~cm}$ [12 in.] below the surface) contained the majority of the window glass remains. It seems that this may be part of the demolition, rather than earthen-floor maintenance (Cromwell 2006:207).

The archaeological evidence is consistent with the structure inferred to be House 2 in Gibbs' illustration (Figure 52). Both have a foundation sill and a hearth and chimney on the north side of the house. The illustration shows two windows on the west wall. Archaeologically, we have no evidence for the west wall, but we have evidence for the opposite wall hidden in the drawing. The east wall may have also had two windows, based on the large quantity of glass. The illustration also suggests that House 2 sat within a large fenced area. The possibility of a door at the northeast corner is not directly inconsistent with the illustration, since Gibbs did not depict the north or east walls. 


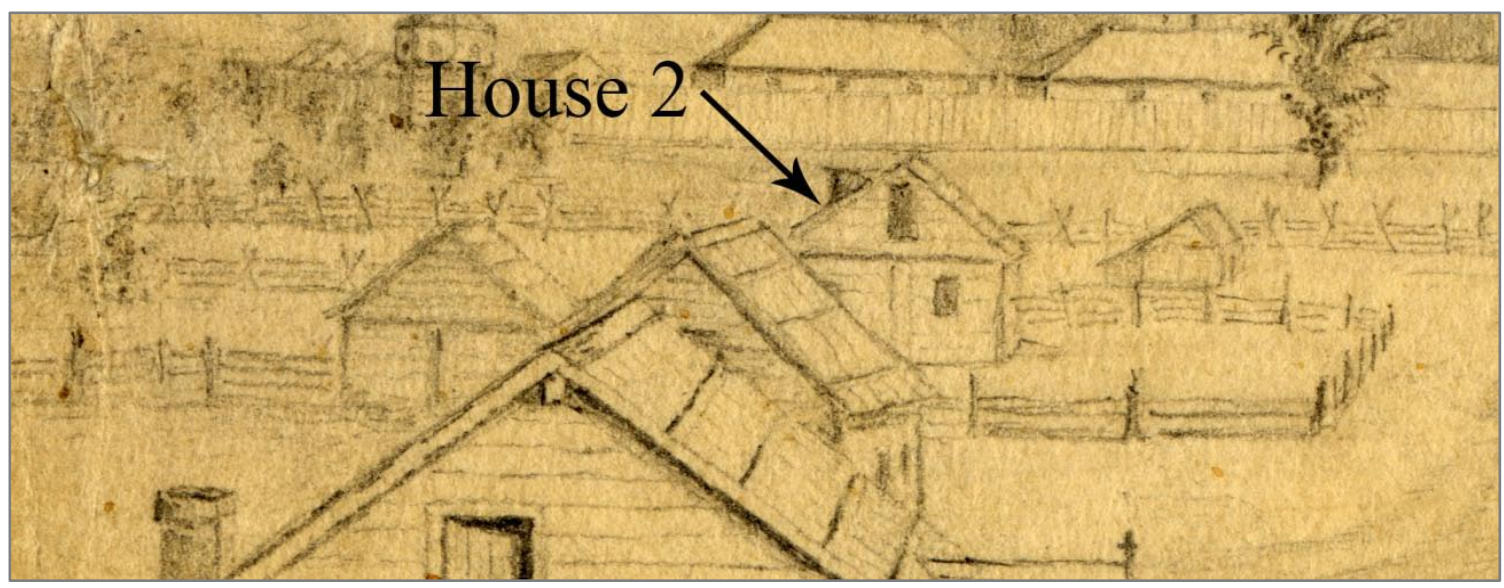

FIGURE 52. Detail of George Gibbs's 1851 illustration of the Village, showing the inferred "House 2" (Courtesy of Fort Vancouver National Historic Site). 


\section{CHAPTER 8 \\ HOUSE 3}

House 3 is located $45 \mathrm{~m}$ (150 ft.) southeast of House 2 and $25 \mathrm{~m}(82 \mathrm{ft}$.$) from the$ eastern edge of the NPS Village boundary. In 1969, archaeologists first uncovered a wood-lined pit in two units of the North-South Trench and followed the concentration of associated artifacts to the east, where a dark gray sediment layer was found (Kardas 1969:45). The 13 excavation units identified as House 3 account for $26.68 \mathrm{~m}^{2}$ with approximately $7.67 \mathrm{~m}^{3}$ excavated. This analysis includes an additional 12 units (42.04 $\mathrm{m}^{2} ; 12.51 \mathrm{~m}^{3}$ excavated) adjacent to the north and south. In 2003, four 1-meter square excavation units $\left(4 \mathrm{~m}^{2} ; 1.4 \mathrm{~m}^{3}\right.$ excavated) revealed the same brick and rock feature within 10 to $15 \mathrm{~cm}$ (4 to 6 in.) of the surface.

\section{Stratification}

The 1970 report included no stratigraphic profile for House 3, only a cross-section drawing of the wood-lined pit. No artifacts were reported below the 5-cm (2-in.) thick compact gray clay sediment in the main house area, but it is not clear whether the excavation penetrated this surface (Kardas 1970:45). The structural remains extended 10 cm (4 in.) above the prepared floor (Cromwell 2006:223). There is some discrepancy regarding the absolute elevations: the report (Kardas 1970) states that the compact gray "clay" sediment was found $30 \mathrm{~cm}$ (12 in.) below surface. The student field notes, however, depict the "clay floor" at $20 \mathrm{~cm}$ and $25 \mathrm{~cm}$ (8 in. and $10 \mathrm{in}$.) below the sod. Tree roots, burrowing rodent activity, and previous archaeological excavation mixed the House 3 sediments encountered in 2003. The first $30 \mathrm{~cm}$ (12 in.) of EU01 and the first $15 \mathrm{~cm}$ (6 in.) of EU02 and EU03 were previously excavated and backfilled. 
Below the NPS sod, these previously excavated levels were a homogenous brown sediment. An 8-cm (3 in.) thick compact grayish brown deposit, laden with charcoal and bisque, was recorded in the southwest corner of EU01. Both EU03 and EU04 had patches of this compact light brownish gray ash lenses at approximately $15 \mathrm{~cm}(6 \mathrm{in}$.) below surface.

\section{Features}

Although a 1936 map shows a CCC barracks building over the House 3 study area, no specific 20th century deposits or features were reported in 1969 . The only nonstructural features found in the House 3 Study area were two horse burials found approximately $4.5 \mathrm{~m}$ (15 ft.) south of House 3 (Table 25, Figure 53) (Cromwell 2006:220). The skeleton in Horse Burial No.1 was folded; the skeleton in Horse Burial No. 2 was still articulated and laid out on its left side (Kardas 1970:85). Both horses were covered with HBC artifact deposits, but only the artifact-rich deposit above Horse Burial No. 1 was explicitly called out as a trash pit (filled after the animal was buried). Kardas (1970:77-78) noted that the artifact assemblage of this trash deposit appeared unrelated to the House 3 deposit based on the types and conditions of artifacts present. The structural features were concentrated around the original location of House 3 (Table 26). Figure 53 shows the location of the features listed in Tables 25 and 26.

TABLE 25

FORMAL CHARACTERISTICS OF HOUSE 3 MISCELLANEOUS FEATURES

\begin{tabular}{lccccc}
\hline \hline & $\begin{array}{c}\text { Max. } \\
\text { Diameter/ } \\
\text { Length } \\
(\mathrm{cm})\end{array}$ & $\begin{array}{c}\text { Width } \\
(\mathrm{cm})\end{array}$ & $\begin{array}{c}\text { Depth } \\
(\mathrm{cmbs})\end{array}$ & Location \\
No. & Type & $\sim 152$ & $\sim 152$ & $10-25$ & M1N-M2N \\
NA & Trash Pit & 198 & 76 & 33 & M1N-M2N, M2N-M3N \\
NA & Horse Burial No. 1 & 228 & 152 & 61 & K0N-K1N, K1N-K2N, J1N-J2N \\
\hline
\end{tabular}

Notes: * Maximum length and width of feature complex based on area excavated 


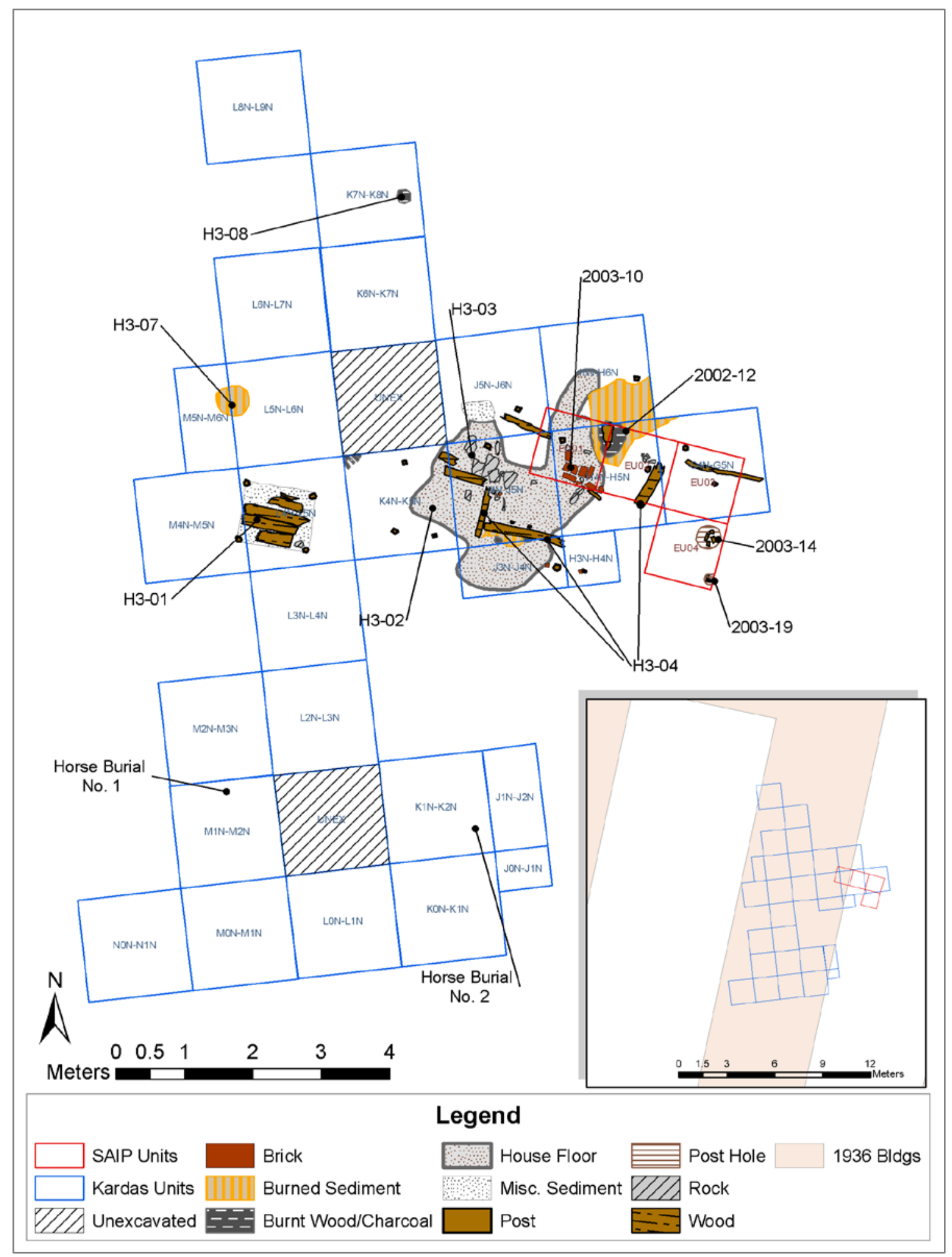

FIGURE 53. House 3 features, inset shows location of 1930s CCC barracks (Map by author, 2011). 
TABLE 26

FORMAL CHARACTERISTICS OF HOUSE 3 STRUCTURAL FEATURES

\begin{tabular}{|c|c|c|c|c|c|}
\hline No. & Type & $\begin{array}{l}\text { Max. } \\
\text { Diameter/ } \\
\text { Length } \\
(\mathrm{cm})\end{array}$ & $\begin{array}{l}\text { Width } \\
(\mathrm{cm})\end{array}$ & $\begin{array}{l}\text { Depth } \\
(\mathrm{cmbs})\end{array}$ & Location \\
\hline H3-01 & Wood-Lined Pit & 117 & 89 & $25-76$ & L4N-L5N; M4N-M5N \\
\hline H3-02 & House Floor & 354 & 275 & 30 & $\begin{array}{l}\text { H4N-H5N; H5N-H6N; J3N-J4N; } \\
\text { J4N-J5N; } \\
\text { J5N-J6N; K4N-K5N }\end{array}$ \\
\hline H3-03 & Hearth Rocks* & 94 & 76 & $\sim 15$ & J4N-J5N \\
\hline 2003-10 & Hearth Bricks* & 78 & 45 & 15 & H4N-H5N (EU01, EU02) \\
\hline H3-04a & Wood Plank & 26 & 11 & $\sim 25$ & K4N-K5N; J4N-J5N; \\
\hline H3-04b & Wood Plank & 57 & 14 & $\sim 25$ & K4N-K5N; J4N-J5N; \\
\hline $\mathrm{H} 3-04 \mathrm{c}$ & Wood Plank & 73 & 10 & $\sim 25$ & J4N-J5N \\
\hline H3-04d & Wood Plank & 120 & 13 & $\sim 25$ & J4N-J5N, J3N-J4N \\
\hline H3-04e & Wood Plank & 78 & 10 & $\sim 25$ & $\mathrm{~J} 5 \mathrm{~N}-\mathrm{J} 6 \mathrm{~N}$ \\
\hline $\mathrm{H} 3-04 \mathrm{f}$ & Wood Plank & 24 & 6 & $\sim 25$ & H4N-H5N \\
\hline $\mathrm{H} 3-04 \mathrm{~g}$ & Wood Plank & 35 & 17 & $\sim 25$ & $\mathrm{H} 4 \mathrm{~N}-\mathrm{H} 5 \mathrm{~N}$ \\
\hline H3-04h & Wood Plank & 68 & 17 & $\sim 25$ & H4N-H5N \\
\hline H3-04i & Wood Plank & 114 & 7 & $\sim 25$ & G4N-G5N \\
\hline H3-05 & Vertical Wood/Posts & N/A & N/A & N/A & $\begin{array}{l}\text { G4N-G5N; H3N-H4N; H4N- } \\
\text { H5N; H5N-H6N; J3N-J4N; J4N- } \\
\text { J5N; J5N-J6N; K4N-K5N }\end{array}$ \\
\hline H3-06 & Bisque and Charcoal & 70 & 33 & 20 & J4N-J5N \\
\hline H3-07 & $\begin{array}{l}\text { Burned Sediment/ } \\
\text { Post mold }\end{array}$ & 50 & 45 & $\sim 22$ & M5N-M6N; L5N-L6N \\
\hline H3-08 & $\begin{array}{c}\text { Charcoal } \\
\text { Concentration/ Post }\end{array}$ & 21 & 22 & UKN & $\mathrm{K} 7 \mathrm{~N}-\mathrm{K} 8 \mathrm{~N}$ \\
\hline 2003-12 & Bisque and Charcoal & 139 & 110 & $\sim 15$ & EU02; H4N-H5N; H5N-H6N \\
\hline 2003-14 & Post Hole Fill and Post & 39 & 35 & 63 & EU04 \\
\hline 2003-16 & Charcoal Stain & 30 & 19 & 30 & EU03 \\
\hline 2003-19 & Wood Post & 21 & 16 & 42 & EU04 \\
\hline
\end{tabular}

Notes: * Max. length and width of feature complex (cluster), based on area excavated. When depths are singular, they represent initial depths.

The wood-lined pit (Feature H3-01) was the first feature discovered at House 3 in 1969, five feet west of the primary floor deposit. It contained a highly rich and diverse assemblage of domestic and architectural artifacts, including square nails, window glass, two door hinges, and a door latch hook. The base of the pit was lined with five parallel cedar planks, and two planks more lined the north and south walls (Kardas 1970:47). The report implicitly suggests that the wood lined pit was an associated exterior feature, and "stood open at the time of house demolition" (Kardas 1970:45, 47-49). However, if the 
house floor extended to the wood-lined pit it may have functioned as an interior cellar or storage pit for House 3, similar to the pit found at OP 14 by Thomas and Hibbs (1984).

The presence of the gray clay sediment layer (Feat. H3-02), portions of which were found in six units, confirmed the discovery of the third Village house site. There was a gap in artifacts between the pit and the floor sediment. The student sketch maps differs from the final report on the full extent of this "clay floor," the former shows the floor deposit present around the wood lined pit in M4N-M5N and L4N-L5N (not pictured) and at the far east side of the excavation in G4N-G5N.
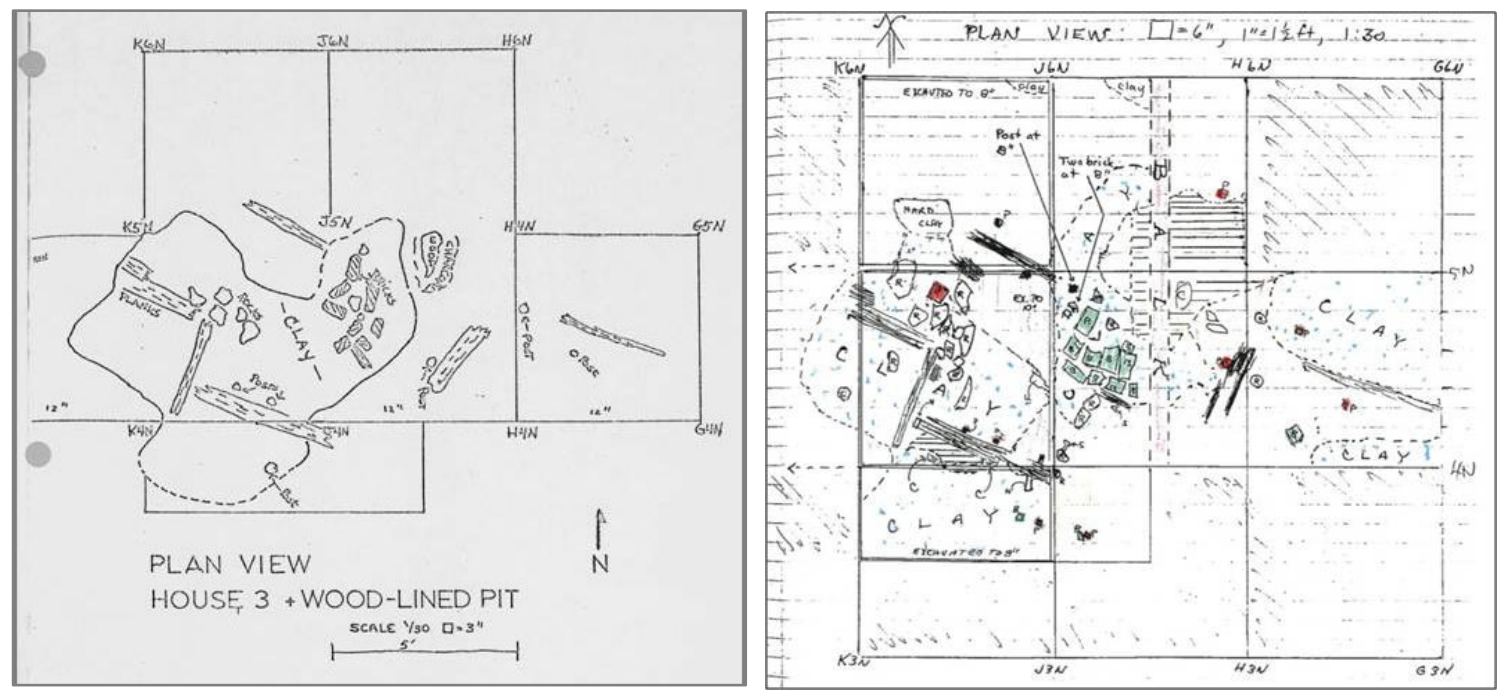

FIGURE 54. The plan view of features discovered at House 3 as documented in the final excavation report (left) (Kardas 1970) is missing some of the wood posts, patches of clayey sediment, and other bisque and charcoal features that were documented by a field school student in 1969 (right). Without Susan Kardas' notes, the reason for the discrepancies is unknown. (Courtesy of Fort Vancouver National Historic Site.)

The brick and rock features (Feat. H3-03 and 2003-10) were likely related to a hearth. The [English] brick feature was rediscovered in EU01 and EU02 in 2003. It did not maintain the same arrangement as in 1969 (cherry tree roots had grown between the bricks), but the presence of a few uniquely shaped bricks confirmed this was the same brick feature from 1969. When the bricks were removed and collected, an underlying 
compact surface was interpreted as the same floor feature seen in 1969. Water screen samples were taken of the feature matrix and compact sediment, but have not been fully analyzed. A similar house floor surface was identified in EU 04, Level 5-an area that was not excavated in 1969.

There were 16 post-related features (Features H3-05, 2003-14; and 2003-19), including postholes, post supports, and vertical wood remains. Not all of the posts drawn on student sketch maps were replicated in the final report plan view sketch map; additionally, the five posts that did appear in the final report are drawn as round, but were square in the student field notes. This analysis gives more weight to the sketch maps drawn on site, at the time of excavation. Based on the scales of 1969 sketch maps, 14 of these "posts" are less than $15 \mathrm{~cm}$ (6 in.) wide-perhaps "stake" is a more appropriate identification. Five vertical wood posts are within the boundary of the central gray clay sediment, but are not in regular alignments.

There were five sediment features that in addition to the house floor sediment. Three of these (Features H3-07, H3-08, and 2003-12) may be charred post molds. A piece of wood (Feature H3-04g) was depicted in the 1969 illustration of Feature 2003-12, but the wood was not present when this charcoal and bisque deposit was rediscovered in 2003. The shapes of two other features (H3-06 and 2003-16) do not resemble posts, although they are found near to other post features.

The cedar planks found on the house floor sediment were allegedly charred (Kardas 1970:45). Six planks (Features H3-04a, b, d, e, f, and i) are oriented approximately east-west, in a similar alignment to the wood planks at the base of the 
wood-lined pit. Three planks (Features H3-04c, g, h) are oriented perpendicular to the rest, approximately north-south. All wood remains surround the house floor (Figure 53).

\section{Architectural Artifacts}

The analysis of the House 3 study area included 2401 architectural artifacts (Tables 27 and 28). The densest concentrations of artifacts were found around the pit features - the two horse burials and the wood-lined pit (Figure 55). The SAIP excavations also recovered a high number of artifacts by screening, especially in areas that had not previously been excavated (EU04). It became clear that the dense concentration of structural debris in the southern vicinity skewed the analysis of the larger study area. The horse burials alone contained approximately 400 window glass fragments and 600 square nails. This is approximately equal to as many nails as were in the pre-established "House 3" units, and nearly twice as much window glass.

Brick. The bricks account for only $6 \%(n=143)$ of the total construction materials collected. The 1969 report did not include bricks in the artifact distribution table, but bricks were reported in House 3 as part of a presumed hearth or chimney feature. The bricks from the brick and rock features were not collected in 1969, as the 2003 excavation encountered bricks that were recognizable from photos, albeit disturbed by tree roots and previous excavation. In 2003, 121 whole and fragmentary bricks were found; 57 of these (most of the larger fragments) were part of Feature 2003-10. Only four fragments, smaller than $40 \mathrm{~mm}$, were identified as American Brick (three fragments came from EU04, where most of the late-19th century window glass was found). The remaining [Type 1] English brick fragments (ranging in size from 10mm-82mm) were mostly found in EU01 and EU03, levels 3-5. The 22 brick fragments that were collected 
from the House 3 Vicinity in 1969 were all American bricks collected from the horse

burials, with the exception of two English brick fragments.

TABLE 27

HOUSE 3 ARCHITECTURAL ARTIFACT COUNTS

\begin{tabular}{|c|c|c|c|c|c|c|c|}
\hline Excavation & $\begin{array}{c}\text { Window } \\
\text { Glass }\end{array}$ & $\begin{array}{c}\text { Square } \\
\text { Nails }\end{array}$ & Brick & $\begin{array}{c}\text { Architectural } \\
\text { Hardware }\end{array}$ & Total & $\begin{array}{c}\text { Avg. Density } \\
\mathrm{n} / \mathrm{m}^{2}\end{array}$ & $\begin{array}{l}\text { Std. } \\
\text { Dev. }\end{array}$ \\
\hline Acc 0120 (1969) & 605 & 1277 & 22 & 5 & 1909 & 24.6 & 34.61 \\
\hline Acc 3023 (2003) & 177 & 194 & 121 & 0 & 492 & 100.8 & 48.49 \\
\hline Total & 782 & 1471 & 143 & 5 & 2401 & 32.2 & 42.32 \\
\hline
\end{tabular}

TABLE 28

HOUSE 3 STUDY AREA ARTIFACT COUNTS PER UNIT

\begin{tabular}{|c|c|c|c|c|c|c|c|c|c|c|c|}
\hline Unit & WG & SN & $\mathrm{B}$ & Total & $\mathrm{n} / \mathrm{m}^{2}$ & Unit & WG & SN & $\mathrm{B}$ & Total & $\mathrm{n} / \mathrm{m}^{2}$ \\
\hline EW12-13 & 0 & 7 & & 7 & 5.0 & K6N-K7N & 0 & 34 & 0 & 34 & 14.7 \\
\hline EW 13-14 & 0 & 5 & & 5 & 3.6 & K7N-K8N & 1 & 25 & 0 & 26 & 11.2 \\
\hline EW 14-15 & 0 & 18 & & 18 & 12.9 & L0N-L1N & 5 & 36 & 3 & 44 & 18.9 \\
\hline EW 15-16 & 0 & 28 & & 28 & 20.1 & L2N-L3N & 15 & 37 & 0 & 52 & 22.4 \\
\hline EW 16-17 & 0 & 26 & & 26 & 18.7 & L3N-L4N & 0 & 18 & 0 & 18 & 7.8 \\
\hline EW 17-18 & 0 & 23 & & 23 & 15.4 & L4N-L5N & 86 & 116 & 0 & 202 & 87.1 \\
\hline EW 18-19 & 0 & 15 & & 15 & 10.8 & L5N-L6N & 0 & 16 & 0 & 16 & 6.9 \\
\hline EW 19-20 & 2 & 12 & & 14 & 10.1 & L6N-L7N & 11 & 47 & 0 & 58 & 25 \\
\hline EW 20-21 & 0 & 3 & & 3 & 2.0 & L8N-L9N & 0 & 12 & 0 & 12 & 5.2 \\
\hline EW 21-22 & 0 & 7 & & 7 & 4.7 & M1N-M2N & 228 & 200 & 17 & 445 & 191.8 \\
\hline G4N-G5N & 0 & 20 & & 20 & 8.6 & M2N-M3N & 39 & 75 & 1 & 115 & 49.6 \\
\hline H3N-H4N & 0 & 13 & & 13 & 22.4 & M1N-M3N & 4 & 3 & 0 & 7 & 1.5 \\
\hline $\mathrm{H} 4 \mathrm{~N}-\mathrm{H} 5 \mathrm{~N}$ & 0 & 39 & & 39 & 16.8 & M4N-M5N & 45 & 54 & 0 & 99 & 42.7 \\
\hline H5N-H6N & 3 & 8 & & 11 & 4.7 & M5N-M6N & 0 & 4 & 0 & 4 & 3.4 \\
\hline J1N-J2N & 52 & 17 & & 69 & 29.7 & N0N-N1N & 30 & 0 & 0 & 30 & 12.9 \\
\hline J3N-J4N & 7 & 38 & & 45 & 25.9 & & & & & & \\
\hline J4N-J5N & 12 & 105 & & 117 & 50.4 & EU01 & 39 & 44 & 44 & 127 & 127 \\
\hline J5N-J6N & 1 & 7 & & 8 & 3.4 & EU02 & 26 & 25 & 0 & 51 & 51 \\
\hline K0N-K1N & 12 & 105 & & 117 & 50.4 & EU03 & 27 & 26 & 17 & 70 & 70 \\
\hline K1N-K2N & 46 & 97 & 1 & 144 & 62.1 & EU04 & 79 & 73 & 3 & 155 & 155 \\
\hline K4N-K5N & 6 & 7 & 0 & 13 & 5.6 & F. $2003-10$ & 6 & 26 & 57 & 89 & NA \\
\hline
\end{tabular}

$\mathrm{WG}=$ window glass; $\mathrm{SN}=$ square nails; $\mathrm{B}=$ brick; $\mathrm{n} / \mathrm{m}^{2}=$ artifact density per excavation unit 


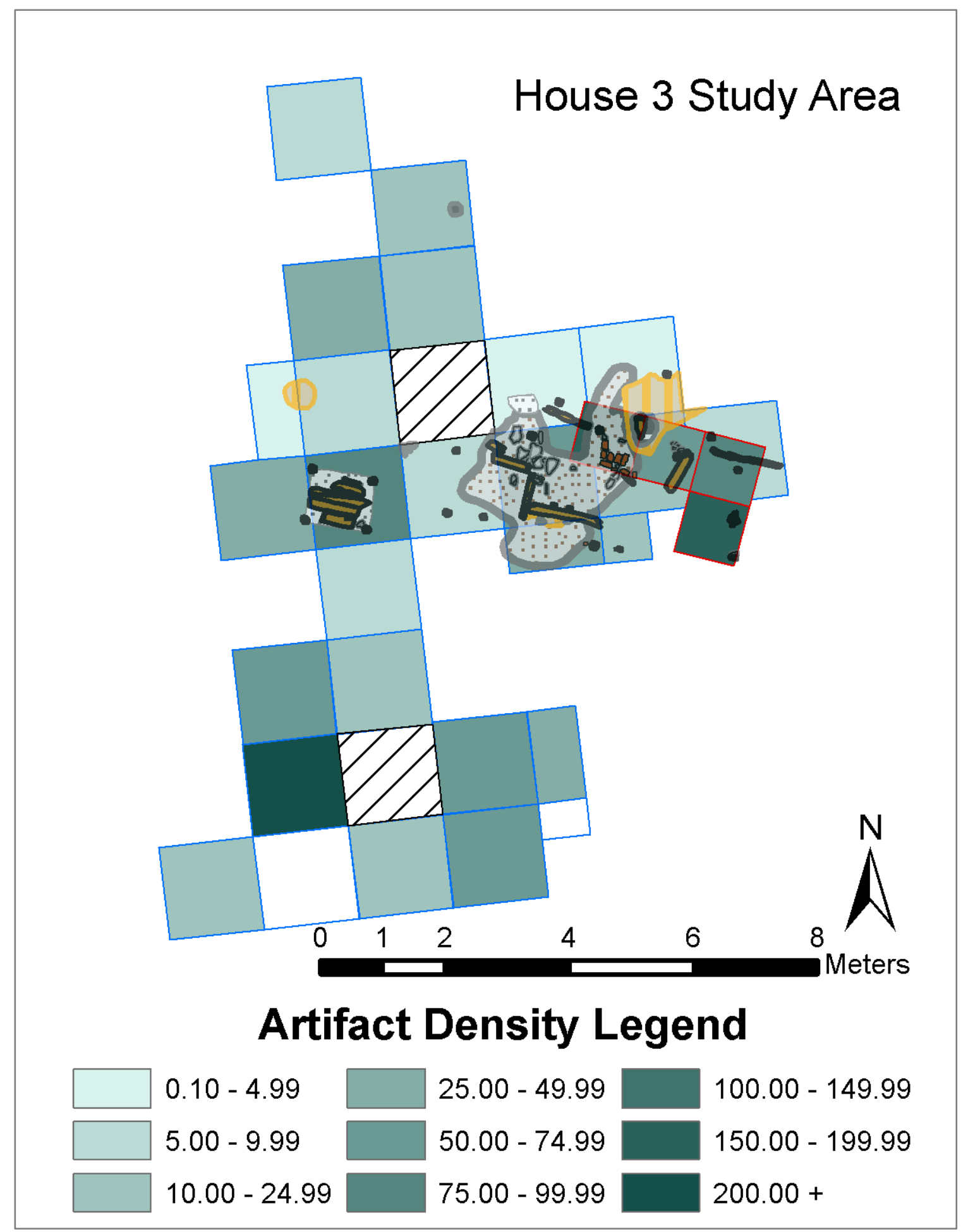

FEATURE 55. Architectural artifact distribution in House 3 study area (density is $n / \mathrm{m}^{2}$ ) (Map by author, 2011). 
Window Glass. The 782 fragments of window glass accounted for $32 \%$ of the architectural assemblage. The clustered distribution of window glass suggests that window glass from the Village structures was swept into existing pits and depressions after demolition (Figure 56). Aside from the wood-lined pit, the Kardas excavation recovered very little window glass around the structural features. The SAIP excavations recovered almost three to four times as many fragments per unit, with 79 in EU04. When the wood-line pit $\left(28.2 / \mathrm{m}^{2}\right)$ and SAIP units $\left(42.75 / \mathrm{m}^{2}\right)$ were excluded, the window glass density in the original House 3 units averaged only $5.3 / \mathrm{m}^{2}$. The density of window glass fragments in the southern study area is $\left(64.5 / \mathrm{m}^{2}\right)$, a result of the high artifact counts from the two horse burials/trash pits. When the spatial distributions of window glass thicknesses and sizes were analyzed, the southern study area stood out as a deposit distinct from the House 3 area, as Kardas (1970) originally suggested.

House 3 window glass thicknesses ranged from $0.36 \mathrm{~mm}(0.014$ in.) to $3.09 \mathrm{~mm}$ (0.122 in.). The overall primary mode of window glass thickness is 0.055 in. (Figure 57), but this is partially a result of skewing by the horse burials in the south. The southern study area units also have a primary mode of $0.055 \mathrm{in}$., but the wood lined pit and the units containing House 3 structural features have a 0.045 in. primary mode (Figure 58). The original House 3 units and the SAIP units are consistent with one another: the primary mode is $0.045 \mathrm{in}$., with a secondary mode of $0.055 \mathrm{in}$. (Figure 59). The whole study area assemblage was dominated by window glass manufactured and used during the HBC's 1827-1860 tenure in the Village (0.035-0.075 in.). Only 15 fragments of 782 recovered from the House 3 study area and correspond to the post-HBC-era (Roenke 1982). 


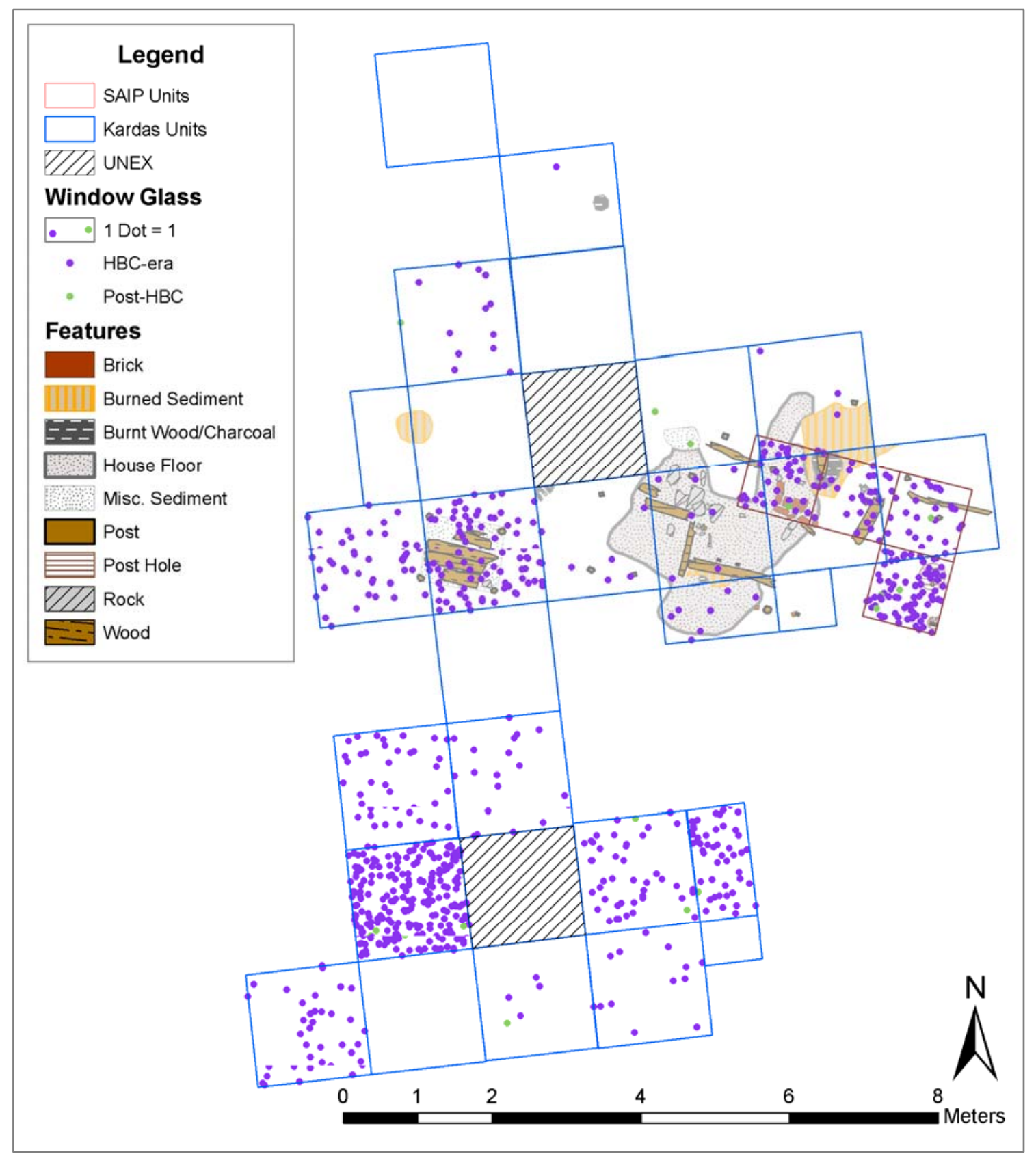

FIGURE 56. House 3 Study Area window glass distribution (May by author, 2011). 


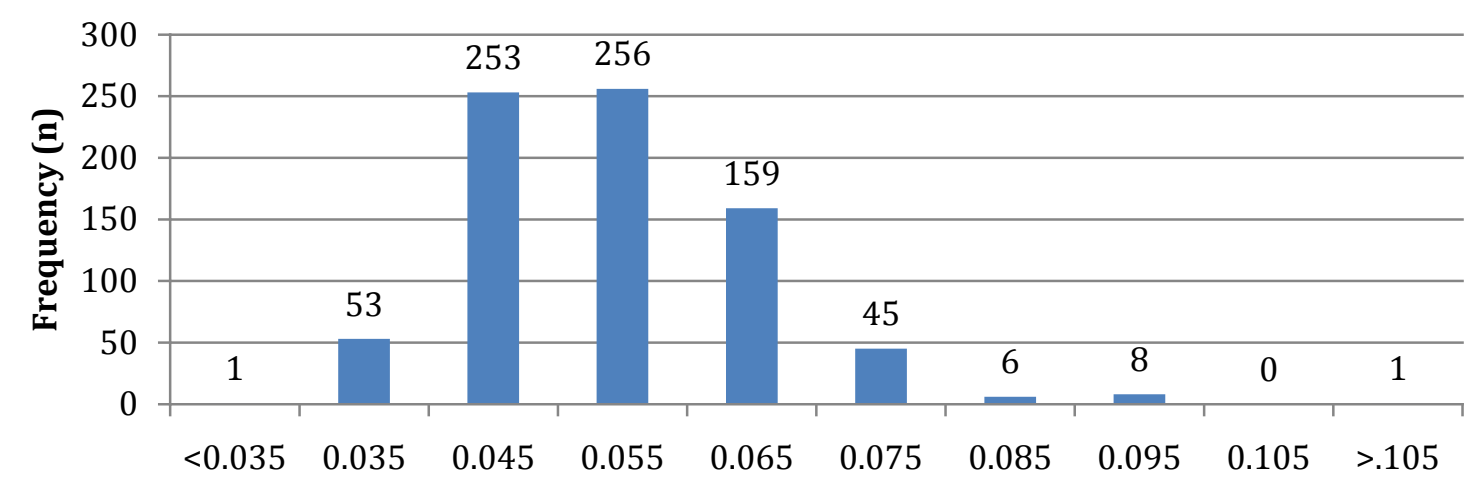

Thickness Interval Midpoints (in.)

FIGURE 57. House 3 study area window glass thickness distribution (Chart by author, 2011).

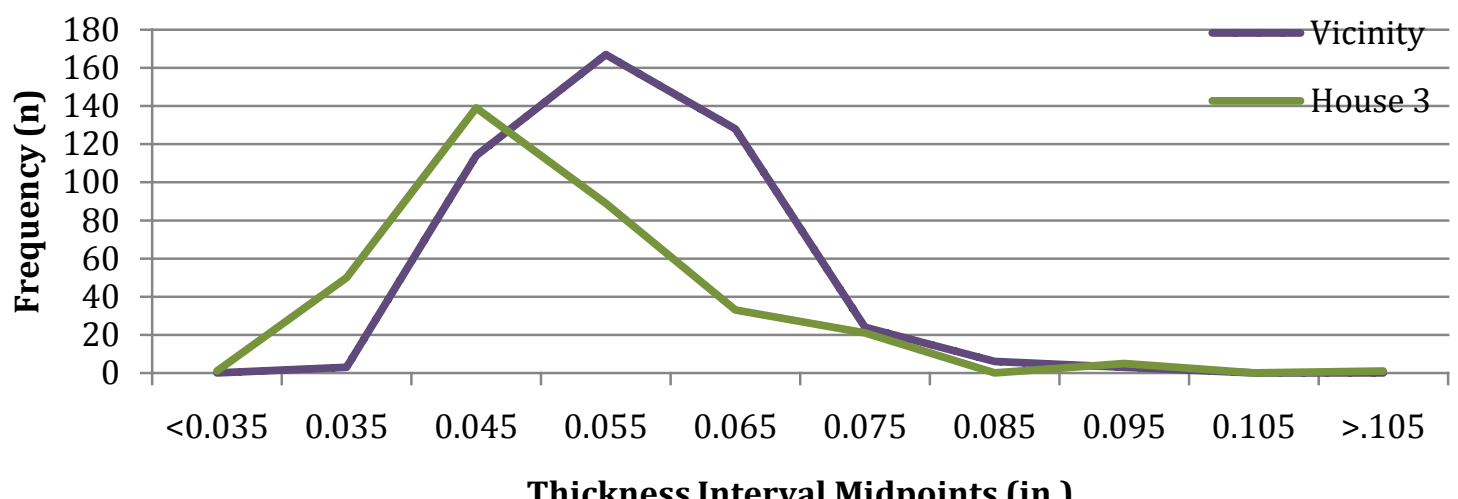

Thickness Interval Midpoints (in.)

FIGURE 58: Comparing the distribution of window glass in units previously identified as House 3 and those vicinity units included in the study area for this analysis (Chart by author, 2011).

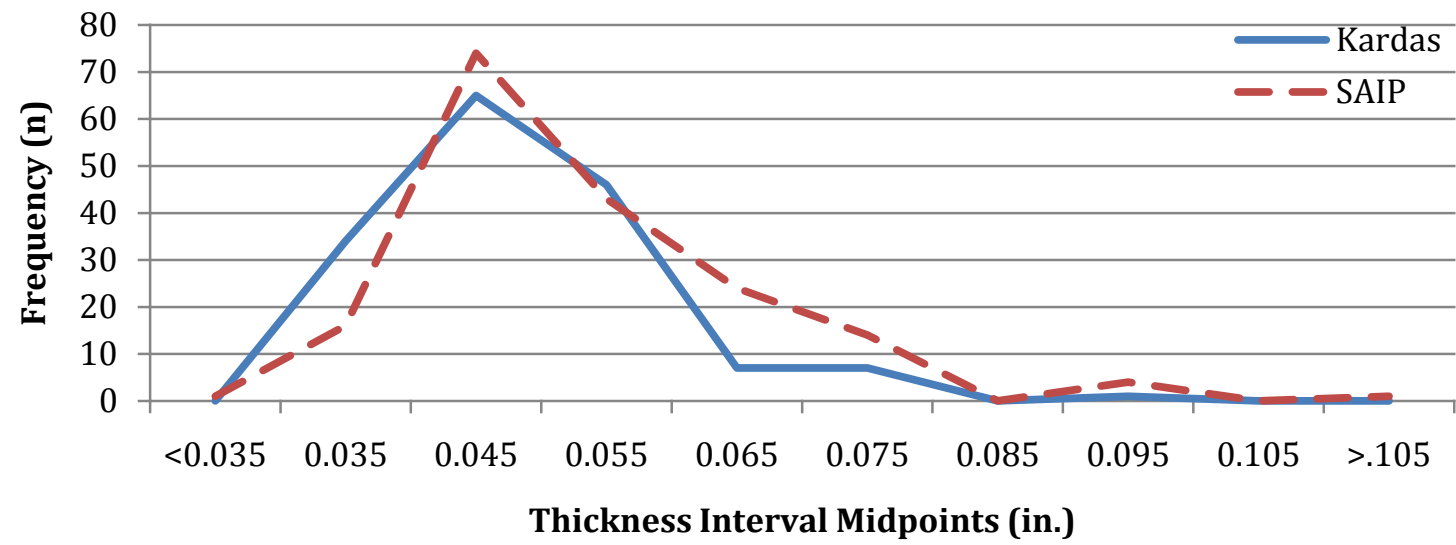

FIGURE 59: A comparison of the SAIP and KARDAS window glass data from the area specifically identified as House 3, again shows that despite different densities and sizes from recovery methods, the data is overall consistent (Chart by author, 2011). 
The post-1860 window glass, found in nine excavation units, only accounts for $1.6 \%(n=10)$ of the Kardas window glass assemblage and $2.8 \%(n=5)$ of the SAIP window glass. The distribution of the individual HBC-era thicknesses is presented in Figure 60a and 60b.

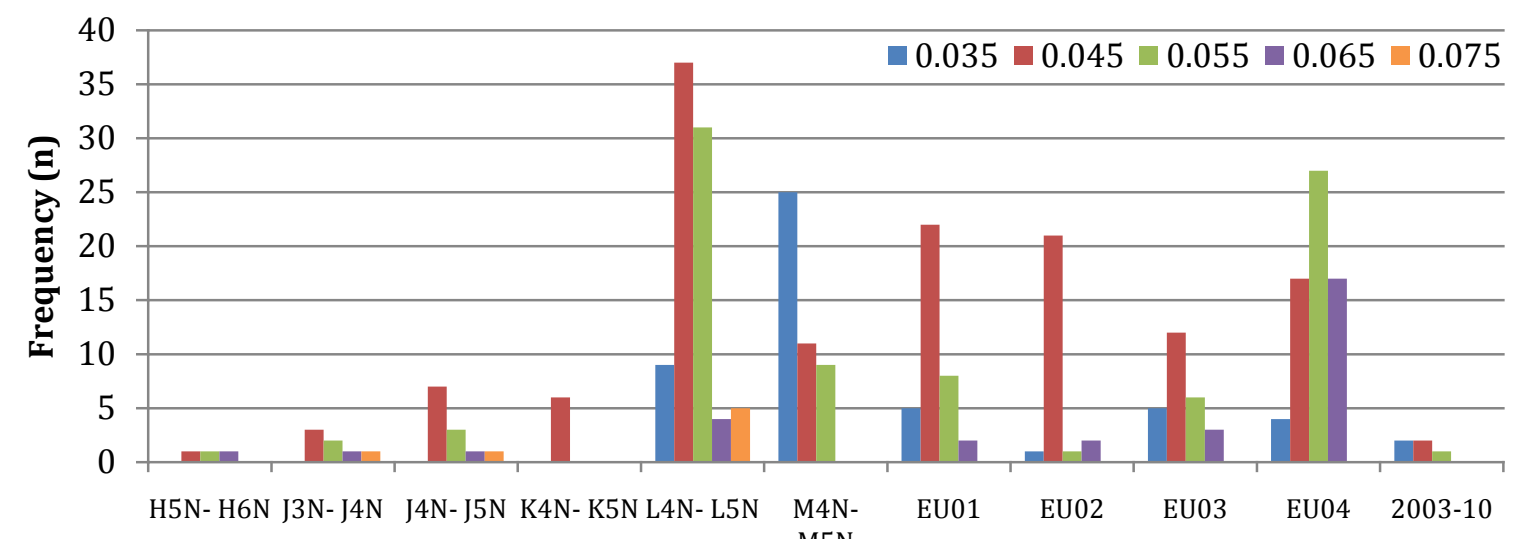

Excavation Units

FIGURE 60a. HBC-era window glass thickness across House 3 units, including 1969 and SAIP units, and the hearth feature (2003-10) (Chart by author, 2011).

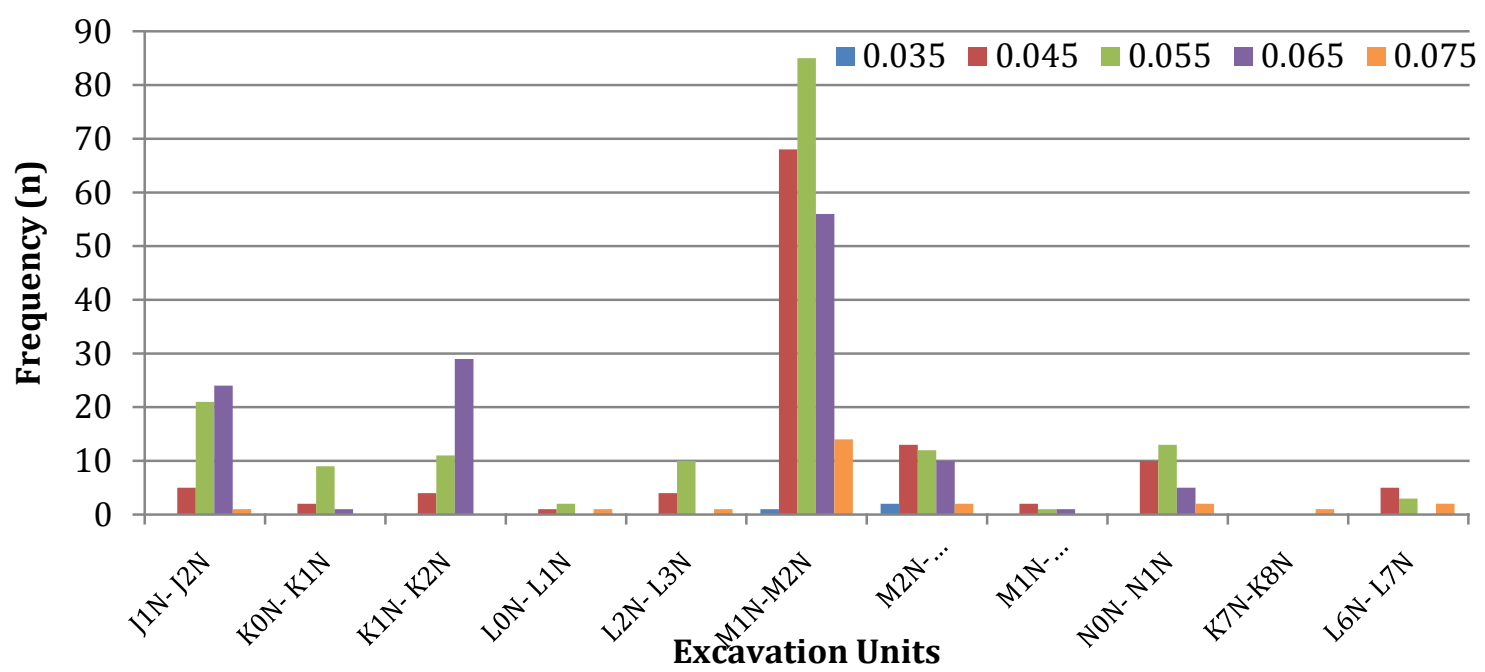

FIGURE 60b. HBC-era window glass thicknesses across southern and northern (K7N-K8N and L6N-L7N) study area units (Chart by author, 2011).

The window glass in the northern portion of the House 3 study area, including the original house site, contained larger window glass fragments. Obviously screening during the SAIP excavations recovered a greater percentage of sub-20mm fragments (Table 29). The northern 1969 assemblage included only 2 fragments smaller than $15 \mathrm{~mm}$; 30mm was 144 
the most represented fragment size (Table 30). The largest fragments 40mm+ mostly were recovered from the wood-lined pit. The southern units in the study area contained only five $40 \mathrm{~mm}$ (1.5 in.) fragments; the remaining 440 fragments ranged from $6 \mathrm{~mm}$ to $30 \mathrm{~mm}(0.25$ in. to $1.2 \mathrm{in.})$.

TABLE 29

HOUSE 3 WINDOW GLASS FRAGMENT SIZES

\begin{tabular}{lccccccccc}
\hline \hline & \multicolumn{1}{c}{ Size (mm) } & & & & \\
& 6 & 10 & 15 & 20 & 30 & 40 & 50 & $>50$ & Total \\
\hline Kardas (n) & 0 & 39 & 178 & 152 & 140 & 55 & 30 & 11 & 605 \\
SAIP (n) & 1 & 55 & 63 & 27 & 23 & 7 & 1 & 0 & 177 \\
\hline \hline
\end{tabular}

TABLE 30

HOUSE 3 WINDOW GLASS FRAGMENT SIZES COMPARISON FROM 1969

\begin{tabular}{lccccccccc}
\hline \hline & \multicolumn{1}{c}{ Size $(\mathrm{mm})$} & & & & \\
& 6 & 10 & 15 & 20 & 30 & 40 & 50 & $>50$ & Total \\
\hline Northern & 0 & 2 & 10 & 28 & 54 & 28 & 28 & 10 & 160 \\
Southern & 27 & 148 & 132 & 104 & 29 & 5 & 0 & 0 & 445 \\
\hline \hline
\end{tabular}

Square Nails. 1471 nails from the House 3 study area were analyzed. Tables 31 and 32 show a breakdown of the nail assemblage by manufacture-type and penny size. Wrought nails and indeterminate square nails were found across the entire study area. Some machine cut nails were present in the wood-lined pit and the house floor, but the primary concentration of machine cut nails was in the horse burials (Figure 61). The SAIP assemblage had a greater percentage of the indeterminate square nail than the 1969 assemblage. This is probably a sampling bias created by screening deposits that had been previously excavated and collecting the artifacts that were missed.

TABLE 31

HOUSE 3 STUDY AREA NAIL COUNTS

\begin{tabular}{lcccc}
\hline \hline & Total & Wrought & Machine Cut & Square \\
\hline Kardas 1969 & 1277 & 828 & 344 & 105 \\
SAIP 2003 & 194 & 93 & 20 & 81 \\
Total & 1471 & 921 & 364 & 186 \\
\hline \hline
\end{tabular}


TABLE 32

HOUSE 3 SQUARE NAIL FREQUENCIES BY TYPE AND PENNY SIZE

\begin{tabular}{|c|c|c|c|c|c|c|c|c|c|c|c|c|c|c|}
\hline Type & $2 \mathrm{~d}$ & $3 d$ & $4 d$ & $5 \mathrm{~d}$ & $6 \mathrm{~d}$ & $7 \mathrm{~d}$ & $8 \mathrm{~d}$ & $9 \mathrm{~d}$ & $10 \mathrm{~d}$ & $12 \mathrm{~d}$ & $16 \mathrm{~d}$ & $\begin{array}{l}20- \\
60 d \\
\end{array}$ & $\begin{array}{l}\text { Frag. } \\
\text { Nails }\end{array}$ & $\mathrm{N}$ \\
\hline Wrought & & & & & & & & & & & & & & \\
\hline $\begin{array}{l}\text { Nails } \\
\text { American Cut }\end{array}$ & 8 & 6 & 7 & 13 & 13 & 30 & 48 & 40 & 37 & 33 & 49 & 47 & 578 & $909 *$ \\
\hline $\begin{array}{l}\text { Nails } \\
\text { British Cut }\end{array}$ & 5 & 14 & 9 & 8 & 17 & 6 & 10 & 11 & 12 & 6 & & 2 & 113 & $213 *$ \\
\hline Nails & 1 & & 6 & 3 & 5 & 4 & 2 & 4 & 4 & 2 & & 2 & 18 & 51 \\
\hline Cut Nails & 3 & & & & & & & & & & & & 96 & 99 \\
\hline Square Nails & & & & & & & & & 1 & & & & 185 & 186 \\
\hline Totals & 14 & 20 & 19 & 32 & 42 & 40 & 65 & 69 & 55 & 46 & 52 & 54 & 951 & $1458 *$ \\
\hline
\end{tabular}

*10 complete wrought nails and 3 complete American cut nails could not be sized.

Excavation unit EU04 contained the highest quantity of wrought and machine cut nails (of the SAIP units) and it was the unit that fell outside the previously excavated areas of House 3 (Figure 61 and 62a). The highest peak of wrought nails is the wood lined pit (L4N-L5N). The second highest (J4N-J5N) is from the House 3 house floor deposit (Figure 62a). Seeing as the window glass thicknesses tracked closely between Kardas and SAIP assemblages, it seems likely that if not for the indeterminate square nails the SAIP wrought/machine cut ratio would have resembled the 1969 excavations.

The units in the south had nearly equal percentages of Wrought and Machine Cut nails, whereas House 3 had $~ 70 \%$ wrought (Kardas and SAIP) compared to $9.4 \%$ machine cut nails (Figures 62a-b). The only excavation unit where machine cut nails comprised the majority of the nail assemblage was in M1N-M2N, or Horse Burial No. 1/ trash pit. Overall, the horse burials in the southern vicinity have a larger relative frequency of machine cut nails to wrought nails. The northern vicinity (K6N-K8N, L6NL7N, and L8N-L9N) and the far southern vicinity (the 1968 E-W Trench), however, have a greater relative frequency of wrought nails when compared to machine cut nails. 


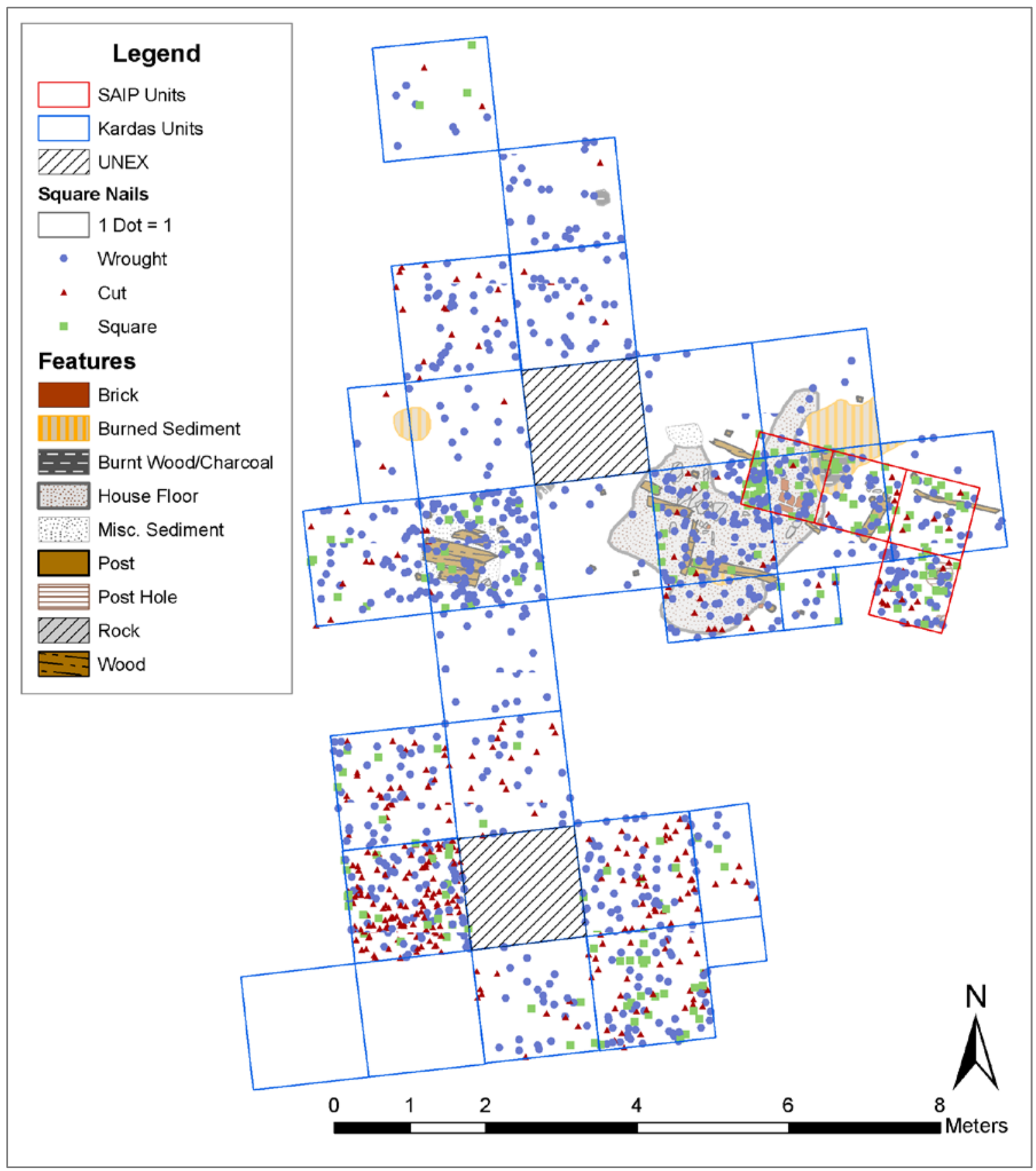

FIGURE 61. Distribution of square nail types in House 3 Study Area (Map by author, 2011) 


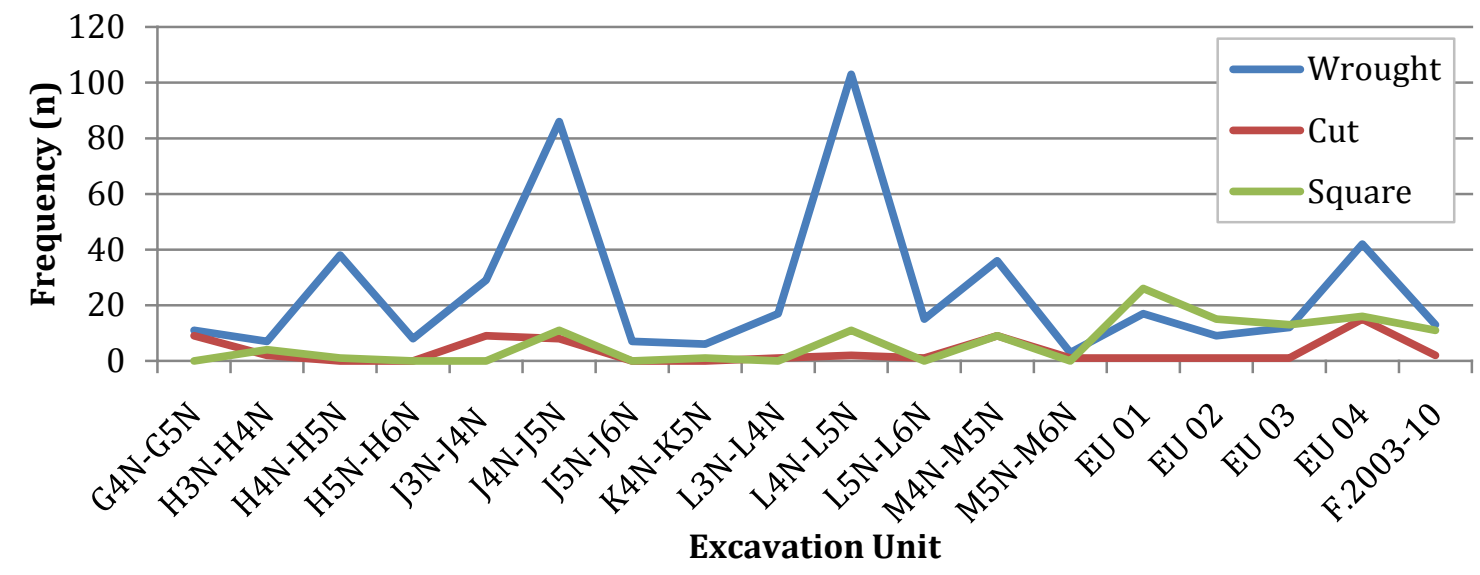

FIGURE 62a. The distribution of square nails manufacture types in the original 1969 House 3 and SAIP units (Chart by author, 2011).

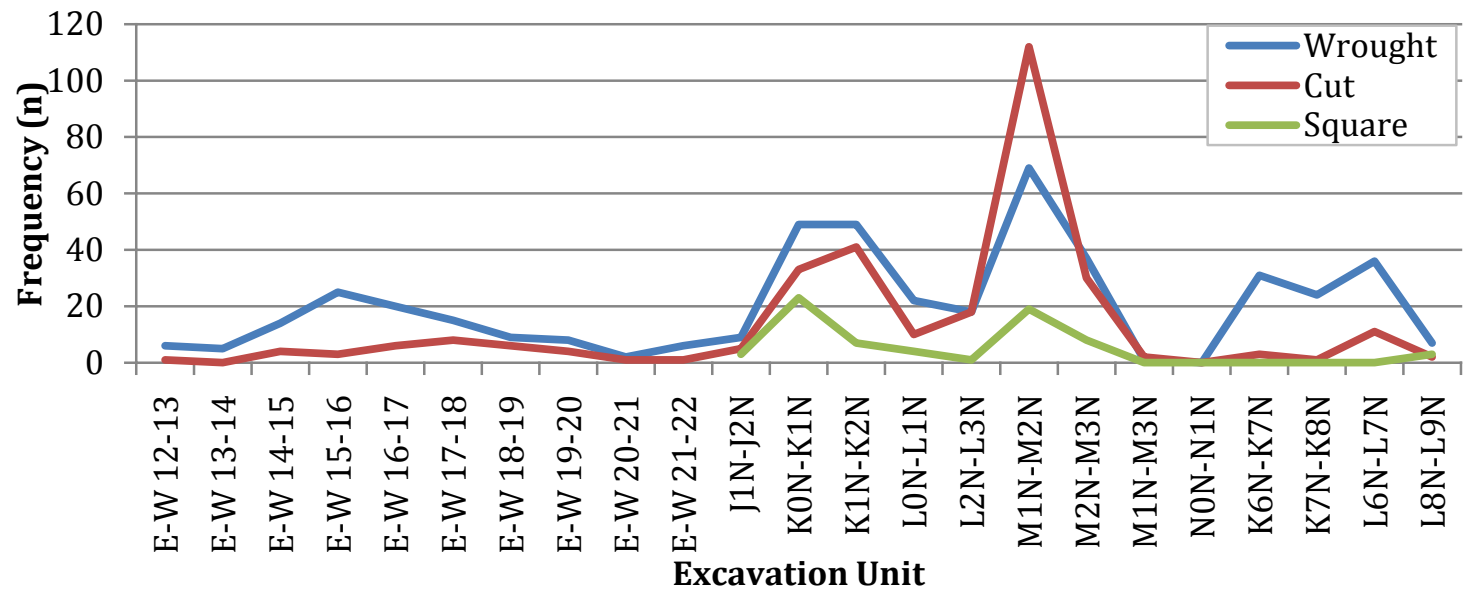

FIGURE 62b. The distribution of square nails manufacture types in the north and south vicinity units of the House 3 study area (Chart by author, 2011).

The nail condition ratios provide additional evidence that the House 3 deposit (including the northern study area units) is distinct from the structural remains deposited in and around the horse burial pits. The latter included a high quantity of fragmented nails, and among the complete wrought nails there were 40 unaltered, 68 pulled, and 53 clinched. This ratio (0.75:1.3:1) most closely approximates what Young (1994) expects for a secondary refuse deposit for a torn down structure (1:3:1). The presence of unaltered (not bent) nails may indicate a structure was nearby. On the other hand, the House 3 deposit and northern study area units included 124 unaltered nails, 42 pulled, 
and 35 clinched wrought nails. This is consistent with a structure's location, if the structure had deteriorated in place.

Hand wrought nails were the most common manufacture type (341 complete and 578 fragmentary) (Table 31 ). The complete nails range in size from $2 \mathrm{~d}$ to $60 \mathrm{~d}$ and most of the wrought nails are evenly distributed between general construction sizes (8d-10d) and heavy construction sizes (20d-60d). Over 400 wrought nails could be identified by style variety. The most commonly recovered nail variety was the rosette sharp (no. 1002, $\mathrm{n}=190$ ). The next most common nail varieties were: wrought clasp nails (no. 1001, $\mathrm{n}=85$ ); indeterminate rosette head nails ( $\mathrm{n}=60)$; and clench nails (no 1060, $\mathrm{n}=35$ ).

The rosette sharps present in the primary House 3 deposit, are mostly sizes used for general construction (8d-16d). Some rosette sharps used in heavy construction (20d$60 \mathrm{~d}, \mathrm{n}=23$ ) were found in the L-line, J-line, and H-line of units, near the edges of the house floor feature, as depicted in the student field notes (Figure 61). The wrought clasp nails (6d-20d) are less widely distributed across House 3, but are primarily located in the L-, J-, and H-lines of units. They were concentrated in units containing the gray clay floor in the east, and in the wood-lined pit area. The L-line may represent the nails that were pushed toward the wood pit during demolition or the location of a wall. The clench nails, which are usually associated with doors and siding, were not abundant around the House 3 deposit $(n=4)$; they were mostly located in the southern pits.

In the primary House 3 deposit, there were 34 complete machine cut nails and 21 fragments. Forty-four of these were identified by style variety. There were only five British machine cut (clasp) nails within House 3. All are complete and range in size from 4d-10d. They were found in EU 04, G4N-G5N (at the east end) and in M4N-M5N (wood 
lined pit at west end). Three of these are bent. The 31 American common machine cut nails (variety no. 2002) were evenly distributed across the House 3 site. Twenty-one were complete and ranged from $2 \mathrm{~d}$ to $12 \mathrm{~d}$, but most fall within the $6 \mathrm{~d}-9 \mathrm{~d}$ range. Only three specimens of the reverse crimp cut nails (variety no. 2004) were found in the House 3 deposit. The southern study area units contained a more diverse machine cut nail assemblage than the northern units, with 45 British Cut Clasp nails (2d-20d), 173 American common cut nails (3d-12d), 3 British rose cut nails (variety no. 2005), and an additional 89 unknown machine cut nails.

Hardware. Five architectural hardware objects were collected from the House 3 study area in 1969, including two wrought iron hinge pintles, one door hook, a wrought key escutcheon, and a cupreous key and socket cock (Figures 63a-b and 64a-b). The last object may not be explicitly structural; perhaps it is more suitable for a chest or box. The broken hinge pintle (cat. no. 3319) was found in the East-West Trench, 20-21' in 1968. The other hinge pintle and the door hook were found in M4N-M5N, one of the units containing the Wood Lined Pit. These artifacts could (potentially) have served as hardware for a cellar door. Finally the key escutcheon and key cock and socket were recovered above the gray clay sediment layer in $\mathrm{H} 3 \mathrm{~N}-\mathrm{H} 4 \mathrm{~N}$ and J3N-J4N, respectively.

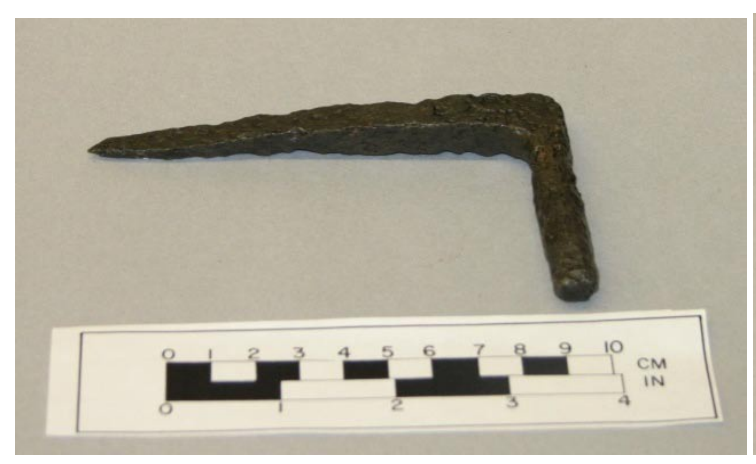

FIGURE 63a: Pintle hinge, Cat. no. 3611 (Photo by author, 2011).

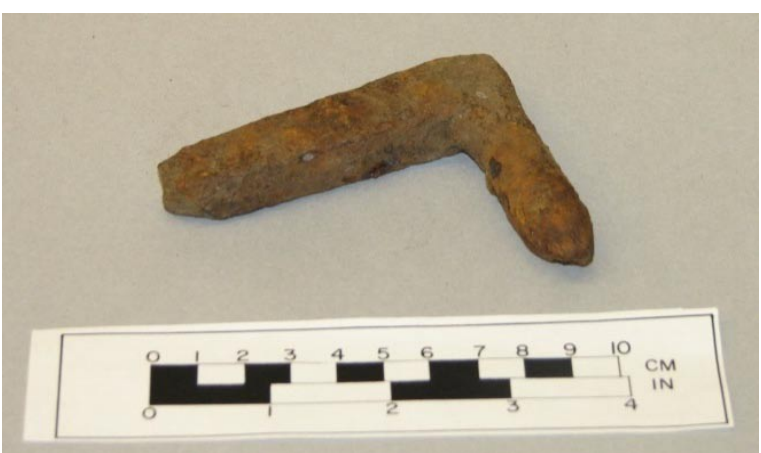

FIGURE 63b: Hinge pin[tle], Cat. no. 3319 (Photo by author, 2011). 


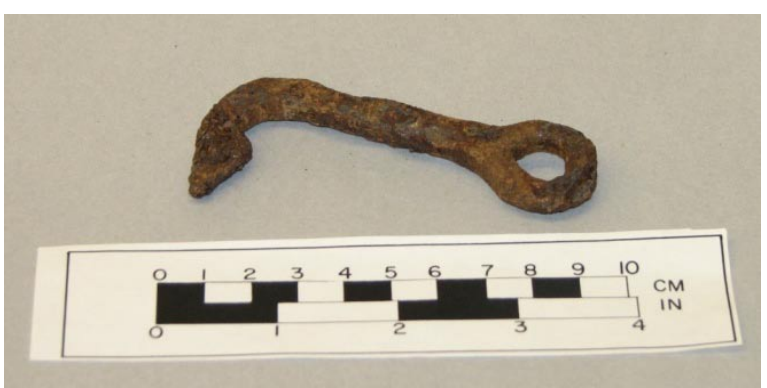

FIGURE 64a. Door hook, Cat. no. 3580 (Photo by author, 2011).

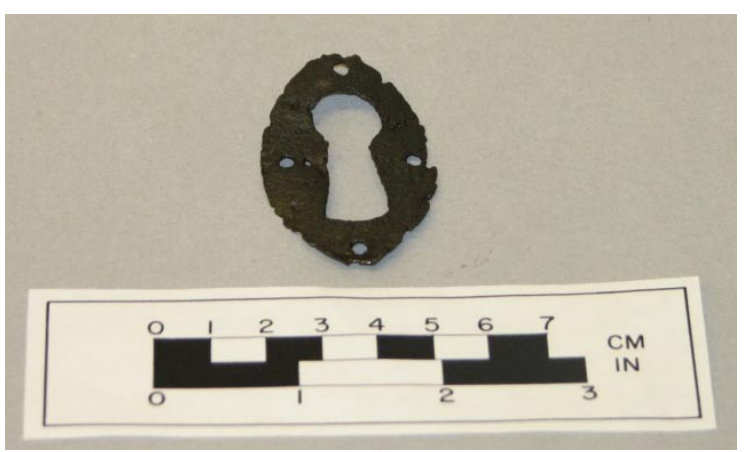

FIGURE 64b. Key escutcheon, Cat. no. 3544 (Photo by author, 2011).

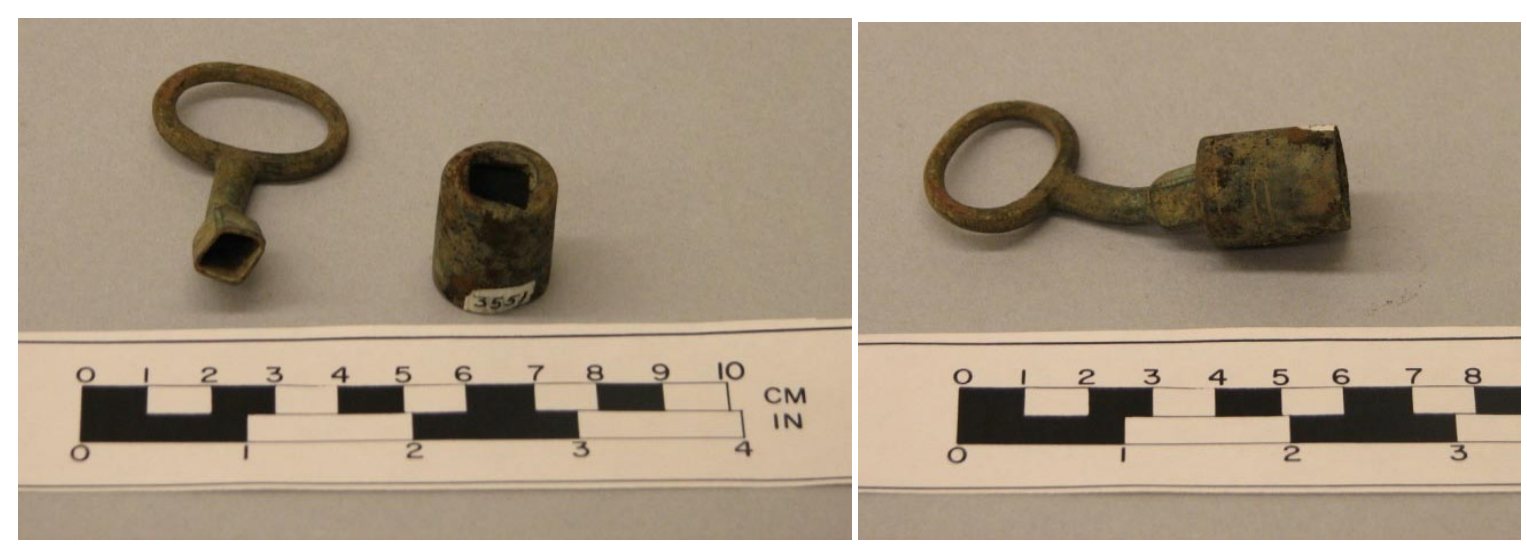

FIGURE 65. Key and socket cock, Cat. no. 3551. Cupreous socket has 3 incised lines around circumference (right) (Photos by author, 2011).

\section{Interpretation}

The presence of three pits in the vicinity of House 3 likely skewed the density and spatial analyses (Figure 66). If building materials had been swept into these existing pits after demolition, the precision of spatial data decreases. For example, there is no way to be certain whether the window glass collected from the wood-line pit came from a single window originally near the wood-lined pit, or from multiple walls.

The horse burials/trash pits in the southern half of the study area were beyond the structural limits of House 3. These burials are approximately $3 \mathrm{~m}$ (10 ft.) from the House 


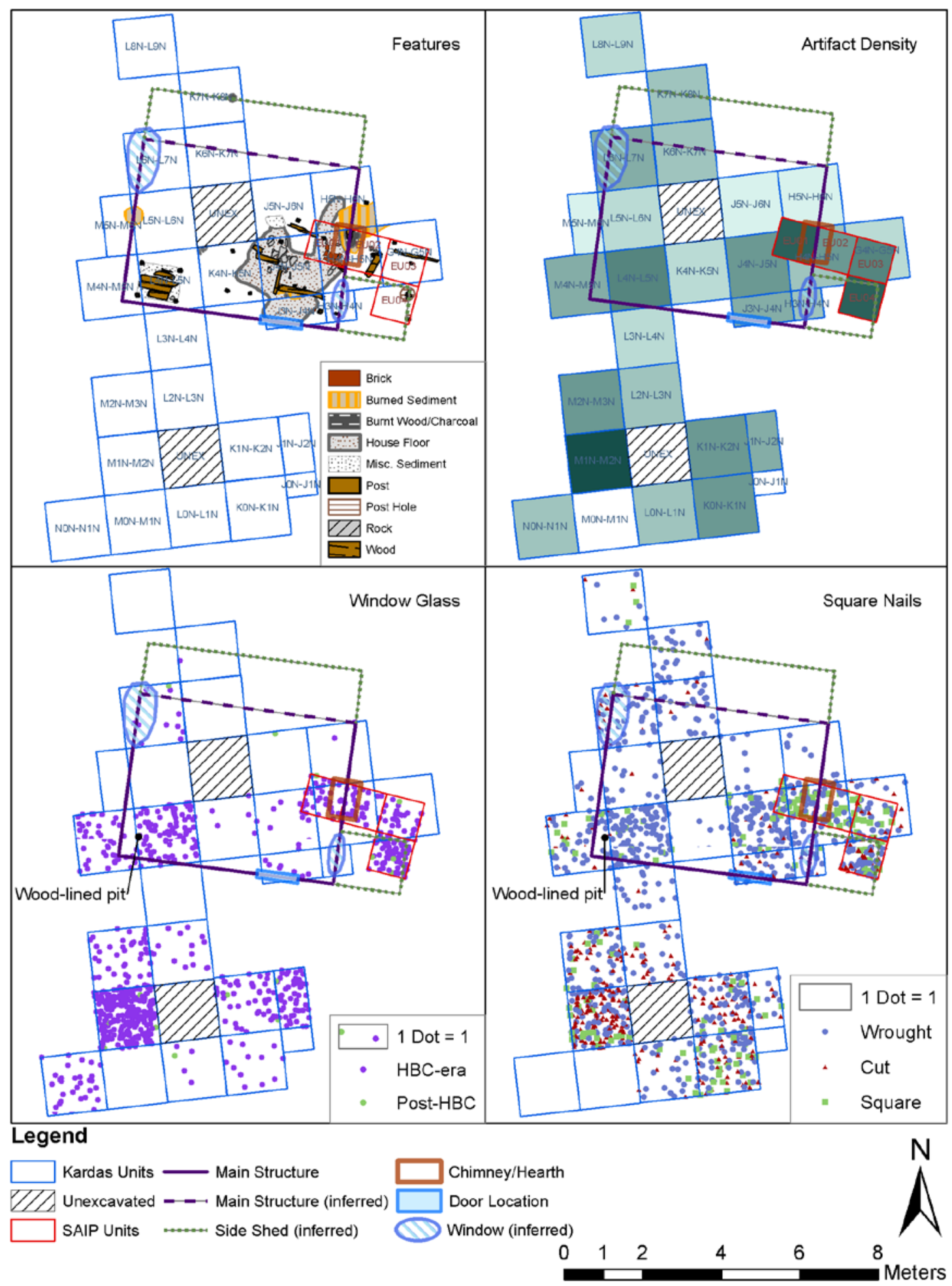

FIGURE 66. House 3 interpretation, showing features (upper left), artifact densities (upper right), window glass (lower left), and square nail distribution (lower right) (Map by author, 2011). 
3 floor, and the artifact assemblage differed from the assemblage collected around the structural features. The higher frequency of 0.055 -in. and 0.065 -in. thick window glass and machine cut nails found above and below the horse skeletons indicate the burial pits were related to later activities (Figure 58 and 62a,b). The nails recovered above and around the horse burials exhibit a higher frequency of pulled and clinched nails than unaltered nails, which is characteristic of a refuse deposit (Young 1994). These artifact attributes confirmed Kardas' (1970:77-78) hypothesis that the trash pit deposits above the horse burials were not directly associated with House 3 .

Sixteen excavation units from 1969 and 4 from 2003 were attributed to the footprint of House 3 (Table 33). Most of the features associated with House 3 were contained within a $3 \times 4.5 \mathrm{~m}(10 \times 15 \mathrm{ft}$.) section at the center of the study areaexcavations units that Kardas (1970) had identified as "House 3." Three units at the north end of the study area, and outside the primary feature concentration, (L6-L7, K6-K7, and K7-K8) were added to the limits of the structure based on similar artifact content and condition as units containing the house floor.

TABLE 33

HOUSE 3 ARTIFACT RECOVERY DATA

\begin{tabular}{lrrrr}
\hline \hline & \multicolumn{2}{c}{ Window Glass } & \multicolumn{2}{c}{ Square Nails } \\
& KARDAS & \multicolumn{1}{c}{ SAIP } & \multicolumn{1}{c}{ KARDAS } & \multicolumn{1}{c}{ SAIP } \\
& $1968-1969$ & \multicolumn{1}{c}{$2001-2003$} & \multicolumn{1}{c}{$1968-1969$} & $2001-2003$ \\
\hline Excavation Units $(\mathrm{n}$ and area) & $16\left(33.64 \mathrm{~m}^{2}\right)$ & $4\left(4 \mathrm{~m}^{2}\right)$ & $16\left(33.64 \mathrm{~m}^{2}\right)$ & $4\left(4 \mathrm{~m}^{2}\right)$ \\
Avg. frequency $\left(\mathrm{n} / \mathrm{m}^{2}\right)$ & 4.7 & 42.8 & 16.3 & 41.5 \\
Min $\left(\mathrm{n} / \mathrm{m}^{2}\right)$ & 0 & 26 & 3 & 24 \\
Max $\left(\mathrm{n} / \mathrm{m}^{2}\right)$ & 37 & 79 & 50 & 73 \\
Std Deviation $\left(\mathrm{n} / \mathrm{m}^{2}\right)$ & 9.90 & 24.87 & 14.26 & 22.93 \\
\hline \hline
\end{tabular}

Fourteen vertical "wood posts" scattered around the house floor appear too small

(less than the $15 \mathrm{~cm}$ [6 in.] minimum established for wall posts) and too irregularly arranged to represent the outer walls of the house (Thomas and Hibbs 1984:125-128). These may have been variously related to interior room divisions, furnishings, chimney 
supports, or even exterior supports used to prop up a decaying structure. Unfortunately, few recorded details about these posts were available, beyond the plan view excavation maps (Kardas 1970). Features that may have been associated with supportive wall posts, based on size and shape, include:

- A $50 \mathrm{~cm}$-wide (19.7 in.) circular burned sediment patch (Feat. H3-07, Units M5N-M6N and L5N-L6N)

- A $22 \mathrm{~cm}$-wide (8.7 in.) circular charcoal concentration (Feat. H3-08, Unit K7N-K8N)

- A $35 \mathrm{~cm}$-wide (13.8 in.) post hole and wood post (Feat. 2003-14, EU04)

- A $16 \mathrm{~cm}$-wide (6.3 in.) wood post (Feat. 2003-19, EU04)

None of these posts were aligned to form a single wall around the structural features, as is seen at House 1 and House 5. Without clearly identifiable foundation features to delineate wall locations, the structural outline was estimated and drawn to encompass the extent of the structural features (Table 26, Figure 66). The wall alignments were then adjusted based on artifact density fluctuations surrounding the structural features.

The east-west orientation of House 3 was inferred based on the same orientation of the wood-lined pit and some assorted planks (Figure 66a). The wood-lined pit was assumed to have been an interior storage area, like the storage pit or cellar feature identified at OP 14 (Thomas and Hibbs 1984:291). The inferred south wall framed the southern edges of the wood-lined pit (Feat. H3-01) and the compacted earthen floor (Feat. H3-02). Likewise, the west wall likely framed the west edge of the wood-lined pit and passed through Feat H3-07, a circular burned sediment feature that could be a charred posthole. Assuming the wood-lined pit is in the southwest corner, and Feat. H307 was a center post, the west wall length was estimated at approximately $4 \mathrm{~m}(13 \mathrm{ft}$.) 
long. The east wall alignment parallels the west wall (and the wood-lined pit) and was likely located beyond the east edge of the house floor sediment.

The north wall was inferred based on artifact density and the estimated (4m [13 ft.]) length of the west wall, which placed the northwest corner in unit L6N-L7N. There were few features of any kind north of the $5 \mathrm{~N}-6 \mathrm{~N}$ line of the study area, but the condition and density of the nail assemblage in the northern units (L6N-L7N, K6N-K7N, and K7N$\mathrm{K} 8 \mathrm{~N}$ ) resembled the properties of the original House 3 location assemblages, suggesting that the house walls extended to here (Figure 66, Table 34). The low density of nails in units $\mathrm{H} 5 \mathrm{~N}-\mathrm{H} 6 \mathrm{~N}$ though L5N-L6N and K4N-K5N, despite their association with the floor feature and being surrounded by areas of higher artifact density, may represent the interior of the structure.

TABLE 34

HOUSE 3 NAIL ASSEMBLAGE COMPARISON

\begin{tabular}{llll}
\hline \hline & Original & Northern & Southern \\
& House 3 & Vicinity & Vicinity \\
\hline Wrought & $88 \%$ & $85 \%$ & $53 \%$ \\
Machine Cut & $12 \%$ & $15 \%$ & $47 \%$ \\
Nail Condition ratio (unaltered: pulled: clinched) & $7: 3: 1$ & $1: 2: 4$ & $3: 3: 1$ \\
\hline
\end{tabular}

Note: Does not include SAIP excavation units.

Three extraneous possible-post features (H3-08, 2003-14, and 2003-19) are shown in Figure 66 as part of potential side sheds because of the density of artifacts between these features and the inferred walls of the main structure. The nail density around Feat. H3-08 in unit K7N-K8N (11/m²) was closer to the density of unit K6N-K7N $\left(14 / \mathrm{m}^{2}\right)$ than to that of unit L8N-L9N $\left(5 / \mathrm{m}^{2}\right)$. The distance between this shed wall and the

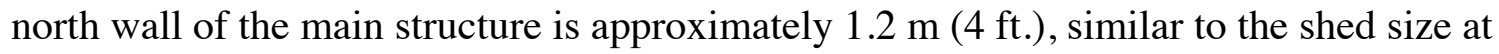
House 1. If a side shed was located on the east wall, it did not extend past the chimney. Features 2003-19 and 2003-14 were found only $50 \mathrm{~cm}$ (20 in.) apart, which is much 
closer than other wall post intervals seen at other houses. These posts may have served different functions. If one post (Feat. 2003-14) was part of a side-shed wall, the other (Feat. 2003-19) could have used to prop up House 3 near the end of its "life."

This proposed footprint of the mains structure appears to lack corner post features. There are at least two possible explanations to consider: 1) House 3 was larger than currently estimated and foundations features extend outside the excavated study area, 2) the 1930s CCC barracks building disrupted and removed evidence of the foundation features, or 3) the builders of House 3 employed a house construction method not previously observed at Fort Vancouver, but documented in other French-Canadian communities. This construction method is known as pièce sur pièce en queue d'aronde. The center wall post and wallboards are joined with the tenon-in-groove pièce sur pièce method, but corner posts were not used. Instead, the horizontal logs were hewn and joined with a dove-tail corner joint (Figure 16) (Hébert 2007:38-39). Based on the lack of foundation sills or trenches and the presence of a potential charred center-wall post feature in M5N-M6N, the archaeological patterning is consistent with a pièce sur pièce en queue d'aronde interpretation. This assumption is, admittedly, based on tenuous "absence of evidence" and requires testing in the unexcavated areas to determine whether additional foundation features exist.

The wrought nails assemblage included many rosette sharp nails (variety no. 1002) ranging in size from 8d-16d (Figure 67). These nails were used for "general construction" so it is difficult to identify specific functions. The average density of the nail assemblage is indicative of a non-nail-intensive construction method - the House 3 area contained an average of 21 nails $/ \mathrm{m}^{2}$, only $4 \%$ of which were large framing nails 
(20d-60d) (Table 33). But the presence or absence of a wood floor and the style and material of the roof could not be established based on the archaeological remains.

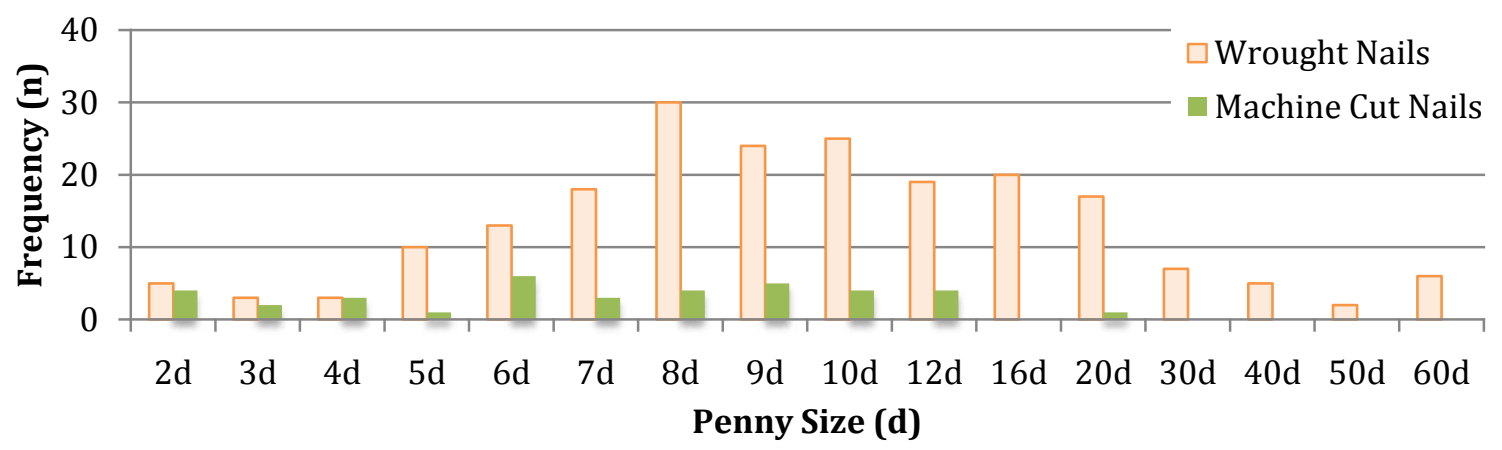

FIGURE 67. Penny size distribution of wrought and machine cut nails from the House 3 study area (Chart by author, 2011).

The majority of the architectural artifacts were recovered from the wood-lined pit, decreasing the precision of door and window placement. Hypothesized east wall windows are based primarily on the partially disturbed SAIP excavation units (EU01-EU03). No windows were inferred on the west wall, as a result. An unknown number of windows were located on the east gable façade, or built into the east wing. Beyond that, window location is unconfirmed (Figure 66). Very few nails associated with doors (variety no. 1060) were found at House 3. Door-related hardware was concentrated in the southeast corner of the house. The door was likely located on the south-facing main façade.

The hearth and chimney were likely centrally located on the exterior of the east wall, evidenced by the brick and rock concentrations (Feat. 2003-10) near to a bisque and charcoal concentration (Feat. 2002-12) on the east side of the study area. The widespread, low-density scatter of faunal remains did not aid in confirming the hearth location. The defining feature of House 3 during excavation was its brick and rock hearth remains, but the exterior of the chimney could have been constructed out of wood and clay, based on timbers strewn nearby, like those illustrated presented in Figures 20a and 21b. 
The window glass and nail evidence reflect a house that was built and potentially modified prior to the arrival of the U.S. Army in 1849 . The presence of 0.035 -in. thick window glass (15\% of the assemblage) in unit M4N-M5N (the wood-lined pit) suggests that some windowpanes were manufactured prior to 1830 . In conjunction with the dominance of 0.045 in.-thick window glass fragments, House 3 was likely built in the early 1830s (Figure 68).

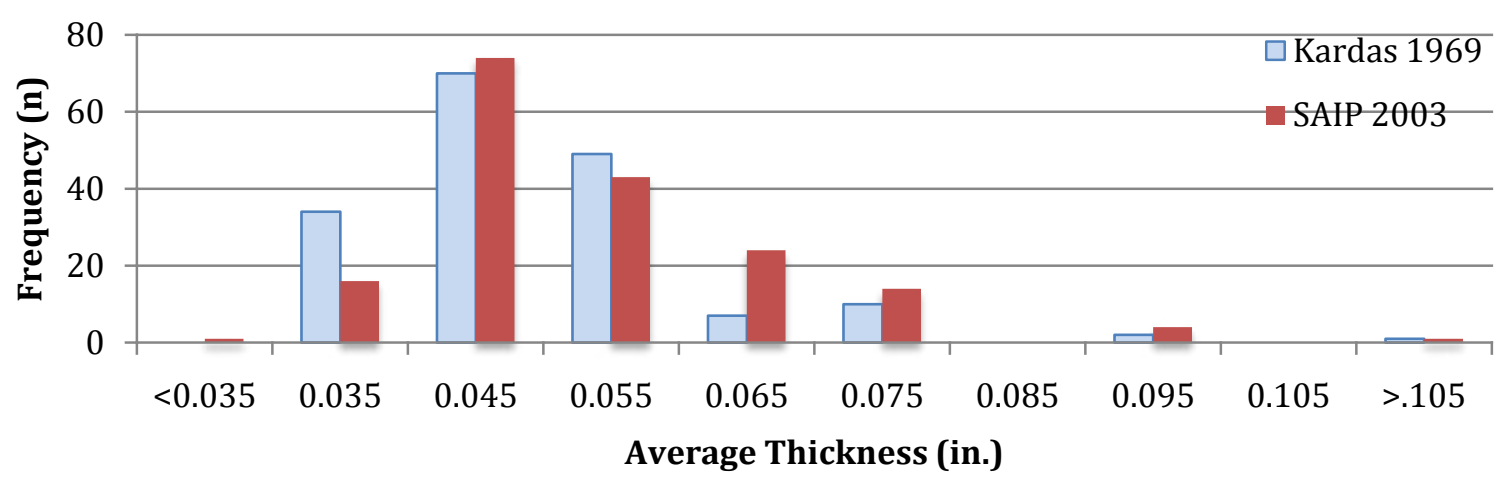

FIGURE 68. Comparison of House 3 window glass (including only the units associated directly with the structure's footprint) (Chart by author, 2011).

It seems that House 3 underwent minimal, or no, maintenance during the time when the U.S. Army was in Vancouver. Approximately $92 \%$ of the window glass in the House 3 study area dates to the when only the HBC employees resided in the Village (through 1850), and most of the $8 \%$ that is from the U.S. Army period of occupation predates 1860 . The square nails also reflect HBC-only activities - wrought nails outnumber machine cut nails $3: 1$. The secondary window glass thickness mode $(0.055$ in.) (Figure 68) might represent a second phase of construction or maintenance, but many fragments were collected from the wood-lined pit and cannot be used to pinpoint maintenance loci. Most likely, the structure was occupied by HBC personnel for its "life history," and was not reoccupied after its abandonment, at which point usable materials may have been salvaged before demolishing the structure. 
Kardas (1970:45) theorized that the structure was burned and then cleared to the ground. The wrought nails around the structural features exhibit a 7:3:1 (unaltered: pulled: clinched) condition ratio, confirming that House 3 was intentionally torn down. However, aside from the reported charred planks and burned sediment patches there is no clear evidence of a preceding fire, like either the widespread ash layer seen at House 4 or an abundance of annealed nails - characterized by a reddish patina caused by fire.

Charred wood could be related to the chimney, or stem from fire-treating posts to stave off rotting when buried in the ground.

The inferred "House 3" in Gibbs' illustration is located on the east side of the Village, in the back of the sketch. The distance and size of this structure in the illustration makes comparisons challenging. A center post is faintly visible on the west wall, a door is located on the south wall, the north wall has an adjoining shed, and no windows are visible (Figure 69). The archaeological patterns discussed above could have been produced by such a structure, but more archaeological data is required for confirmation. The chimney and windows inferred on the east wall could be obscured by the illustration's visual perspective.

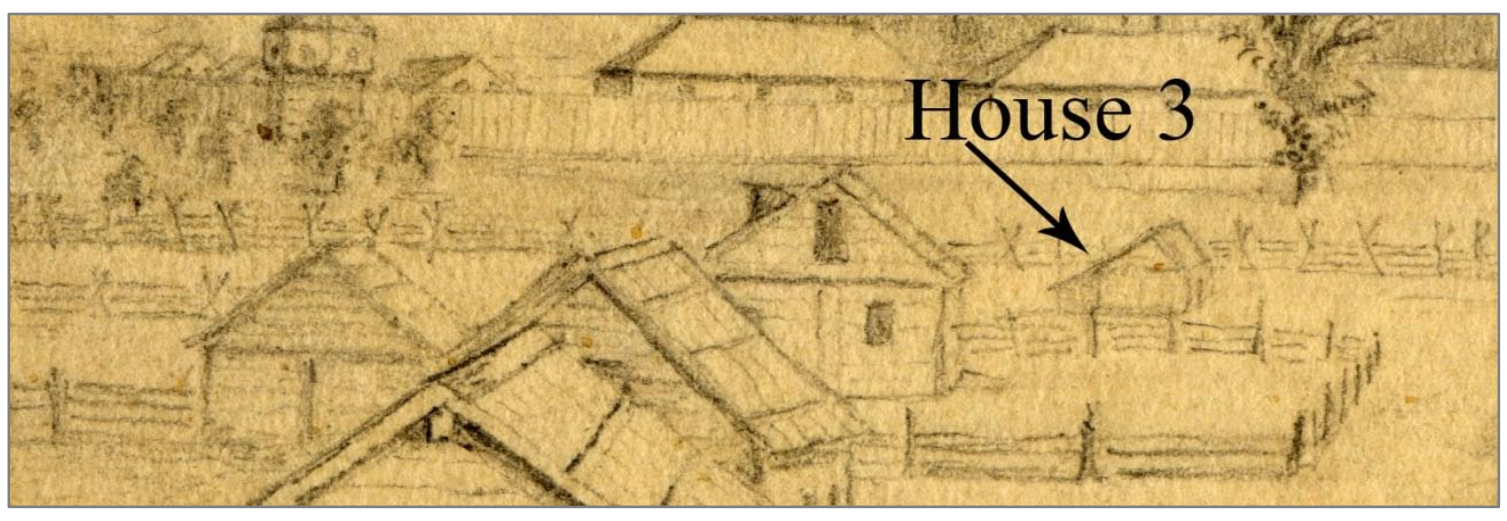

FIGURE 69. Detail of 1851 illustration by George Gibbs, showing "inferred" House 3 at right (Courtesy of Fort Vancouver National Historic Site.) 


\section{CHAPTER 9 \\ HOUSE 4}

House 4 is located at the southern end of the NPS-owned Village property. The excavation proceeded hastily at the end of the 1969 field season, and House 4 is less thoroughly documented than the other three houses. The remains of House 4 were only noticed in cross-section, after the "Diagonal Trench" cut through the compact dark gray sediment and ash layers (Kardas and Larrabee 1970: 61-62). The 0.75-m wide (2.5 ft.) diagonal trench started at the southern park service boundary and extended northwest for

$21 \mathrm{~m}$ (70 ft.). House 4 was observed around the $19 \mathrm{~m}$ (65 ft.) marker, in the north wall of the trench. Four trenches $(32 \mathrm{~S}, 33 \mathrm{~S}, 34 \mathrm{~S}$, and $35 \mathrm{~S})$ were extended from the diagonal trench, to follow the structural features. The House 4 site is characterized by "ash and charred wood, nails, and numerous artifacts" in a 2 x $2.5 \mathrm{~m}(6.5 \mathrm{x} 8 \mathrm{ft}$.) area (Kardas 1970:61). House 4 was not revisited during the SAIP excavations because a 1993 systematic survey that included shovel tests and remote sensing overlapped the study area and was considered sufficient for the purpose of surveying. The study area includes 13 excavation units, totaling an area of approximately $21 \mathrm{~m}^{2}$ and a volume of $7.2 \mathrm{~m}^{3}$.

\section{Stratification}

Kardas (1970) did not provide a profile sketch of House 4, so this stratigraphic picture comes from student field notes and the final report. A layer of fine white ash capped the House 4 deposit, approximately $5 \mathrm{~cm}$ ( 2 in.) below the surface. Below this, structural debris were found between 5 and $15 \mathrm{~cm}$ ( 2 and 6 in.) below the surface, imbedded in a coarser reddish ash with burned wood remnants (Kardas 1970:61). The majority of the artifacts came from below this ashy debris layer. A "thin patchy layer of 
clay" (Kardas 1970:61) underlay the artifacts; profile sketches from student field notebooks show this "gray clay" at an initial depth of 30-40 cm (12-16 in.) below the sod and extending another 4-5 cm (1.5-2 in.), otherwise no mention of its depth is made. The deepest excavations reached $45-50 \mathrm{cmbs}$ (18-20 in.). The A Horizon matrix was a brown silty loam. The mottled orange and brown B Horizon matrix had no artifacts.

\section{Features}

The House 4 plan view only shows a cluster of stones in an area of "gray clay" (Kardas 1970:65). The reported layer of wood shingles and burnt planks above the artifacts, were not drawn or photographed for the final report. The other structural features discussed below come from student field notes (Table 35, Figure 70).

TABLE 35

FORMAL CHARACTERISTICS OF HOUSE 4 STRUCTURAL FEATURES

\begin{tabular}{|c|c|c|c|c|c|}
\hline No. & Type & $\begin{array}{c}\text { Max. Diameter/ } \\
\text { Length }(\mathrm{cm})\end{array}$ & $\begin{array}{l}\text { Width } \\
\text { (cm) }\end{array}$ & $\begin{array}{l}\text { Depth } \\
\text { (cmbs) }\end{array}$ & Location \\
\hline $\mathrm{H} 4-01$ & House Floor & 243 & $\sim 200$ & $25-30$ & $\begin{array}{l}\text { DT 60-70', 33S 0-5', } \\
34 \mathrm{~S} 0-5^{\prime}, 35 \mathrm{~S}\end{array}$ \\
\hline $\mathrm{H} 4-02$ & Rock Cluster & 120 & $\sim 30$ & & $34 \mathrm{~S} 0-5,35 \mathrm{~S}$ \\
\hline H4-03a & Hearth & 45 & 5 & 23 & $32 \mathrm{~S} 0-5$ \\
\hline $\mathrm{H} 4-03 \mathrm{~b}$ & Charcoal \& Bisque & 20 & 10 & 23 & $33 \mathrm{~S} 0-5$ \\
\hline H4-04 & Ash and Debris & $\sim 245$ & $\sim 200$ & 15 & All \\
\hline $\mathrm{H} 4-05$ & Wood Cluster & 90 & 30 & $15-25$ & DT 60-70' \\
\hline
\end{tabular}

A patchy thin lens of gray clay was interpreted as the house floor (Feature H4$01)$. It covers an area of approximately $2 \times 2.5 \mathrm{~m}(6.5 \times 8 \mathrm{ft}$. $)$ and is below the structural debris, artifacts, and the rock cluster (aka "stone hearth"). The rock cluster (Feature H402) is located in the southeast corner of the house floor. Kardas (1970:61) described these rocks as being "fitted together without mortar" and set above the house floor.

The reddish ash layer with burnt planks and wood shingles may very well be what remained of the roof and superstructure, as it seems to have covered the entire house floor 
(Kardas 1970:61). No measurements are available for the planks or shingles, nor is it clear whether any nails potentially embedded in the wood were removed and collected, or left in the field.

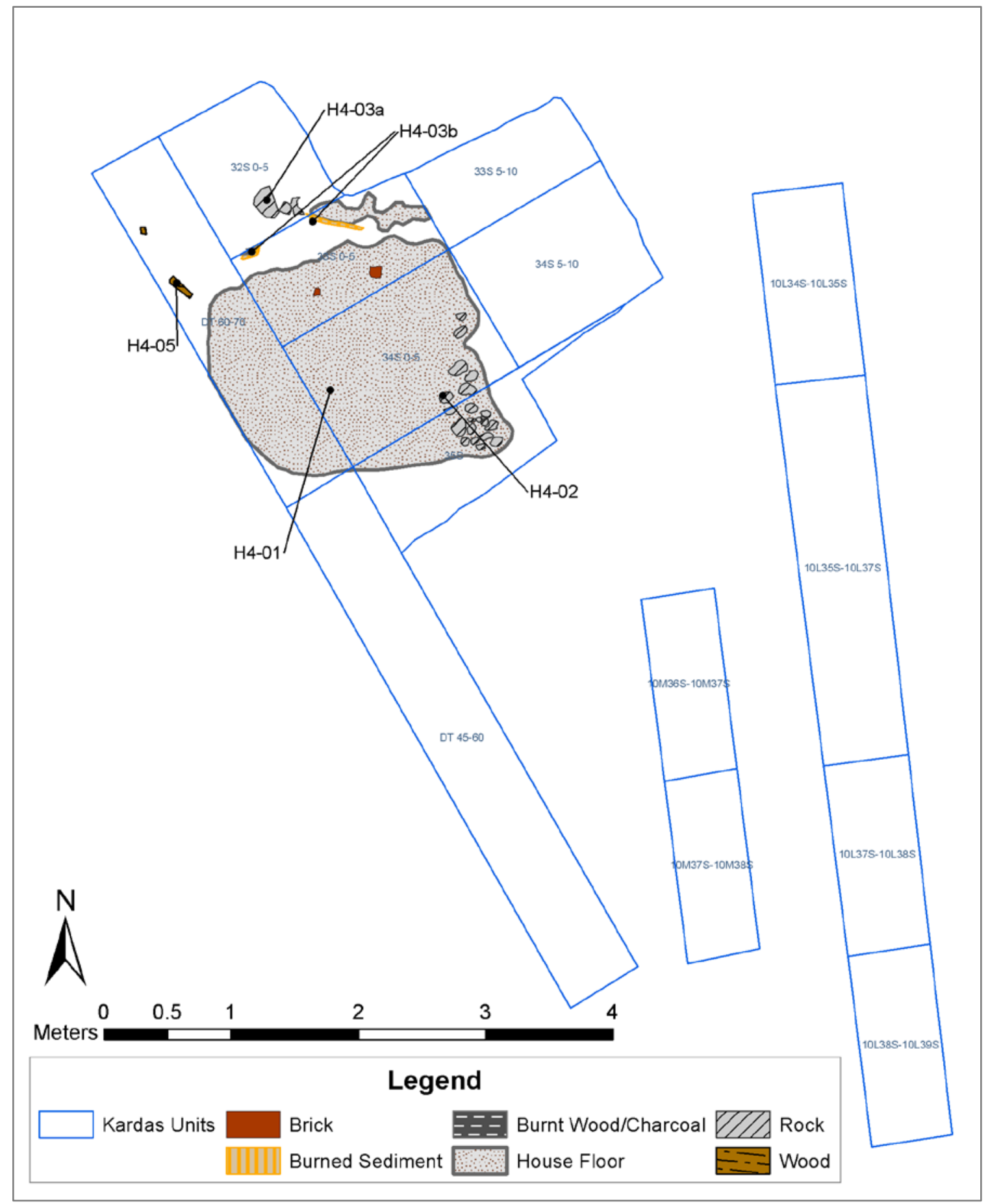

FIGURE 70. House 4 Study Area structural features (Map by author, 2011). 
A photograph of House 4 after excavation (Kardas 1970:66) shows the house floor and the rock cluster at the upper left corner. This photograph (Figure 71) also shows two or three larger rocks (lower right) beyond the north side of the house floor overlapping the boundary between units $32 \mathrm{~s}$ and $33 \mathrm{~s} 0-5$. These rocks are located near patches of coal, charcoal and bisque, according to the student field notes. This area (H403a, b) seems more likely to be hearth-related than the rock cluster that was associated with a dense cluster of square and wire nails.

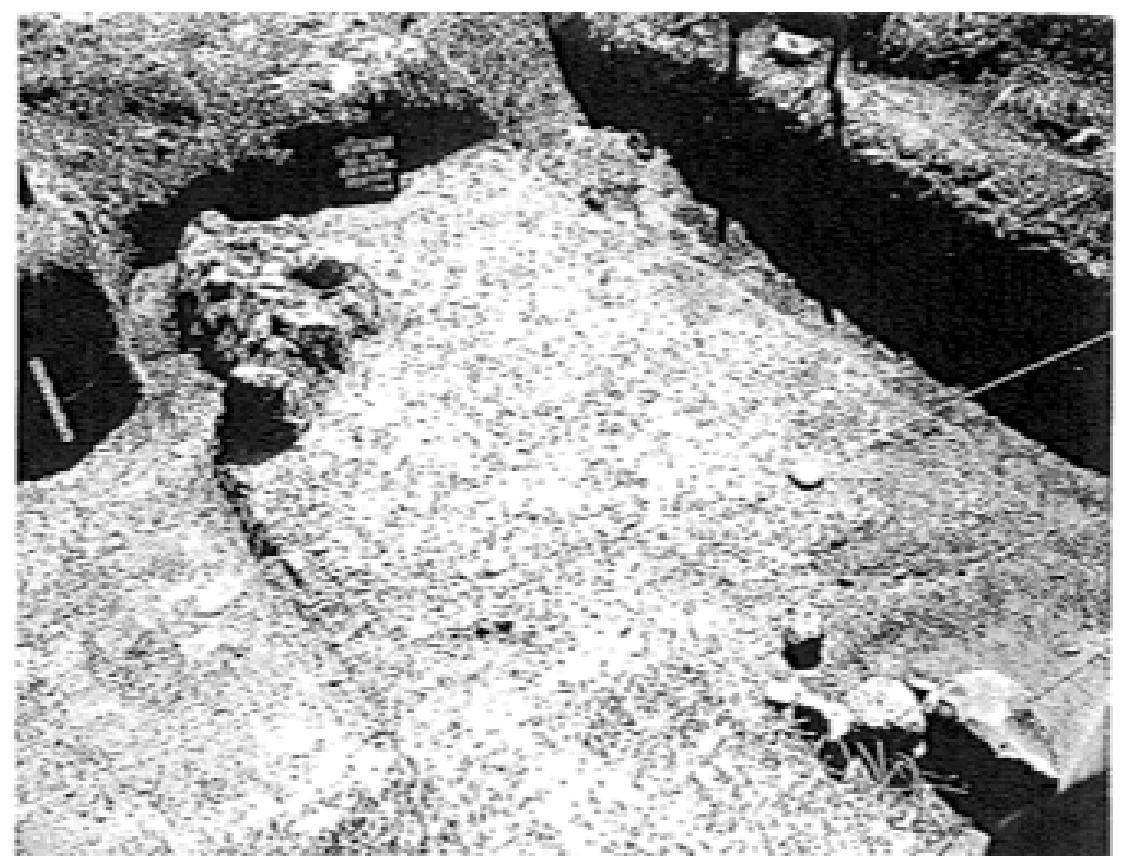

FIGURE 71: House 4 after excavation, showing clay floor and feature H4-02 in the center and H4-03 in the lower right, view to the southeast (Kardas 1970:66).

Three pieces of wood were found at three different depths in the Diagonal Trench 60-70'. These were found prior to the identification of House 4 and not noted in the final report. At $15 \mathrm{cmbs}$ (6 in.) (after initial bulldozing), a piece of wood $20 \times 5 \times 0.9 \mathrm{~cm}(8 \times 2$ x $3 / 8$ in.) with nails was observed at approximately $66-\mathrm{ft}$. marker in the DT, and less than $30 \mathrm{~cm}$ (1 ft.) from the west wall of the trench. At $20 \mathrm{cmbs}(8 \mathrm{in}$.$) another fragment was$ noted $60 \mathrm{~cm}$ ( $2 \mathrm{ft}$.) north of the previous piece (at the 68 -ft. mark), and the same distance 
from the west wall of the trench. The wood fragment was removed at approximately $23 \mathrm{cmbs}$ (9 in.). The third piece of wood was not illustrated; found at $25 \mathrm{cmbs}$ (10 in.), somewhere between the $67-\mathrm{ft}$. and 65 -ft. marks. All are located at elevations above the house floor, and possibly beyond the north edge of the ash deposits. No mention is made of the nail types associated with the first wood piece, so it is not clear whether these are associated with the HBC structure (wrought nails) or later construction (machine cut or wire nails).

\section{Architectural Artifacts}

Most artifacts were found beneath the reddish ash and burnt wood plank layer (Kardas 1970:61). The majority of structural artifacts were recovered from units containing the dark gray sediment, although segment of the Diagonal Trench (DT 45-60) also contained a high density of artifacts (Figure 72) (Kardas 1970:23). A door hinge pin, a latch plate, 385 square nails, and 92 window glass fragments were collected from the House 4 study area (Table 36).

TABLE 36 HOUSE 4 ARTIFACT COUNTS PER UNIT

\begin{tabular}{|c|c|c|c|c|c|}
\hline Unit & Window Glass & Square Nails & Bricks & Total & $\overline{\left(n / m^{2}\right)}$ \\
\hline Diagonal Trench 45-60 & 9 & 81 & & 90 & 31.9 \\
\hline Diagonal Trench 53-55 & 1 & 3 & & 4 & 10.8 \\
\hline Diagonal Trench 60-70 & 1 & 5 & & 6 & 3.2 \\
\hline $32 \mathrm{~S}$ Trench $0-5$ & 3 & 15 & & 18 & 17.6 \\
\hline $33 \mathrm{~S}$ Trench $0-5$ & 16 & 104 & & 120 & 117.6 \\
\hline $33 \mathrm{~S}$ Trench 5-10 & 7 & 38 & & 45 & 44.1 \\
\hline $34 \mathrm{~S}$ Trench $0-5$ & 13 & 83 & $\begin{array}{l}\text { No } \\
\text { Prol }\end{array}$ & 96 & 60.8 \\
\hline 34 S Trench 5-10 & 4 & 25 & Bricks & 29 & 18.4 \\
\hline 34 S Trench 1' S Ext. & 10 & 18 & Conected & 28 & 86.2 \\
\hline $35 \mathrm{~S}$ Trench & 9 & 12 & & 21 & 18.1 \\
\hline 10M36S-10M37S & 4 & 48 & & 52 & 44.8 \\
\hline 10L34S-10L35S & 2 & 27 & & 30 & 25.9 \\
\hline 10L36S-10L37S & 11 & 39 & & 51 & 21.9 \\
\hline $10 \mathrm{~L} 38 \mathrm{~S}$ & 2 & 0 & & 2 & 1.7 \\
\hline TOTAL & 92 & 385 & 0 & $477^{*}$ & (avg) 35.9 \\
\hline
\end{tabular}

*Does not include the 2 architecture hardware 


\section{House 4 Study Area}
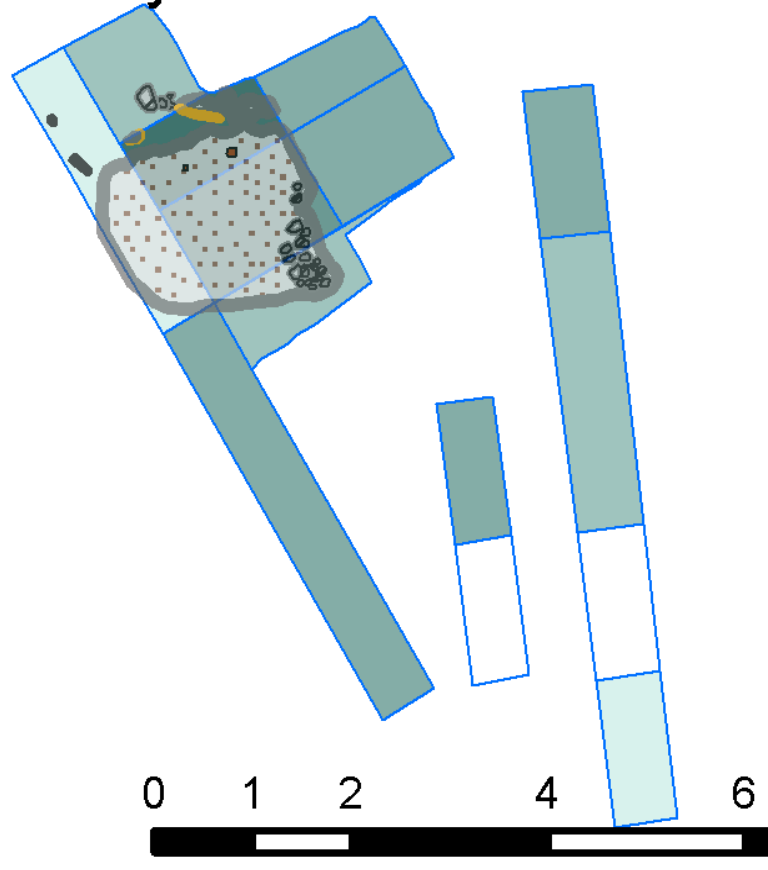

6

8

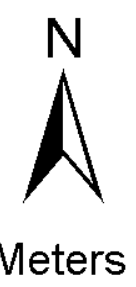

\section{Artifact Density Legend}

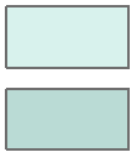

$0.10-4.99$

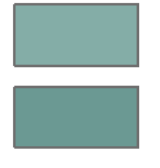

$25.00-49.99$

$100.00-149.99$

$5.00-9.99$

$50.00-74.99$

$10.00-24.99$

$75.00-99.99$

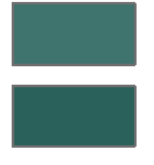

$150.00-199.99$

$200.00+$

FIGURE 72. Artifact densities for House 4 study area (Mullaley 2011).

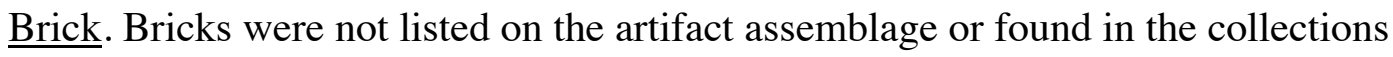

for House 4, one sketch map of unit 33s 0-5 at $23 \mathrm{cmbs}$ (9 in.) in the student field

journals depicts two bricks not discussed in the final report. The proximity to the bisque

features suggests that these were associated with a hearth location in the north portion of the house.

Window Glass. With 92 fragments of window glass, House 4 had three times as many window glass fragments as House 1 (1968), but far fewer than House 2 or 3. Only four fragments were smaller than $20 \mathrm{~mm}$ (Table 37). The window glass thicknesses 
ranged from $0.92 \mathrm{~mm}(0.036 \mathrm{in}$.) to $3.26 \mathrm{~mm}(0.128 \mathrm{in}$.). The House 4 study area had a bimodal thickness distribution. The primary window glass thickness mode for the entire House 4 study area is 0.085 in., and the secondary mode is 0.055 in. (Figure 73).

TABLE 37

HOUSE 4 WINDOW GLASS FRAGMENT SIZES

\begin{tabular}{cccccccccc}
\hline \hline & \multicolumn{9}{c}{ Size $(\mathrm{mm})$} \\
& 6 & 10 & 15 & 20 & 30 & 40 & 50 & $>50$ & Total \\
\hline Kardas (n) & 0 & 0 & 4 & 10 & 42 & 19 & 11 & 6 & 92 \\
\hline \hline
\end{tabular}

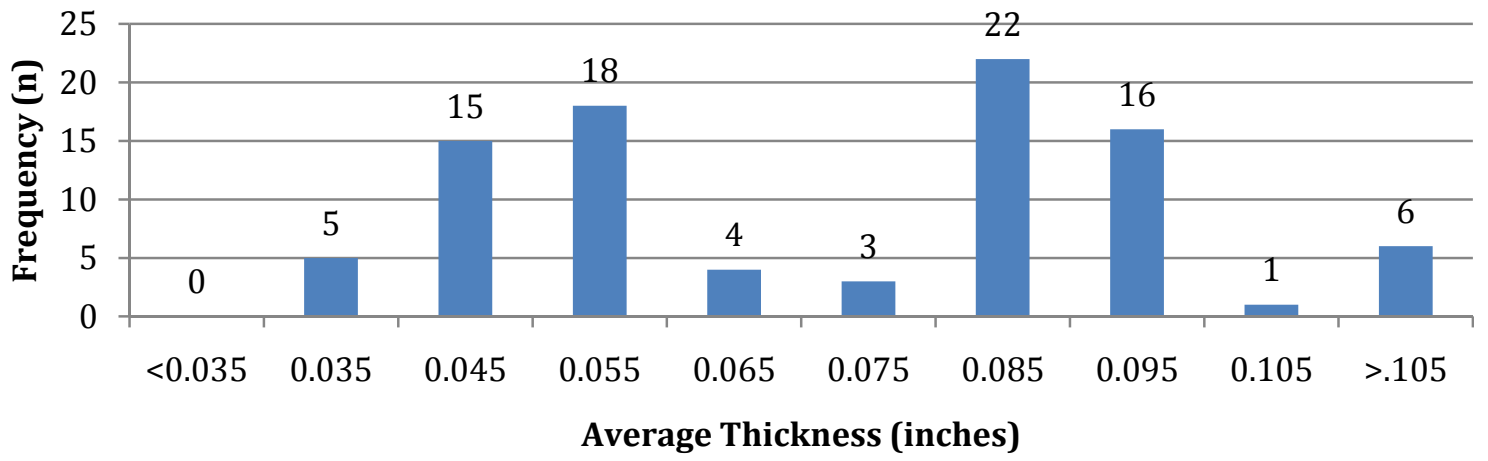

FIGURE 73: House 4 window glass thickness distribution

The primary mode ( 0.085 in.) technically dates between 1855 and 1880 , but for the most part glass of this thickness was imported and used by the U.S. Army, not the HBC. Within full the study area, $70 \%$ of the post-HBC era window glass (1860-1900) was concentrated in the southern and eastern units although a few of these later fragments were collected from the eastern edge of the house floor. The window glass associated with the $\mathrm{HBC}$ occupation (0.035-0.065 in.) is found predominately in the northern and western units, around the House 4 features (Figure 74). Although there is some early (pre-1830s) window glass, the House 4 feature area is equally dominated by 0.055 in. $(n=15)$ and 0.045 in. $(n=14)$ window glass (Figure 75$)$. No unit had more than 4 fragments of any thickness interval. 


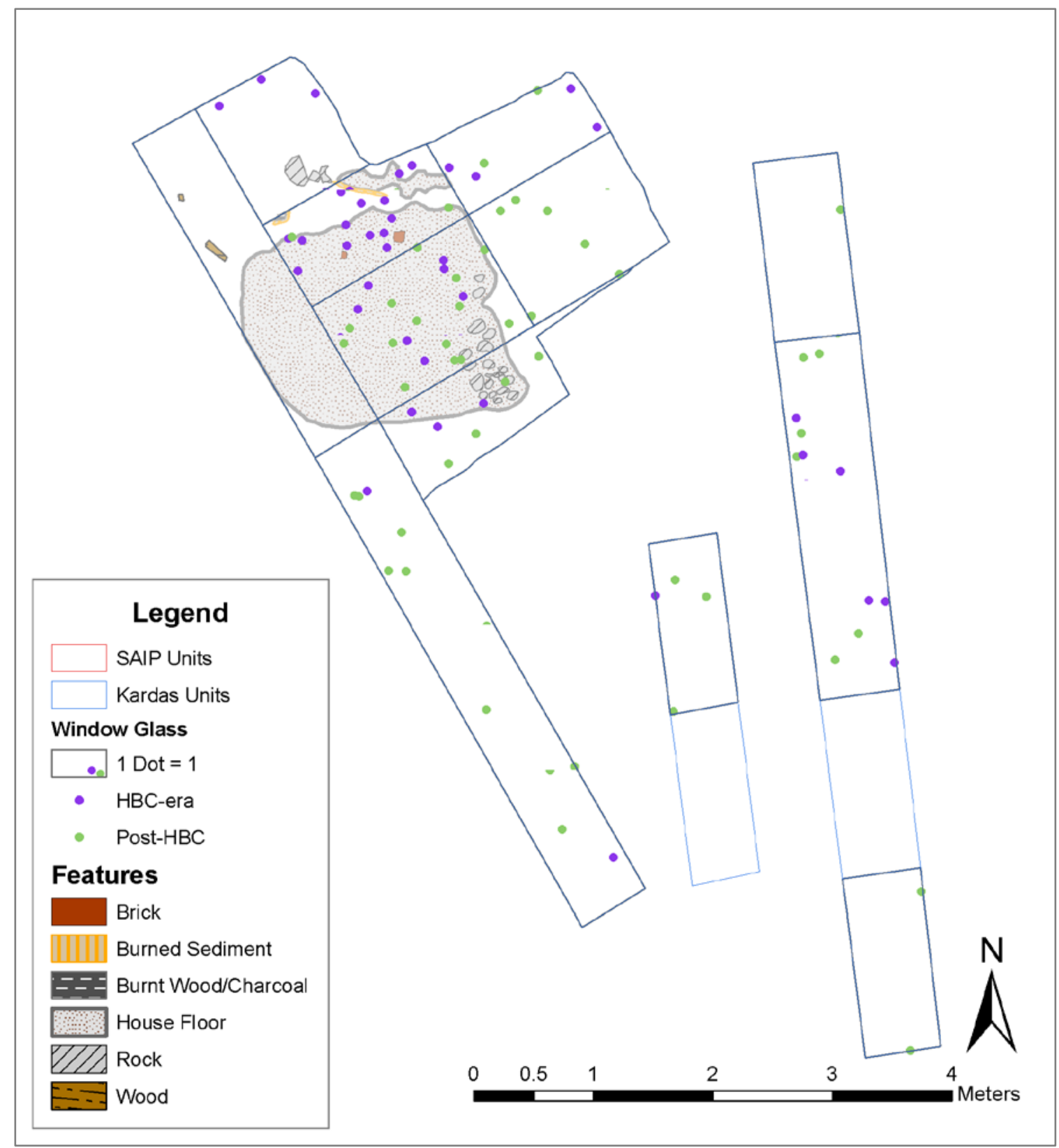

FIGURE 74. Window glass distribution in House 4 Study Area (Map by author, 2011) 


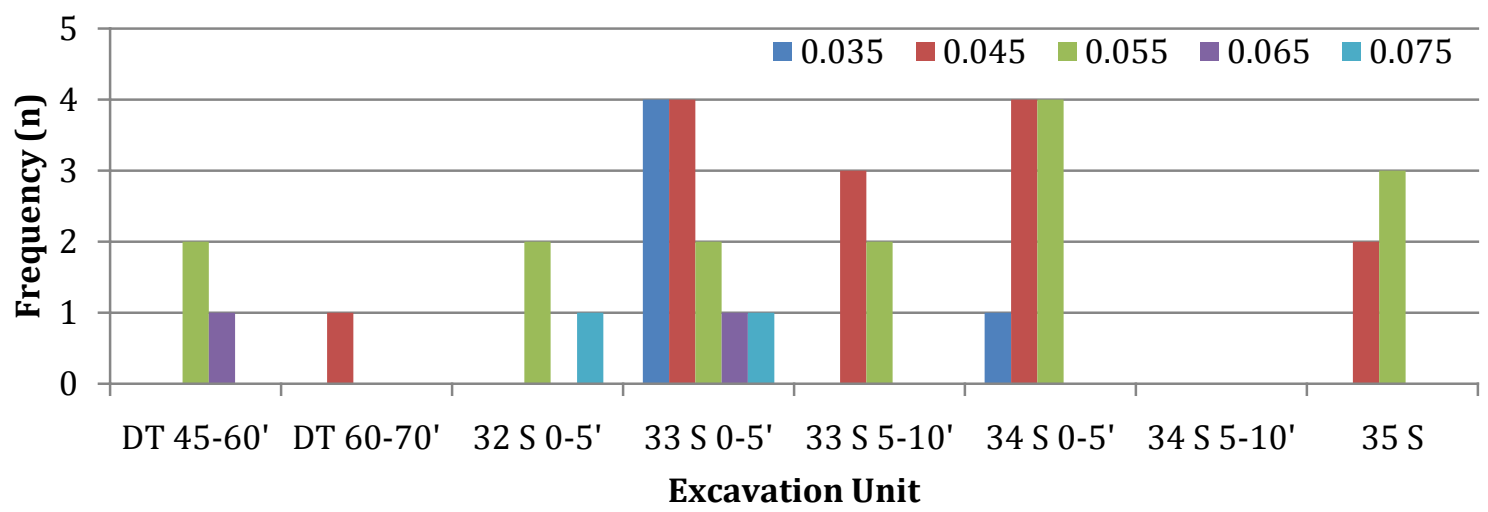

FIGURE 75. Spatial distribution of HBC-era window glass (divided by thickness intervals) in the original House 4 units (vicinity study area units excluded) (Chart by author, 2011).

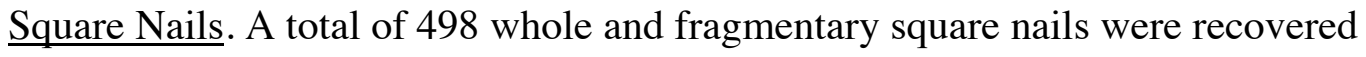
from the House 4 study area. The manufacturing technology of 478 (95.9\%) nails could be determined. Wrought nails outnumber machine cut nails nearly 3:1 (Table 37). The nails were cataloged according to broad excavation depths ("2-18 in.” or "0-20 in.”) so no vertical provenience variation could be attributed to the nails. Nearly two-thirds of the assemblage was fragmentary, but analysts were able to identify $30.8 \%(n=104)$ of the wrought nails and $65.9 \%(n=93)$ of the machine cut nails by their FOVA-style classification (Tables 38 and 39).

TABLE 38

HOUSE 4 STUDY AREA NAIL COUNTS

\begin{tabular}{lcccc}
\hline \hline & Total & Wrought & Machine Cut & Square \\
\hline 1969 Totals & 498 & 337 & 141 & 20 \\
Complete & 196 & 132 & 64 & 0 \\
Fragmentary & 302 & 205 & 77 & 20 \\
Style Identified & 197 & 104 & 93 & N/A \\
\hline
\end{tabular}

Wrought nails were by far the most abundant nail type (67\% of House 4 nail assemblage). Present across the study area, wrought nails were most highly concentrated around the house floor feature; unit $33 \mathrm{~S}$ Trench $0-5^{\prime}$ ' had the greatest wrought nail density (Figure 76). Thirteen wrought nail style varieties were identified, but the majority of the 
typed nails were divided between four styles: wrought clasp nail (no. 1001; n=18), rosette sharp (no. 1002; n=42), diamond-head spikes (no. 1014; n=10), and clench nail (no.

$1060 ; n=19)$. Similar to the House 3 study area, the clasp nails were few $(n=4)$ adjacent to the structural features, but relatively abundant $(n=14)$ in the eastern study units, $3 \mathrm{~m}$ (10ft.) from the house floor. The rest of these nail varieties were distributed between the units containing the house floor. Variety no. 1014 is one of six large nail/spike styles collected from around the house floor. The majority of complete wrought nails were allocated for heavy construction $(20 \mathrm{~d}-60 \mathrm{~d}, \mathrm{n}=35)$ and general construction (8d-10d, $\mathrm{n}=68$ ), with few related finishing trim or roofing ( $2 \mathrm{~d}-7 \mathrm{~d})$. Of the 132 complete wrought nails, 61 are unaltered (not bent), 56 are pulled, and 19 are clinched.

TABLE 39

HOUSE 4 SQUARE NAIL FREQUENCIES BY TYPE AND PENNY SIZE

\begin{tabular}{|c|c|c|c|c|c|c|c|c|c|c|c|c|c|c|}
\hline Type & $2 \mathrm{~d}$ & $3 d$ & $4 d$ & $5 d$ & $6 \mathrm{~d}$ & $7 \mathrm{~d}$ & $8 \mathrm{~d}$ & $9 \mathrm{~d}$ & $10 \mathrm{~d}$ & $12 \mathrm{~d}$ & $16 \mathrm{~d}$ & $\begin{array}{l}20- \\
60 \mathrm{~d} \\
\end{array}$ & $\begin{array}{l}\text { Frag. } \\
\text { Nails }\end{array}$ & $\mathrm{N}$ \\
\hline \multicolumn{15}{|l|}{ Wrought } \\
\hline Nails * & & & 1 & 2 & 3 & 3 & 18 & 27 & 23 & 9 & 8 & 35 & 205 & $334 *$ \\
\hline \multicolumn{15}{|l|}{ American Cut } \\
\hline Nails & & 1 & 2 & 2 & 8 & & 5 & 4 & 8 & 7 & 3 & 2 & 52 & 94 \\
\hline \multicolumn{15}{|l|}{ British Cut } \\
\hline Nails & & & 1 & 1 & 1 & 4 & 1 & 3 & 3 & 1 & 1 & 2 & 7 & 25 \\
\hline Cut Nails & & & & 2 & 1 & & & & & 1 & & & 18 & 22 \\
\hline Square Nails & & & & & & & & & & & & & 20 & 20 \\
\hline Totals & 0 & 1 & 4 & 7 & 13 & 7 & 24 & 34 & 34 & 18 & 12 & 39 & 302 & 495 \\
\hline
\end{tabular}

A total of 141 complete and fragmentary were identified as machine cut nails, of which 93 were classified into only two style types: the British cut clasp nail (variety no. 2001) and the American common cut nail (variety no. 2002). One half of all the machine cut nails in the House 4 study area were fragmentary or too corroded to determine style type. 


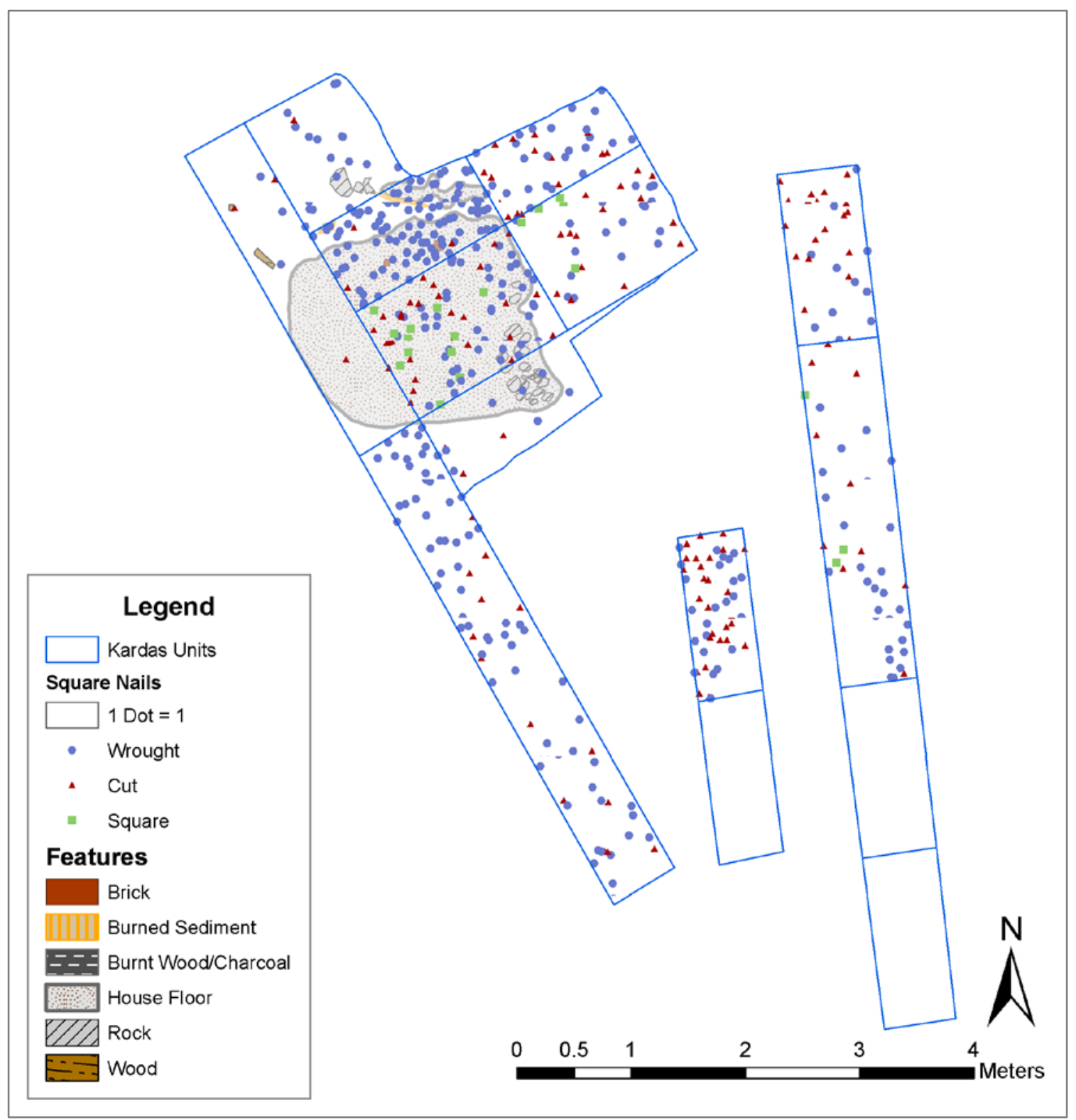

FIGURE 76. Square nail distribution (distinguished by manufacture type) in the House 4 study area (Map by author, 2011).

Overall, there is a slightly higher density of machine cut nails in the vicinity units $\left(7.69 / \mathrm{m}^{2}\right)$ than in the House 4 feature-containing units $\left(6.91 / \mathrm{m}^{2}\right)$. Field notes referenced a cluster of wires, square nails and wire nails near the stone cluster in $34 \mathrm{~S} 0-5$ and $35 \mathrm{~S}$. If these were wire nails, found beneath the burnt planks, they likely suggest postdepositional disturbances to the House feature. The presence of machine cut nails may 
indicate that the collapse of House 4 may not have occurred as early as originally assumed, or these are related to subsequent building projects in the area. Unit $34 \mathrm{~S} \mathrm{0-5}$ accounts for nearly half of the cut nails recovered from the in the House 4 site deposit, otherwise the presence of machine cut nails is concentrated to the east. When that unit is excluded, the average cut nail density around the house floor is closer to $4.08 / \mathrm{m}^{2}$. Of the cut nails that could be sized $(n=64)$, approximately half $(n=27,46 \%)$ fall between $9 d-12 d$. Only two nails were larger than 20d. The complete machine cut nail assemblage includes 32 unaltered; 22 pulled; and 3 clinched.

Hardware. Two architectural hardware artifacts were recovered from the House 4 area: a latch plate (Figure 77a) and a pintle hinge (Figure 77b). The pintle hinge, potentially suggestive of a door, was found in unit 34S 0-5. The latch plate (also door related) was found in DT 45-60, which was $4.5 \mathrm{~m}$ (15 ft.) long, so the exact location of the latch plate is not clear.

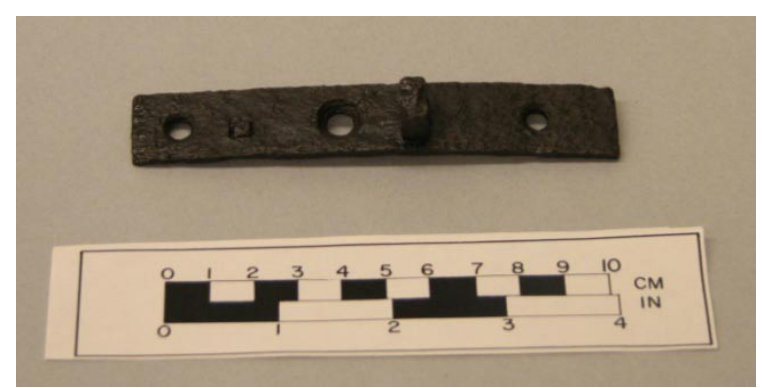

FIGURE 77a. Latch plate, (Cat no. 3694) (Photo by author, 2011).

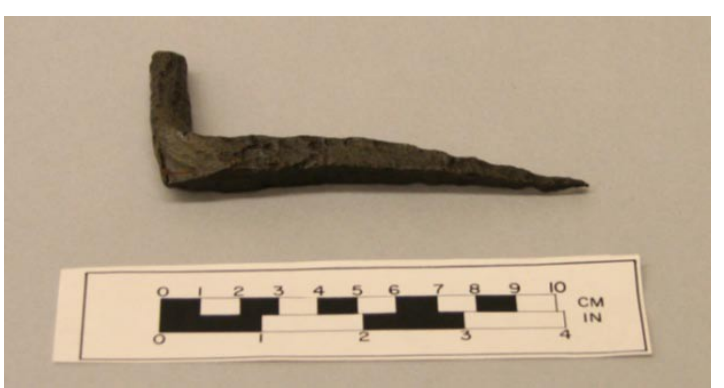

FIGURE 77b. Pintle Hinge, (Cat no. 3648) (Photo by author, 2011). 


\section{Interpretation}

The interpretation of House 4-a probable poteaux-sur-sole structure built in the early 1830 s - was hindered by hurried excavation and documentation at the end of the 1969 field season. Archaeologists did not document any details about a layer of "burnt planks and wood shingles" that may have contained details about the walls and roof (Kardas 1970:61). This layer likely covered the same 2.4 x $2.4 \mathrm{~m}(8 \mathrm{x} 8 \mathrm{ft}$.$) area as the$ compact clay-laden house floor. The only recorded wood remains (Feature H4-05) were small and provided no interpretive data (Figure 70). This is perhaps the reason why they were only documented in student field notes and not addressed in the final report.

The excavated remains of House 4 in trenches $32 \mathrm{~S}, 33 \mathrm{~S}, 34 \mathrm{~S}, 35 \mathrm{~S}$, and the Diagonal Trench represent only a portion of the original structure (likely the northeast corner). The units to the east of the house floor (10M36S-10M38S, 10L34S-10L39S) appear to be associated with a separate, subsequent structure based on the greater relative frequency of late 19th-century window glass and machine cut nails (Figure 78). This fits with the hypothesis that the remains of multiple structures overlapped and intermingled in the vicinity of House 4 (Thomas 1993; Lynch 2009). The machine cut nails and postHBC-era window glass fragments encroach on House 4 from the south and east. Kardas suggested that House 4 remained undisturbed after its collapse, but the presence of wire nails and window glass manufactured between 1855 and 1900 in unit 34S 0-5 point to some kind of late 19th- or early 20th-century intrusion (Figure 78). 


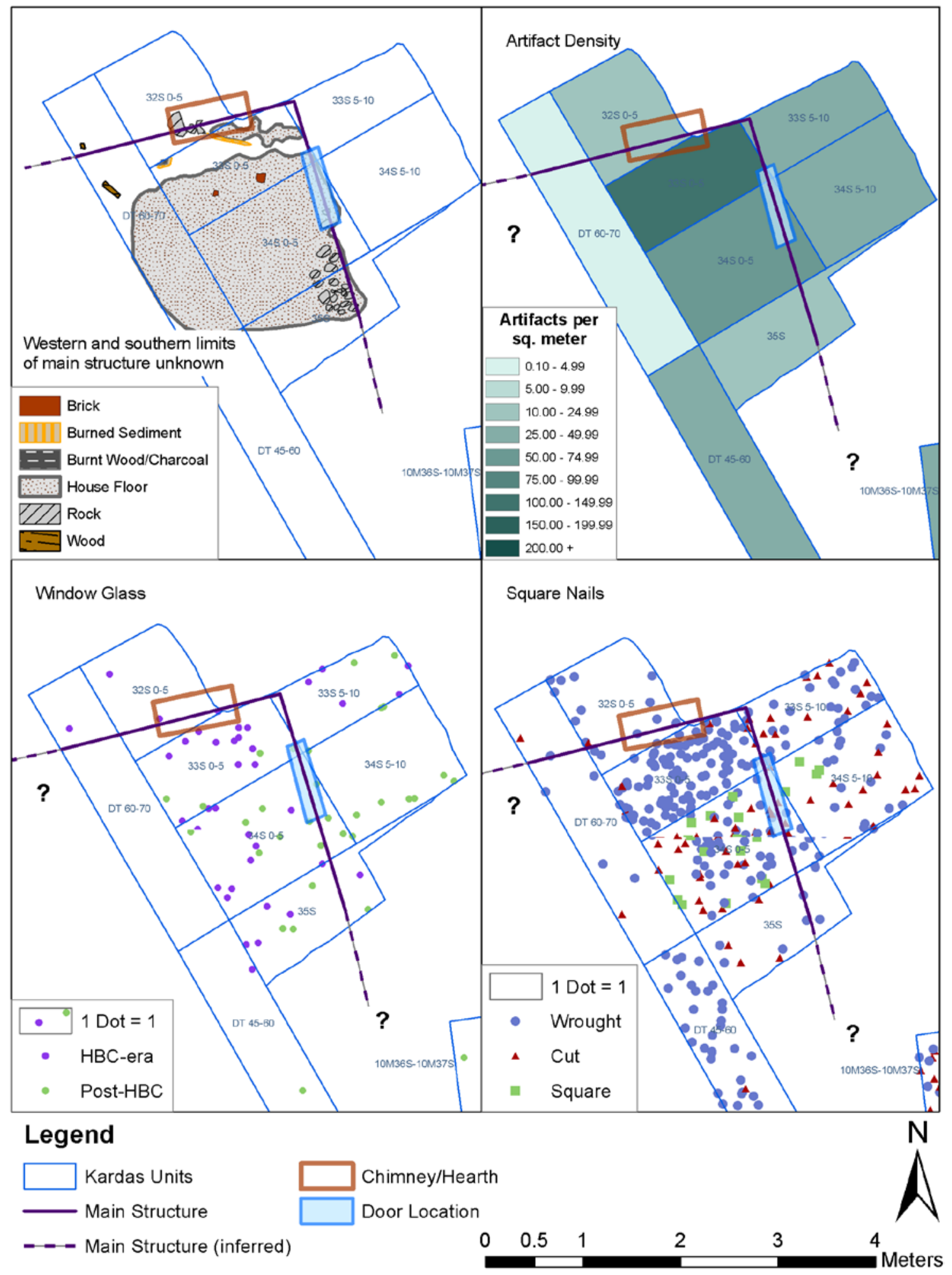

FIGURE 78. House 4 interpretation, showing features (upper left), artifact densities (upper right), window glass (lower left), and square nail distribution (lower right) (Map by author, 2011). 
The north and east wall locations (Figure 78) were inferred based on the edges of the house floor, the lower artifact densities beyond the house floor (Table 35), and features. It was difficult to use the provenience of specific nail types as a line of evidence given the relatively large area of each excavation unit. The east wall likely followed the alignment of a rock cluster (Feat. H4-02), which protrudes above the house floor sediment feature and may have functioned as a foundation sill (Figure 78). The artifact densities in units 33S 5-10 and 34S 5-10 (east of the house floor) were lower than those of 33S 0-5 and 34S 0-5 (which contain two-thirds of the house floor) (Figure 78). The lower artifact densities of units 33S 5-10 and 34S 5-10, the location outside the house floor, and a nail assemblage that contains few unaltered nails suggest that these northeastern units were outside the House 4 footprint (Figure 78). The north wall is demarcated by the presence of 12 large nails (20d-60d) and hearth remains in units $32 \mathrm{~S}$ and 33S 0-5, and the absence of house floor sediments further to the north. It is possible that the structure extended farther to the south and west, especially since DT 45-60 contained a large number of wrought nails, but no excavation units were placed to the west of the diagonal trench because the house floor in DT 60-70 was indistinct.

House 4 is tentatively interpreted as a poteaux-sur-sole structure. The only potential foundation-related feature was initially identified as a hearth (Feature H4-02). This $1.2 \times 0.3 \mathrm{~m}(4 \times 1 \mathrm{ft}$.) concentration of stones protrudes above the house floor and the ash concentration (presumably found below the burnt planks). The small area of excavation at House 4 might be the cause for the apparent dearth of foundation features. Posts or foundation sill segments could still be outside the excavated area. Alternatively, the lack of such features would be expected if the foundation sills of a poteaux-sur-sole 
structure were placed directly on the ground surface or upon a rock footing, rather than buried in trenches like at House 2. The rocks may have functioned as a footing to level the ground for the wood sills along the east wall. Seven large nails (20d-60d) used in framing and heavy construction were found in units 34S $0-5$ and $34 \mathrm{~S} 5-10$, but without more detailed provenience, it is not clear if these large nails immediately surrounding the rock cluster or if they were found at the opposite ends of these units. In a poteaux-sursole structure, these nails would have fastened the coulisse to the foundation sills.

Despite the ambiguity regarding the foundation style, the average nail density of $\left(36.1 / \mathrm{m}^{2}\right)$ suggests that House 4 had pièce-sur-pièce walls (Table 40$)$. The average nail density is greater than the 1969 nail density of House $2\left(27.1 / \mathrm{m}^{2}\right)$, but this might be an inflation of artifacts stemming from the overlapping remains of other structures.

TABLE 40

HOUSE 4 ARTIFACT RECOVERY DATA

\begin{tabular}{lrr} 
& \multicolumn{1}{c}{ Square Nails } \\
& Window Glass & KARDAS 1968-1969 \\
\hline Excavation Units $(\mathrm{n}$ and area $)$ & $8\left(12.5 \mathrm{~m}^{2}\right)$ & $8\left(12.5 \mathrm{~m}^{2}\right)$ \\
Avg. frequency $\left(\mathrm{n} / \mathrm{m}^{2}\right)$ & 6.4 & 36.1 \\
Min $\left(\mathrm{n} / \mathrm{m}^{2}\right)$ & $<1$ & 2.7 \\
Max $\left(\mathrm{n} / \mathrm{m}^{2}\right)$ & 13 & 89 \\
Std Deviation $\left(\mathrm{n} / \mathrm{m}^{2}\right)$ & 4.40 & 30.25 \\
\hline \hline
\end{tabular}

Even with such a high nail density, the nail sizes commonly associated with roofing (2d-5d) were nearly absent from this assemblage (Figure 79). Wood shingles were observed among those burnt structural remains (Kardas 1970:61). Since the alleged roof remains were not documented in the report or in the student field notes, it is not clear whether the lack of roofing nails is a result of a non-nail-intensive roof style or because the nails were embedded in and discarded with the burned shingles and timbers. Wrought nails associated with wood floors (sizes 8d-9d) were present in units containing the house 
floor (Figure 79). Could the "burnt roof" materials have also included floorboards? The data allows for the possibility of a wood floor, but not enough of House 4 has been excavated to know whether these nail types were evenly distributed across the whole house, or if their presence in the eastern half of the house is associated with another function such as the construction of a door.

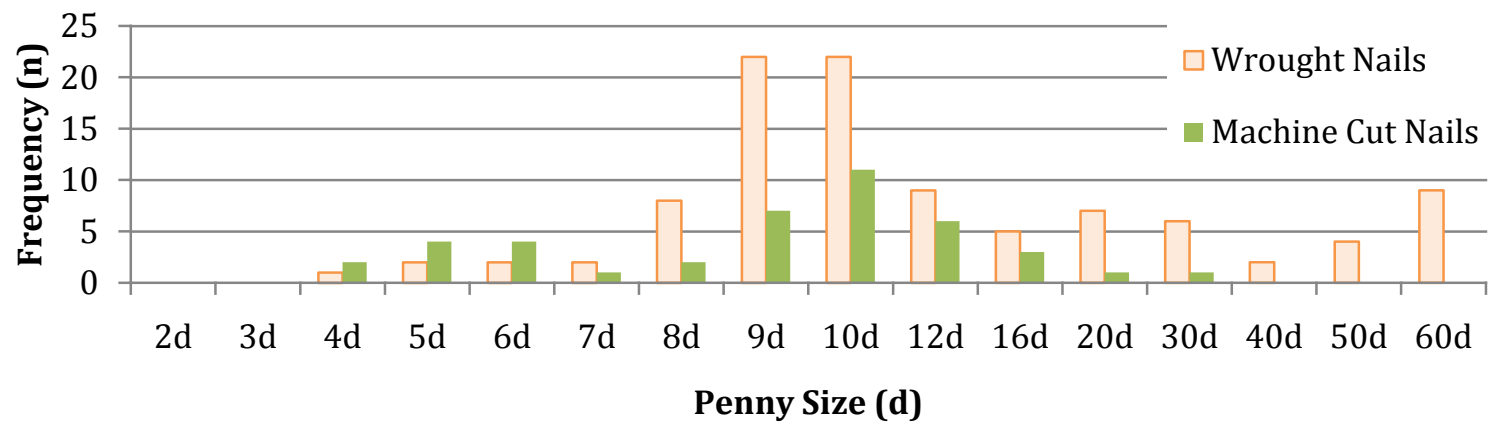

FIGURE 79. Comparison of House 4 wrought and machine cut nail penny sizes (Chart by author, 2011).

There is not enough specific nail or window glass spatial data to infer exact locations of windows and doors. The HBC-era window glass assemblage is relatively sparse; the average window glass density is $6.4 / \mathrm{m}^{2}$ (Table 39). Although, based on thirteen wrought clench nails (variety no. 1060) collected from units 33S 0-5, 33S 5-10, $34 \mathrm{~S} 0-5$ and 34S 5-10 and a pintel hinge collected from $34 \mathrm{~S} \mathrm{0-5}$, there is enough hardware data to suggest the presence of a door somewhere on the east wall. The door may have been located near where these units intersect, at the north end of the rock foundation (Figure 78).

The location of the hearth is evidenced by burned sediments and bone fragments along the inferred north wall (Figure 78). The cluster of stones (H4-02) in the southeast section of the house floor originally interpreted as the hearth did not include burned earth, charcoal, or bone (Figure 70) (Kardas 1970:61). Unit 33S 0-5 on the other hand contained 
three concentrations of bisque, charcoal, and artifacts. A student's plan view sketch of this unit shows two bricks and a photograph shows two or three large rocks just inside unit 32S (Figure 71), and archaeologists cataloged 44 unworked bone fragments from unit $32 \mathrm{~S}$. Although the limits of this hearth or chimney cannot be discretely defined, this area is a stronger candidate for the hearth than the rock cluster in the southeast corner of the floor.

House 4's life history began and ended sometime before 1845. The domestic artifact assemblage also suggests an early occupation date (Kardas 1970; Cromwell 2006). Cromwell (2006:237) established a mean ceramic date range of circa 1840 to 1847. House 4 was built in the early 1830 s when most of the window glass imported to Fort Vancouver was 0.045 -in. thick and employees still had access to 0.035 -in. glass (Figure 73). Sometime in the late 1830s broken windowpanes were replaced with the 0.055-in.-thick crown glass. No window modifications or updates appear to have been made between 1845 and 1855 (Figure 73).

The results of this architectural analysis suggest that fire was not the only "cause of death" to House 4, as is commonly accepted (Kardas 1970; Cromwell 2006). The wrought nail condition ratio (42 unaltered: 50 pulled: 18 clinched, or 2.3:2.7:1) is suggestive of a house that was intentionally torn down rather than burned in place. Had this structure only burned down, the unaltered nails would have outnumbered both pulled and clinched nails 3:1. The nearly equal relative frequency of unaltered and pulled nails points to some kind of intentional deconstruction. One possible scenario that accounts for the layer of charred roof debris is: the house burned partially, making it uninhabitable and 
then it was torn down. During the demolition phase some useable materials may have been salvaged for use in other structures.

Based on the window glass-derived construction and demolition dates, it seems unlikely that House 4 was standing when Gibbs drew the Village in 1851, yet there is a cluster of structures where House 4 would be expected at the right side of the drawing (Figure 80). These structures likely represent the additional structures in the House 4 vicinity inferred based on artifact densities greater and more widespread than expected from a single house (Thomas 1994; Lynch 2009). Not enough architectural details are known about House 4 from the archaeology to determine if House 4 was represented in the sketch. The middle structure has a hipped gable roof, which became common within the stockade by 1846, possibly suggesting this middle structure was built around 1845 .

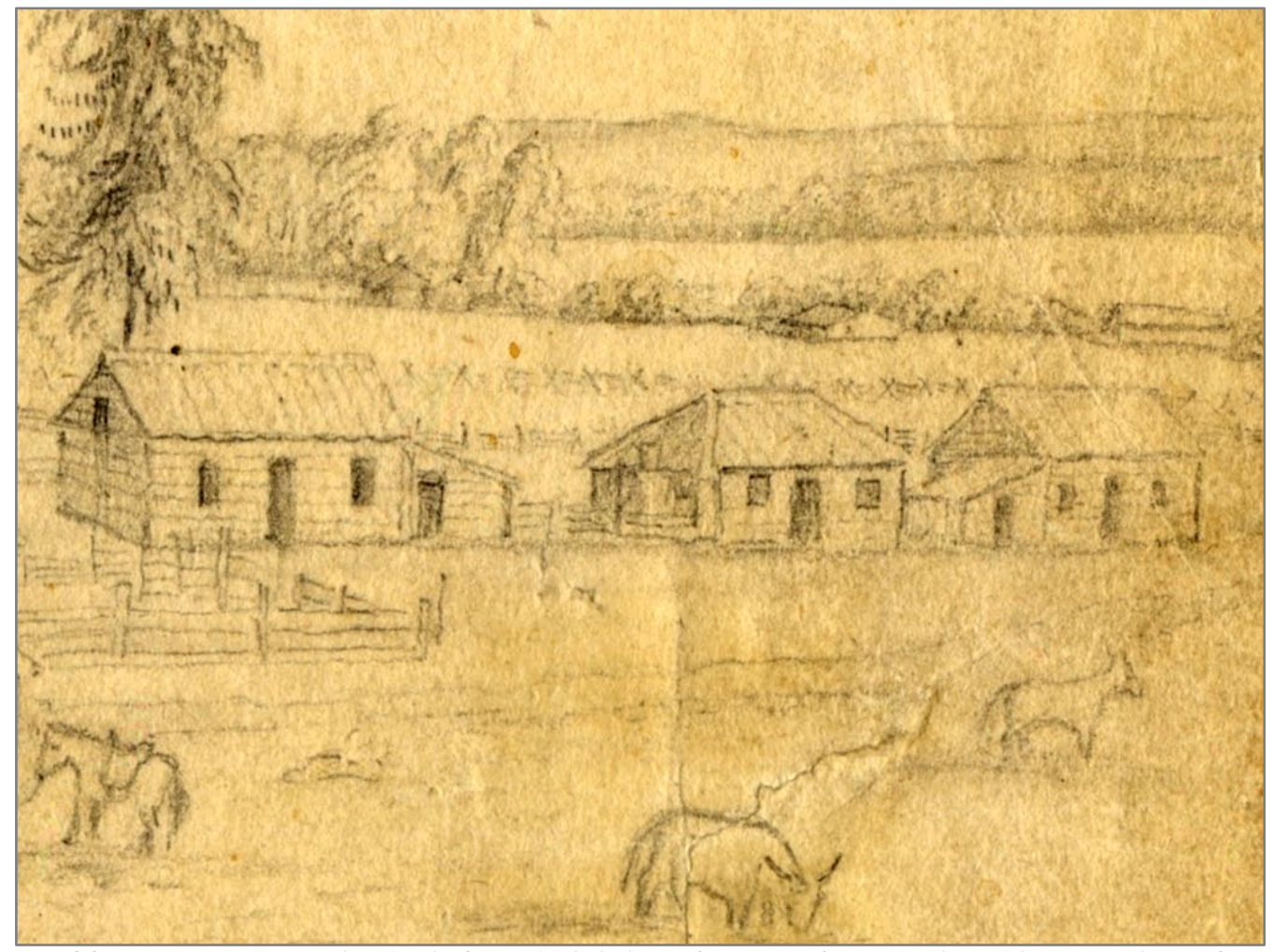

FIGURE 80. Houses shown in the inferred vicinity of House 4 , as depicted in a portion of Gibbs's 1851 sketch (Courtesy of Fort Vancouver National Historic Site). 


\section{CHAPTER 10}

\section{HOUSE 5}

Archaeologists discovered House 5 during the first phase of the SAIP Project in 2001. Subsequent excavation over the next two field seasons uncovered intact portions of an HBC-era structure perforated by 20th-century intrusions. House 5 is located approximately $3.5 \mathrm{~m}$ (10 ft.) north of the CCC loop road, at the northeastern edge of the NPS Village property (Figure 23). A shovel test (ST30) exposed a chain at $45 \mathrm{cmbs}$ (18 in.). This $50 \times 50 \mathrm{~cm}$ shovel test was expanded into a $1 \times 1 \mathrm{~m}$ unit and excavated to reveal a hearth containing a variety of HBC era artifacts. The results of a 2002 electrical resistivity remote sensing survey suggested that there was a small $5 \mathrm{~m}$-wide (16 ft.) square-shaped anomaly around ST30/EU01 (Kvamme 2003:10). The House 5 study area includes eighteen $1 \times 1 \mathrm{~m}$ excavation units and one $0.5 \times 1 \mathrm{~m}$ excavation unit. A total of 4,707 artifacts were recovered from a total of $5.36 \mathrm{~m}^{3}$ of excavated sediment between 2001 and 2003.

Beginning in 2002, House 5 elevations were taken using an optical level. An arbitrary datum was designated $100 \mathrm{~m}$ elevation (placed in the ground at $41.84 \mathrm{ft}$. in elevation above mean sea level (12.753 m amsl). The "imaginary datum" above which the elevations would be measured was $0 \mathrm{~m}$ elevation (or $100 \mathrm{~m}$ below the arbitrary datum). All level and feature elevations refer to meters above imaginary datum (m AID), such as $99.5 \mathrm{~m}$ AID; occasionally the estimated depths (cmbs) are also provided.

\section{Stratification}

Stratigraphic data were recorded on level forms and in profile drawings. Strata I through V were all present at House 5. Archaeologists found a dense assemblage of 20th 
century structural debris in the upper levels of most excavation units. A 1935 Army map shows a building labeled "granary" (built in 1904) over the House 5 study area. Most of the units contained U.S. Army and 20th century deposits only through level 3 or 4, at which point the number of 19th century artifacts began to increase. Many HBC artifacts were mixed with a few late 19th and early 20 th century artifacts. This mixture was likely caused by the deep placement of granary footings. At its deepest granary deposits (mostly brick and concrete features) extended beyond $45 \mathrm{cmbs}$, penetrating through the $\mathrm{HBC}$ cultural stratum. Krotavina activity was also abundantly evidenced in the upper levels. The 1894 flood silt deposit, indentified in EU07 level 4 (approximately $37 \mathrm{cmbd}$ ), indicates the presence of 19th century deposits below that depth.

The hearth and very dark gray sediment were observed at 30-40 cmbs (approx. $1.5 \mathrm{ft}$. below surface). Generally by $40 \mathrm{cmbs}$ the $\mathrm{HBC}$ stratum was clearly present. The houses that Kardas excavated were found between 15 and $30 \mathrm{~cm}$ (6 and 12 in.) below the surface. This deeper depth at House 5 could be attributed to extra fill related to the granary or NPS landscaping (Stratum I). This HBC stratum was generally darker and more compact, with higher clay content than the preceding U.S. Army stratum.

\section{Features}

Twenty-six features were recorded in the House 5 study area. Twentieth century structural features were present throughout the study area (Figure 81, Table 41). Brick and concrete features in $\mathrm{EU} 2,4,5,14,15,16,17,18$, and 19 were interpreted as foundation footings (non-HBC) or less clearly defined arrangements were termed "granary debris." A variety of 20th century construction materials (such as tar paper, wire nails, asphalt, wood, and plastic) were found in association with the footings. Most 
footings were found within $15-30 \mathrm{~cm}$ of the surface, and extended at least $40 \mathrm{cmbs}(18$ in.), into the top of the HBC stratum. The structural details of the granary will not be expounded here, but their deep installation has clearly truncated and disturbed portions of the 19th century structural remains. A large deposit of concrete in EU 02 and EU 03 extends to $60 \mathrm{cmbs}$ ( $2 \mathrm{ft}$. ), and no evidence of the HBC stratum was seen under this concrete.

TABLE 41 FORMAL CHARACTERISTICS OF HOUSE 5 MISCELLANEOUS FEATURES

\begin{tabular}{lccccc} 
& \multicolumn{5}{c}{ Max. } \\
No. & Type & $\begin{array}{c}\text { Diameter/ } \\
\text { Length }(\mathrm{cm})\end{array}$ & $\begin{array}{c}\text { Width } \\
(\mathrm{cm})\end{array}$ & Depth $(\mathrm{mbd})$ & Location \\
\hline $2002-03$ & Granary Footing & 24 & 22 & 99.74 & EU04 \\
$2002-04$ & Granary Foundation & 164 & 110 & 99.86 & EU02, EU05 \\
$2002-06$ & Granary Footing & 49 & 35 & 99.73 & EU14 \\
$2002-07$ & Granary Footing & 67 & 65 & $99.71-99.51$ & EU15 \\
$2002-09$ & Granary Footing & 39 & 34 & 99.76 & EU09 \\
$2002-12$ & Wood Planks & 75 & 60 & 99.56 & EU15 \\
$2003-01$ & Wood Block & 18 & 13 & 99.78 & EU18 \\
$2003-05$ & Granary Debris & 100 & 100 & $99.75-99.68$ & EU16 \\
$2003-07$ & Granary Debris & 100 & 50 & $99.88-99.58$ & EU19 \\
$2003-08$ & Granary Debris & 100 & 80 & 99.78 & EU17 \\
$2003-13$ & Granary Footing & 44 & 25 & 99.58 & EU18, EU19 \\
Notes: $*$ Max. length and width of feature complex, based on area excavated &
\end{tabular}

Feature 2002-12 is a crosshatched configuration of at least four timbers fastened together with wire nails in the NW quadrant of EU15. Likely related to the 20th century structure in the vicinity, (99.56 m AID). Unfortunately, the window glass collected from the feature fill (containing bisque and charcoal) could not be found for analysis. It may still be in the wet screen buckets. An upright piece of wood, $5 \mathrm{~cm}(2$ in.) wide, was located $20 \mathrm{~cm}(8 \mathrm{in}$.$) to the east of this feature. It is not clear from the field notes whether$ it is associated with the wire nail-laden wood feature or if it is HBC-era. Another smaller wood feature (2003-01) with wire nails was found in EU 18. 


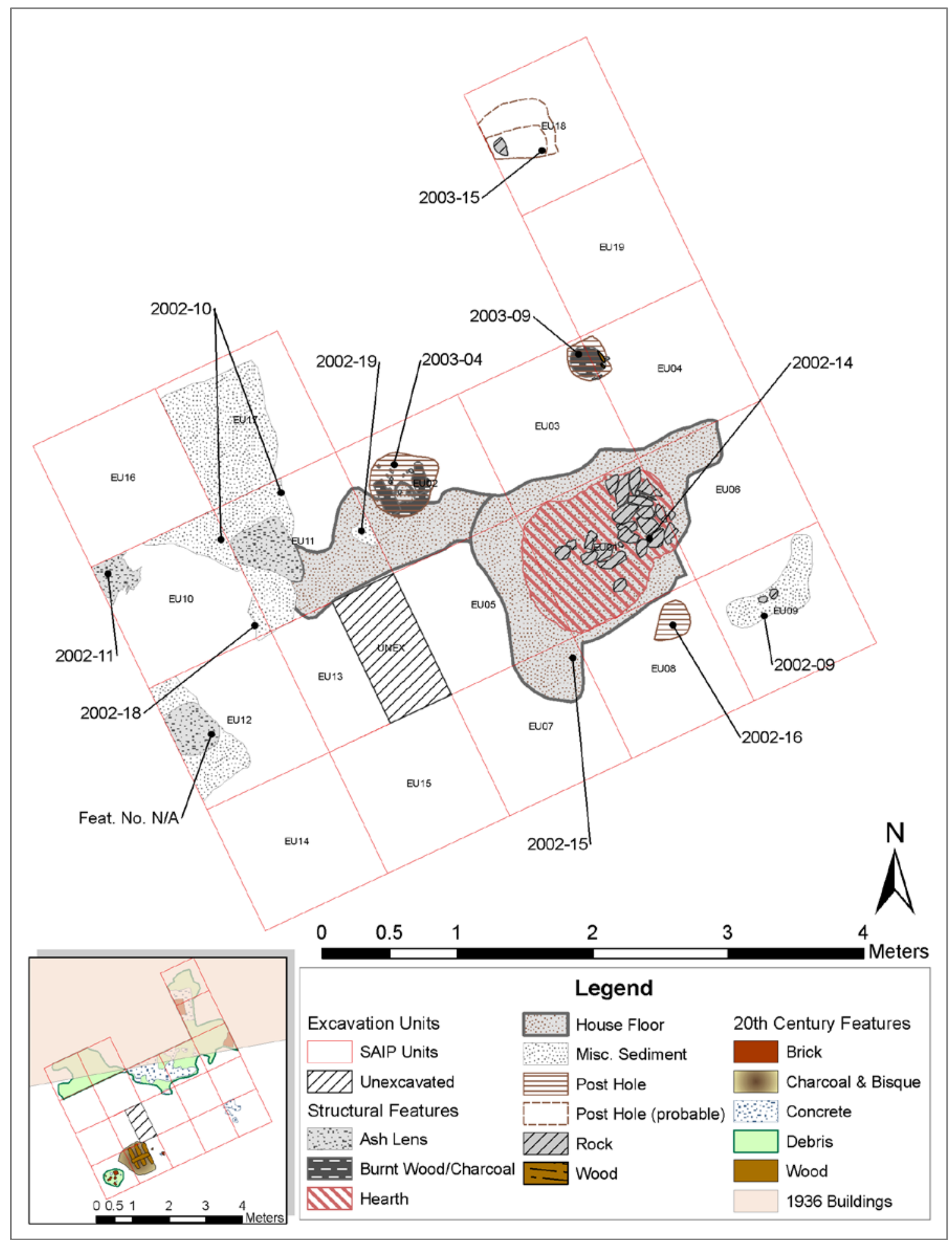

FIGURE 81. House 5 Study Area Features (Map by author, 2011) 
Beneath the 20th century disturbances some 19th century structural features were found intact, specifically in the southern half of the study area (Figure 81; Table 42). The hearth feature included 16 fire-cracked cobbles surrounded by a dark-stained silt loam (Feature 2002-14), with charcoal, baked clay, and grey silt mottling. It covered most of EU01 and extended slightly into EU05 and EU06. The chain found in ST30 was likely associated with cooking over the hearth.

TABLE 42 FORMAL CHARACTERISTICS OF HOUSE 5 STRUCTURAL FEATURES

\begin{tabular}{lccccl}
\hline \hline No. & Type & $\begin{array}{c}\text { Max. } \\
\text { Diameter/ } \\
\text { Length }(\mathrm{cm})\end{array}$ & $\begin{array}{c}\text { Width } \\
(\mathrm{cm})\end{array}$ & Depth (mbd) & \multicolumn{1}{c}{ Location } \\
\hline $2001-\mathrm{xx}$ & Hearth & 75 & 30 & 99.51 & EU01, EU06 \\
$2002-10$ & Ash and charcoal & 124 & 100 & 99.66 & EU11, EU10 \\
$2002-11$ & Ash lens & 30 & 25 & 99.60 & EU10 \\
$2002-14$ & Hearth (stain) & 100 & 90 & $99.46-99.38$ & EU01, EU05 \\
$2002-15$ & House Floor & $200+$ & 165 & $99.45-99.40$ & EU01-08 \\
$2002-16$ & Posthole & 31 & 26 & 99.54 & EU08 \\
$2002-18$ & Charcoal \& bisque stain & 30 & 12 & 99.52 & EU10 \\
$2002-19$ & House Floor (?) & 20 & 17 & 99.50 & EU11 \\
$2003-02$ & Ash \& charcoal stain & 70 & 36 & $99.50-99.45$ & EU09 \\
$2003-04$ & Posthole & 41 & 22 & $99.48-99.34$ & EU02 \\
$2003-09$ & Posthole & 41 & 25 & $99.45-$ & EU03, EU04 \\
$2003-15$ & Posthole & 43 & 35 & $99.50-38$ & EU18 \\
$2003-17$ & Sediment Stain & 34 & 21 & $55 / 99.45$ & EU05; EU07 \\
$2003-18$ & Sediment Stain & 40 & 32 & 55 & EU15 \\
NA & Ash Charcoal, clay & 92 & 45 & 99.63 & EU12 \\
\hline
\end{tabular}

Notes: * Max. length and width of feature complex (cluster), based on area excavated

A large area of mottled dark brown (10yr 3/3) and dark grey (10yr 4/1) clayey sediment resembled the "imported clay" floors observed at previous Village house excavations. The identified "house floor" is a composite of Feature 2002-15, 2002-19, and areas of "charcoal and bisque/house floor" that were not formally designated as features. Figure 81 shows the positively identified house floor sediments (covering an area of approximately $10.5 \mathrm{~m}^{2}$ ) as well as miscellaneous sediment stains that might be associated with the house floor. The irregular shape of the house floor may be a result of 
the disturbances to the HBC structure caused by the 20th century construction and demolition activities, it is also possible that the variation in the "house floor" composition is tied to activity spaces within the house. Feature 2002-15 is an area of burned earth (bisque), ash, and charcoal surrounding the hearth. Features 2003-17 and 2003-18 were initially interpreted as "potential postholes," but excavation revealed that these dark grayish circular stains within the HBC deposits were only a few centimeters thick. They first appeared at approximately the same elevation as the house floor. These were likely depressions that were filled in with the gray house floor sediment, which contains small amounts of charcoal, bone, and bisque.

There was also a series of ash lenses and ash/charcoal/bisque concentrations (including Features 2002-10, 2002-11, 2002-18, and an undesignated lens in EU12) in the northwestern portion of the House 5 study area (Figure 81). These sediment features are all at least 10 to $15 \mathrm{~cm}$ (4 to 6 in.) above the house floor at 99.66-99.52 $\mathrm{m}$ AID. There were trace amounts of 20th century debris (plasterboard and concrete) mixed in with HBC-era artifacts, charcoal, ash, bisque, and bone fragments. Feature 2003-02, located in the southeast corner of the study area (EU09) began at $99.50 \mathrm{~m}$ AID. This very dark grayish brown gravelly silt loam contained over 40 pieces of FCR and a variety of HBC domestic and structural artifacts. It is the farthest east of the HBC features, and is likely an external disposal locus.

Three postholes containing wood or charcoal were positively identified during excavation (Features 2003-09; 2002-16; and 2003-15). These three features form a relatively straight north-south oriented line at the east side of the study area. Feature 2003-09 (EU03, EU04) was a charcoal and bisque concentration with fragments of 
unburned, apparently milled wood at $99.42 \mathrm{~m}$ AID ( $3 \mathrm{~cm}$ below the start of the feature). The $23 \mathrm{~cm}$-wide (9 in.) post (mostly charred) is circular, in a circular postmold (the $3-\mathrm{cm}$ [1.2 in.] radius around the post is mottled differently than the surrounding sediments. The charcoal-filled post mold ended at $99.31 \mathrm{~m} \mathrm{AID,} \mathrm{(containing} \mathrm{about} 10 \mathrm{~cm}$ [4 in.] of wood/charcoal). This is approximately 10 to $15 \mathrm{~cm}$ (4 to $6 \mathrm{in}$.) below the house floor surface. Feature 2002-16, a dark grayish brown stain with about $22 \mathrm{~cm}$ (8.6 in.) diameter area of charcoal, baked clay nodules, was excavated to $99.33 \mathrm{~m}$ AID The hollow sound of the feature lead to the initial interpretation as a burned out post in the northeast corner of EU08. The sediment within the feature was loose. Bone fragments/faunal remains were encountered at 99.36 and $99.32 \mathrm{~m}$ AID. At $99.29 \mathrm{~m}$ AID, approximately eight medium to large subrounded pebbles were noted, perhaps the base of the post-hole. Feature 2003-15 is less clearly defined. It is a deep feature containing a variety of HBC domestic artifacts in dark gray compact sediment next to a $15 \mathrm{~cm}$ (6 in.) long cobble. This feature was likely truncated by the granary footing in EU18 and EU19.

A fourth posthole-like feature was found in EU02. Feature 2003-04 started out looking like a secondary hearth, containing FCR, mammal bones, and a concentration of ash and charcoal. Below the $99.35 \mathrm{~m}$ AID elevation, the charcoal concentrations took a square shape. The wood grains of the charcoal were oriented different ways, so it did not appear to be a single piece of wood. What appeared to be a plank extended deeper into the unit's north wall. Most likely this is a burned footing for a post. The four window glass fragments recovered within the charcoal and bisque concentration ranged from 0.035 in. to 0.065 (each fragment a different thickness). The shape of the charcoal looks as if the plank is at least $15 \mathrm{~cm}(6 \mathrm{in}$.$) wide.$ 


\section{Architectural Artifacts}

House 5 contained a large quantity of both 19th- and 20th-century structural artifacts. Concrete and asphalt dominated the upper levels. The 20th century construction debris were not collected from the $1 / 8$ in. $(3 \mathrm{~mm})$ hardwire mesh screens; many modern or non-diagnostic construction materials were weighed and discarded in the field. SAIP archaeologists collected 985 fragments of window glass, 919 square nails, and 2324 brick fragments. The average density of 19th century architectural artifacts is $97.8 / \mathrm{m}^{2}$ (min: 28/m², max: $270 / \mathrm{m}^{2}$, std. dev.: $51.47 / \mathrm{m}^{2}$ ). Additional artifacts may be present in the unsorted wet screen and microartifact samples housed in the NCRI lab. The wire nails and other clearly 20th century construction materials were not included in this analysis. All bricks were analyzed, but it is clear that many were associated with the 1904 granary. Figure 82 shows the distribution of artifact densities. Table 43 shows the artifact counts and densities for each artifact-bearing unit.

The detailed provenience data from the SAIP excavation enabled greater distinction between artifacts associated with these later features and those part of the original HBC-era structure. For the interpretations, greater weight was given to the artifacts found within HBC levels. Defined based on the stratigraphic profiles, sediment descriptions, and feature descriptions, the beginning depths of the HBC levels vary between units as the 20th century disturbances were not uniform across the study area. Based on the sediment descriptions from the field notes, two stratigraphic zones were identified approximating the 20th century and 19th century deposits. The field methods used to excavate House 5 allowed for this distinction to be made, whereas the other houses did not have tight enough vertical provenience. The depths of each are not 
uniform across all 19 units. The 20th century disturbances were deeper in the northern units. In general the $\mathrm{HBC}$ levels begin around level 4 (or approximately $45-50 \mathrm{~cm}$ below surface).

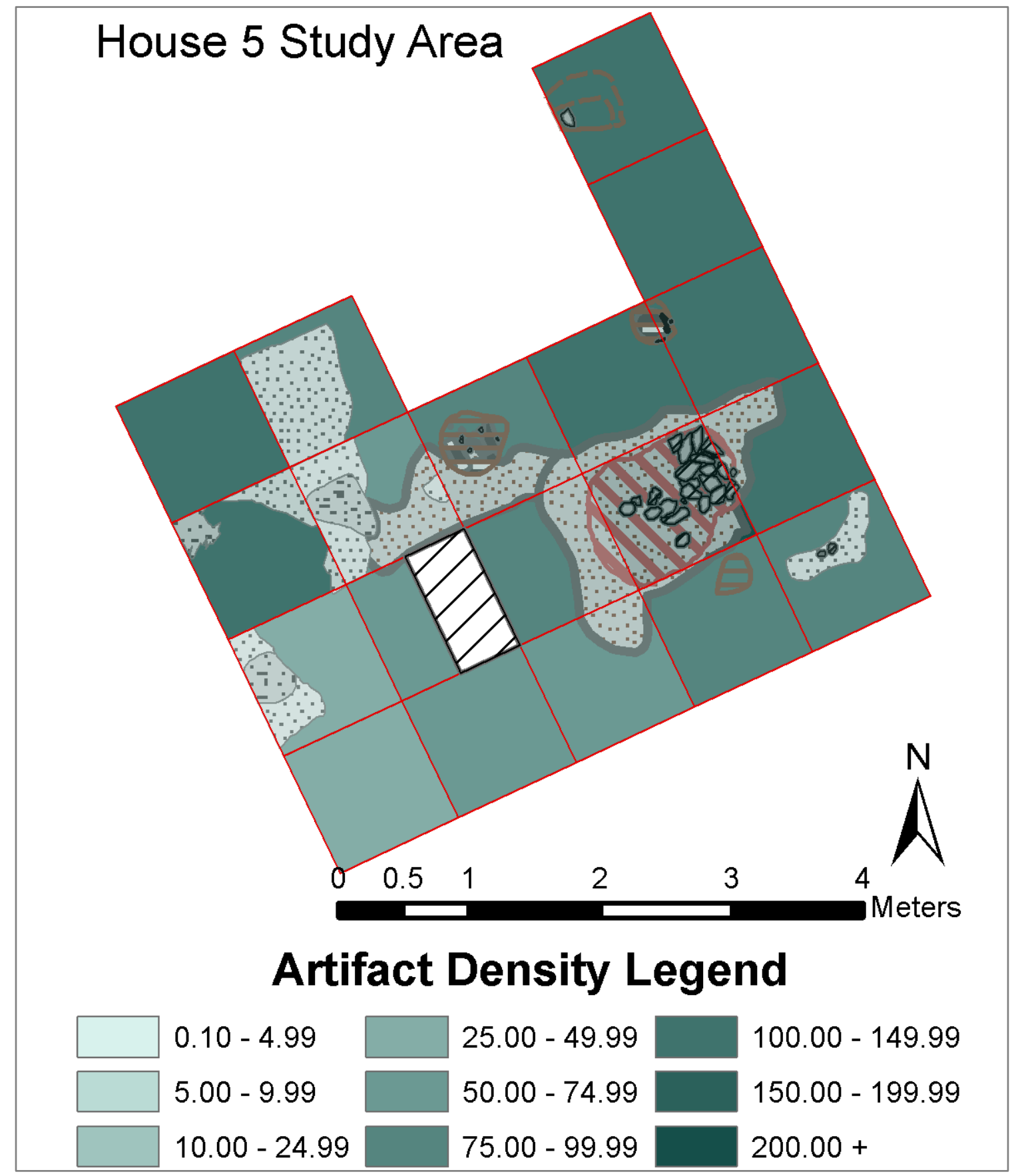

FEATURE 82. House 5 study area artifact density per unit (Map by author, 2011). 
TABLE 43

HOUSE 5 STUDY AREA ARTIFACT COUNTS PER UNIT AND FEATURE

\begin{tabular}{lccccc|cccccc}
\hline \hline Unit & WG & SN & B & Total & n/m & Feature* & WG & SN & B & Total & $\mathrm{n} / \mathrm{m}^{2}$ \\
\hline EU01 & 158 & 112 & 240 & 510 & 510 & & & & & & \\
EU02 & 52 & 25 & 74 & 151 & 151 & $2002-03$ & 1 & 0 & 4 & 5 & 94.7 \\
EU03 & 72 & 53 & 122 & 247 & 247 & $2002-04$ & 18 & 9 & 52 & 79 & 43.8 \\
EU04 & 56 & 62 & 116 & 234 & 234 & $2002-07$ & 4 & 0 & 13 & 17 & 39 \\
EU05 & 38 & 48 & 33 & 119 & 119 & $2002-10$ & 10 & 15 & 6 & 31 & 25 \\
EU06 & 59 & 55 & 45 & 159 & 159 & $2002-15$ & 1 & 3 & 0 & 4 & 1.2 \\
EU07 & 31 & 38 & 26 & 95 & 95 & $2003-04$ & 4 & 4 & 0 & 8 & 88.7 \\
EU08 & 41 & 38 & 94 & 173 & 173 & $2003-08$ & 3 & 4 & 87 & 94 & 117.5 \\
EU09 & 55 & 33 & 453 & 541 & 541 & $2003-15$ & 3 & 0 & 0 & 3 & 19.9 \\
EU10 & 34 & 86 & 94 & 214 & 214 & $2002-14$ & & 2 & 0 & 2 & 2.22 \\
EU11 & 38 & 18 & 41 & 97 & 97 & $2003-13$ & & 1 & 2 & 3 & 27.3 \\
EU12 & 14 & 26 & 15 & 55 & 55 & $2003-01$ & & 1 & 3 & 4 & 170.9 \\
EU13 & 8 & 27 & 45 & 80 & 80 & $2003-05$ & & & 9 & 9 & 9 \\
EU14 & 23 & 5 & 77 & 105 & 105 & $2003-07$ & & & 4 & 4 & 8 \\
EU15 & 40 & 34 & 103 & 177 & 177 & $2002-12$ & & & 5 & 5 & 11.1 \\
EU16 & 47 & 55 & 134 & 236 & 236 & Unprov. & & & 2 & 3 & NA \\
EU17 & 37 & 47 & 93 & 177 & 177 & & & & & & \\
EU18 & 53 & 57 & 109 & 219 & 219 & & & & & & \\
EU19 & 90 & 59 & 223 & 372 & 372 & & & & & \\
\hline
\end{tabular}

*Only includes artifacts with explicit feature provenience.

$\underline{\text { Brick. }}$. Of the 2,324 bricks analyzed from the House 5 study area, only 32 were identified as English bricks. Only EU02 and EU11 (Feature 2002-10) contained English bricks in the HBC-stratum $(\mathrm{n}=20)$, all of which were fragments $(15-55 \mathrm{~mm})$. The 12 English brick fragments were collected from mixed contexts and 20th century features. The majority of the brick assemblage were identified as American bricks and either directly associated with the 1904 granary features $(n=179)$ or in the vicinity $(n=1545)$. The HBC era domestic hearth did not include bricks, only rocks. The House 5 artifact densities exclude bricks because most American bricks belonged to the granary footings.

Window Glass. The window glass fragments recovered from House $5(n=985)$ were small; only 57 fragments $(5.8 \%)$ were $40 \mathrm{~mm}$ or larger (Table 44$)$. Approximately half of these larger fragments were from thicker windowpanes from the late 19th and 
20th centuries, distributed across the study area. Two fragments were too fragmented and small to take accurate thickness measurements.

TABLE 44

HOUSE 5 WINDOW GLASS FRAGMENT SIZES

\begin{tabular}{|c|c|c|c|c|c|c|c|c|c|}
\hline \multicolumn{10}{|c|}{ Size (mm) } \\
\hline & 6 & 10 & 15 & 20 & 30 & 40 & 50 & $>50$ & Total \\
\hline SAIP (n) & 32 & 246 & 297 & 187 & 166 & 47 & 8 & 2 & 985 \\
\hline
\end{tabular}

The window glass fragments ranged in thickness from $0.71 \mathrm{~mm}(0.027 \mathrm{in})$ to $5.49 \mathrm{~mm}(0.216 \mathrm{in})$. The primary mode for the entire House 5 excavation area is $0.045 \mathrm{in}$. $(n=204)$, which correlates to a date range of 1830-1840 (Figure 83). The secondary mode was 0.075 in. HBC-era window glass accounts for $76 \%$ of the window glass found at House 5. Glass thicker than $0.085 \mathrm{in}$. is outside of the 19th century date range. When only the HBC-excavation levels were taken into account, 0.045 -in. glass still is the primary mode, but the secondary mode is 0.035 in (Figure 84). In these lower levels, $0.055-0.075-$ in. window glass is minimal. The presence of the thinner (and earlier) glass may be related to a period when the early windows broke but the house was still occupied. The flat glass from the HBC levels totaled 465 . The post-HBC window glass (19th century= $13 \%$; 20th century $=11 \%$ ) was found in all excavation units, but was clustered mostly in the northern and eastern portions of the study area (Figure 85).

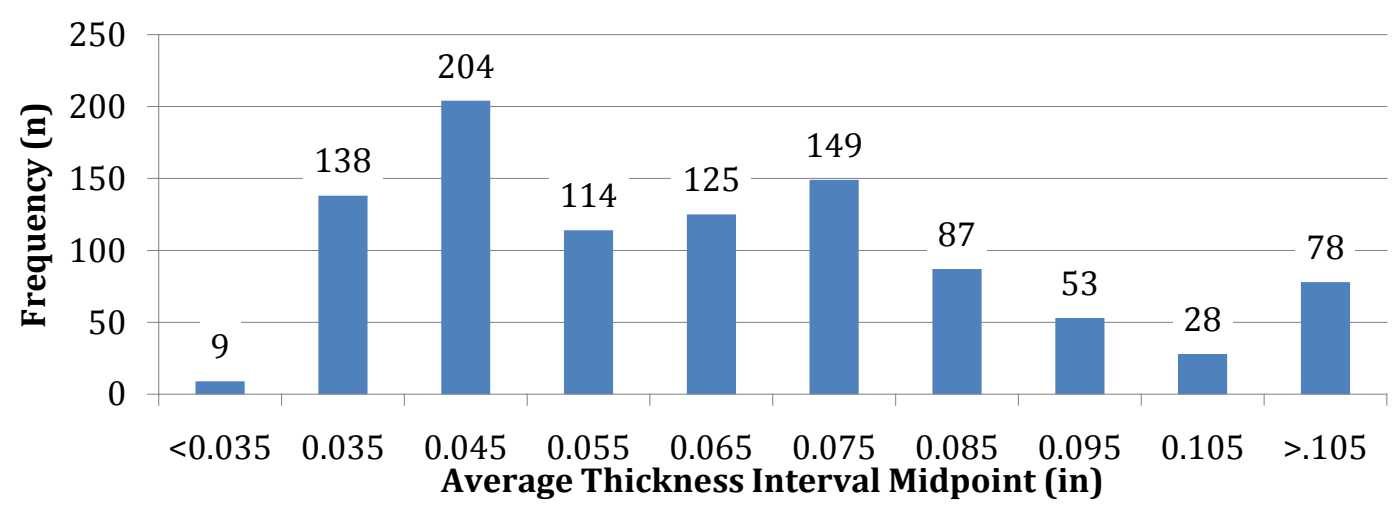

FIGURE 83: House 5 Window Glass Thickness Modal Distribution 


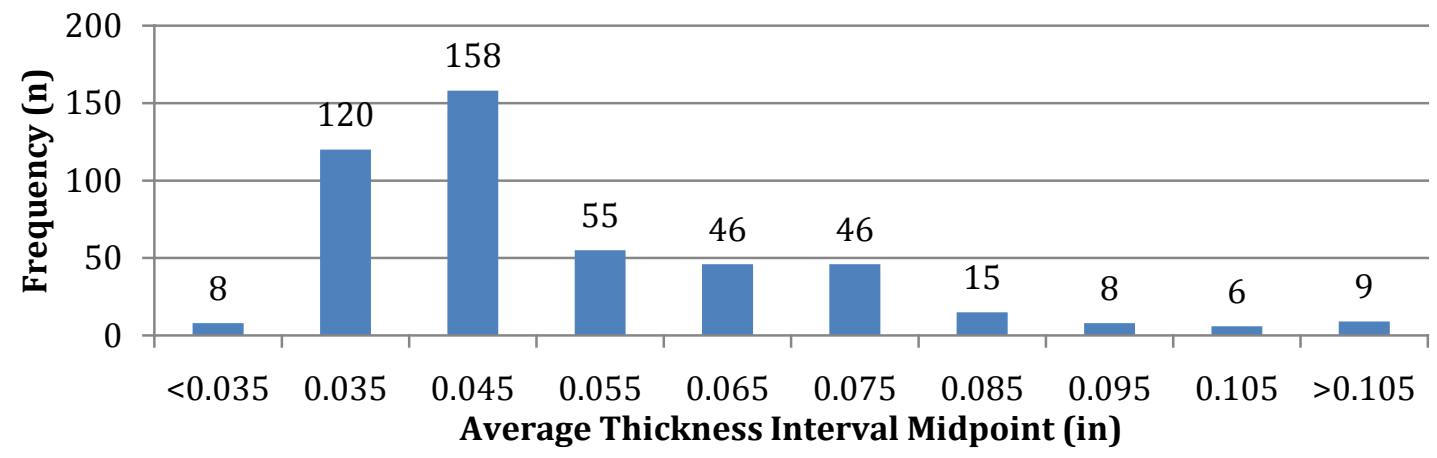

FIGURE 84. Thickness modal distribution of glass collected from HBC-levels.

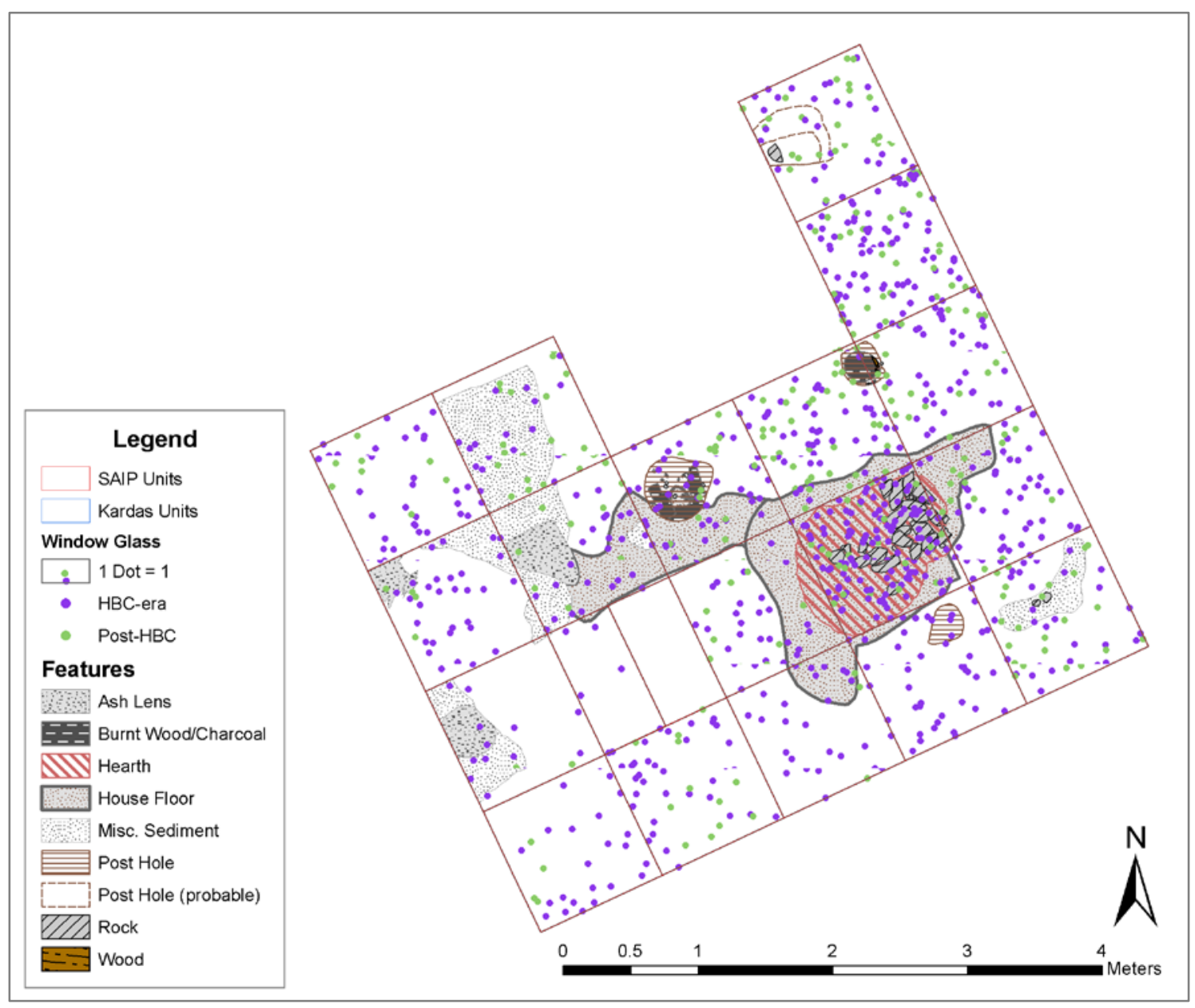

FIGURE 85. Spatial distribution of HBC-era (purple) and post-HBC era (green) window glass (Map by author, 2011). 
Square Nails. 916 square nails were recovered from House 5. Over $80 \%$ of these $(\mathrm{n}=744)$ were fragmentary. The average nail density for the House 5 study area is $47.6 / \mathrm{m}^{2}$. Hand wrought nails were more common than machine cut nails, nearly $2: 1$. Less than one-fifth of the nail assemblage $(n=160)$ was identified as indeterminate square nails (Table 45). Figure 86 shows the distribution of nail manufacture types.

\section{TABLE 45}

HOUSE 5 SQUARE NAILS FREQUENCIES BY TYPE AND PENNY SIZE

\begin{tabular}{|c|c|c|c|c|c|c|c|c|c|c|c|c|c|c|}
\hline Type & $2 d$ & $3 d$ & $4 d$ & $5 \mathrm{~d}$ & $6 \mathrm{~d}$ & $7 \mathrm{~d}$ & $8 \mathrm{~d}$ & $9 \mathrm{~d}$ & $10 \mathrm{~d}$ & $12 \mathrm{~d}$ & $16 \mathrm{~d}$ & $\begin{array}{l}20- \\
60 d\end{array}$ & $\begin{array}{l}\text { Frag. } \\
\text { Nails }\end{array}$ & $\mathrm{N}$ \\
\hline Wrought & & & & & & & & & & & & & & \\
\hline $\begin{array}{l}\text { Nails* } \\
\text { American Cut }\end{array}$ & & & 1 & 2 & 9 & 7 & 9 & 7 & 9 & 9 & 8 & 11 & 406 & 478 \\
\hline Nails & 1 & 2 & 4 & 2 & 2 & 9 & 26 & 25 & 2 & 5 & 1 & 3 & 88 & 170 \\
\hline British Cut & & & & & & & & & & & & & & \\
\hline Nails & & & & & & & 1 & 1 & 2 & & 1 & & 13 & 18 \\
\hline Cut Nails & 1 & & & 2 & & & & 5 & & & & & 82 & 90 \\
\hline Square Nails & 1 & & & & 2 & 1 & & & & 1 & & & 155 & 160 \\
\hline Totals & 3 & 2 & 5 & 6 & 13 & 17 & 36 & 38 & 13 & 15 & 10 & 14 & 744 & 916 \\
\hline
\end{tabular}

Only 72 of the 478 wrought nails from House 5 were complete, ranging in size from $4 \mathrm{~d}-60 \mathrm{~d}$ (Table 45 ). Analysts were able to identify 82 wrought nails by style variety. Variety No. 1002 (rosette sharps) was the most abundant category ( $n=47)$, variety no. 1001 (clasp nails) is the second most abundant $(\mathrm{n}=20)$. Another eight style varieties were represented by fewer than 5 nails each. The nails appear evenly distributed between most penny sizes associated with general and heavy construction functions. The complete nails included 31 unaltered nails, 10 pulled, and 8 clinched. 


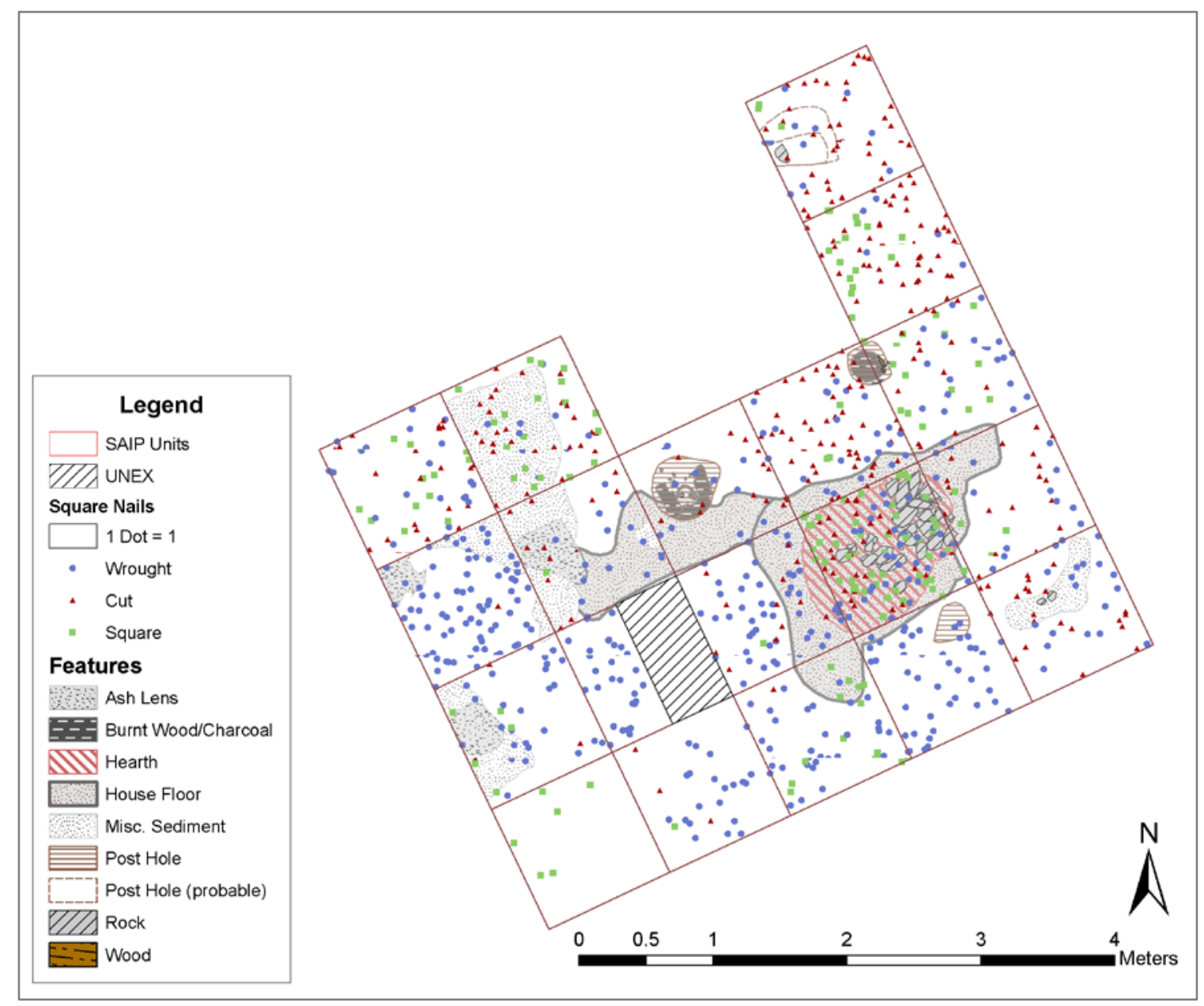

FIGURE 86. Nail distribution at House 5.

The machine cut nail assemblage $(n=278)$ was composed of 95 complete and 183 fragmented nails. American common cut nails (variety no. 2002) are the most abundant (60\%). Very few British cut nails (variety nos. 2001 and 2005) were reported $(n=18)$. The machine cut nails ranged in size from $2 \mathrm{~d}$ to $30 \mathrm{~d}$; sizes $8 \mathrm{~d}$ and $9 \mathrm{~d}$ are the most represented sizes (Table 45). Among the complete machine cut nails included 40 that were unaltered, 27 pulled, and 2 clinched.

Machine cut nails outnumbered wrought nails in the northern and eastern units only (Figure $87 \mathrm{a}$ ), but primarily in the upper levels. Figure $87 \mathrm{~b}$ shows the relative 
frequencies of the wrought, machine cut, and indeterminate square nails in the HBC

levels only. In these lower, less disturbed levels, machine cut nails outnumber wrought in only EU03 and EU17.

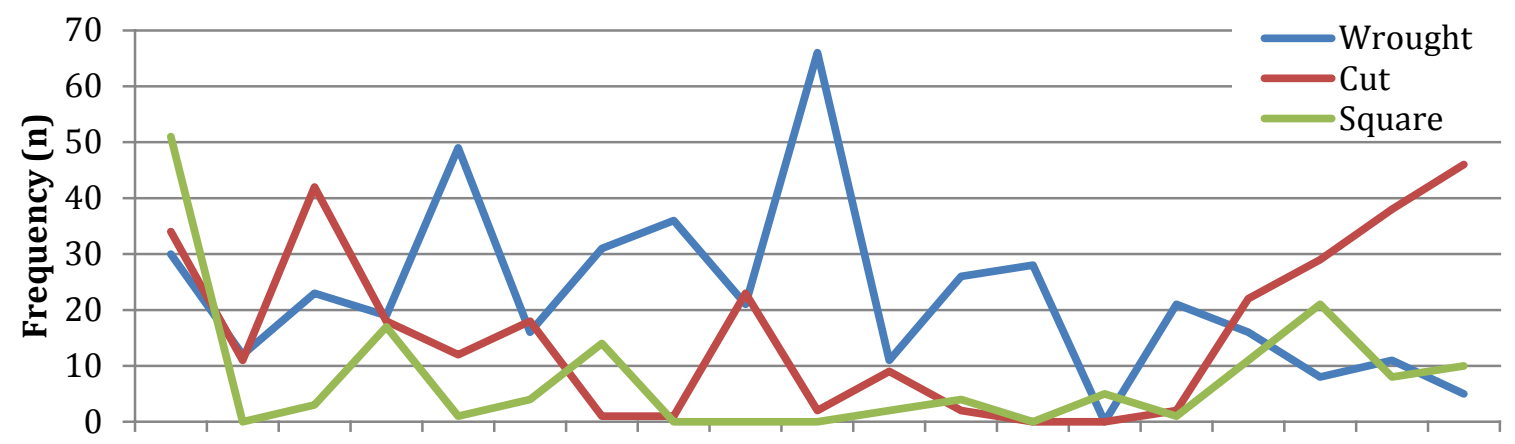

EU 01EU 02EU 03EU 04EU 05EU 06EU 07EU 08EU 09EU 10EU 11EU 12EU 13EU 14EU 15EU 16EU 17EU 18EU 19 Excavation Unit

FIGURE 87a. Nail frequencies from entire House 5 study area.

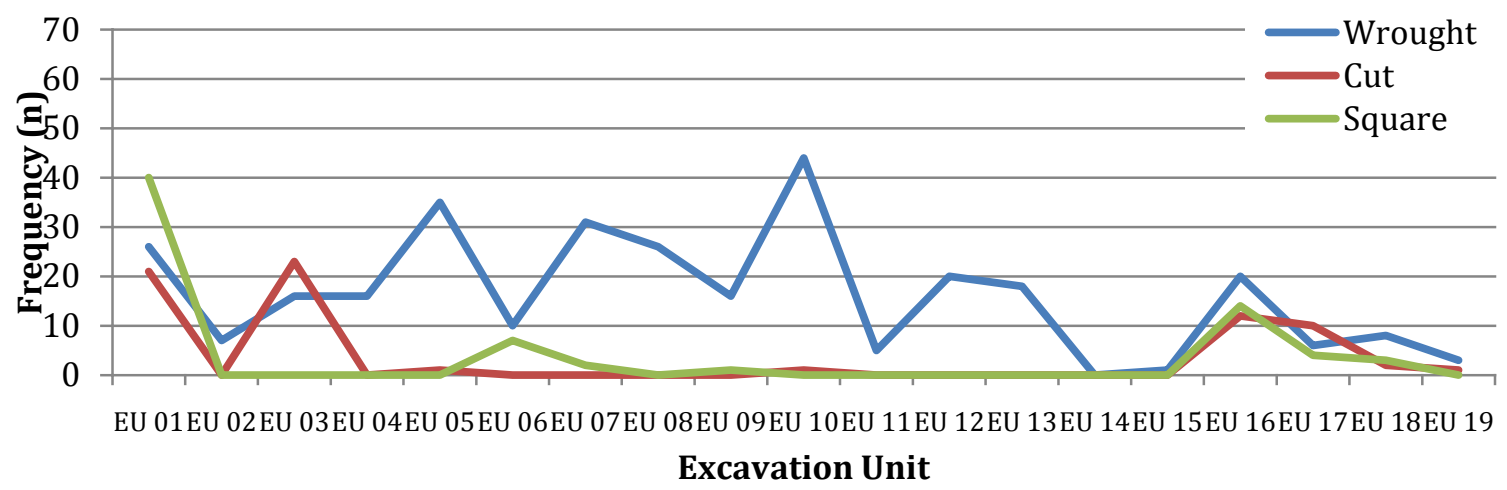

FIGURE 87b. Nail frequencies from HBC/19th century levels only.

\section{Interpretation}

The structural remains appear to derive from a single house; there were no overlapping 19th-century foundation features, all were found approximately at the same depth (Table 42). Based on boundaries established by features and nail and window glass densities, the core area of the house appears to cover approximately $14 \mathrm{~m}^{2}\left(150 \mathrm{ft}^{2}{ }^{2}\right)$. There were no sections of the House 5 study area that could be eliminated based on severe drops in artifact density. The artifacts were more concentrated in the east than in 
the west (Figure 88), but the decrease to the west was gradual. In contrast to the other four houses, which were identified during the excavation of large exploratory trenches, the excavation of House 5 extended outward from the one shovel test that discovered the hearth. The extent of the study area followed the domestic and structural deposits.

The most clearly defined section of the house is the east wall, the evidence for which includes three post features, the hearth feature, and a high density of square nails and window glass. The post features (Feat. 2002-16, 2003-09, and 2003-15) were spaced

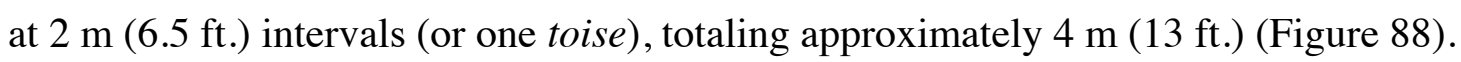
The location of the hearth reinforces this wall interpretation; the rock cluster of the hearth is centered on the alignment of the post features, and even matches the NNW-SSE orientation. The excavation units on both sides of this wall alignment contain a high and relatively uniform density of window glass and square nails.

The inferred location of the south wall is evidenced by the house floor feature, low artifact densities in the southernmost units, and the alignment of the east wall. A perpendicular line extending west from Feat. 2002-16 encompasses the majority of the house floor and excludes many excavation units with low artifact densities (Figure 88). The south wall is depicted as a "potential" location. The study area extends less than one meter beyond the southernmost post feature (Feat. 2002-16), so it is possible that the east wall continued to the farther to the south. The lower densities of nails and window glass in the south could indicate the southern edge of the house or they might be associated with the interior of the house, away from the walls (Figure 88). 


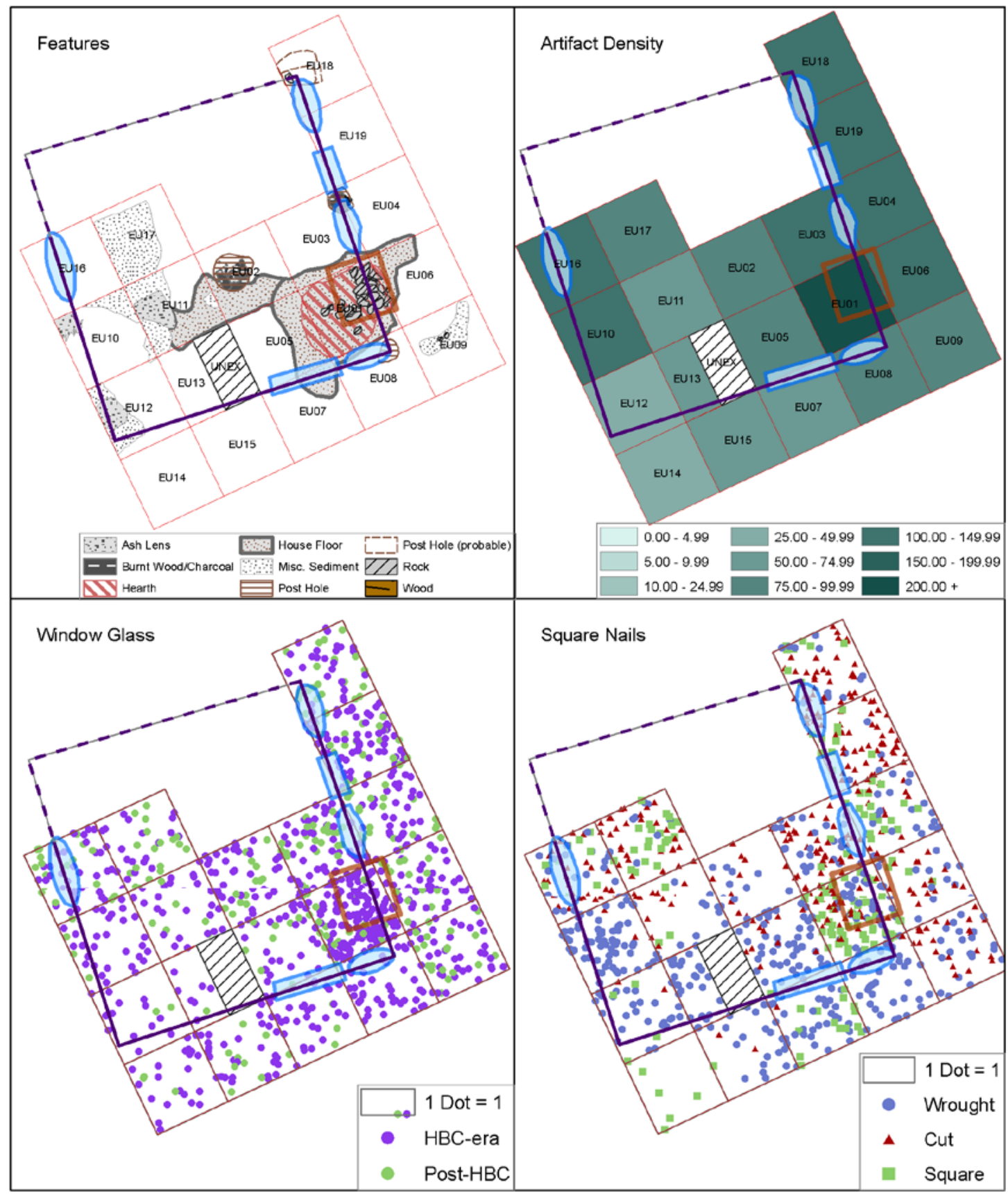

\section{Legend}
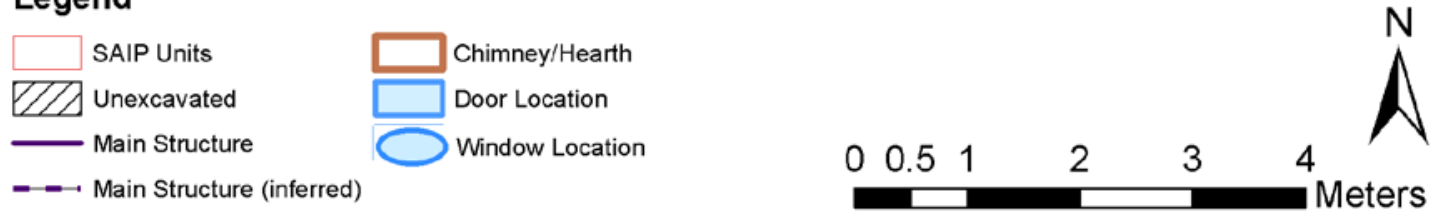

FIGURE 88. House 5 interpretation, showing features (upper left), artifact densities (upper right), window glass (lower left), and square nail distribution (lower right) (Map by author, 2011). 
The decision to show the west wall within the study area was based only on the location of a circular sediment stain in relation to the east wall alignment (Figure 88). No postholes were identified along the western edge of the study area-only ash and charcoal stains in EU10 and EU12. The west wall could easily be located outside the study area. The inferred location of the north wall was not based on archaeological evidence; it crosses an unexcavated area. A perpendicular line was extended from the northernmost east wall post feature (Feat 2003-15) and connected to the inferred alignment of the west wall (Figure 88). With only one wall positively confirmed with features, the other three walls represent the minimum size of the House 5 based on the existing data. If excavations resume at House 5 archaeologists may discover additional structural features that redefine the placements of the north, west, and south walls.

House 5 was likely a rectangular pieux-en-terre structure based on the three post features that comprise the east wall. The walls were likely pièce-sur-pièce. The House 5 study area averages a square nail density of $47.6 / \mathrm{m}^{2}\left(4.5 / \mathrm{ft}^{2}\right)$ (Table 46$)$. Although this is higher than the pièce-sur-pièce criterion $\left(43.1 / \mathrm{m}^{2}\right)$ established by Stilson (1990), this difference likely stems from the use of $1 / 8$ in. $(3 \mathrm{~mm})$ screenings during the SAIP excavation, while Stilson's hypothesis is based on 1/4 in. $(6 \mathrm{~mm})$ screens. The average nail density is still lower than the expected density of a balloon frame structure $\left(64.6 / \mathrm{m}^{2}\right)$.

TABLE 46

HOUSE 5 ARTIFACT RECOVERY DATA

\begin{tabular}{lrr}
\hline \hline & Window Glass & Square Nails \\
\hline Excavation Units (n and area) & $19\left(18.5 \mathrm{~m}^{2}\right)$ & $19\left(18.5 \mathrm{~m}^{2}\right)$ \\
Avg. frequency $\left(\mathrm{n} / \mathrm{m}^{2}\right)$ & 50.2 & 47.6 \\
Min $\left(\mathrm{n} / \mathrm{m}^{2}\right)$ & 14 & 5 \\
Max $\left(\mathrm{n} / \mathrm{m}^{2}\right)$ & 158 & 112 \\
Std Deviation $\left(\mathrm{n} / \mathrm{m}^{2}\right)$ & 31.93 & 24.13 \\
\hline \hline
\end{tabular}


House 5 likely had an earthen floor; compact gray sediments consistent with other house floor deposits were present in seven units (Feature 2002-15) (Figure 88). There was insufficient data to interpret the architectural details about the floor and roof based solely on nail attributes. The highly fragmentary condition of the nail assemblage (approximately 80\%) limited the identification of nail style varieties and common size classes - two attributes essential to ascribing nail function. The location of the granary deposits may explain the increase in fragmented square nails that could not be assigned manufacture type in the northern units (Figures 86 and 87).

Window locations were placed where HBC-era window glass clustered, and door locations were based primarily on the provenience of door-related hardware. The distribution of HBC-era window glass suggests windows were located near the southeast, northeast, and northwest corners of the inferred footprint (Figure 88). The hearth feature (EU01) contained the greatest density of artifacts, including window glass, possibly because broken glass fragments became nestled between the hearth rocks. A window was placed near this concentration, on the south wall, because the hearth and chimney occupy the southern half of the east wall. The majority of potentially door-related clinched nails were equally distributed between the eastern and western excavation units; these nails were not incorporated into the door inference. A doorknob and door latch/lock were found in EU03, in the center of the east wall. A door placed next to the center post on the east wall would have provided direct access to the north-south road that ran along the eastern edge of the Village. A pintle hinge was found in EU08 near the southeast corner and may indicate a second door at House 5 (Figure 88). However, this hardware was not located in the museum collection and potentially may not be related to a door. 
The range of window glass thicknesses suggests House 5 was the longest-living and most regularly maintained structure in this study. The primary window glass thickness mode is 0.045 in. $(n=204,20.7 \%)$ (Figures 83 and 84). In contrast, the other houses in this study yielded only one or two thickness intervals that dominated the window glass assemblage. The initial construction of House 5 likely took place in the early $1830 \mathrm{~s}$, when both 0.035 -in. and 0.045 -in. thick windowpanes were available. Together, these two interval classes account for 342 window glass fragments, or nearly one-third of House 5's window glass assemblage. If the structure had been built in the late 1830 s, this assemblage would include a larger percentage of 0.055 -in. thick glass. In the positively identified HBC-excavation levels, window glass averaging 0.055 in., 0.065 in., and 0.075 in. were equally represented (Figure 84). The frequency of window glass fragments decreased sharply after 0.075 in., suggesting that no new windows were added or repaired after 1855 .

Evidence for repair or modification phases includes concentrations of thicker window glass fragments and machine cut nails in the eastern the northern sections of the study area (Figure 88d). Regular window maintenance was conducted throughout the $1830 \mathrm{~s}, 1840 \mathrm{~s}$, and 1850s. Fragments of the thicker windowpanes (0.055 in. to 0.075 in.) were collected from nearly all of the House 5 excavation units, but a concentration of only 0.055 in., 0.065 in., and 0.075 in. thick window glass in the northeast corner of House 5 (EU18 and EU19) likely indicates the installation of a new window. This northeast window was installed as early as 1840 or 1845 , and panes were likely replaced through the late 1850 s. 
Structural maintenance may have occurred using wrought nails, but these events would not appear distinct from the initial construction phase. The focused spatial distribution and the dominance of $8 \mathrm{~d}$ and $9 \mathrm{~d}$ nails (over $60 \%$ of machine cut nails) may be an indication that targeted repairs or modifications were made to House 5 (Figure 89). American machine cut nails account for approximately $30 \%$ of the square nail assemblage, and were collected mostly from the northern and eastern excavation units (Figure 88). In contrast, the modifications at House 2 were more widespread-more than half of the nails were machine cut and multiple sizes (and functions) were represented within the assemblage. The lack of British machine cut nails suggests that this repair phase occurred no earlier than the late 1840s (Table 45). Given the concentration of wrought nails in the southern half of the study area (Figure 88d), and the abundance of machine cut nails (and dearth of wrought nails) in the northern units, perhaps the northern portion of House 5 was built as a later extension to the original structure. Additional excavations would be needed to test this. After repairs ceased in the late 1850s, House 5 met the same fate as its neighbors. The nail condition ratios of complete wrought (3.8:1.3:1) and machine cut nails (4:3:0.3) denote the structure was torn down.

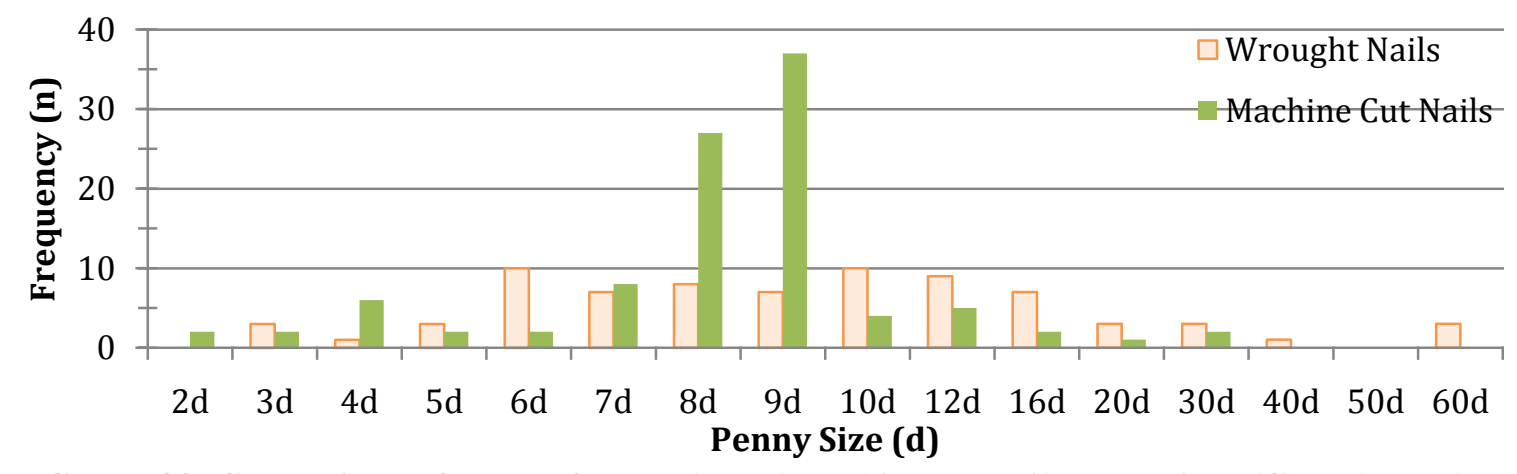

FIGURE 89. Comparison of House 4 wrought and machine cut nail penny sizes (Chart by author, 2011). 
Based on its life history and relative location to Houses 1,2, and 3 and East 5th Street, House 5 should appear in Gibbs' 1851 illustration. A comparison of excavation maps, historical maps, and the illustrations by Gibbs and Sohon point to one likely location in the far left of Gibbs's drawing (Figure 90). Some of these northeast corner houses (to the left) are likely those excavated by Thomas and Hibbs (1984). The southern-most structure could be House 5, but the architectural features differ somewhat from the archaeology. The house indicated in Figure 90 appears to be oriented northsouth, with a possible south-facing door (or large window), a roof made of wood planks, and a side shed on the west wall. Unfortunately, this structure is not the clearest part of the drawing. The Gibbs and Sohon illustrations depict the houses in the northeast section of the Village as having plank roofs with north-south oriented gables.

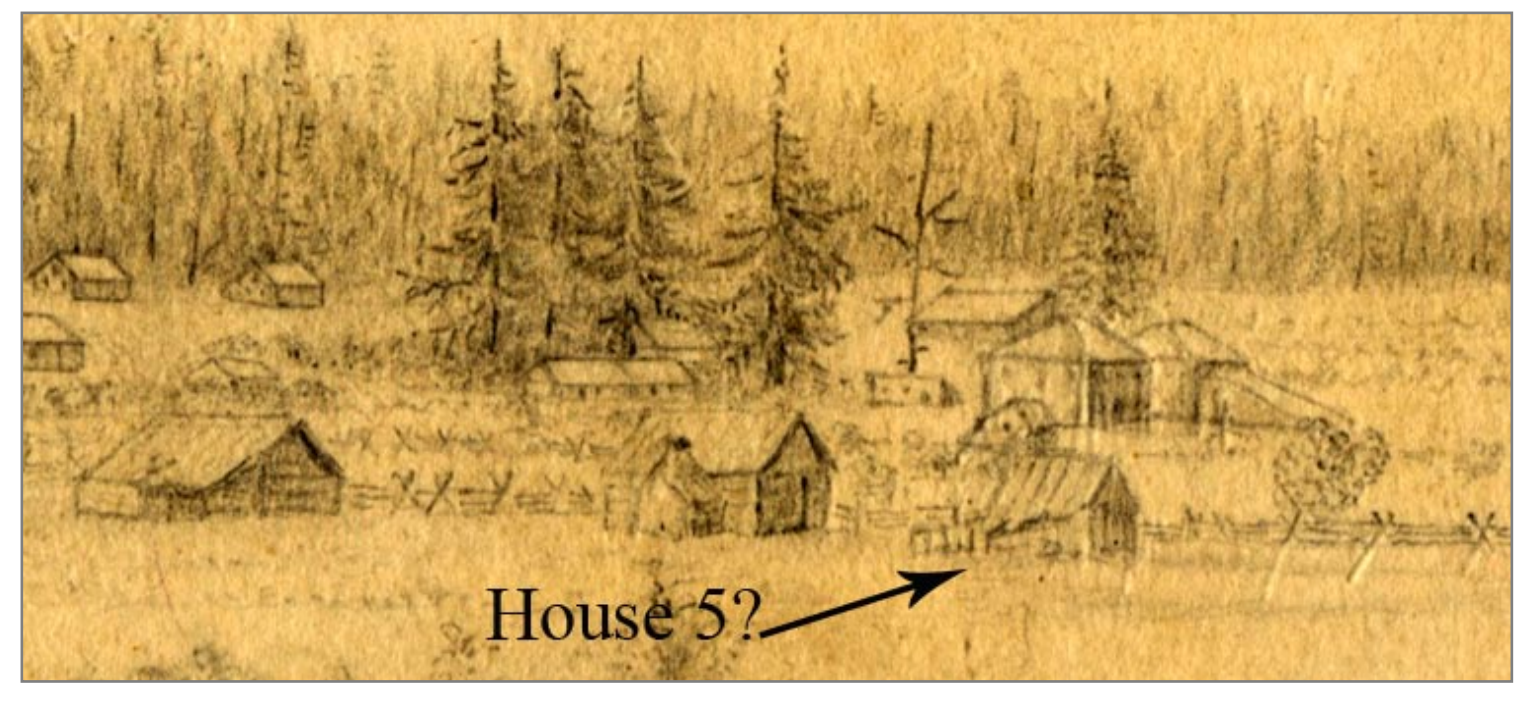

FIGURE 90. Detail of Gibbs's 1851 sketch, showing the northeast section of the Village, and a possibly candidate for House 5, based on relative location to the houses excavated in 1980-1981. (Courtesy of Fort Vancouver National Historic Site.) 


\section{CHAPTER 11 \\ DISCUSSION}

This chapter discusses the houses and the Village vernacular landscape in light of the community dynamics that they influenced, and were influenced by. The first section characterizes the level of variation and similarity that exist between the five houses at the heart of this study. The second section examines how these houses related (spatially and temporally) with the rest of the Village landscape, drawing on archaeological data and historical records. The final section addresses research question findings regarding the community dynamics in the Village over time.

\section{Architectural Variation}

The five houses share a number of formal traits linked to common construction methods, but differ in the placement, quantity, and formal details of architectural elements (where comparisons could be made) Table 47 summarizes the interpretations for each house, regarding foundation construction method, size, estimated date range of the house, and the dates of changes to the structure.

\section{TABLE 47}

HOUSE INTERPRETATIONS IN BRIEF

\begin{tabular}{lllll}
\hline \hline Structure & Construction & Size (est.)* & Date Range & Additional Phase $(\mathrm{s})$ \\
\hline House 1 & Pieux-en-terre & $18 \times 18.5 \mathrm{ft}$. & $1834-1850 \mathrm{~s}$ & $1845-1850$ \\
House 2 & Poteaux-sur-sole & $24 \times 18.75 \mathrm{ft}$. & $1840-1850 \mathrm{~s}$ & $1845-1850 \mathrm{~s}$ \\
House 3 & Queue d'aronde? & $18 \times 13.8 \mathrm{ft}$. & $1830-1850 \mathrm{~s}$ & $1840-1850$ \\
House 4 & Poteaux-sur-sole & $8 \times 10+\mathrm{ft}$. & $1820 \mathrm{~s}-1845$ & NA \\
House 5 & Pieux-en-terre & $12.5 \times 12.5 \mathrm{ft}$. & $1830-1860$ & $1840 \mathrm{~s}$ and $1850 \mathrm{~s}$ \\
\hline
\end{tabular}

* Size in English units because it most closely approximates the measurement systems used by the builders.

Some of the interpretive differences between the houses can be attributed to different field methodologies. The use of 1/4-in. and 1/8-in. (6 $\mathrm{mm}$ and $3 \mathrm{~mm}$ ) mesh screens increased artifact recovery in 2001-2003, even in previously excavated areas 
(Table 48, Figure 91). The five excavations were not consistent in area or depth, and some (House 3 and 5) appeared to sample a greater percentage of the original structure than others (House 2 and 4) causing some archaeological datasets to be more complete than others. This meant that the plan to compare houses based on their layouts and details of architectural elements like hearths, side sheds, windows, and doors could not be fully realized in this study.

TABLE 48

COMPARATIVE ARTIFACT RECOVERY DATA

\begin{tabular}{|c|c|c|c|c|}
\hline & \multicolumn{2}{|c|}{ Window Glass } & \multicolumn{2}{|c|}{ Square Nails } \\
\hline & KARDAS & SAIP & KARDAS & SAIP \\
\hline & 1968-1969 & $2001-2003$ & 1968-1969 & 2001-2003 \\
\hline \multicolumn{5}{|l|}{ House 1} \\
\hline Excavation Units ( $\mathrm{n}$ and area) & $21\left(42.5 \mathrm{~m}^{2}\right)$ & $8\left(7.5 \mathrm{~m}^{2}\right)$ & $21\left(42.5 \mathrm{~m}^{2}\right)$ & $8\left(7.5 \mathrm{~m}^{2}\right)$ \\
\hline Avg. frequency $\left(\mathrm{n} / \mathrm{m}^{2}\right)$ & 0.4 & 17.5 & 5.2 & 13.6 \\
\hline $\operatorname{Min}\left(\mathrm{n} / \mathrm{m}^{2}\right)$ & 0 & 1 & 0 & 4 \\
\hline $\operatorname{Max}\left(\mathrm{n} / \mathrm{m}^{2}\right)$ & 5 & 34 & 14 & 24 \\
\hline Std Deviation $\left(\mathrm{n} / \mathrm{m}^{2}\right)$ & 1.19 & 9.90 & 4.39 & 7.20 \\
\hline \multicolumn{5}{|l|}{ House 2} \\
\hline Excavation Units ( $\mathrm{n}$ and area) & $21\left(41.5 \mathrm{~m}^{2}\right)$ & $6\left(6 \mathrm{~m}^{2}\right)$ & $21\left(41.5 \mathrm{~m}^{2}\right)$ & $6\left(6 \mathrm{~m}^{2}\right)$ \\
\hline Avg. frequency $\left(\mathrm{n} / \mathrm{m}^{2}\right)$ & 54.7 & 102.2 & 27.1 & 35.2 \\
\hline $\operatorname{Min}\left(\mathrm{n} / \mathrm{m}^{2}\right)$ & $<1$ & 58 & 0 & 30 \\
\hline $\operatorname{Max}\left(\mathrm{n} / \mathrm{m}^{2}\right)$ & 538 & 145 & 184 & 43 \\
\hline Std Deviation $\left(\mathrm{n} / \mathrm{m}^{2}\right)$ & 123.54 & 30.25 & 41.68 & 4.71 \\
\hline \multicolumn{5}{|l|}{ House 3} \\
\hline Excavation Units ( $\mathrm{n}$ and area) & $16\left(33.64 \mathrm{~m}^{2}\right)$ & $4\left(4 \mathrm{~m}^{2}\right)$ & $16\left(33.64 \mathrm{~m}^{2}\right)$ & $4\left(4 \mathrm{~m}^{2}\right)$ \\
\hline Avg. frequency $\left(\mathrm{n} / \mathrm{m}^{2}\right)$ & 4.7 & 42.8 & 16.3 & 41.5 \\
\hline $\operatorname{Min}\left(n / m^{2}\right)$ & 0 & 26 & 3 & 24 \\
\hline $\operatorname{Max}\left(\mathrm{n} / \mathrm{m}^{2}\right)$ & 37 & 79 & 50 & 73 \\
\hline Std Deviation $\left(\mathrm{n} / \mathrm{m}^{2}\right)$ & 9.90 & 24.87 & 14.26 & 22.93 \\
\hline \multicolumn{5}{|l|}{ House 4} \\
\hline Excavation Units ( $\mathrm{n}$ and area) & $8\left(12.5 \mathrm{~m}^{2}\right)$ & $\sim$ & $8\left(12.5 \mathrm{~m}^{2}\right)$ & $\sim$ \\
\hline Avg. frequency $\left(\mathrm{n} / \mathrm{m}^{2}\right)$ & 6.4 & $\sim$ & 36.1 & $\sim$ \\
\hline $\operatorname{Min}\left(n / m^{2}\right)$ & $<1$ & $\sim$ & 2.7 & $\sim$ \\
\hline $\operatorname{Max}\left(\mathrm{n} / \mathrm{m}^{2}\right)$ & 13 & $\sim$ & 89 & $\sim$ \\
\hline Std Deviation $\left(\mathrm{n} / \mathrm{m}^{2}\right)$ & 4.40 & $\sim$ & 30.25 & $\sim$ \\
\hline \multicolumn{5}{|l|}{ House 5} \\
\hline Excavation Units ( $\mathrm{n}$ and area) & $\sim$ & $19\left(18.5 \mathrm{~m}^{2}\right)$ & $\sim$ & $19\left(18.5 \mathrm{~m}^{2}\right)$ \\
\hline Avg. frequency $\left(\mathrm{n} / \mathrm{m}^{2}\right)$ & $\sim$ & 50.2 & $\sim$ & 47.6 \\
\hline $\operatorname{Min}\left(\mathrm{n} / \mathrm{m}^{2}\right)$ & $\sim$ & 14 & $\sim$ & 5 \\
\hline $\operatorname{Max}\left(\mathrm{n} / \mathrm{m}^{2}\right)$ & $\sim$ & 158 & $\sim$ & 112 \\
\hline Std Deviation $\left(\mathrm{n} / \mathrm{m}^{2}\right)$ & $\sim$ & 31.93 & $\sim$ & 24.13 \\
\hline
\end{tabular}

Note: The number of excavation units refers specifically to the units associated with the house footprint. House 4 and House 5 were not excavated twice 


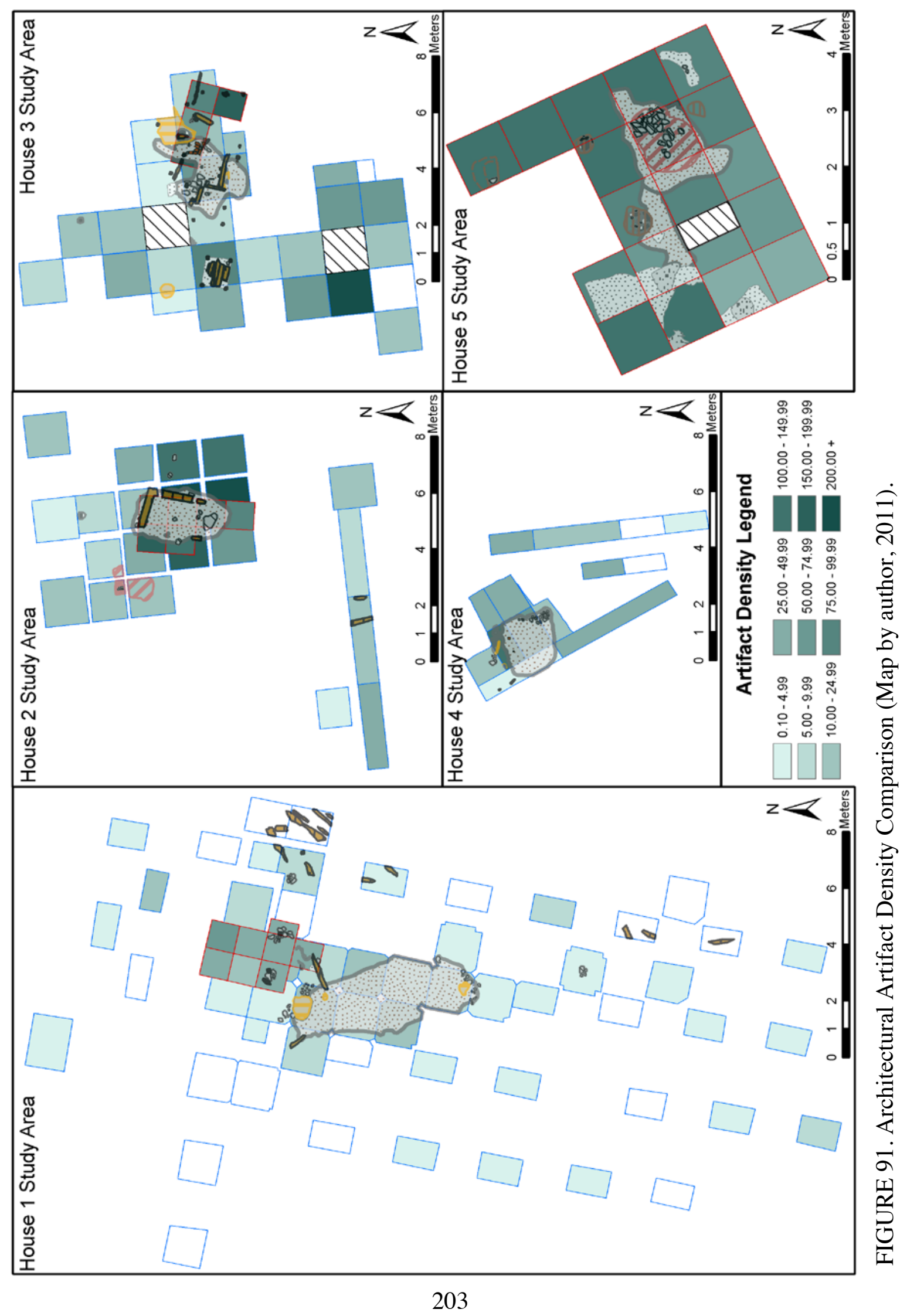


Some variation between the assemblages (artifact densities, condition of features) was likely a result of post-depositional formation processes and disturbances. In the nearly 100 years between the demolition of the Village and its archaeological rediscovery, the U.S. Army, NPS, and natural forces subjected the Village to grounddisturbing activities. House 1 was discovered adjacent to a 20th-century trash pit, Houses 2, 3, and 5 were partially covered by U.S. Army structures in the 1940 s, cherry trees planted by the NPS after 1969 disrupted a brick hearth feature at House 3, and burrowing rodents demonstrated their skill at ground disturbance.

While the field methods and the site formation processes might dilute the densities and spatial distributions of architectural artifacts, the character of the assemblages that point to some inherent differences between the structures did emerge through the data. For example, the window glass thickness distributions were not affected by screening methods. The Kardas and SAIP window glass assemblages followed the same general thickness distribution trends (Figure 92). This also suggests that despite the screening inconsistencies in 1968 and 1969, the window glass variations stem from the structures themselves. Likewise, the relative frequencies of nail size classes (Figure 93) and nail manufacture types (Table 49).

TABLE 49

NAIL TYPE DATA FOR ALL FIVE HOUSES

\begin{tabular}{|c|c|c|c|c|c|c|c|c|c|c|}
\hline & \multicolumn{2}{|c|}{ "House 1} & \multicolumn{2}{|c|}{ House 2} & \multicolumn{2}{|c|}{ House 3} & \multicolumn{2}{|c|}{ House 4} & \multicolumn{2}{|c|}{ House 5} \\
\hline & $\mathrm{n}$ & $\%$ & $\mathrm{n}$ & $\%$ & $\mathrm{n}$ & $\%$ & $\mathrm{n}$ & $\%$ & $\mathrm{n}$ & $\%$ \\
\hline Hand Wrought & 171 & 50 & 460 & 36 & 535 & 75 & 281 & 73 & 478 & 52 \\
\hline Machine Cut, American & 48 & 14 & 329 & 26 & 40 & 6 & 41 & 11 & 170 & 19 \\
\hline Machine Cut, British & 26 & 8 & 51 & 4 & 9 & 1 & 9 & 2 & 18 & 2 \\
\hline Machine Cut, other & 63 & 18 & 209 & 17 & 26 & 3 & 35 & 9 & 90 & 10 \\
\hline Square, Indeterminate & 35 & 10 & 217 & 17 & 105 & 15 & 18 & 5 & 160 & 17 \\
\hline Total & 343 & 100 & 1266 & 100 & 715 & 100 & 384 & 100 & 916 & 100 \\
\hline
\end{tabular}

Note: Frequencies represent the house remains and do not include the entire study areas

Nail counts have been combined from the 1968-1969 and SAIP excavations for Houses 1, 2, and 3. 


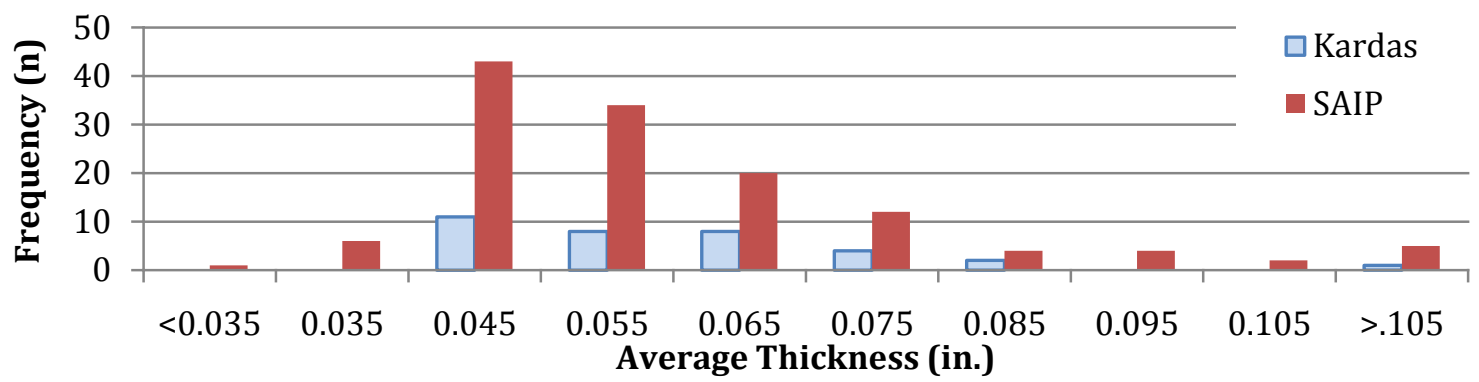

(a)

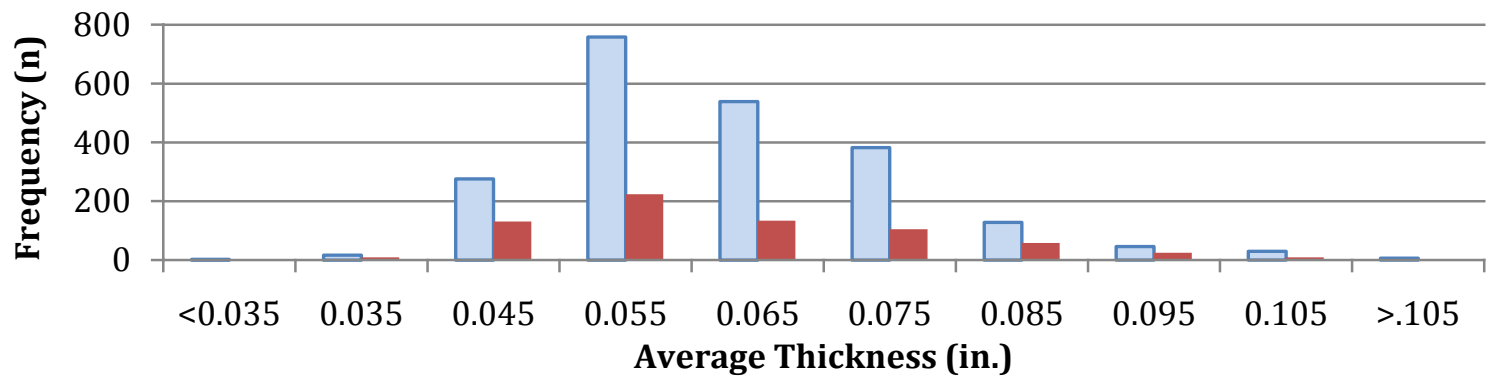

(b)

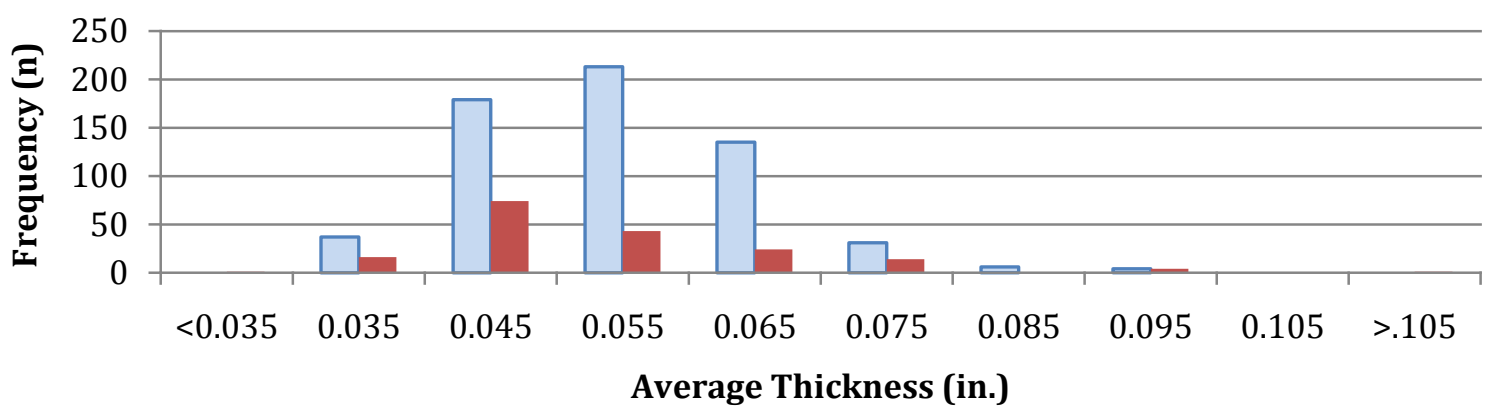

(c)

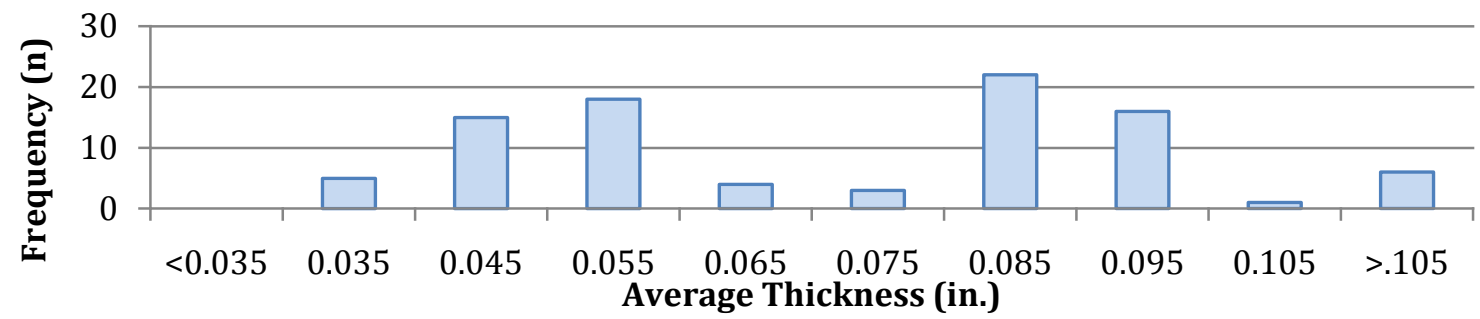

(d)

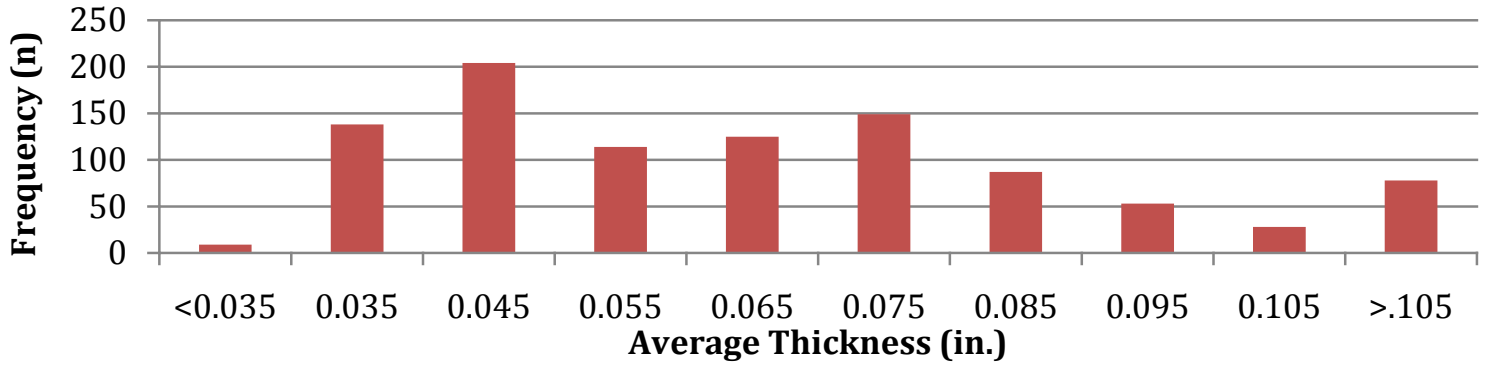

(e)

FIGURE 92. Comparison of the window glass thickness distributions recovered from study areas of House 1 (a), House 2 (b), House 3 (c), House 4 (d), and House 5 (e), separated by excavation (Charts by author, 2011) 


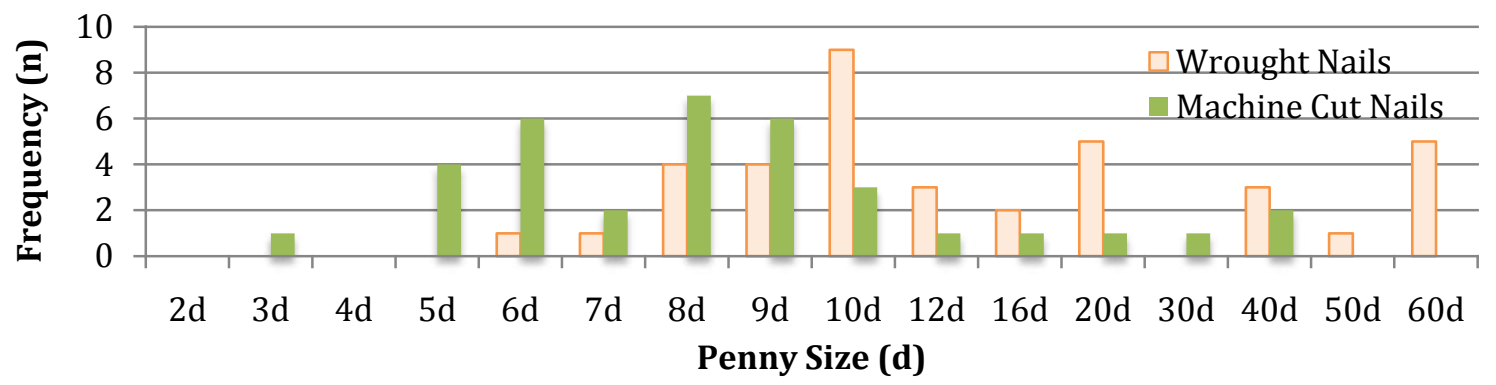

(a)

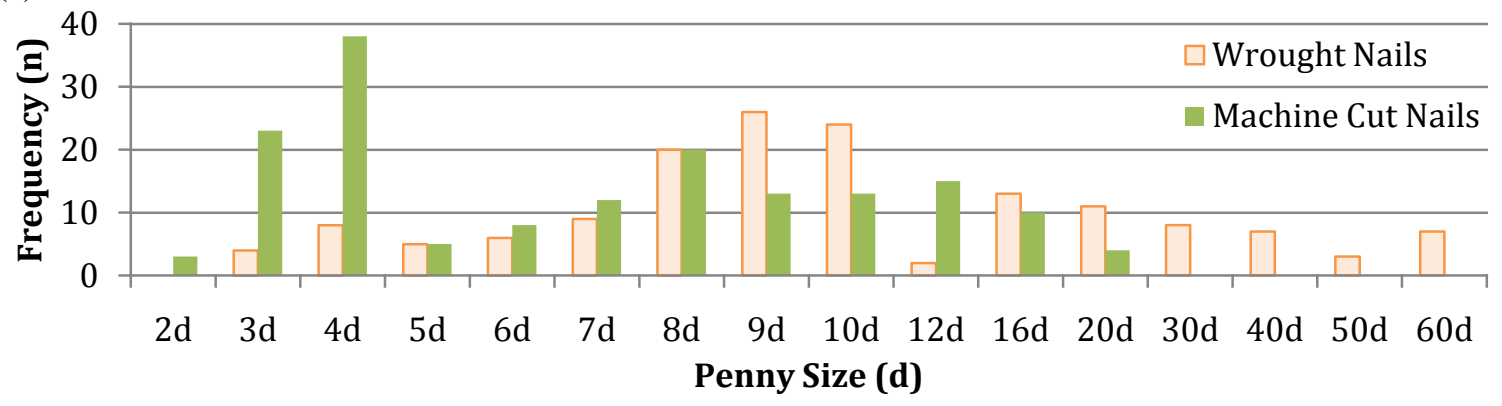

(b)

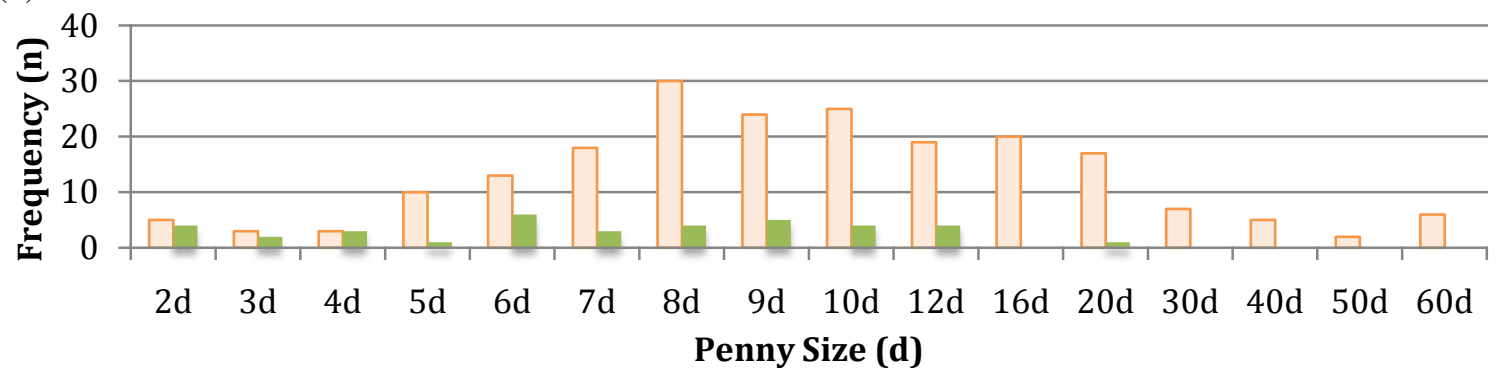

(c)

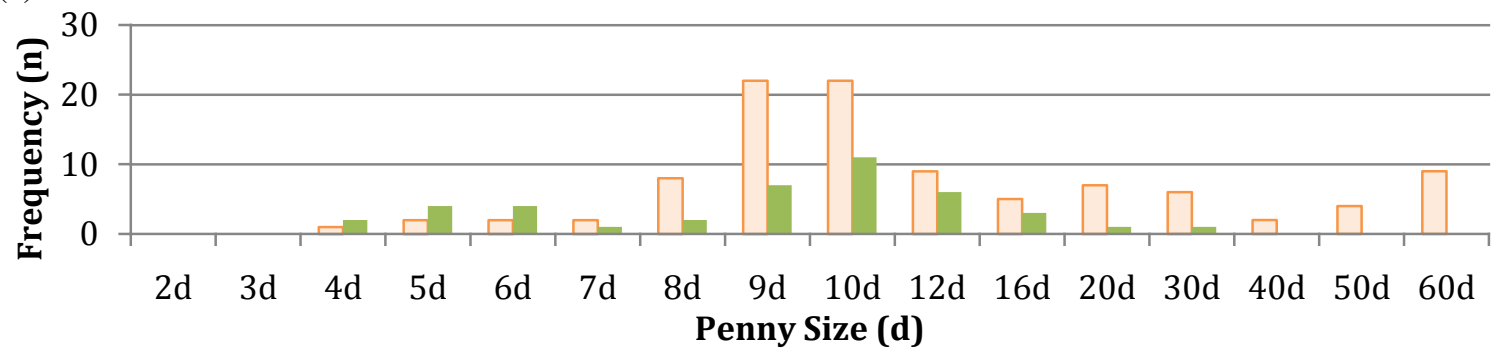

(d)

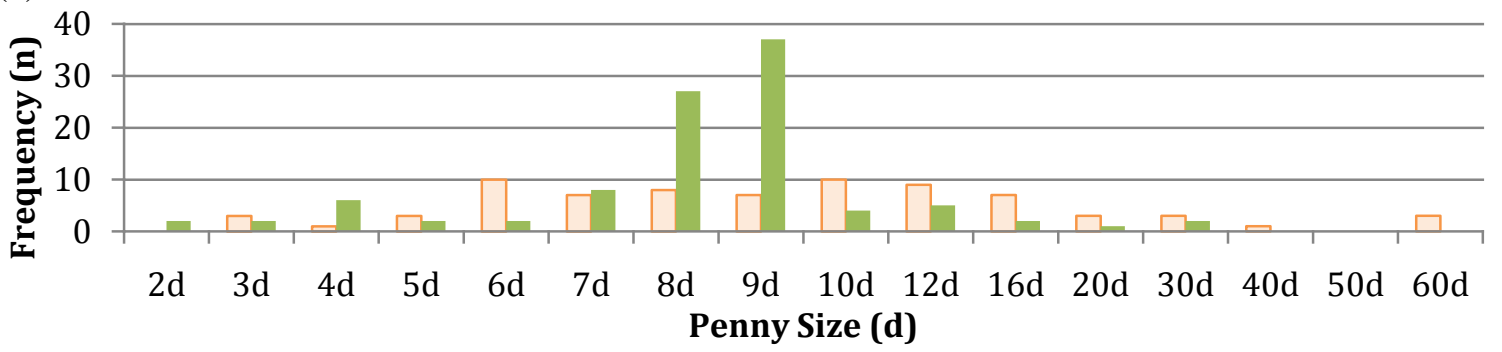

(e)

FIGURE 93. Comparison of the nail penny size distributions recovered from study area of House 1 (a), House 2 (b), House 3 (c), House 4 (d), and House 5 (e), separated by manufacture type (Charts by author, 2011). 
The builders of these five houses appear to have relied on architectural "templates" that originated with the French-Canadian and Métis in Canada. The nail assemblages and foundation features from Houses 1-5 are consistent with the patterns expected from French-Canadian earthfast architectural styles. Nail density data suggest that all five houses consistently had pièce-sur-pièce walls and earthen floors. Both the familiar pieux-en-terre and poteaux-sur-sole foundation styles were represented, as well as a potential dovetail corner-notched variation (piece sur piece en queue d'aronde). This style was common in eastern Canada and the Red River settlement, but not previously identified at Fort Vancouver.

Some variation between the houses was observed in the number and location of windows, hearth type and location, the potential size of the structures, and the measurement system used during construction (Figure 94). Table 50 tries to compare the houses based on the attributes inferred archaeologically. The hearths at House 3 and House 5 were lined with stones and bricks; the other hearths were identified based on concentrations of burned earth, charcoal, and bone. The placement of windows is the most obvious architectural variation. House 5 had at least three distinct clusters of window glass. House 2 had twice the average window glass density as House 5, so likely had more than three windows, but not enough area was exposed to define discrete window locations. In comparison, the House 1 remains barely suggested the presence of one window. House 3 (which had at least two windows) and House 4 had similar window glass densities, so it is likely that another window location existed but was not exposed during the House 4 excavation. 


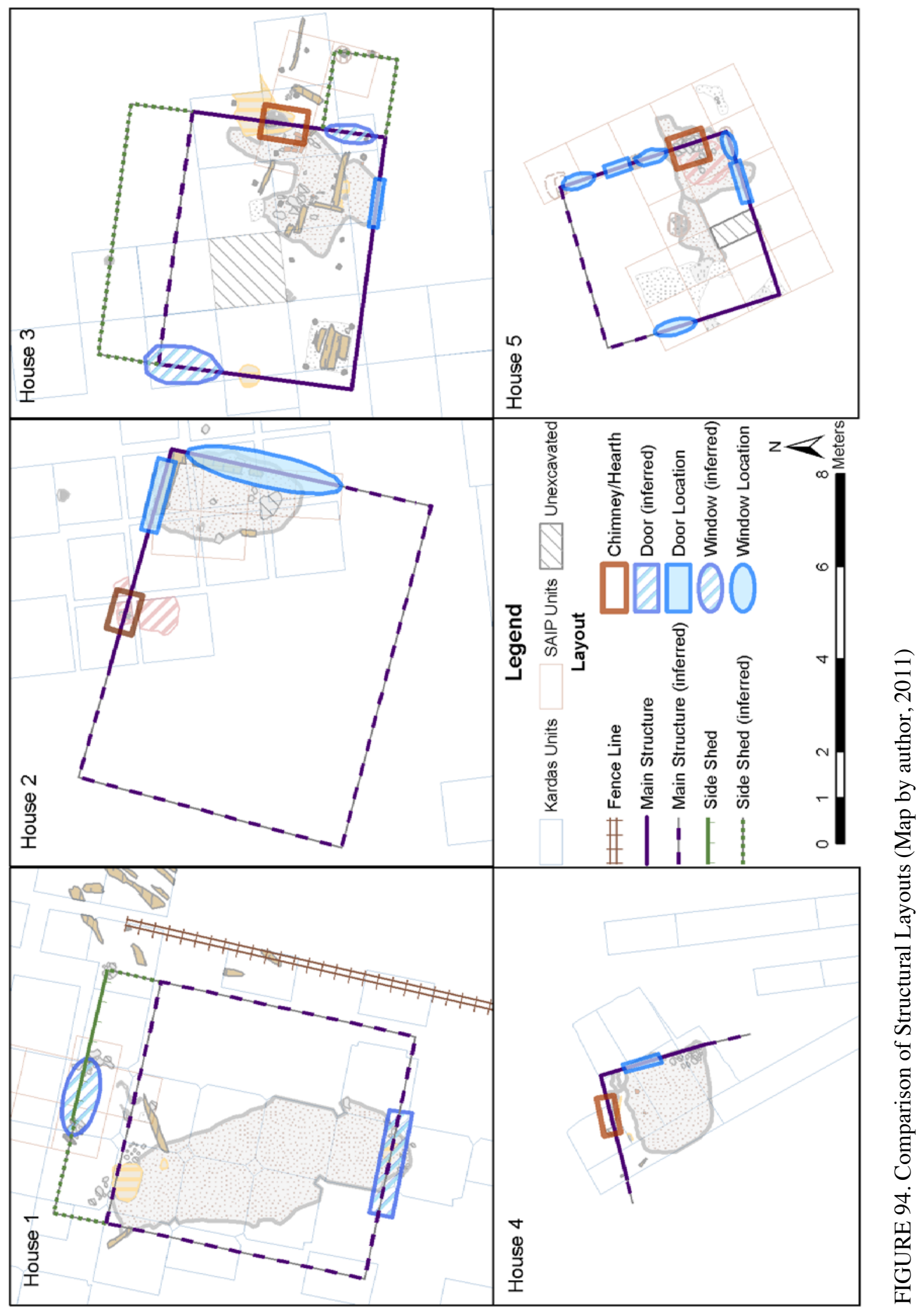


TABLE 50

COMPARISON OF INFERRED STRUCTURAL CHARACTERISTICS OF HOUSES 1 - 5

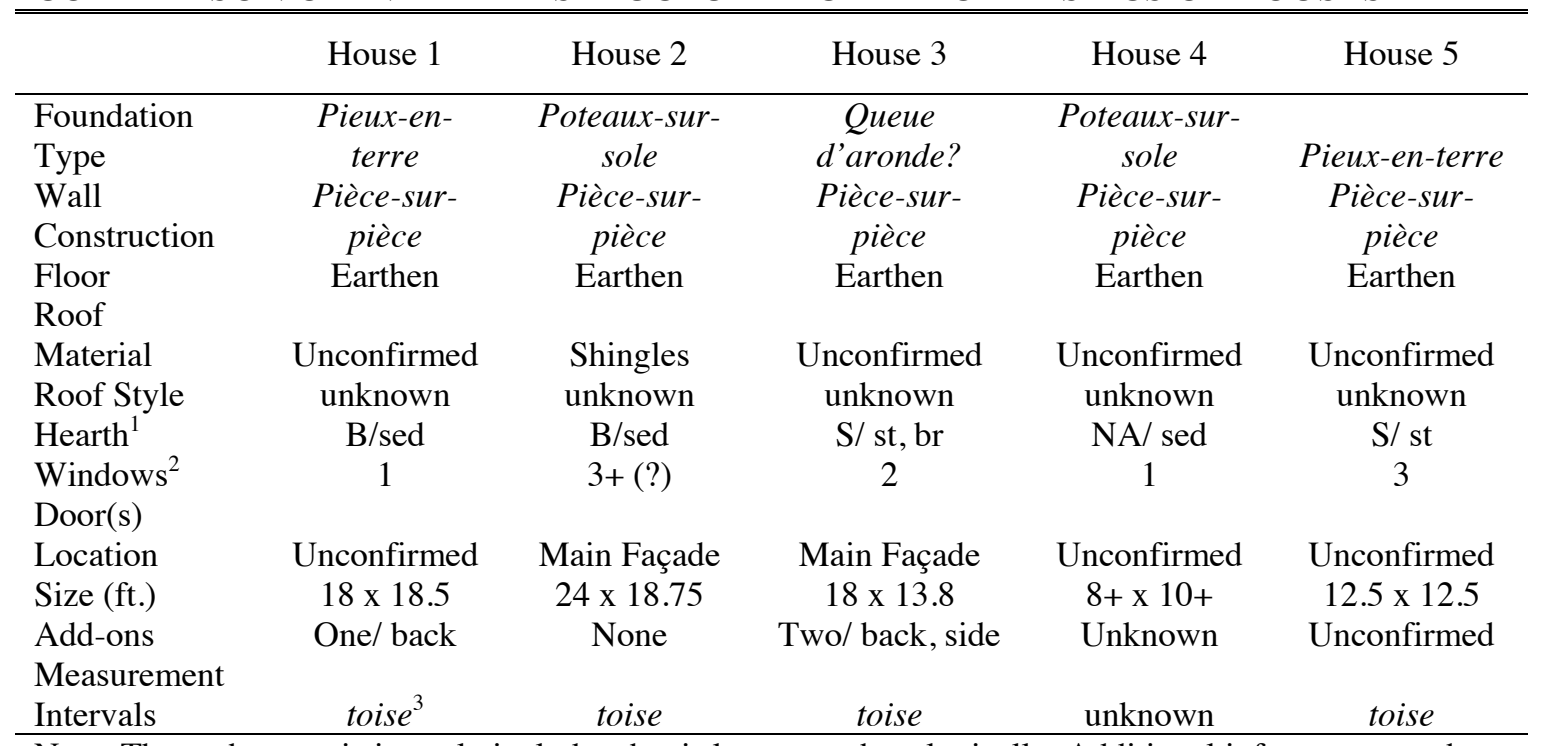

Note: These characteristics only include what is known archaeologically. Additional inferences may be drawn from the Gibbs illustration at a later time.

1. Hearth code: (location) $B=$ back wall, $S=$ side; (construction): sed= sediment, $s t=$ stone, br=brick

2. Number of windows often translates to how many walls have windows because discrete clusters could not be distinguished.

3. Some post features at House 1 were spaced $6.5 \mathrm{ft}$, others were spaced $5 \mathrm{ft}$ apart.

Comparing structure size proved difficult because it was not possible to define all four walls for any of the five structures. The house sizes listed in Tables 47 and 50 were extrapolated and estimated based on the greatest visible extents of the house floor and foundation features. Most wall lengths were multiples of approximately $2 \mathrm{~m}$, or 6 to 6.5 $\mathrm{ft}$ - - the toise unit of measure. House 4 was insufficiently excavated to confidently estimate its size or unit of measure. House 1 did include one 5-ft. interval distance between two wall posts on the north shed, but overall its wall lengths were multiples of six. Like the foundation styles, the toise is a French-Canadian architectural trait (Hébert 2007:130). Intervals of $5 \mathrm{ft}$. could indicate either an English or French-Canadian unit of measure, as the French-Canadian interval of five pieds (approximately $5 \mathrm{ft}$.) was also common (Hébert 2007:130). This variation may have come from the architectural 
traditions of the builders, or employees had to work around whatever available lumber dimensions the HBC supplied from the sawmill. No documentation was found indicating the standard timber dimensions from the sawmill.

From the standpoint of understanding the [architectural] history of the Village, the different "life experiences" of the houses are more significant than the variations in form. The construction of the five houses took place over a span of 10 to 15 years (circa 18301840), but the repairs occurred within a five-year time span (circa 1840-1845). Houses 1 , 2, and 3 had a single repair phase, House 5 had two, and House 4 was not refurbished during any stage of its "life" (Figure 95). House 2 appears to have been the most elaborate structure, with a substantial maintenance phase that included a new roof, windows, and general structural repairs.

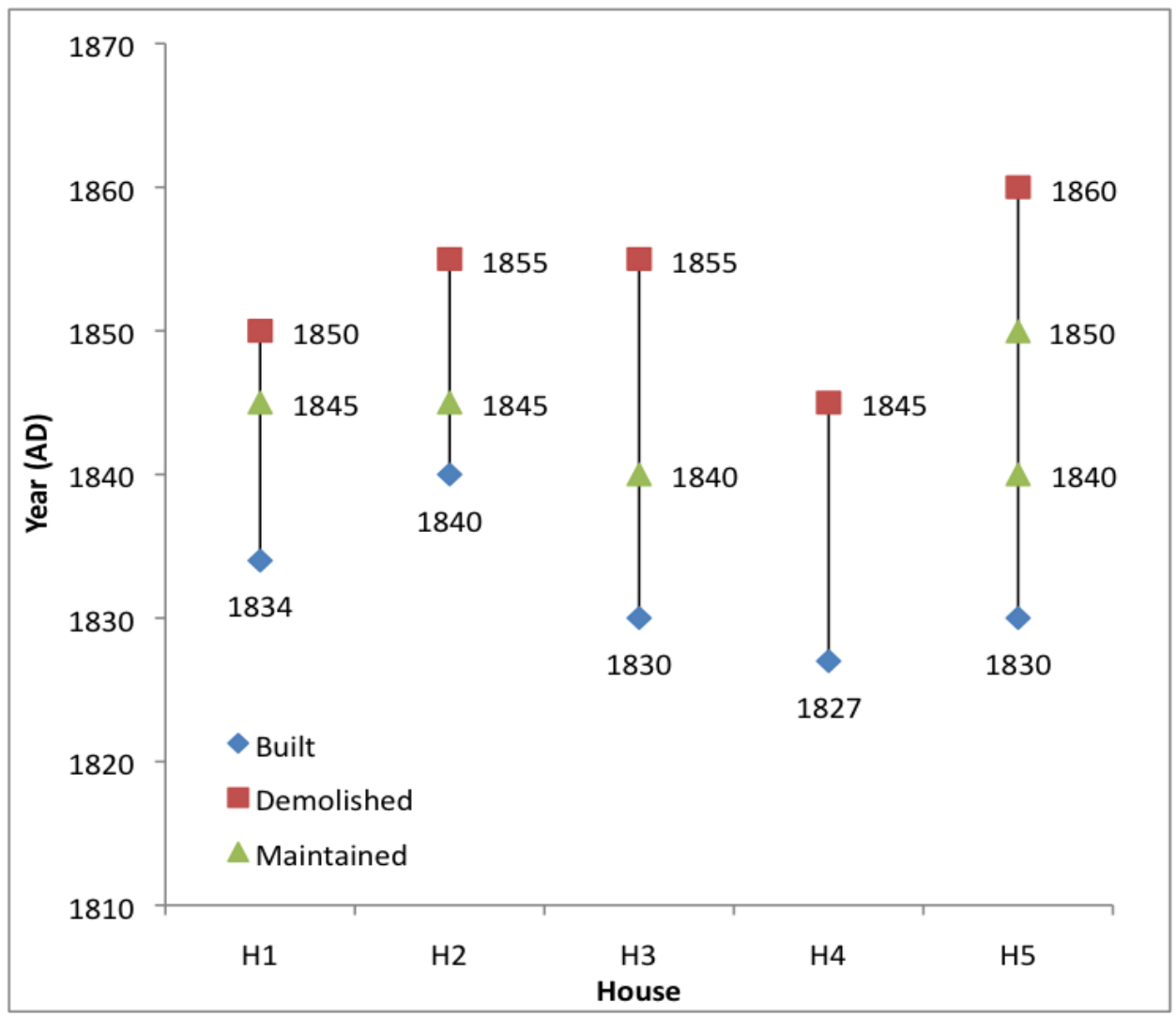

FIGURE 95. Dates of house construction, maintenance, and demolition (Chart by author, 2011). 


\section{The Village Vernacular Landscape}

The placement of houses, as evidenced in the historical literature and archaeological data, was used to understand the vernacular sense of landscape (Figure 96). A large part of the following discussion refers to Village house locations that were established by Thomas and Hibbs (1984). Based on their cartographic research and archaeological investigations, they postulated that between 1845-1860 (the date range of available maps and illustrations) the "village settlement pattern...remained remarkably stable," intersected by a network of roads (Thomas and Hibbs 1984:722). Drawing on the life histories of Houses 1-5 and preliminary window glass-derived dates for other houses, a chronology has been applied to the accepted building locations to identify changes in the vernacular landscape over time. The occupation dates of the WSDOT houses in Table 51 are based on the 1984 excavation report only, and are meant to show the general trends of the landscape's development. Some occupation dates estimated by Thomas and Hibbs (1984:719) were derived from window glass analysis (OP 6, OP 14, OP 20A, and OP 58), but other structures were assigned terminus post quem dates based on their presence in datable maps and illustrations (OP 55, OP 56, OP 57).

The five houses in this study occupy three different "sections" of the settlement (Figure 96 and 97). House 5 part of a house cluster in the northeast section, which also includes the structural features and domestic artifacts found at OP 55, OP 56, and OP 57. Houses 1,2, and 3 follow a slight northwest-southwest orientation through the center of the Village on the north side of this east-west road, and House 4 is in the southern section of the Village. 


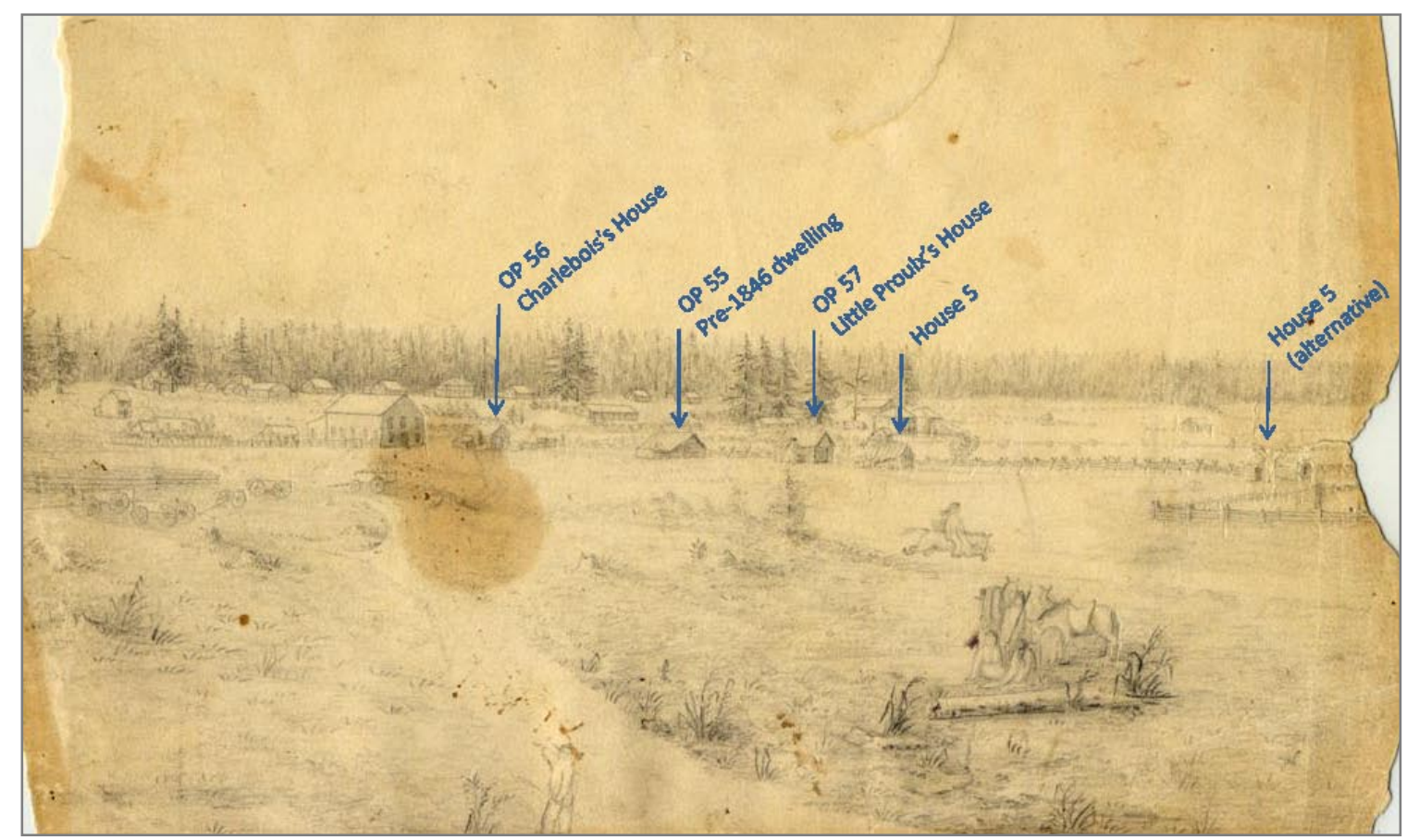

(Left half)

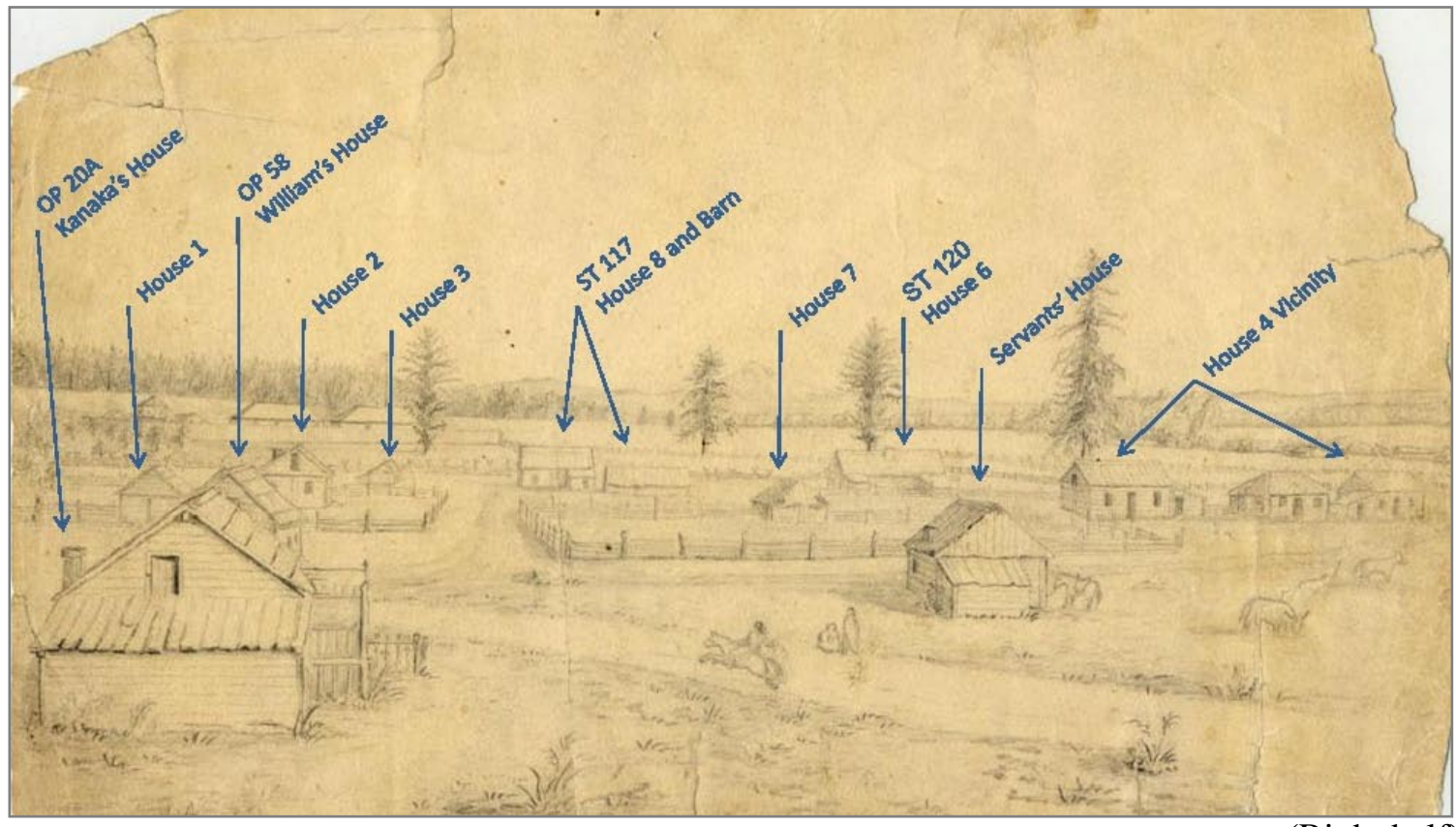

(Right half)

FIGURE 96. Inferred archaeological and cartographic identifications for the houses depicted by Gibbs in 1851. Identifications refer to location and do not necessarily confirm their physical appearance. (Courtesy of Fort Vancouver National Historic Site.) 


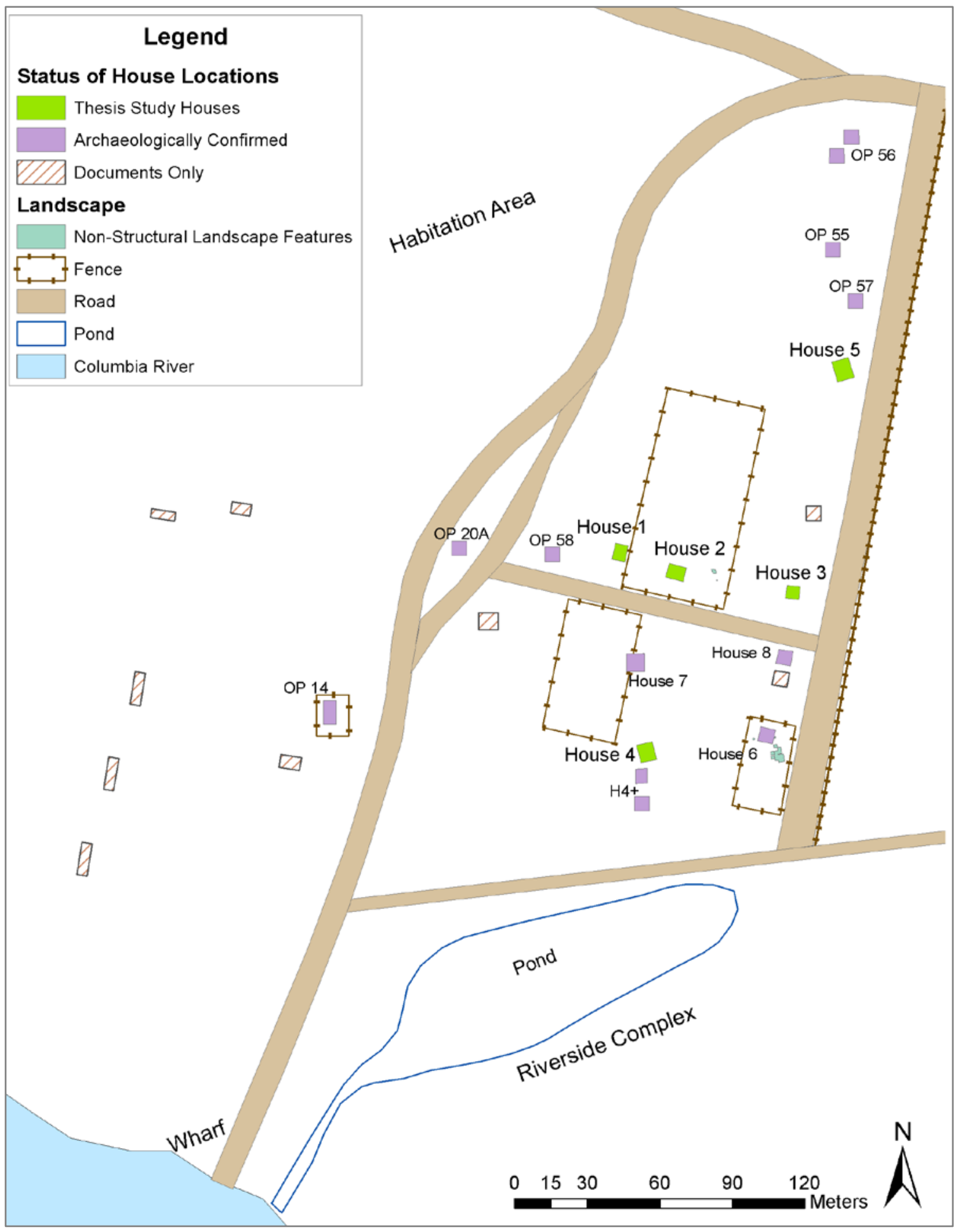

FIGURE 97. Synthetic map of Village house locations on the landscape, based on archaeological and documentary data (Map by author, 2011). 
TABLE 51

INFERRED OCCUPATION DATES FOR VILLAGE HOUSES (ARCHAEOLOGICAL)

\begin{tabular}{lll}
\hline \hline Designation & Date Range (approx.) & Additional Phase \\
\hline House $1^{*}$ & $1834-1850 \mathrm{~s}$ & $1845-1850$ \\
House 2* & $1840-1850 \mathrm{~s}$ & $1845-1850 \mathrm{~s}$ \\
House 3* & $1830-1850 \mathrm{~s}$ & $1840-1850$ \\
House 4* & $1820 \mathrm{~s}-1845$ & None \\
OP 6-2 & Pre-1845 & N/A \\
OP 14 & $1825-1857$ & $1835 ; 1846$ (QMD) \\
OP 20A & $1845-1855$ & N/A \\
OP 55-1 & $1846-1854$ & N/A \\
OP 56 & $1846-1855$ & N/A \\
OP 57 & $1846-1855$ & N/A \\
OP 58 & $1830 \mathrm{~s}-1860 \mathrm{~s}$ & 1845 \\
House 5* & $1830-1860$ & $1840 \mathrm{~s}$ and 1850s \\
House 6 & $1835-1850 \mathrm{~s}$ & N/A \\
House 7 & N/A & N/A \\
House 8 & $1835-1850 \mathrm{~s}$ & N/A \\
\hline
\end{tabular}

Note: $\mathrm{N} / \mathrm{A}=$ no available data

* Houses at the focus of this study

Based on the inferred occupation dates of the houses, the chronological development of the Village settlement pattern proceeded in a north and west direction (Figure 98). The majority of the pre-1835 structures (Houses 3, 4, 5, and OP 14 -1) are located along the eastern and southern Village peripheries, which provided more direct access to the stockade and the Riverside Complex (Figure 97). The Riverside Complex was an area near the wharf set aside for industrial activities. Most of the buildings were stables, warehouses, and workshops but Covington's map indicates some "servants" houses were also present (Carley 1982:1-2). A hospital, where the lower class employees were treated during the malaria outbreaks in the 1830s, also occupied this location. House 4's early construction date, in conjunction with its southern location, may point to a direct relationship between the Village and the wharf before and during the time the second stockade was built (Wilson 2005). 

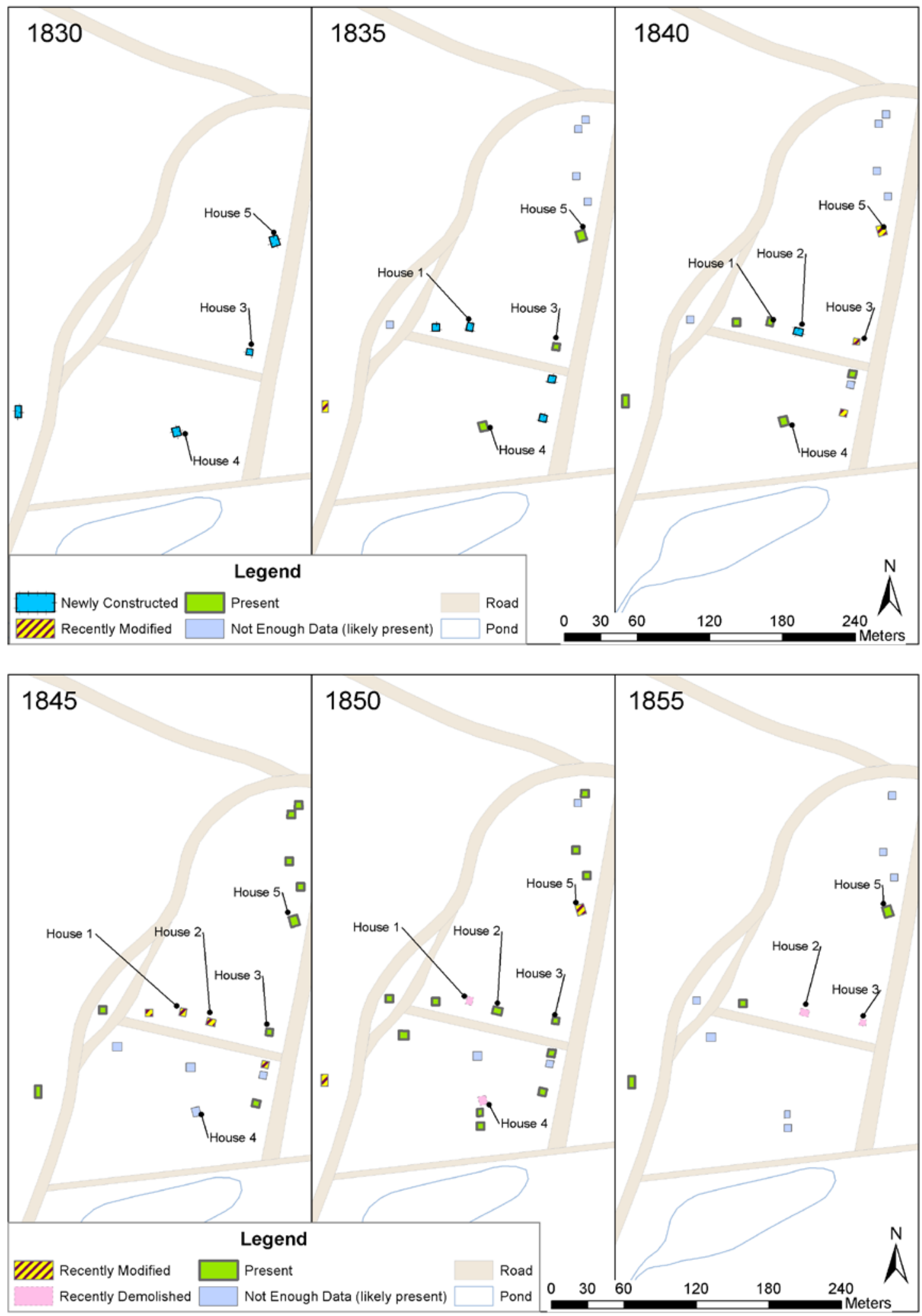

FIGURE 98. Chronological and spatial development of the Village, 1830-1855 (Map by author, 2011). 
The Village continued to expand in the 1830s: House 1 and OP 58 were constructed along the east-west road, OP 14 was enlarged, and a 4 x $5.5 \mathrm{~m}$ (13 x $18 \mathrm{ft}$. house was constructed at the southeast corner of the fort stockade (not mapped). Newly constructed houses continued to fill the central and eastern area of the Village through the 1830s and 1840s, (including Houses 6 and 8). House 2 "wedged" itself and a large fenced yard in between House 1 and House 3.

Sometime in the late 1840s, House 4 caught fire and was torn down, and as many as three new structures were constructed in the vicinity. Thomas (1995) and Lynch (2009) observed that the spatial distribution of artifact densities around House 4 covers an area larger than one house. Two or three houses in the vicinity of House 4 can be seen at the right side of the Gibbs sketch (Figure 80).

Between 1840 and 1845 , there was a great amount of refurbishment occurring to existing Village houses. Based on the window glass, with the exception of House 4, the other four structures underwent a maintenance phase around this time. House 3 and House 5, being slightly older, may have required maintenance as early as 1840 . By the 1840s, the shift in Fort Vancouver's economic focus created a demand for more landbased employees who needed to live in the Village. The new residents, who felt their homes were in need of repair, may have performed this maintenance.

No HBC structures have construction dates after 1846. OP 55, OP 56, and OP 57 were assigned construction dates of 1846 based on Covington's map; these structures were likely built earlier but no window glass or square nail analysis was reported to confirm this hypothesis (Thomas and Hibbs 1984:583-596). 
With the exception of the Village structures that the U.S. Army rented (OP 14 and OP 20A), the unoccupied houses closest to the new Quartermasters Depot on the west side of the Village were the first to be demolished (House 1 and House 2). Houses along the eastern edge (House 5, OP 55-1, OP 56, OP 57) endured until the late 1850s and possibly 1860 .

The Gibbs sketch shows fences encircling three separate structures in this southern section (House 7, House 8, and the double house near House 4) (Figure 96). Covington's map also shows OP 14 with a fence, which was confirmed by a line of small post features (Thomas and Hibbs 1984). In Quebec and French Prairie, fences were used to separate parcels of agricultural land. Le rang was a long, narrow rectangular lot that often abutted a river at one end (Hébert 2007). This does not appear to be replicated at the Village. The arrangement of the houses does not allow for long lots, with the houses located at the end closest to the river.

In general, archaeological research has confirmed the presence of most structures depicted in the historical record (Figures 96 and 97). This is probably because the archaeological research in the Village relied on cartographic data to plan excavation strategies and locations. To ensure that undocumented houses were not overlooked, the SAIP survey blanketed the NPS property 50 x $50 \mathrm{~cm}$ shovel tests at $12 \mathrm{~m}$ intervals but the houses identified (House 5, 6, 7, and 8) appear to coincide with clusters of buildings on the historical drawings and maps. The area between these houses and House 5 is a seemingly empty field, except for a fence that encircled House 2. The SAIP survey results show that few architectural artifacts were found in this space (Gembala et al. 2006). It is possible this space was used as a temporary camp. As early as 1826 , the 
northwestern periphery of the Village (confirmed beyond the precursor to the historic McLoughlin Road) was “occupied intermittently by a seasonal population” (Figure 97) (Thomas and Hibbs 1984:87, 439). Archaeologists identified fire pits, domestic artifacts, and insubstantial structural remains, such as small wood posts and stakes. The seasonal inhabitants included local Native Americans trading at Fort Vancouver and the Voyageurs' summer brigade encampments.

\section{Projects and Community Dynamics}

The Village houses were the results of "projects" that HBC employees pursued. The form and arrangement of the Village vernacular landscape was shaped by the cumulative, albeit occasionally disparate, intentions and needs of its community (Ortner 2006b:136). Historical, social, economic, and environmental conditions impact the amount of work or investment a community puts into houses meant to fulfill humans' universal need for shelter (Carson et al. 1981:168,176). The mercantile colonialist setting at Fort Vancouver brought multiple cultural systems (or worldviews) into contact with each other over a long period of time and superimposed a labor-hierarchy that imbued intra-group social relations with unequal power relations (Silliman 2005:67). The Hudson's Bay Company defined the social structure in which the employees lived and then controlled personal access to resources (building materials) by tying the prices of goods and the financial limits of an employee's wages to ethnicity and job-class differences.

The research hypotheses assumed most employees, once hired by the HBC, would build their own house. Assuming that employees would have had the opportunity to influence the design of a house, even if their company wages limited their means, led to 
the expectation that if the community developed a unified identity, the degree of architectural variation would decrease with time. The lifespan of a house was also assumed to be relatively short, given the damp Pacific Northwest climate and wooden earthfast construction techniques. The results of the life history analysis suggest that, however, many houses appear to have "outlived" the employment tenures of their builders and original inhabitants. In light of the historical and economic changes in the 1830s and 1840s, the discussion of the Village architecture and vernacular landscape must distinguish two phases: the Fort Vancouver Fur Trade phase and the Fort Vancouver Industrial phase. The workforce demographics differ; the ideas of settlement permanence differ; and the available resources differ. The second wave of employees had access to pre-existing, vacant houses. They were not faced with as urgent a need to build shelter. All these factors influenced the types of projects the employees could pursue differed.

The late 1830s and 1840s brought changes to Fort Vancouver and the Village. As early as the mid-1830s retired employees began moving into the Willamette Valley, vacating houses at the same time as when Fort Vancouver switched to a land-based production economy (Towner 1984:796). Many of the land-based jobs were located closer to the fort so the increasingly permanent workforce required more from their earthfast homes, including longevity. Most of the architectural changes at these five houses and the apparent halt in construction of new houses coincide with this shift in economic focus at Fort Vancouver. The dates of employment listed in Towner's (1984:794) historical demographic study of the Village suggests that 1827-1830, 18371838, and 1841-1843 were the most common "hiring periods." At least those were the 
"start of employment" years most frequently represented. William R. Kaulehelehe was provided a ten-year-old structure for housing (Thomas and Hibbs 1984:623-624). The repairs in the 1840s likely represent the actions of residents (continuing and new) who were settling in for a more permanent residence in the Village.

When houses acquired a new resident, many of the attributes (foundation and wall construction methods) were already in place and would not change even when the demographics changed. It is unlikely that a resident would rebuild foundations and walls of the main structure, although they can expand the house, like they did at OP 14 (Thomas and Hibbs 1984). House 1 and House 5, although built at different times both were pieux-en-terre structures and both went through repair phases that appear to only target a few elements of the house. This may suggest that new residents moved in, found the structures lacking in certain aspects (broken windows, not enough light, short on storage) and set about augmenting and repairing the house. Based on the inferred dates of construction of Houses 1-5, for discussion of the projects behind the construction of the houses the focus must turn to Fort Vancouver's fur trade phase.;

The preexisting fur trade culture that originated in Canada was overlooked as a factor when developing these research hypotheses. The houses in this study were built during the initial fur trade phase, at which time French-Canadians and other fur trade veterans dominated the workforce. The three foundation types represented by the five houses in this study originated from the French-Canadian and Métis architectural templates that traveled west with the Northwest Company employees (Garth 1947:122). The use of these construction methods should not be viewed as ethnic markers. In the early years of Fort Vancouver's operation the Métis or French-Canadian employees spent 
the most time away from the post working water-based jobs, making them the least likely to build these French-Canadian-style houses in the Village. Any of the fur trade veterans would have been familiar with the pièce-sur-pièce constructions, regardless of cultural background. Because of this familiarity, the foundation and wall construction process might qualify as a "routine" action (Ortner 2006b). Based on what Monks (1992) and Hamilton (2000) describe in Canada, the architectural elements used to establish intentional distinctions were size, location, and orientation.

The apparent dominance of pieux-en-terre structures over poteaux-sur-sole structures in the Village, whereas the latter were the most common foundation style inside the Fort Vancouver stockade, reflects an intentional time management strategy by the employees. Pieux-en-terre construction can be accomplished more quickly and with fewer materials than poteaux-sur-sole, and even pièce sur pièce en queue d'aronde. This may have been the preferred building technique for employees who had limited down time, limited finances, and little intention of making this house a permanent home. Earthfast houses persisted for centuries in the Southern United States because vital activities necessary for survival, such as agriculture, pulled labor and money away from house construction (Carson et al. 1981:168; Maygarden 2006). Thomas and Hibbs (1984:43-44) interpreted the spatial organization of the Village-houses lined along roads - as signifying longevity and regularity in the settlement, but most of the structures identified appear to have used the cheapest and quickest framing method.

House 2 represents a distinctive project that an employee in the 1840 s pursued. House 2 stands out from the other four structures because it was the largest, had the most windows, and was located within a large fenced area. The foundation sill was buried in a 
trench; this required more time, effort, and timber resources. In addition, this poteauxsur-sole structure potentially had four or more windows-based on Gibbs's depiction of the west wall and the dense concentration of window glass found along the east wall. While a few windowpanes may have been salvaged from earlier structures, the abundance of window glass suggests greater economic standing. The labor and financial investment put into House 2 point to a structure that was built with the intention of longterm residence, at a time when the industrial operations were developing at Fort Vancouver. The same can be said of OP 14 (Jon Johnson house), which underwent a series of expansions during its life cycle. Occupational and wage differences impacted the employees' capabilities to invest in their homes. Perhaps the better-off tradesmen took the opportunity to showcase their relatively higher status when they built, maintained, and refurbished their homes.

A fence surrounds House 2. Given the proximity of this fence to House 1 (Figure 18), the fence may have been use to carve out and claim space, distinct from the neighbors in House 1 and House 3. The Gibbs drawing does not show any garden within this fenced area, nor are any outbuildings visible. To the northeast of House 2 there was a pig burial (perhaps indicating that this fenced area contained livestock). A dog burial is also located north of House 2; perhaps this was a herding dog for the livestock. The southern section of the Village (according to Gibbs) included the greatest concentration (four) of fenced "yards." None were as large as the fence around House 2. While farming was not the purpose of the Village, the employees who worked and resided at Fort Vancouver possibly sought to supplement the wages and company rations that were insufficient to support a family. If temporally diagnostic fence line features can be found 
in future excavations, it would help to determine if this fence was added immediately after construction or during a later phase of occupation.

Chronological data proved to be the most useful line of evidence; it placed each house and its structural changes within the larger history of Fort Vancouver. Evidence for the projects of the industrial phase employees and Village residents are most likely found in the changes made to the superstructure and the use of space in and around the houses. Unfortunately, in an already small dataset of five partially excavated houses, the incomplete interpretation and comparison of the houses limited the reach of this discussion. It is not clear how much variation in windows, doors, hearths, roofs, and side sheds is acceptable before these French-Canadian construction styles are identified as something new. 


\section{CHAPTER 12 SUMMARY AND CONCLUSIONS}

Inspired by an 1845 description of the Village, with houses that were "as various in form" as their occupants (Hussey 1957:218), the goal of this investigation was to examine community-level social relationships in the Fort Vancouver Village through vernacular architecture and landscape. Previous research into Village cultural diversity overlooked architectural artifacts and features as a valuable source of information. The research questions and hypotheses looked at the degree of architectural similarity or variation between five houses for evidence of an affirmation or rejection of a community with shared goals and a common social identity.

\section{Summary of Research Findings}

The first series of research questions investigated the architectural history of five individual houses and the Village as a whole:

- Did the Village community implement a single architectural style?

- How do these five houses relate (spatially and temporally) with the larger Village landscape?

- Do their archaeologically defined locations correspond with historical maps and illustrations of the Village?

The life history interpretations demonstrated that the five houses were built using common construction methods, different approaches were taken regarding the placement of hearths, windows, and side-sheds. The quality and quantity of archaeological data varied between the houses, so some architectural elements could not be fully articulated or compared with the other houses. As a result, specifically where the roof and upper story are concerned, there may be additional ways in which the houses resembled or differed from one another. How Houses 1-5 stylistically compare with the rest of the 
Village houses will remain unclear without additional analysis of the nail and window glass assemblages.

The archaeologically defined locations of Houses 1-5 are consistent with the arrangement of structures in the documentary record, specifically the maps and illustrations of the Village (Figures 5 through 9). Based on the occupation dates and relative locations with georeferenced historical maps and the WSDOT excavation results, Houses 1-5 represent a wide cross-section of the Village. Chronologically this sample includes some of the earliest built (House 4) and longest standing (House 5) Village houses. Spatially they represent clusters of structures in the northeast quadrant (House 5), the row north of the east-west road (House 1,2, and 3), and the southern quadrant (House 4) (Figure 97). Like the rest of the houses in the eastern half of the Village, Houses 1-5 are located along paths and roads. The houses in the western half of the Village, as depicted on historical maps, do not appear to have the same type of interwoven road network. Fences are present around a few houses, but most of the "yard" spaces are undefined. It is not clear how the space between the houses was used without additional landscape analyses.

The second series of research questions investigated the influencing factors and social implications of the five architectural life histories:

- Were the Village houses designed and built in pursuit of [individual or collective] projects (if so, what kind) or were they the result of more routine actions?

- What were the social, historical, and economic factors that influenced the form of the vernacular landscape?

- Did similar architectural elements stem from the existence of an emergent Pacific Northwest fur trade culture? 
The primary hypothesis drew on previous architectural and landscape research: more architectural variation should be expected if no overarching community identity or shared "project" was present in the Village. If employees were actively emphasizing the HBC-defined job and racial differences, the architectural variation and styles should change when the workforce demographics changed. Alternatively, in the presence of an emergent fur trade culture with a shared value system, collective project, or identity the Village is likely to develop style conformity and a homogenous architectural landscape (Burley 2000:31).

These hypotheses incorrectly assumed that all employees had the opportunity to build their own houses, and the resulting architectural products would encapsulate the occupants' goals and projects. This thesis found that the weight of history and colonial power relations limited the abilities of the employees to build their own homes. The greatest limitation came from the $\mathrm{HBC}$ practice of reassigning pre-existing houses to new employees. The hypotheses did not take into account the apparent prevalence of new employees moving into older houses. This thesis concludes that in a complex, colonialist context like that at Fort Vancouver, the existence of similar and varied architectural attributes may derive from multiple sources unrelated to community social relations.

The goals and intentions of the employees (as expressed in their domestic architecture) generally reflect two broad trends that correspond to the two different economic phases at Fort Vancouver. During the fur trade years, fewer houses dotted the landscape as most of the employees were Voyageurs away on trapping brigades. The relatively small number of tradesmen, farmers, and laborers built houses quickly and 
relatively cheaply. At this time, the Village was not a permanent settlement. It was not uncommon for employees to have a higher turnover rate.

The foundations of all five houses were from the French-Canadian and Métis architectural tradition, reflecting the fur trade culture in the $1820 \mathrm{~s}$ and 1830 s. By this time, the French-Canadian "Red River Frame" was the standard building style of both the NWC and HBC, regardless of the specific cultural identity of the builders. The buildings at Fort Vancouver and the Village did reflect a common fur trade culture and architectural tradition, one that had traveled from eastern Canada, rather than develop at Fort Vancouver.

As the fur trade faded and the agricultural, industrial, and manufacturing activities ramped up, a greater number of employees worked around the fort. The Village population swelled. Older houses were inhabited by new occupants, many of whom made structural refurbishments. Some new houses, like House 2, included more substantial foundations and fences to contain their kitchen gardens or livestock. Many former HBC employees remained in their homes even after the HBC had abandoned Fort Vancouver. Among them was William R. Kaulehelehe, who had to be forced from his house before the U.S. Army burned it.

Using the life history results to create a Village development timeline revealed that the shift from a fur trade-based economy to an industrial production-based economy coincided with many of the changes or enhancements made to the individual structures. A "changing of the Village guard" occurred in the 1830s and 1840s when the fur trade employees retired and general laborers were hired from Hawai'i and local Native American tribes. Whether explicitly stated or not in the previous research, the Village 
houses are often conceptualized as the possession of a single household. This thesis suggests that many of the houses went through multiple owners, creating a palimpsest in the architecture and in the associated artifact assemblages. As a production-related activity, construction provides a tangible window into the physical actions of the Village residents.

\section{Examination of Methods and Recommendations for Future Research}

Considering the ephemeral nature of earthfast houses, the apparent zeal of the U.S. Army demolition squad, and the subsequent U.S. Army building activities through the 19th and 20th centuries, the extant archaeological patterning is a patchy reflection of the original structures. Nevertheless, this study demonstrates that revisiting old excavation assemblages with newer analytic techniques can illuminate previously unknown architectural and landscape details. More significantly, the Village landscape provides a new window to explore the social and economic situation at Fort Vancouver.

Hundreds of employees worked and lived in the vicinity of Fort Vancouver for the HBC's nearly 30-year tenure on the north bank of the Columbia. This study focused on five houses, which is a very small sample size considering that an estimated 30 to 50 houses populated the Village. Other houses were excavated during the WSDOT (19741981) excavations, but the structures were inconsistently analyzed, despite many of the methods used in this thesis being in practice at the time. These houses should be reanalyzed and added to the dataset.

In order to examine how the space between the houses was used, multiple lines of evidence from the built and natural landscape should be incorporated with the architectural data (Orser 2010). This should include the non-structural built-environment 
features like refuse pits, rock features, and wells (Kardas 1970). Botanical analyses have been conducted on excavations in the HBC formal garden (Dorset 2010). Based on Dorset's methods, the 2010 field school made an effort to collect pollen and phytolith samples in order to explore land use in the Village and identify what people were gardening and what [natural or cultivated] vegetation was present.

The field and laboratory methods of previous excavations shaped the research findings. Future architectural analyses would benefit from 1) tight provenience control during excavation; 2) the use of Roenke's window glass analysis and chronology; and 3) the recordation of the nail conditions (pulled, clinched, and unaltered) used in Young's 1994 nail study.

The analyses used in this study provide the greatest amount of details when there is tight provenience control during excavation. Without being able to isolate vertical and horizontal sections of the Kardas assemblages, only general statements could be made about the dates of a structure or the imprecise location of windows and doors. The specific dates of post features, hearths, or pits could not be distinguished from the rest of the unit. Architectural history is based on an expectation of change over time, and tracking change over time requires precise vertical provenience. The current standards used at Fort Vancouver National Historic Site are ideal, excavating natural strata or arbitrary levels no greater than $10 \mathrm{~cm}$ and excavating features separately.

With the use of $1 / 4$ in. $(6 \mathrm{~mm})$ and $1 / 8$ in. $(3 \mathrm{~mm})$ mesh screens, the SAIP excavations recovered average artifact frequencies $\left(\right.$ per $\left.^{2}\right)$ at least two times greater than the Kardas excavations, even in previously excavated areas. The SAIP excavations recovered a greater quantity of smaller artifacts (such as window glass in the 6 to $15 \mathrm{~mm}$ 
range) and a higher number of fragmented nails. In terms of artifact data such as window glass thickness and square nail type ratios, there was little qualitative difference between the Kardas and SAIP assemblage at Houses 1,2, and 3. This means that future work in the Village is qualitatively comparable with the older assemblages.

Based on the nail density hypotheses proposed by Stilson (1990), architectural analyses would benefit from a minimum of 1/4-in. screens in order to be directly comparable. The excavations in Nisqually Village (Stilson 1990, 1991) used 1/4-in. screens and recovered sufficient quantities of artifacts to develop life histories. With a lack of screening in 1968 and 1969, many architectural artifacts were overlooked. At the same time, 1/8-in. screens may not be necessary. The smaller fragments of window glass did not change the thickness mode distributions Kardas and SAIP assemblages of Houses 1, 2 and 3 (Figure 92a-92c). Certainly the window glass fragments that are collected from wet screen or microartifact samples were too small to obtain thickness measurements. However, if botanical analyses are to be incorporated into a Village landscape study, the 1/8-in. screens are useful for collecting bulk samples.

With square nails, the smaller screens recovered many more fragmented, and unidentifiable square nail fragments. Such "indeterminate square nails" are not useful to the architectural analyses which depend on complete nails (condition ratios), or at least including an identifiable head (style/function identification). An assemblage that is dominated by fragmented nail shanks also run the risk of skewing the density data to suggest it had more nails than an assemblage where the majority of the square nails remained complete, or at least identifiable. Nail density calculations using MNI may 
ultimately be the best option for identifying architectural styles (walls and roofs) by specific densities; similar to methods used to quantify long bones in faunal assemblages.

There are a variety of window-glass analytic methods that seek to derive manufacture dates from the tiny glass fragments, many of which provide different date ranges. It is this author's opinion that for research at Fort Vancouver NHS, Roenke's chronology is sufficient. His theory and chronology originated from the Village Pond assemblage and is specific to the site. Other methods are based on other sites with different window glass acquisition history and different construction circumstances, many of which do not provide accurate results when houses have been repaired.

Although the NCRI lab methods record nail condition, it only indicates "bent shank." If analysis were to regularly classify the bend as pulled or clinched, architecturalspecific research would not require a re-analysis of nails.

Finally, this study used practice theory as the main theoretical approach to exploring the social relationships in the Village. In regards to the life history analyses, practice theory had no bearing on the interpretation of the house styles through the archaeological patterning. The aforementioned architectural dataset can be compiled without factoring in Ortner's concept of "power and projects." The culture-history-power trinity emphasized in the "new" practice theory encourages the examination of history and power in the context of the dynamic relationship between the organization of one's physical and social environment and the collection of behaviors, identities, and social relations that all together comprise culture. The usefulness of practice theory was in giving meaning to the life histories. Through practice theory, specifically Ortner's idea that "projects" I realized that: 
- The form of the houses may be created by routine actions - everyday ways people used space in their homes - as well as intentional actions (projects).

- The influence of history and power was going to affect the construction methods used by the Village residents; they may not be faithfully recreating the architectural styles of their birth culture.

- All of the communicative and symbolic functions of architecture, cited by a number of architectural and archaeological scholars, cannot be universally achieved even if the builder desires to do so.

In trying to negotiate the new power relations present in the $\mathrm{HBC}$ workforce, practice theory suggests that the traditional practices of individuals may be restricted or intentionally adapted to the new social setting. Previous research in the Village looked for evidence of traditional material culture and found mostly European goods. The impact of power relations on an individual's ability to "pursue projects" (Ortner 2006), caused me to look more closely at the historical background to identify ways in which the $\mathrm{HBC}$ hierarchical social organization influenced the construction of employee housing. It led me to the realization that the history of Fort Vancouver, specifically the economic shift, would change the demographics as well as the needs of the employees. If the $\mathrm{HBC}$ owned the vacant structures of its former employees, the need of the new employees to build their own homes decreased.

The influence of the new residents on the preexisting houses was likely restricted to repairs, the occasional side shed addition, and the use of space within and around the houses. Research into activity areas of the Village houses, which was not part of this thesis and includes many other artifact types, would benefit heavily from the tenants of practice theory. The majority of the material culture is European-manufactured and the relative frequencies of certain artifact types are not statistically different between the structures, but the spatial patterning of these materials reflects how they were used. The 
activity areas develop from repeated behaviors like refuse disposal, food preparation, and hygiene. It would be beneficial to understand the structural remains in relation to the interior artifact assemblages. Do the French Canadian-style houses have similar or different activity areas? Which activity areas were public and which were private? Can cultural diversity be seen in how the Village residents used their material culture?

As more houses are added to the architectural dataset in the future, emphasis should be placed on the chronology of the life histories. If a relative chronology of the houses and specific activity areas could be compiled, the Village palimpsest could be dissected and examined against the relevant period of Fort Vancouver's economic and social histories. 


\section{REFERENCES}

Ames, Kenneth M.

2001 Slaves, chiefs and labour on the northern Northwest Coast. World Archaeology 33(1):1-17.

Amos-McGraw, Juliet

2008 Final Report on Analysis of House 2 Nails. Paper presented at the Northwest Anthropological Conference, Victoria, British Columbia.

Barbeau, Maurice

1945 The House That Mac Built. The Beaver: A Magazine of the North Outfit. Pp. 1013.

Blanchette, Robert A.

2000 A review of microbial deterioration found in archaeological wood from different environments. International Biodetrioration \& Biodegradation, 46:189-204.

Bourdieu, Pierre

1977 Outline of a Theory of Practice. Cambridge University Press, Cambridge.

Branton, Nicole

2009 Landscape Approached in Historical Archaeology: The Archaeology of Places. In The International Handbook of Historical Archaeology. Teresita Majewski and David Gaimster, editors, pp. 51-66.

Bray, Tamara

1984 Ethnic Differences in the Archaeological Assemblages at Kanaka Village. In: Report of Investigations at Kanaka Village Vancouver Barracks, Washington 1980/1981, by Bryn Thomas and Charles Hibbs. Archaeological and Historical Services, Eastern Washington University. Report prepared for the Washington State Department of Transportation; pp. 815-831.

British and American Joint Commission on Hudson's Bay and Puget's Sound Agricultural Company's Claims (BAJC)

1865-1869 British and American Joint Commission on Hudson's Bay and Puget's Sound Agricultural Company’s Claims. 14 Volumes, Washington, D.C., Montreal.

Brown, Jennifer S. H., W. J. Eccles, and Donald P. Heldman (editors) 1994 The Fur Trade Revisited: Selected Papers of the Sixth North American Fur Trade Conference, Mackinac Island, Michigan, 1991. Michigan State University Press, East Lansing.

Burley, Edith 1997 Servants of the Honorable Company: Work, discipline, and conflict in the Hudson's Bay Company, 1770-1870. Oxford University Press, Toronto, Montreal. 
Burley, David V.

1989 Function, Meaning and Context: Ambiguities in Ceramic Use by the Hivernant Metis of the Northwestern Plains. Historical Archaeology 23(1):95-106.

2000 Creolization and Late Nineteenth Century Métis Vernacular Log Architecture on the South Saskatchewan River. Historical Archaeology 34(3):27-35.

Burley, David V., Gayel A. Horsfall and John D. Brandon

1992 Structural Considerations of Métis Ethnicity: an archaeological, architectural, and historical study. University of South Dakota Press, Vermillion.

Carley, Caroline D.

1982 HBC Kanaka Village/Vancouver Barracks 1977. Reports in Highway

Archaeology 8. University of Washington, Office of Public Archaeology, Seattle,

Washington.

Carson, Cary, Norman F. Barka, William M. Kelso, Garry Wheeler Stone, Dell Upton 1981 Impermanent Architecture in the Southern American Colonies. Winterthur Portfolio 16(2/3): 135-196-

Caywood, Louis R.

1955 Final Report: Fort Vancouver Excavations. National Park Service, San Francisco.

Chance, David H. and Jennifer V. Chance

1976 Kanaka Village/Vancouver Barracks, 1974. Office of Public Archaeology, University of Washington, Seattle.

Chance, David H., Jennifer V. Chance, Caroline Carley, Karl Gurcke, Timothy Jones, George Ling, Michael Pfeiffer, Karl Roenke, Jacqueline Storm, Robert Thomas and Charles Troup

1982 Kanaka Village/ Vancouver Barracks 1975. Office of Public Archaeology, University of Washington, Seattle.

Chapman, Judith and Terry Ozbun 2002 The Archaeology of Ragged Creek Cabin. Contributions to the Archaeology of Oregon 2002, AOA Occasional Papers (7): 49-69

Clark, Bonnie J. and Kathleen Corbett 2006 Finding Common Ground in Common Places. In Between Dirt and Discussion: Methods, Methodology, and Interpretation in Historical Archaeology, edited by Kevin Bartoy and Steven N. Archer, pp. 151-167. Springer, New York.

Cromwell, Robert J.

2006 "Where Ornament and Function Are So Agreeably Combined": Consumer Choice Studies of English Ceramic Wares at Hudson's Bay Company Fort Vancouver, Graduate School of Syracuse University, Syracuse, NY. 
Cusick, James G.

2000 Creolization and Borderlands. Historical Archaeology 34(3):46-55.

De Cunzo, Lu Ann and Julie H. Ernstein

2006 Landscapes, ideology and experience in historical archaeology. In The Cambridge

Companion to Historical Archaeology, edited by Dan Hicks and Mary C. Beaudry.

Cambridge University Press, New York.

Deetz, James F

1996 In Small Things Forgotten: An Archaeology of Early American Life. expanded and revised version of the 1977 edition ed. Anchor Books, New York.

1982 Households: A Structural Key to Archaeological Explanation. American Behavioral Scientist 25(6):717-724.

Department of Archaeology and Historical Preservation (DAHP)

1978 Architectural Description Guide. Office of Archaeology and Historical Preservation, Olympia, WA.

Eccles, William J.

1988 The Fur Trade in the Colonial Northeast. In History of Indian-White Relations, edited by Wilcomb E. Washburn, pp. 324-334. Vol 4: Handbook of North American Indians. Smithsonian Institute, Washington.

Erigero, Patricia C.

1992 Cultural Landscape Report: Fort Vancouver National Historic Site. Vol.2.

National Park Service, Seattle, WA.

Fiske, Jo-Anne, Susan Sleeper-Smith and William Wicken (editors)

1998 New Faces of the Fur Trade: Selected Papers of the Seventh North American Fur Trade Conference, Halifax, Nova Scotia, 1995. Michigan State University, East Lansing.

Fontana, Bernard

1965 The Tale of a Nail: On the Ethnological interpretation of Historic Artifacts. The Florida Anthropologist 18(3):85-102.

Garth Jr., Thomas R.

1947 Early Architecture in the Northwest. Pacific Northwest Quarterly:215-232.

Gembala, Danielle D.M., Robert J. Cromwell and Douglas C. Wilson 2004 Results of the Systemwide Archaeological Inventory Project Excavations in the HBC Village Site (45CL300) Fort Vancouver National Historic Site 2001-2003. National Park Service, Vancouver, WA. 
Gibson, James R.

1988 The Maritime Trade of the North Pacific Coast. In History of Indian-White Relations, edited by Wilcomb E. Washburn, pp. 375-390. Vol 4:Handbook of North American Indians.. Smithsonian Institute, Washington.

Glassie, Henry H.

1975 Folk Housing in middle Viginia: a structural analysis of historic artifacts. University of Tennessee Press, Knoxville.

Gurke, Karl

1982 Kanaka Village Bricks. IN Kanaka Village/ Vancouver Barracks 1975.eds. Chance, David H., Jennifer V. Chance. Pp. 69-82. Office of Public Archaeology, University of Washington, Seattle.

Hajda, Yvonne P.

2005 Slavery in the Greater Lower Columbia Region. Ethnohistory 52(3):563-588.

Hale, Richard W.

1960 The French Side of the "Log Cabin Myth." Proceedings of the Massachusetts Historical Society 72:118-125.

Hamilton, Scott

2000 Dynamics of Social Complexity in Early Nineteenth-Century British Fur-Trade Posts. International Journal of Historical Archaeology 4(3):217-272.

Hampton Adams, William

2002 Machine Cut Nails and Wire Nails: American Production and Use for Dating 19th-Century and Early-20th-Century Sites. Historical Archaeology 36(4):66-88

Hébert, James Michael

2007 Culture Built Upon the Land: A Predictive Model of Nineteenth-Century Canadien/Métis Farmsteads. Master's Thesis. Department of Anthropology, Oregon State University, Corvallis.

Hicks, Dan and Audrey Horning 2006 Historical Archaeology and Buildings. In The Cambridge Companion to Historical Archaeology, Dan Hicks and Mary C. Beaudry, editors, pp. 273-292. Cambridge University Press, Cambridge, England.

Hoffman, J.J. and Lester A. Ross

1972 Fort Vancouver Excavations I: Northeast Corner Stockade. National Park Service, Fort Vancouver National Historic Site.

Hussey, John 1957 History of Fort Vancouver and its Physical Structure. Abbot, Kerns \& Bell, Portland, OR. 
1972 Historic Structures Report, Historical Data, Volume I, Fort Vancouver National Historic Site, Washington. U.S.D.I, National Park Service, Denver Service Center.

1977 The Women of Fort Vancouver. On file, Fort Vancouver National Historic Site.

Irving, Washington

1967 Astoria. Binfords \& Mort, Portland.

Jameson, Jennifer E.

2007 Iroquois in the Pacific Northwest Fur Trade: Their Archaeology and History. Master's Thesis. Department of Anthropology, Oregon State University, Corvallis. http://hdl.handle.net/1957/7808

Kardas, Susan

19701969 Excavations at Kanaka Village Site, Fort Vancouver, Washington. Report to National Park Service, Report to National Park Service, San Francisco, CA.

1971 The People Bought This and the Clatsop Became Rich: a View of Nineteenth Century Fur Trade Relationships on the Lower Columbia between Chinookan Speakers, Whites, and Kanakas. Doctoral Dissertation, Department of Anthropology, Bryn Mawr College, Bryn Mawr, PA.

Kent, Susan (editor)

1990 Domestic Architecture and the Use of Space: An interdisciplinary cross-cultural study. Cambridge University Press, Cambridge.

Kvamme, Ken

2003 Final Report: Electrical Resistance Surveys at the Fort Vancouver National Historic Site, Washington. Report to the Vancouver National Historic Reserve, Vancouver, from Archeo-Imaging Lab, Department of Anthropology, University of Arkansas, Fayetteville

Larrabee, Edwarrd M. and Susan Kardas

1968 Exploratory Excavations for the Kanaka Village Fort Vancouver National Historic Site, Vancouver, Washington. Report to National Park Service, Fort Vancouver National Historic Site, Vancouver, WA.

Lightfoot, Kent G.

2005 Indians, Missionaries, and Merchants: The Legacy of Colonial Encounters on the Colonial Frontiers. University of California Press, Berkeley.

Lightfoot, Kent G., Antoinette Martinez and Ann M. Schiff

1998 Daily Practice and Material Culture in Pluralistic Social Settings: An Archaeological Study of Culture Change and Persistence from Fort Ross, California. American Antiquity 63(2):199-222. 
Loren, Diana DiPaolo

2000 The Intersections of Colonial Policy and Colonial Practice: Creolization on the Eighteenth-Century Lousiana/Texas Frontier. Historical Archaeology 34(3):85-98.

Lynch, Michelle

2009 Testing the Boundaries: New Interpretations on the Locations of Probable Hudson's Bay Company Village Household Locations Using Previous Archaeological Survey Data. Paper presented at 2010 Northwest Anthropological Conference.

Maygarden, Benjamin D.

2006 Building in Colonial Louisiana: Creolization and the Survival of French

Traditions. International Journal of Historical Archaeology 10(3):211-239.

McGuire, Randall H. and Michael B. Schiffer

1983 A Theory of Architectural Design. Journal of Anthropological Archaeology 2:277-303

Monks, Gregory G.

1992 Architectural Symbolism and Non-Verbal Communication at Upper Fort Garry." Historical Archaeology 26(2): 37-57.

Nassaney, Michael S., Deborah L. Rotman, Daniel O. Sayers and Carol A. Nickolai 2001 Southwest Michigan historic landscape project: exploring class, gender, and ethnicity from the ground up. International Journal of Historical Archaeology 5(3):219.

Nelson, Lee H.

1962 Nail Chronology as an Aid to Dating Old Buildings. History News Technical Leaflet 48(11).

Nelson, Peter

2007 Power and Place: the Dynamics of Non-Verbal Communication in the HumanLandscape Interrelationship at Fort Vancouver. Undergraduate Thesis, Department of Anthropology, University of Washington, Seattle.

Nielsen, Axel

1991 Trampling the Archaeological Record: An Experimental Study. American Antiquity. 56(3):483-503.

Nielson, Rebecca

2003 Architectural Traditions and Outbuildings of the Hudson's Bay Company Village at Fort Vancouver. In Fort Vancouver Village Interpretation Project.

Orser Jr., Charles E.

2010 Twenty-First-Century Historical Archaeology. Journal of Archaeological Research, 18:111-150. 
Ortner, Sherry B.

1994 Theory in Anthropology since the Sixties. In Culture/Power/History: A Reader in Contemporary Social Theory, edited by Nicholas B. Dirks, Geoff Eley and Sherry B.

Ortner. Princeton University Press, Princeton.

2006a Introduction: Updating Practice Theory. In Anthropology and Social Theory: Culture, Power, and the Acting Subject. Duke University Press, Durham.

2006b Power and Projects: Reflections on Agency. In Anthropology and Social Theory, pp. 129-153. Durham, North Carolina: Duke University Press.

Paynter, Robert

2000 Historical and Anthropological Archaeology: Forging Alliances. Journal of Archaeological Research 8(1):1-37

Pierson, Heidi K.

2006. Mini Nail Guide. Fort Vancouver National Historic Site, Vancouver.

Pierson, Heidi K., Martin E. Adams, and Douglas C. Wilson

2009 Fort Vancouver Powder Magazine Archaeology 2004, Fort Vancouver National Historic Site, Vancouver, Washington. National Park Service, Vancouver WA.

Rapoport, Amos

1982 The Meaning of the Built Environment: A Nonverbal Communication Approach. Sage, Beverly Hills, California.

1969 House Form and Culture. Foundations of Cultural Geography Series. PrenticeHall Inc., Englewood Cliffs.

Ritchie, T.

1971 Plankwall Framing, a Modern Wall Construction with an Ancient History. Journal of the Society of Architectural Historians 30(1):66-70.

Roenke, Karl

1978 Flat Glass: Its Use as a Dating Tool for Nineteenth Century Archaeological Sites in the Pacific Northwest and Elsewhere. Northwest Anthropological Research Notes 12(2).

1982 Window Glass Thickness at Vancouver. IN Kanaka Village/Vancouver Barracks 1975. Reports in Highway Archaeology 7. Office of Public Archaeology, University of Washington. Seattle.

Rogers, Donnell J.

1993 Ku on the Columbia: Hawaiian Laborers in the Pacific Northwest Fur Industry. MAIS Thesis. Oregon State University, Corvallis. 
Ross, Lester A.

1976 Fort Vancouver 1829-1860: A Historical Archaeological Investigation of the Goods Imported and Manufactured by the Hudson's Bay Company. National Park

Service, Washington D.C.

Rubertone, Patricia

1989 Landscape as artifact: Comments on "The archaeological use of landscape treatment in social, economic, and ideological analysis." Historical Archaeology 23(1):50-54.

Sanders, Judith A., Mary K. Weber, and David R. Brauner

1983 Willamette Mission Archaeological Project: Phase III Assessment. Anthropology

Northwest Series, No. 1. Department of Anthropology, Oregon State University,

Corvallis.

Schiffer, Michael B.

1972 Archaeological Context and Systemic Context. American Antiquity. 37(2):156165.

1983 Toward the Identification of Formation Processes. American Antiquity. 48(4):675706.

1987 Formation Processes of the Archaeological Record. University of Utah Press, Salt Lake.

Silliman, Stephen W.

2005 Culture Contact or Colonialism? Challenges in the Archaeology of Native North America. American Antiquity. 70(1): 55-74.

South, Stanley

2002 Method and Theory in Historical Archaeology, expanded and revised from 1977 edition ed. Percheron Press, New York.

Sprague, Roderick

1980 A Functional Classification for Artifacts from 19th and 20th Century Historical Sites. North American Archaeologist 2(3):251-261.

Speulda, Louann

1988 Champoeg, A Perspective of Frontier Community in Oregon 1830-1861.

Anthropology Northwest, Number 3, Department of Anthropology, Oregon State University, Corvallis.

Steadman, Sharon R.

1996 Recent Research in the Archaeology of Architecture: Beyond the Foundations. Journal of Archaeological Research. 4(1):51-93 
Steele, Harvey

1975 U.S. Customs and the Hudson's Bay Company, 1849-1853. Northwest

Anthropological Research Notes 9(1):87-102.

1977 Euroamerican Artifacts in Oregon Territory, 1829-1860. Northwest

Anthropological Research Notes 11(2):174-183.

Steele, Harvey W., Lester A. Ross, and Charles H. Hibbs, Jr.

1975 Fort Vancouver Excavations--XII: OAS Sale Shop Excavation. On File at Fort Vancouver National Historic Site, Vancouver, WA

Stilson, M. Leland

1990 A Data Recovery Study of 45-PI-401 Hudson's Bay Dwellings, at Northwest

Landing, Pierce County, Washington. Western Heritage, Olympia.

1991 A Data Recovery Study 45-PI-405, The Fort Nisqually Village at Northwest

Landing, Pierce County, Washington. Vol 1. Western Heritage, Olympia, Washington.

Thomas, Bryn

1987 Archaeological Testing and Data Recovery Excavation for a Proposed Utility

Corridor at Fort Vancouver National Historic Site. Report prepared for Northwest

Natural Gas Company by Archaeological and Historical Services, Eastern Washington

University, Cheney.

1995 Archaeological Test Excavations for the Washington State Department of Transportation's SR 14 Pedestrian Undercrossing Project at Fort Vancouver National Historic Site, Clark County, Washington. Archaeological and Historical Services, Eastern Washington University.

Thomas, Bryn and Charles Hibbs Jr.

1984 Report of Investigations of Excavations at Kanaka Village/Vancouver Barracks, Washington, 1980/1981. Washington State Department of Transportation, Seattle. On file at Fort Vancouver National Historic Site.

Towner, Ron

1984 Demographic of Kanaka Village 1827-1843. In Report of Investigations at

Kanaka Village Vancouver Barracks Washington 1980/1981, Vol. 2., Bryn Thomas and

Charles Hibbs Jr, editors. Washington State Department of Transportation.

Upton, Dell and John Michael Vlach

1986 Common Places: Readings in American Vernacular Architecture. The University of Georgia Press. Athens, GA.

Voss, Barbara

2008 Between the Household and the World-System: Social Collectivity and

Community Agency in Overseas Chinese Archaeology. Historical Archaeology 42(3):3752. 
Voss, Barbara L. and Rebecca Allen

2008 Overseas Chinese Archaeology: Historical Foundations, Current Reflections, and New Directions. Historical Archaeology 42(3):5-28.

Willis, Corinne

2008 House 2 Flat Glass Final Report. Paper presented at the Northwest

Anthropological Conference, Victoria, British Columbia.

Wilson, Douglas C.

2005 The Confluence Project Land Bridge at the Fort Vancouver National Historic

Reserve, Vancouver Washington: Archaeological Survey, Test Excavations and

Treatment Plan. Vancouver National Historic Reserve, Vancouver, Washington.

Wilson, Douglas, Robert Cromwell, Danielle Gembala, Theresa Langford, and Debra Semrau

2003 Archaeology Lab Manual. On File at Fort Vancouver National Historic Site.

http://www.nps.gov/fova/historyculture/upload/Archaeology\%20Lab\%20Manual\%20200 $\underline{3 . p d f}$

Young, Amy

1994 Spatial Patterning on a Nineteenth-Century Appalachian Houselot: Evidence from Nail Analysis. Southeastern Archaeology 13(1):56-63. 